\title{
Costs and effects of implementation of a short admission programme following breast cancer surgery in the Netherlands
}

Citation for published version (APA):

de Kok, M. (2010). Costs and effects of implementation of a short admission programme following breast cancer surgery in the Netherlands. [Doctoral Thesis, Maastricht University]. Maastricht University. https://doi.org/10.26481/dis.20100604mk

Document status and date:

Published: 01/01/2010

DOI:

10.26481/dis.20100604mk

Document Version:

Publisher's PDF, also known as Version of record

Please check the document version of this publication:

- A submitted manuscript is the version of the article upon submission and before peer-review. There can be important differences between the submitted version and the official published version of record.

People interested in the research are advised to contact the author for the final version of the publication, or visit the DOI to the publisher's website.

- The final author version and the galley proof are versions of the publication after peer review.

- The final published version features the final layout of the paper including the volume, issue and page numbers.

Link to publication

\footnotetext{
General rights rights.

- You may freely distribute the URL identifying the publication in the public portal. please follow below link for the End User Agreement:

www.umlib.nl/taverne-license

Take down policy

If you believe that this document breaches copyright please contact us at:

repository@maastrichtuniversity.nl

providing details and we will investigate your claim.
}

Copyright and moral rights for the publications made accessible in the public portal are retained by the authors and/or other copyright owners and it is a condition of accessing publications that users recognise and abide by the legal requirements associated with these

- Users may download and print one copy of any publication from the public portal for the purpose of private study or research.

- You may not further distribute the material or use it for any profit-making activity or commercial gain

If the publication is distributed under the terms of Article $25 \mathrm{fa}$ of the Dutch Copyright Act, indicated by the "Taverne" license above, 


\section{Costs and effects of implementation of a short admission programme following breast cancer surgery in the Netherlands}

Mascha de Kok 


\section{Colofon}

Layout \& design

Bart Witteman

Cover illustration

Dagmar de Kok, "Krijg nou tieten", 2010

Photography cover illustration

Ellen den Ouden

Print

Optima Grafische Communicatie, Rotterdam

\section{ISBN}

Copyright () 2010 M. de Kok

All rights reserved. No part of this publication may be reproduced, stored in a retrieval system, or transmitted, in any form or by any means, electronic, mechanical, photocopying, recording or otherwise, without prior permission of the author or the copyright-owning journals for previously published chapters. 


\section{Costs and effects of implementation of a short admission programme following breast cancer surgery in the Netherlands}

\section{PROEFSCHRIFT}

ter verkrijging van de graad van doctor aan de Universiteit Maastricht, op gezag van Rector Magnificus, Prof. mr. G.P.M.F. Mols volgens het besluit van het College van Decanen in het openbaar te verdedigen op vrijdag 4 juni 2010 om 14.00 uur door

Mascha de Kok geboren te Liempde 
Promotor

Prof. dr. M.F. von Meyenfeldt

Copromotores

Dr. C.D. Dirksen

Prof. dr. T. van der Weijden

Beoordelingscommissie

Prof. dr. H. Severens (voorzitter)

Prof. dr. R.F.P.M. Kruitwagen

Prof. dr. E. Rutgers (Nederlands Kanker Instituut)

Dr. H. Tange

Prof. dr. J. de Vries (Universiteit van Tilburg)

Financial support by ZonMw - the Netherlands Organisation for Health Research and Development (ZonMW, project number 945-14-411) for this study and the publication of this thesis is gratefully acknowledged.

Additional financial support was generously provided by Advocatenkantoor de Kok, Afdeling Heelkunde MUMC, Agendia, AstraZeneca, Boehringer Ingelheim, GROW-Research Institute Growth and Development, Livit, Roche. 
Voor oma, opa Marinus, Emi en opa 


\section{Contents}

Chapter 1 Introduction and Outline of the Thesis

Part One: Outline of the Research Protocol

Chapter 2 Introduction of a Breast Cancer Care Programme Including Ultra Short Hospital Stay in 4 Early Adopter Centres: Framework for an Implementation Study

Part Two: Development of a Questionnaire on Quality of Care 46

Chapter 3 The Patient's Perspective of the Quality of Breast Cancer Care: the Development of an Instrument to Measure Quality of Care through Focus Groups and Concept Mapping with Breast Cancer Patients

Chapter 4

A Patient-Centred Instrument for Assessment of Quality of Breast Cancer Care: Results of a Pilot Questionnaire

Part Three: Perceived Barriers and Facilitators before Implementation of the Programme

Chapter 5 Implementation of an Ultra-Short-Stay Program After Breast Cancer Surgery in Four Hospitals:

Perceived Barriers and Facilitators

Part Four: Results of the Study on Implementation of the Short Stay Programme following Breast Cancer Surgery 104

Chapter 6 Implementation of a Short-Stay Programme after Breast Cancer Surgery

Chapter 7 Patients' Opinions on Quality of Care before and after Implementation of a Short Stay Programme following Breast Cancer Surgery 
Chapter 8 Cost-Effectiveness of a Short Stay Admission

Chapter 9 A Hospital-Tailored Multi-Faceted Implementation Strategy to Introduce a Short Stay Admission Programme following Breast Cancer Surgery: Calculation of the Policy Cost-Effectiveness

Chapter 10 General Discussion

Chapter 11 Summary 
$\frac{n}{4}$

(1)

4

(1)

들

E

둘

4

5

인

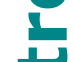

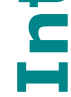




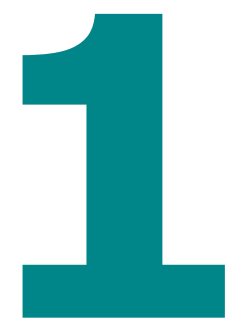

\section{Background}

Breast cancer is the type of malignancy most frequently diagnosed, and the most common cause of mortality in women, on both a European and a global level ${ }^{1-3}$. The highest European incidence rate is in the Netherlands ${ }^{4,5} ; 14.000$ new cases per year ${ }^{6}$ with a population of over 16 million inhabitants ${ }^{7}$. One in every eight Dutch women is affected by breast cancer. Thus, safe, effective, and efficient treatment is necessary.

\section{History of breast cancer treatment}

Surgical treatment has long been the only option for breast cancer. Halsted himself already noted that after the radical mastectomy he introduced, patients would die of distant disease ${ }^{8}$. Subsequently 'supra-radical' surgery was conceived to improve overall survival $^{9,10}$. Randomized trials did not sustain this assumption. While radiotherapy became available ${ }^{11}$ it was clear that it was yet another local treatment. To improve patients' survival it became apparent that a form of systemic treatment was necessary. After the discovery and development of chemotherapy ${ }^{12}$ and later hormonal treatment ${ }^{13}$ the envisioned survival improvement became obtainable. Meanwhile the strategy for local treatment of breast cancer shifted towards minimalization. Thus, through modified radical mastectomy ${ }^{14}$, partial mastectomy, quadrantectomy ${ }^{15}$, lumpectomy ${ }^{16}$ and sentinel node biopsy ${ }^{15,17,18}$ became available as safe and functionally and cosmetically conserving procedures for the surgical part of the multimodal treatment strategies of modern breast cancer treatment. Parallel to these developments, the body of knowledge regarding peri-operative pathophysiology increased, and subsequently adapted perioperative care. The need for hospital based care was reduced for patients undergoing the type of operations used for surgical breast cancer treatment. Thus, other issues than the strictly perioperative care that would traditionally be taken care of in the in-hospital phase of treatment, became matters that needed to be settled in alternative ways: pre-op counseling, mental support, wound and drain care ${ }^{19-21}$, pain management, functional recovery, access in case of emergencies etc. 


\section{Postoperative recovery}

Although this term has often been used as an outcome measure, it has never been clearly defined ${ }^{22}$. In traditional settings, patients recover in the hospital, and are closely observed to detect complications as soon as possible while the grounds for discharge are unclear. More recently, awareness has grown that postoperative recovery induces improving a patient's tolerance for the surgical procedure, and addressing the potential problems arising in the home situation. Thus, the possibility was evaluated of discharging patients after breast surgery with a wound drain as opposed to continued hospital stay until drain removal ${ }^{19-21}$. Currently, physicians focus increasingly on physical aspects that need to have recovered to make basic daily functioning possible, and therefore define the moment of discharge. For example, a programme aimed at early discharge following colonic surgery defined discharge criteria as adequate pain control, intake of solid food, independence of intravenous fluids, mobilization to preoperative level, and willingness to go home ${ }^{23-25}$. The key aspect of the programme is that clinicians are driven by a patient's return to usual, preoperative function as soon as possible. However, this definition of postoperative recovery, focussing on restoration of physical functioning to the preoperative level, has not been adopted widely.

\section{Hospital admission following breast cancer surgery}

As postoperative recovery changed from waiting for complications to dealing with potential problems in the home situation, mean hospital stay following breast cancer surgery decreased from 12 to six days. Three randomized clinical trials were performed in Canada and the USA on the shift from long (eight days) towards shorter mean hospital admission periods (three days). Bundred and colleagues found no negative effect of early discharge on physical and psychological illness, and advised early discharge for patients who were provided with informal care at home ${ }^{19}$. Purushotham and colleagues compared breast surgery with and without drain insertion, and concluded that drains were not needed, thus facilitating early discharge ${ }^{26}$. Bonnema and colleagues reported major cost savings related to a shorter hospital stay ${ }^{27}$. Although motivations for shortening hospital stay may have been rooted in efficiency reasons to accommodate rising healthcare costs, the results of these studies, each describing different outcomes, were nevertheless promising. Compared with traditional care a quick recovery, short mean hospital admission period, comparable complication rates, equally satisfied patients, and lower costs were recorded.

Healthcare givers at the Maastricht University Medical Centre perceived that, generally, after patient monitoring in the recovery, no medically relevant care activities were performed with breast cancer patients which required hospital-based care. They wondered whether the shift towards short admission periods had reached it's maximum 
effect or whether $24 \mathrm{~h}$ or even day care admission was feasible without a negative effect on safety.

In most Dutch surgical centres, the majority of breast cancer surgeries (except for wide local excisions) are still performed in an inpatient setting ${ }^{28}$. Although several Dutch hospitals are actually performing all types of breast cancer surgery in short stay, these hospitals are exceptions to the rule.

A change towards $24 \mathrm{~h}$ or day care surgery would demand a change in the preoperative education and preparation of patients, healthcare professionals, and informal caregivers. Attention should be given to, for example, oral analgesia, early mobilization, home care nursing, and also disease management principles. For example, a pivotal role should be fulfilled by the breast nurse, besides the surgeon. If treated at a day care department, the focus of all care activity is on the patient. She receives more personalized care focused on functional recovery than a patient treated at an inpatient ward and among other (possibly more) seriously ill patients. Hospital care in day care surgery units may be better suited to the patient's needs, and stimulate a patient to return to her familiar environment for further recovery.

Earlier studies were performed in a selection of breast cancer patients, e.g. patients undergoing mastectomy ${ }^{29}$, axillary clearance ${ }^{30}$ or wide local excision with or without a sentinel node procedure ${ }^{31,32}$. Performing all types of breast surgeries in day care or $24 \mathrm{~h}$ admission would show whether, as assumed in previous studies, only patients undergoing certain types of surgery are suitable for admission in short stay. With the above mentioned considerations in mind, the Maastricht University Medical Centre developed a short stay (i.e. surgery in day care or $24 \mathrm{~h}$ admission) programme following all types of breast cancer surgery to assess effectiveness, safety and efficiency of such a programme.

\section{The short stay programme}

Key aspects of the short stay programme are a structured care organisation including adequate education and counselling for patients and medical staff, regular multidisciplinary meetings, dedicated anaesthesia, active patient participation in the decision to go home, home care nursing if requested, and written contact information in case of questions in the home situation. Patients are not scheduled for day care surgery if they cannot rely on sufficient informal care in the home situation during the first night following surgery and if they have complaints (e.g. cardiac) that necessitate postoperative monitoring. The improved organisation of care is reflected in a standardized schedule of activities from the first hospital visit until the end of the surgical treatment. A nurse practitioner or a breast nurse is crucial in the execution of this type of communication: for instance, one of the preoperative visits to the 
outpatient clinic consists of education and counselling. In this one h conversation with a breast nurse the patient receives information on all aspects of the (peri)operative period such as the operation itself, the postoperative process, pain (management) in addition to an exploration of the home care situation. Before discharge, the patient is examined physically (including examination of the wound and drain(s) if applicable), receives prescriptions for pain medication, and oral and written information (e.g. on physical activities, and follow-up appointments). A description of the key recommendations of the programme is provided in Chapter $2^{33}$.

\section{The Maastricht University Medical Centre as an early innovator}

The programme was introduced in a pilot study performed at the Maastricht University Medical Centre from 2001 to 2002. The study aim of this pilot was twofold: to explore whether the short hospital admissions achieved in the RCTs could be realised or minimized even further to day care or $24 \mathrm{~h}$ admissions. And if this appeared to be possible, could it be done safely in a non-selected patient group, that is in all patients irrespective of type of surgery? Results showed day care and $24 \mathrm{~h}$ admission in breast cancer surgery was often achieved. The reduced mean length of hospital stay did not lead to more complications, and hospital costs of day short stay admission were lower compared with traditional care (unpublished results).

Although the programme was successful in the end, several barriers were encountered during the introduction. As the nursing staff did not receive the positive feedback given by patients, and only limited activities were expected from them, they felt less involved than before. Initially, anaesthesiologists were not convinced that day care surgery for breast cancer was feasible. Therefore, they felt no need for an adaptation of the anaesthesia approach. The Dutch breast cancer union was negative about the programme at the start but changed its opinion after being informed about the results. Informal caregivers showed appreciation for the programme, but stressed that they should be more actively involved in the care process from the beginning. Although the results implied that short stay following breast cancer surgery was feasible without a negative effect on outcome, a well outlined plan for implementation was needed. However, the pilot study was conducted in a university centre, and, just like the three RCTs, was a single-centre study. As different hospital organizations have different characteristics, which may influence the uptake and success of an innovation ${ }^{34,35}$, systematic introduction and evaluation of the programme on a larger scale needed to be performed in different hospital organizations. 


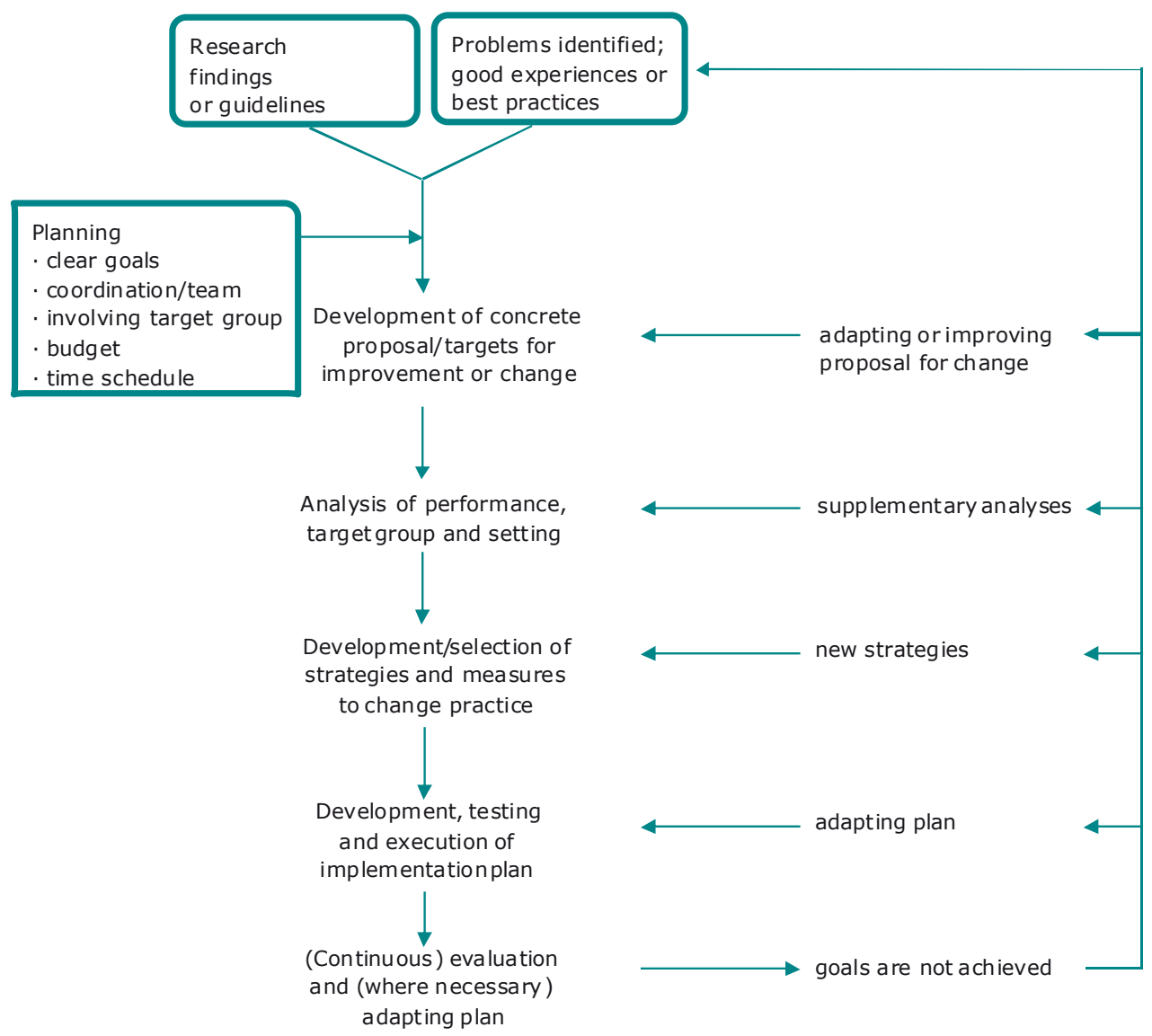

Figure 1. Model of effective implementation of change

\section{Changing surgical care systems with regard to length of hospital stay}

While currently patients are discharged within $24 \mathrm{~h}$ after cholecystectomy and appendectomy, the translation from research ${ }^{36,37}$ to practice took more than ten years. Somehow, the medical world seems to resist change. It is clear that changing practice should be dealt with in a systematic way, starting with a thorough understanding of the problems associated with the introduction of the alternative practice ${ }^{35}$. Singlecentre and multi-centre studies have been published on implementation of short stay care programmes following surgery, related to intensive care admission and hospital admission. Similar safety levels were achieved compared with usual care while admission periods decreased, and the need for a good organization of the short stay care process was emphasized ${ }^{23,38}$. 


\section{STUDY CHALLENGES}

\section{Implementation of the programme}

Implementation is defined as a planned process and systematic introduction of innovations and/or changes of proven value with the aim of giving innovation a structural place in professional practice, in the functioning of organisations or in the healthcare structure ${ }^{39}$. Different items must be taken into account when designing an implementation strategy ${ }^{40}$ : the type of innovation, the type of patient population and the type of professionals, but also the social, organisational, economic, and political aspects related to the change ${ }^{41}$. Figure 1 shows the Model of Effective Implementation of Change by Grol and colleagues in which these aspects are incorporated. In the model different phases and associated important steps are depicted for implementation of a quality improvement cycle ${ }^{39}$. A crucial step is the analysis of performance, target group and setting, the so-called diagnostic analysis, in which barriers and facilitators for change have to be investigated if there appears to be an unacceptable gap between the innovation/clinical practice guideline and the current performance.

The aim of this study was to implement a programme incorporating breast cancer surgery in day care or $24 \mathrm{~h}$ admission in four Dutch hospitals. In the available evidence on breast cancer surgery in short stay, information on implementation strategies, and the rationale for the type and intensity (i.e. frequency, time spent) of the strategies used is missing.

For purposes of comparison and evaluation of the effectiveness of implementation strategies, we performed an evaluation in which our implementation strategy was compared to doing nothing. Implementation of the programme of the Maastricht University Medical Centre was performed adjusted to the needs of each of the participating hospitals to reach a maximum effect, and to discover differences between centres.

\section{Quality of breast cancer care}

Quality of healthcare has gained a major role in healthcare evaluation studies. Yet, there are a number of flaws in most existing questionnaires on quality of care in which patients are asked to assess quality of care. Commonly used satisfaction questionnaires frequently provide skewed scores due to socially desirable answers, and scores that do not provide insight into the reason behind (dis)satisfaction. Besides, often generic quality of care aspects are evaluated instead of disease specific aspects that may differ among patient groups. Another aspect concerns the validity of the existing questionnaires; questionnaires may not adequately evaluate the processes or aspects 
they were supposed to evaluate. It is uncertain whether patients share the same vision on quality of care as policymakers, especially when it concerns for example, circumstances of care, and logistics. However, most questionnaires concerning breast cancer care have been developed by these very policymakers, healthcare managers, insurance companies ${ }^{42}$ and healthcare professionals ${ }^{43,44}$. The questionnaires rarely include patient's opinions, even though they are designed to be filled out by breast cancer patients ${ }^{45}$. Sixma and colleagues ${ }^{46}$ developed a theoretical concept that takes into account these aspects. Based on this concept he designed a questionnaire that is patientbased, readily available, and provides valid and reliable information for assessment of quality of care.

A thorough assessment by breast cancer patients on quality of breast cancer care is lacking. If healthcare professionals wish to provide care tailored to patients' needs, their needs, opinions, and wishes should be assessed before, and evaluated after an intervention. We developed an instrument on quality of breast cancer care assessing all important aspects of breast cancer care, reflecting needs, opinions, and wishes of breast cancer patients, based on Sixma's framework.

\section{Barriers and facilitators for implementation}

In implementation studies, a diagnostic analysis is preferred before start of the implementation. It consists of an assessment of usual care, and a thorough exploration of barriers and facilitators in the target group that are likely to influence an implementation. Results of a diagnostic analysis should be followed by the development of a proposal and targets for change, and serve as a basis for the decision on dissemination and implementation techniques. In addition, results of a diagnostic analysis provide a basis for other healthcare givers with similar organisation structures on how to systematically perform an implementation study. So far, no data have been published concerning the expected and encountered barriers or facilitators on different organisational levels associated with implementation of short stay admission following breast cancer surgery. In this study, such an evaluation was performed.

\section{Cost-effectiveness of the short-stay programme}

As healthcare resources (i.e. people, time, equipment, facilities, and knowledge) are scarce, the interest for assessments of value for money of healthcare treatment and programmes increases. Economic evaluations in which costs and consequences of alternative treatment strategies are compared, correspond with these needs. The goal of an economic evaluation is to identify, measure, value, and compare costs and consequences of alternatives being considered ${ }^{47}$.

There are four main types of economic evaluations. The first type is the cost- 
minimization analysis in which costs of interventions are compared with the assumption that the outcomes (consequences, benefits) are equal. The second is the costeffectiveness analysis in which two or more alternatives are compared expressing effects in natural measurable outcome parameters (e.g. number of cured patients, number of cases detected). The third type is the cost-utility-analysis. A utility represents a valuation of a patient's health condition, or health state. The most commonly used measure in cost utility analysis is the Quality Adjusted Life Year (QALY), in which the utility associated with a health state is multiplied with the duration of that health state. The cost-utility analysis is generally the most preferred type of analysis, as it considers both costs and effects from a societal point of view. The last type is the cost-benefit analysis in which effects of alternatives are described in monetary terms. Although this type of analysis is preferred from a theoretical point of view, expressing outcomes in monetary terms is associated both with moral objections and practical difficulties, and is therefore only rarely applied.

In the three RCTs on the effect of reducing mean hospital stay following breast cancer surgery, costs had not been measured as part of a full economic evaluation, that is including all societal costs and including an assessment of effects using QALYs. Results from the pilot study at the Maastricht University Medical Centre (unpublished data) pointed towards a cost saving from the hospital perspective of about $€ 500$,- per patient. However, in that pilot study, a retrospective cohort was compared with a prospective cohort, and therefore information on all costs outside the hospital was not available, including potential additional costs (e.g. due to increased use of informal care), and possible savings (e.g. due to reduction of productivity losses. Besides, in the pilot study quality of life had not been explored, as the programme was not expected to have effects on quality of life and life expectancy. However, the Dutch breast cancer union had expressed concerns regarding the effects on short term quality of life if breast cancer surgery was performed in a short stay setting. To convince the breast cancer union, and thereby facilitate implementation of the short stay programme in the Netherlands, quality of life assessment seemed warranted.

The cost-effectiveness of the short stay programme was assessed and compared with care as usual, in line with our implementation study. It was expressed as incremental costs per quality adjusted life year (QALY), calculated from results of the EuroQol-5D questionnaire, a measure of generic health-related quality of life $\mathrm{e}^{48}$.

\section{Cost-effectiveness of implementation}

One of the aims of health economics studies is to express efficiency of an implementation strategy in terms of patient outcome to help decision makers explore whether investing in change is worthwhile. Results on cost-effectiveness 
of a programme sometimes yield into very positive (e.g. cost savings, increased effects) results. However, these results may be offset when the efforts and costs spent to implement the programme are taken into account. Therefore, in addition to calculation of cost-effectiveness of a programme, an assessment of policy costeffectiveness is recommended. In this type of cost-effectiveness, the cost-effectiveness of implementation is incorporated, that is the incremental costs of an implementation strategy compared with another implementation strategy (e.g. doing nothing) are divided by the uptake of a programme. By doing so, the policy incremental costeffectiveness ratio can be determined.

Mason and colleagues ${ }^{47}$ developed a formula in which cost-effectiveness of a programme was combined with cost-effectiveness of implementation of the programme to calculate policy cost-effectiveness. For an implementation strategy to be cost-effective from a policy viewpoint, a strategy is demanded that does not burden cost-effectiveness of a programme too much.

We performed an economic evaluation on cost-effectiveness of the implementation strategy compared with 'doing nothing'. These results were combined with the results on cost-effectiveness of the programme to provide an assessment of policy costeffectiveness.

\section{Professionals' performance}

In addition to the above mentioned aspects, professionals' performance during implementation of the new programme should be assessed. Information concerning, for example, the professionals' adherence to recommendations on patient education (e.g. 'has the information on drain care been given') will be important to define and indicate aspects that need further improvement, and to provide feedback to healthcare givers. The basis of the papers presented in this thesis was a multi-centre study on breast cancer treatment in short stay, funded by ZonMw (the Netherlands Organization for Health Research and Development), in which four hospitals throughout the Netherlands participated. The three year study involved two measurement periods, each lasting half a year. First, 'care as usual' was registered and, after implementation of the programme incorporating short stay, data for patients treated 'according to the short stay programme' were registered.

Apart from the general aim to implement the programme (Appendix), study goals were to assess the effect of the programme on outcome, quality of life, quality of care, and societal costs. The study incorporated an implementation plan, assessing results before and after the change including quality of life, and quality of care. To date, this type of study is unique on the topic of short stay for breast cancer care in the Netherlands, but also worldwide. The most important aspects that make this study different from other 
published studies are: the assessment of quality of care as seen through the patients' eyes before and after actual implementation, the use of implementation strategies tailored to the perceived barriers of change, the implementation of the programme in different hospitals simultaneously, the incorporation of a full economic evaluation, and the assessment of policy cost-effectiveness. Different aspects are described of both the successfully applied short admissions and the hindrances encountered when implementing the programme.

\section{Research questions}

1. Is an increase in the percentage of patients scheduled for breast cancer surgery, who are treated in short stay (ambulatory/24 $\mathrm{h}$ care) feasible without an increase in the number of complications?

2. Is the quality of care between diagnosis and six weeks following surgery at least comparable between the period before and after implementation, as perceived by breast cancer patients?

3. What are the barriers and facilitators, as perceived by the professionals, for the implementation of a programme incorporating surgery in day care $/ 24 \mathrm{~h}$ setting in the participating hospitals?

4. Is the short stay programme cost effective as compared to care as usual in the baseline period, or in other words, what is the cost-effectiveness of the programme?

5. Is implementation of the short stay programme cost effective as compared to doing nothing, or in other words, what is the policy cost-effectiveness?

\section{THESIS OUTLINE}

\section{Part one}

Outline of the research protocol

Chapter 2 provides a thorough description of the protocol used for this study.

\section{Part two}

Development of a questionnaire on quality of care

Chapter 3 reports on the results of focus groups and concept mapping meetings aimed at assessment of quality of care, and held with breast cancer patients in the four hospitals. 
Chapter 4 explores the steps leading to a pilot questionnaire to assess quality of care from the point of view of breast cancer patients.

\section{Part three}

Perceived barriers and facilitators before implementation of the programme

Chapter 5 focuses on particular barriers and facilitators perceived in the participating hospitals before actual implementation of the short stay programme.

\section{Part four}

Results of the study on implementation of the short stay programme following breast cancer surgery

Chapter 6 describes the results of the multi-centre implementation study comparing patients treated according to the short stay programme with patients treated in care as usual following breast cancer surgery, and focusing on, complications, reoperations, and readmissions.

Chapter 7 shows the questionnaire results for both study periods describing quality of care through patients' eyes before and after implementation of the programme. Chapter 8 describes a cost-effectiveness study, providing an overview of the total societal costs and effects associated with breast cancer surgery performed according to the short stay programme and according to care as usual.

Chapter 9 reports on a cost-effectiveness study on the costs and effects of implementation compared with doing nothing. This is also termed policy costeffectiveness.

\section{Part five}

\section{General discussion}

Chapter 10 integrates the findings of the previous chapters and discusses them in the light of the aim of this thesis. Also, methodological and theoretical issues are discussed in that chapter, as well as implications for future research and practice.

Due to the fact that most papers have been published, information overlap may occur. The difference in patient numbers is a logic consequence of the fact that different groups of patients were used in the papers as shown in Flowchart 2A and 2B. 


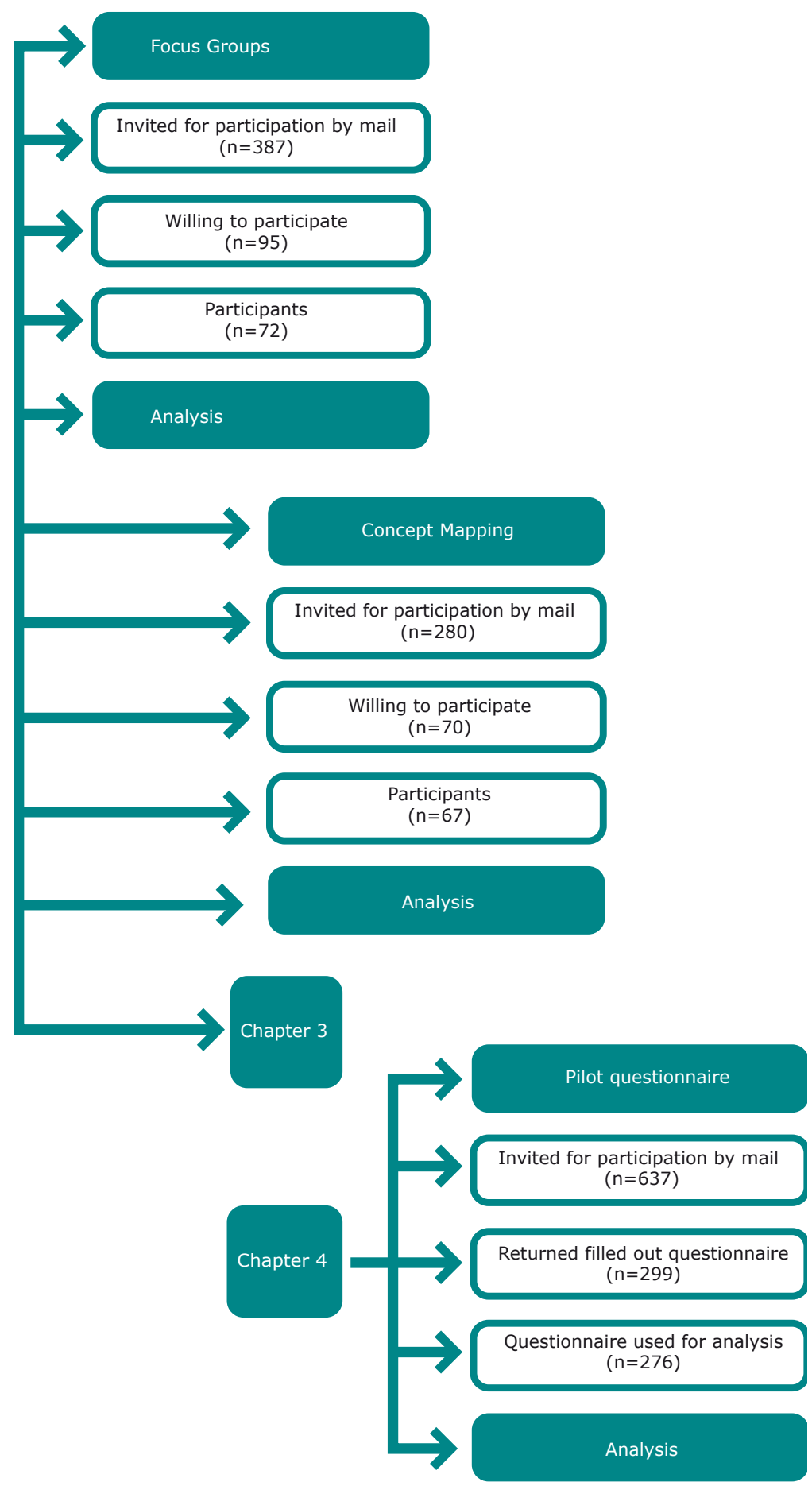

Figure 2a. Flowchart of the study on development of the questionnaire on quality of care. The chart includes the flow of the numbers of patients and a description of which data were used for which chapters. 


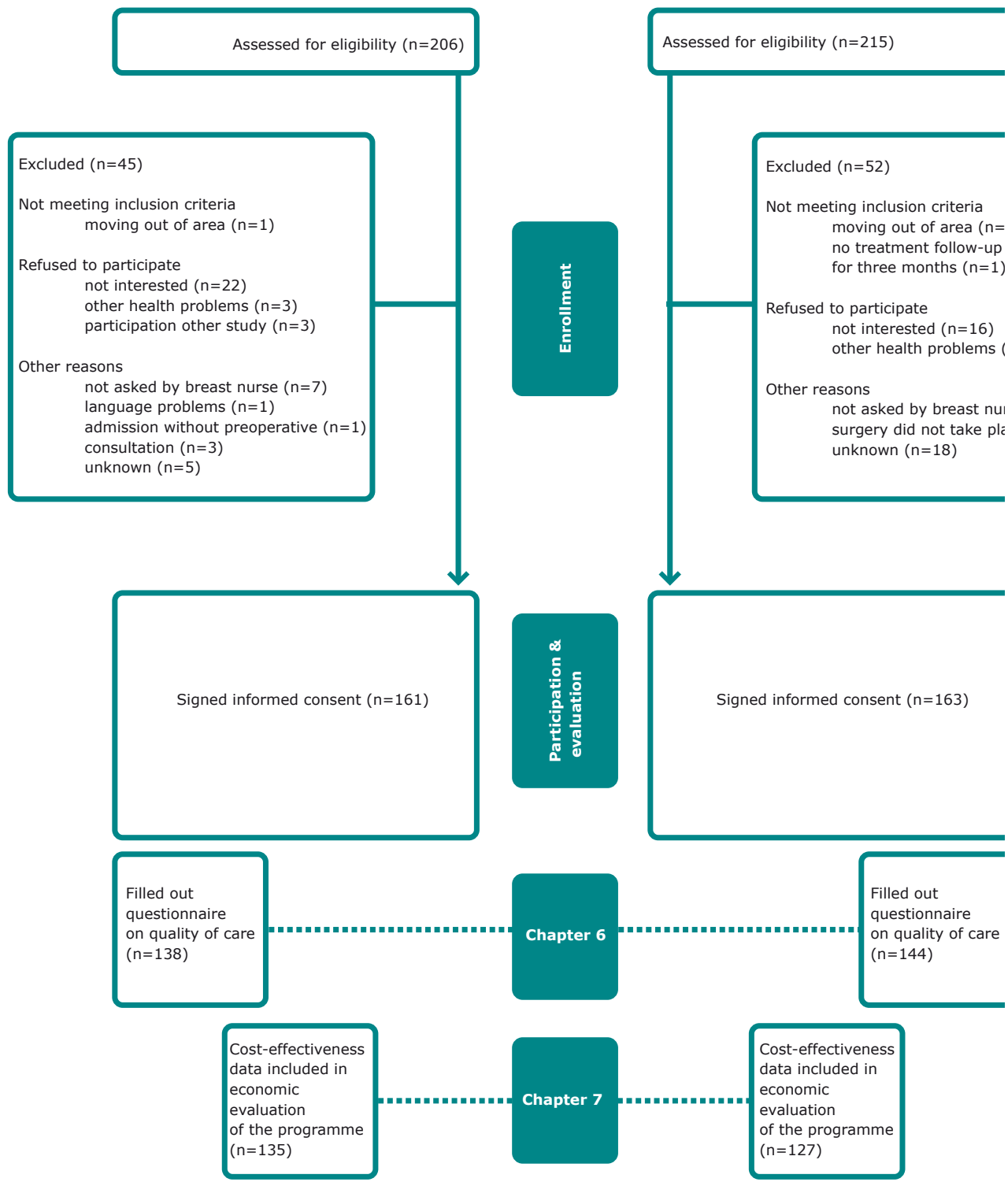

Figure 2b. Flowchart of the study on short stay followingbreast cancer surgery, based on CONSORT guideline, adapted for the prospectivenon-controlled study. The chart includes the flow of the numbers of patients, and a description of which data were used for which chapters

NB:Chapter two and five are not based on patient data and are, therefore, not shown in the flowchart. 
Appendix. All 29 recommendations of the study guideline to enable short stay for breast cancer surgery. Day care admission: admission and discharge at the same day; $24 \mathrm{~h}$ admission: admission and discharge within $24 \mathrm{~h}$ after admission and/or before noon the day after surgery.

\section{No. Recommendation}

1. The breast unit treats over 150 patients per year.

2. A professional from the breast unit is available for consultation during working hours.

3. Treatment of all breast cancer patients is planned in a weekly multidisciplinary meeting.

4. Interval between referral and first visit to the breast unit is 5 working days or less.

5. Interval between diagnostic tests and informing patients about their results is 5 working days or less.

6. Interval between the decision to operate and surgery is 15 working days or less.

7. Interval between surgery and informing patients about the results of tissue examination is 5 working days or less.

8. All diagnostic tests are carried out in no more than 2 hospital visits.

9. Minimisation of the number of preoperative hospital visits.

10. Information given to patients about the diagnostic procedure is supported by written information.

11. Patients who visit the hospital for diagnostic tests are seen by a breast surgeon ${ }^{1}$.

12. Surgeon and breast nurse both ensure that the patient is informed about diagnosis and treatment options.

13. Information given to patients about the diagnosis is supported by written information.

14. The general practitioner is informed about diagnosis, treatment plan, and potential side-effects prior to surgery.

15. Patients diagnosed with breast cancer can consult the breast nurse prior to the day of surgery.

16. Optimal use of staff, occupation of beds and operation rooms for breast cancer surgery in day care ${ }^{2}$.

17. Patients planned for day care treatment are postoperatively given the choice between continuation of admission and discharge.

18. Minimisation of prescription of opiates.

19. Information given to patients about discharge is supported by written information.

20. Decisions on patient discharge are based on clear guidelines.

21. Facilitation of specialised home care ${ }^{3}$ for patients in the period following surgery.

22. If home care becomes involved, the home care nursing company receives a transfer form from the hospital concerning the patient as well as essential treatment information ${ }^{4}$.

23. Breast nurse stays in contact with the patient during the postoperative period.

24. Admissions carried out as planned. 
25. At least one night of hospital admission is planned for patients for whom a sufficient level of care can not be guaranteed because of a suboptimal home care situation ${ }^{5}$.

26. At least one night of hospital admission is planned for patients with co-morbidity and/or insufficient postoperative supervision.

27. Realisation of the number of surgeries as planned.

28. Breast cancer nurse informs the patient about the need for informal care in the home situation.

29. Removal of drain at discharge

${ }^{1}$ Breast surgeon: surgeon who performs more than 50 operations for primary breast cancer per year.

${ }^{2}$ For example, operation rooms open until 1800 hours and short stay ward open for $24 \mathrm{~h}$.

${ }^{3}$ Specialized home care: one or more of the following should apply; a) (not) complicated wound and/or drain care \& psychosocial support and education, and/or b) finished training for breast cancer nurse, and/or c) nurse who completed clinical lecture on breast cancer care.

${ }^{4}$ Essential treatment information: transfer form which contains at least the following information on the operation: the kind of operation, the location of operation, possible complications, and other information relevant for caregivers.

${ }^{5} \mathrm{Home}$ situation: one or both of the following situations where the home situation could disturb a speedy recovery;

a) lack of or insufficient informal care (until $24 \mathrm{~h}$ after surgery patients need constant care (informal care);

b) psychosocial circumstances (disease, death, care for family members etc.) 


\section{REFERENCES}

1. Parkin DM. Global cancer statistics in the year 2000. Lancet Oncol 2001;2(9): 533543.

2. Parkin DM, Bray F, Ferlay J, Pisani P. Global cancer statistics, 2002. CA Cancer J Clin 2005;55(2): 74-108.

3. Ferlay J, Autier P, Boniol M, Heanue M, Colombet M, Boyle P. Estimates of the cancer incidence and mortality in Europe in 2006. Ann Oncol 2007;18(3): 581-592.

4. Curado MP, Edwards B, Shin HR, Storm H, Ferlay J, Heanue M, Boyle P. Cancer Incidence in Five Continents, Vol. IX 2007.

5. Karim-Kos HE, de Vries E, Soerjomataram I, Lemmens V, Siesling S, Coebergh JW. Recent trends of cancer in Europe: a combined approach of incidence, survival and mortality for 17 cancer sites since the 1990s. Eur J Cancer 2008;44(10): 13451389.

6. Comprehensive Cancer Centres (in Dutch), www.ikcnet.nl. In: www.ikcnet.nl; 2006.

7. Statistics Netherlands. http://www.cbs.nl. [May 26 2009].

8. Halsted WS. I. The Results of Operations for the Cure of Cancer of the Breast Performed at the Johns Hopkins Hospital from June, 1889, to January, 1894 (modified). Ann Surg 1894;20(5): 497-555.

9. Urban JA, Baker HW. Radical mastectomy in continuity with en bloc resection of the internal mammary lymph-node chain; a new procedure for primary operable cancer of the breast. Cancer 1952;5(5): 992-1008.

10. Wangensteen $\mathrm{OH}$. Another look at the super-radical operation for breast cancer. Surgery 1957;41(5): 857-861.

11. Lenz M, Freid JR. Metastases to the Skeleton, Brain and Spinal Cord from Cancer of the Breast and the Effect of Radiotherapy. Ann Surg 1931;93(1): 278-293.

12. Fisher B, Ravdin RG, Ausman RK, Slack NH, Moore GE, Noer RJ. Surgical adjuvant chemotherapy in cancer of the breast: results of a decade of cooperative investigation. Ann Surg 1968;168(3): 337-356.

13. Cole MP, Jones CT, Todd ID. A new anti-oestrogenic agent in late breast cancer. An early clinical appraisal of ICI46474. Br J Cancer 1971;25(2): 270-275.

14. Patey $\mathrm{DH}$, Dyson $\mathrm{WH}$. The prognosis of carcinoma of the breast in relation to the type of operation performed. Br J Cancer 1948;2(1): 7-13.

15. Veronesi U, Paganelli G, Galimberti V, Viale G, Zurrida S, Bedoni M, Costa A, de Cicco C, Geraghty JG, Luini A, Sacchini V, Veronesi P. Sentinel-node biopsy to avoid axillary dissection in breast cancer with clinically negative lymph-nodes. Lancet 1997;349(9069): 1864-1867.

16. Porritt A. Early Carcinoma of the Breast. Br J Surg 1964;51: 214-216.

17. Giuliano AE, Kirgan DM, Guenther JM, Morton DL. Lymphatic mapping and sentinel lymphadenectomy for breast cancer. Ann Surg 1994;220(3): 391-398; discussion 398-401.

18. Krag D, Weaver D, Ashikaga T, Moffat F, Klimberg VS, Shriver C, Feldman S, Kusminsky R, Gadd M, Kuhn J, Harlow S, Beitsch P. The sentinel node in breast cancer--a multicenter validation study. N Engl J Med 1998;339(14): 941-946. 
19. Bundred N, Maguire P, Reynolds J, Grimshaw J, Morris J, Thomson L, Barr L, Baildam A. Randomised controlled trial of effects of early discharge after surgery for breast cancer. Bmj 1998;317(7168): 1275-1279.

20. Chadha NK, Cumming S, O'Connor R, Burke M. Is discharge home with drains after breast surgery producing satisfactory outcomes? Ann R Coll Surg Engl 2004;86(5): 353-357.

21. Litvak S, Borrero E, Katz R, Munoz E, Wise L. Early discharge of the postmastectomy patient: unbundling of hospital services to improve profitability under DRGs. Am Surg 1987;53(10): 577-579.

22. Allvin R, Berg K, Idvall E, Nilsson U. Postoperative recovery: a concept analysis. J Adv Nurs 2007;57(5): 552-558.

23. Maessen J, Dejong $\mathrm{CH}$, Hausel J, Nygren J, Lassen $\mathrm{K}$, Andersen J, Kessels AG, Revhaug A, Kehlet $\mathrm{H}$, Ljungqvist $\mathrm{O}$, Fearon KC, von Meyenfeldt MF. A protocol is not enough to implement an enhanced recovery programme for colorectal resection. $\mathrm{Br}$ J Surg 2007;94(2): 224-231.

24. Maessen JM, Dejong CH, Kessels AG, von Meyenfeldt MF. Length of stay: an inappropriate readout of the success of enhanced recovery programs. World J Surg 2008;32(6): 971-975.

25. Maessen JM, Hoff C, Jottard K, Kessels AG, Bremers AJ, Havenga K, Oostenbroek $\mathrm{RJ}$, von Meyenfeldt MF, Dejong $\mathrm{CH}$. To eat or not to eat: facilitating early oral intake after elective colonic surgery in the Netherlands. Clin Nutr 2009;28(1): 29-33.

26. Purushotham AD, McLatchie E, Young D, George WD, Stallard S, Doughty J, Brown DC, Farish C, Walker A, Millar K, Murray G. Randomized clinical trial of no wound drains and early discharge in the treatment of women with breast cancer. $\mathrm{Br} J$ Surg 2002;89(3): 286-292.

27. Bonnema J, van Wersch AM, van Geel AN, Pruyn JF, Schmitz PI, Uyl-de Groot CA, Wiggers T. Cost of care in a randomised trial of early hospital discharge after surgery for breast cancer. Eur J Cancer 1998;34(13): 2015-2020.

28. Prismant, het kennis- en expertisecentrum voor de zorg (in Dutch), http://www. prismant.nl/Informatie-expertise/Thema's/Ziekenhuisstatistieken. [June 15 2009].

29. Case $C$, Johantgen $M$, Steiner $C$. Outpatient mastevvctomy: clinical, payer, and geographic influences. Health Serv Res 2001;36(5): 869-884.

30. Athey N, Gilliam AD, Sinha P, Kurup VJ, Hennessey C, Leaper DJ. Day-case breast cancer axillary surgery. Ann R Coll Surg Engl 2005;87(2): 96-98.

31. Marrazzo A, Taormina P, David M, Riili I, Lo Gerfo D, Casa L, Noto A, Mercadante S. Surgical treatment of early breast cancer in day surgery. Chir Ital 2007;59(5): 687691.

32. Marchal F, Dravet F, Classe JM, Campion L, Francois T, Labbe D, Robard S, Theard $\mathrm{JL}$, Pioud R. Post-operative care and patient satisfaction after ambulatory surgery for breast cancer patients. Eur J Surg Oncol 2005;31(5): 495-499.

33. de Kok M, Frotscher CN, van der Weijden $T$, Kessels AG, Dirksen CD, van de Velde CJ, Roukema JA, Bell AV, van der Ent FW, von Meyenfeldt MF. Introduction of a breast cancer care programme including ultra short hospital stay in 4 early adopter centres: framework for an implementation study. BMC Cancer 2007;7(1): 117. 
34. Davis C, Williams P, Redman S. Early discharge following breast surgery: assessing care, support, and informational needs of women with early breast cancer in Australia. Aust N Z J Surg 2000;70(8): 569-572.

35. Grol R, Grimshaw J. From best evidence to best practice: effective implementation of change in patients' care. Lancet 2003;362(9391): 1225-1230.

36. Mjaland O, Raeder J, Aasboe V, Trondsen E, Buanes T. Outpatient laparoscopic cholecystectomy. Br J Surg 1997;84(7): 958-961.

37. Lillemoe KD, Lin JW, Talamini MA, Yeo CJ, Snyder DS, Parker SD. Laparoscopic cholecystectomy as a "true" outpatient procedure: initial experience in 130 consecutive patients. J Gastrointest Surg 1999;3(1): 44-49.

38. van Mastrigt GA, Heijmans J, Severens JL, Fransen EJ, Roekaerv randomized clinical trial on safety and cost-effectiveness. Crit Care Med 2006;34(1): 65-75.

39. Grol R, Wensing M, Eccles M. Improving patient care. The implementation of change in clinical practice. Butterworth-Heinemann: Toronto, 2005.

40. Grol R. Personal paper. Beliefs and evidence in changing clinical practice. $B m j$ 1997;315(7105): 418-421.

41. Grol R, Jones R. Twenty years of implementation research. Fam Pract 2000;17 Suppl 1: S32-35.

42. Damman OC, Hendriks M, Sixma HJ. Towards more patient centred healthcare: A new Consumer Quality Index instrument to assess patients' experiences with breast care. Eur J Cancer 2009; 45(9): 1569-1577.

43. Birido N, Geraghty JG. Quality control in breast cancer surgery. Eur J Surg Oncol 2005;31(6): 577-586.

44. Rutgers EJ. Guidelines to assure quality in breast cancer surgery. Eur J Surg Oncol 2005;31(6): 568-576.

45. Faber M, Bosch M, Wollersheim H, Leatherman S, Grol R. Public reporting in healthcare: how do consumers use quality-of-care information? A systematic review. Med Care 2009;47(1): 1-8.

46. Sixma HJ, Kerssens JJ, Campen CV, Peters L. Quality of care from the patients' perspective: from theoretical concept to a new measuring instrument. Health Expect 1998;1(2): 82-95.

47. Mason J, Freemantle N, Nazareth I, Eccles M, Haines A, Drummond M. When is it cost-effective to change the behavior of health professionals? Jama $2001 ; 286(23)$ : 2988-2992.

48. EuroQol--a new facility for the measurement of health-related quality of life. The EuroQol Group. Health Policy 1990;16(3): 199-208. 

Part One

Outline of the research protocol 


\section{Chapter 2}

(d)

\section{ह}

\section{8}

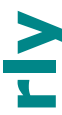

는

แ

的

(1)

(8)

以

8

c

命

为

동

(8)

फ)

운도

$0+$

亩

ช $\frac{1}{6}$

40

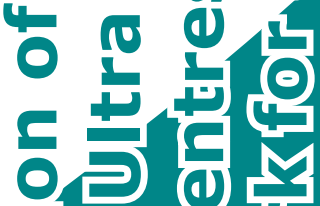

인

母ல

(

든 는

780

잉

인긍응

$\pm \frac{0}{0}$ 은

돈 운

분단
M. de Kok

C.N.A. Frotscher

T. van der Weijden

A.G.H. Kessels

C.D. Dirksen

C.J.H. van de Velde J.A. Roukema

A.V.R.J. Bell

F.W.C. van der Ent

M.F. von Meyenfeldt

BMC Cancer 2007; 7 (1) :117 


\section{ABSTRACT}

\section{Background}

Whereas ultra-short stay (day care or $24 \mathrm{~h}$ hospitalisation) following breast cancer surgery was introduced in the US and Canada in the 1990s, it is not yet common practice in Europe. This paper describes the design of the MaDO study, which involves the implementation of ultra short stay admission for patients after breast cancer surgery, and evaluates whether the targets of the implementation strategy are reached. The ultra short stay programme and the applied implementation strategy will be evaluated from the economic perspective.

\section{Methods}

The MaDO study is a pre-post-controlled multi-centre study, that is performed in four hospitals in the Netherlands. It includes a pre and post measuring period of six months each with six months of implementation in between in at least 40 patients per hospital per measurement period.

Primary outcome measure is the percentage of patients treated in ultra short stay. Secondary endpoints are the percentage of patients treated according to protocol, degree of involvement of home care nursing, quality of care from the patient's perspective, cost-effectiveness of the ultra short stay programme and cost-effectiveness of the implementation strategy. Quality of care will be measured by the QUOTE-breast cancer instrument, cost-effectiveness of the ultra short stay programme will be measured by means of the EuroQol (administered at four time-points), and a cost book for patients. Cost-effectiveness analyses will be performed from a societal perspective. Costeffectiveness of the implementation strategy will be measured by determination of the costs of implementation activities.

\section{Conclusions}

This study will reveal barriers and facilitators for implementation of the ultra short stay programme. Moreover, the results of the study will provide information about the costeffectiveness of the ultra short stay programme and the implementation strategy. 


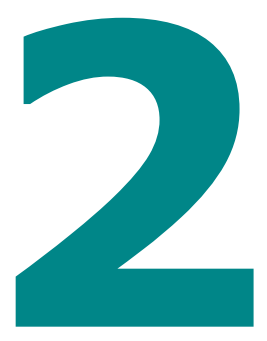

\section{BACKGROUND}

Opinions on more optimal working methods ('best practice') for breast cancer treatment have been changing continuously ${ }^{1-6}$. Increasingly, implementation studies are applied investigating techniques how to change clinical practice to integrate 'best practice' recommendations ${ }^{7,8}$. Whether a new programme is consolidated after implementation depends on the quality of care, the cost-effectiveness of the innovation as such, and of the cost-effectiveness of the innovation incorporating the costs of implementation'. Breast cancer causes a prominent burden on the healthcare budget. Of the total costs of breast cancer treatment $35-50 \%{ }^{10}$ is spent on surgical treatment, of which the largest part is on account of the hospital stay. Since the 1990s, hospital stay has decreased from 10-14 days to 5-7 days and further to the level of day care admission ${ }^{11-15}$. Three randomized clinical trials on the subject of early discharge (2-4 days vs. 5-10 days) reported no adverse effects and lower illness rates, high patient satisfaction and good clinical outcomes for the early discharge as compared to the standard admission group ${ }^{16-}$ 18 .

A decrease in admission time should not affect quality of care in a negative way. Therefore, it is important to introduce a structured programme such as has been developed at Maastricht University Medical Centre (MUMC) that includes current quality of care criteria ${ }^{4,5,19}$. Moreover, criteria for education, support and evaluation of the breast cancer care programme can (provide information to) enhance quality of care. Measurement of quality of care is of fundamental importance when evaluating a new programme.

At the MUMC, an ultra short stay programme for breast cancer surgery was developed and evaluated, incorporating the aspects mentioned above. The programme consists of a structured care organization including education and counseling, dedicated anaesthesia, active participation of the patient in her own treatment plan and in the decision to go home, and home care nursing. NABON guideline quality indicators are 
also incorporated in the programme (e.g. access time for the first visit to the Breast Unit, time spent in the process, number of breast conserving procedures and all diagnostic and treatment decisions being made in an appropriate multidisciplinary setting) ${ }^{19}$. Although the MUMC programme was successful in the end, the programme was greeted with scepticism by both healthcare providers and members of the local breast cancer patient association. For example, in the beginning patients were discouraged by ward nurses to go home in the evening following surgery for the nurses did not trust the quality of the programme at that moment. In addition, it suffered from problems at the anaesthesiology department (e.g. administration of opioids at the recovery unit postoperatively even if patients did not suffer pain) and from organizational flaws. For instance, the day care surgery unit closed at 1800 hours and, therefore, patients operated on late in the afternoon had less recovery time as compared to those operated on early in the morning. Following on those limited opening hours, patients in need of more time to recover after 1800 hours were transferred to the inpatient ward from which discharge the same evening was rarely performed.

Traditionally, implementation strategies have been chosen for pragmatic reasons guided by personal acquaintance with a particular strategy ${ }^{20}$. In this project we chose to perform an extensive diagnostic analysis ${ }^{20}$ of the problem, consisting of three issues:

1) how is current care organised?

2) how does it deviate from optimal care according to the innovative care programme?

3) what are barriers and facilitators for implementation of the ultra short stay programme?

The MUMC experience accumulated valuable insight and knowledge about implementation of an ultra short stay programme for breast cancer. If such a programme is implemented on a wider scale, in other hospitals, these experiences may contribute to the design of implementation strategies that are tailored to local needs. The implementation strategy will be developed on the basis of the results of the diagnostic problem analyses, and tailored to the needs of the stakeholder groups. The insights generated from this study may be translated into generally applicable insights on implementation of the innovative care programme on a larger scale while again defining patient benefits and demonstrating cost containment through the type of care provided. 


\section{AIM AND OBJECTIVES}

\section{Aim}

The aim of this study is to implement a programme incorporating breast cancer surgery in an ambulatory $/ 24 \mathrm{~h}$ stay setting (tailored to the needs of these hospitals).

\section{Objectives}

To evaluate:

1) whether the percentage of patients treated in ultra short stay increases without an increase in the number of complications.

2) whether the quality of care as perceived by patients between the baseline measurement and measurement after implementation does not deteriorate.

3) the cost-effectiveness of the ultra short stay programme versus care as usual (programme cost-effectiveness) in the baseline period.

4) the cost-effectiveness of implementation of the ultra short stay programme versus 'doing nothing' (policy cost-effectiveness).

5) the actual performance of the professionals in the test hospitals according to performance indicators. 
6) the perceived barriers and facilitators for the implementation of the programme incorporating surgery in ambulatory/24 hour stay setting in the participating hospitals so others preparing to change to ultra short stay care can profit from this information.

\section{METHODS/DESIGN}

\section{Study design}

The MaDO study is a multi-centre pre-post uncontrolled prospective study and involves breast cancer patients who are operated on with curative intent. Both pre and postmeasurements last six months with an implementation period of six months in between.

The study is performed in four hospitals which have been selected on three criteria. First, all participating hospitals had to be recognised as early adopters (an active group with high status within the target group $)^{21}$ within the field of breast cancer treatment, expressed by the willingness to appoint a full-time breast nurse. Second, we wished to include one university hospital, one large training hospital, one small training hospital and one non-training hospital to cover the main organisational hospital settings in the Netherlands, and to assess whether difference in results could be explained by differences in setting. Third, recruitment of people from different hospitals from different parts in the Netherlands, enables us to have a representative sample of breast cancer patients in the Netherlands.

\section{Selection of patients}

\section{Inclusion criteria}

All consecutive patients from the four participating hospitals, aged over 17 years, diagnosed with breast cancer, and scheduled to undergo surgery are eligible for participation in the study.

\section{Exclusion criteria}

Concerning surgical techniques, there is no contra-indication for ultra-short stay. Patients whose physiology impedes participation, as assessed by the breast surgeon and breast nurse, are excluded from the study. Patients who cannot rely on sufficient informal care in the home situation during the first night following surgery and patients with complaints that necessitate postoperative monitoring (e.g. cardial, pulmonal or neurological diseases) are scheduled for at least one overnight stay. This decision is made in consultation with the anaesthesiologist. The breast nurse scores the reasons for patients who do not participate. 


\section{Informed consent}

Eligible patients are informed about the study by the breast nurse during a consultation separate from the consultation in which they are informed about the diagnosis breast cancer. Patients are given an informed consent form by the breast nurse when they are informed about the study, and they are asked to return the signed informed consent within a week. The informed consent regards consent to being asked to complete questionnaires with the aim to evaluate the cost-effectiveness of (the implementation of) the innovative care programme.

\section{Sample size calculations}

In the MUMC the percentage of patients discharged within $24 \mathrm{~h}$ has increased from $13 \%$ to $84 \%$. Our assumption is that the clinically significant difference of ultra short stay admissions between the pre and post measurement is at least $30 \%$ in all participating hospitals. To achieve this percentage, 40 patients are sufficient for both the pre and the post measurement in each of the hospitals to demonstrate statistical relevance $(\mathrm{p}<0.05)$ with a power of $0.90^{22}$.

\section{Intervention: the breast cancer care programme including ultra short stay}

The intervention in this study concerns the comprehensive care programme for breast cancer surgery in ultra short stay (=ambulatory $/ 24 \mathrm{~h}$ stay setting). The key figures in the programme are the multidisciplinary team, the breast nurse, and the patient. Traditionally, the surgeon has been the specialist who analyses the type of breast pathology presented. Preventive procedures, early diagnosis of non-palpable lesions, breast conserving therapy, and lymph node sparing therapy have raised possibilities to reduce the burden of breast (cancer) surgery. The role of the breast nurse was introduced to improve patient counseling. Through these developments, diagnosis and treatment of breast pathology have gained a more multidisciplinary character. A decrease in the burden of surgery may limit the need for hospital-based supportive care. Similarly, this leads to a demand for strict coordination of the different steps and disciplines involved. Moreover, responsibilities for aspects of care need to be reallocated to other persons: from hospital- based supportive caregiver towards informal caregiver, from clinician to nurse specialist, from in house nursing staff to outpatient nursing staff, from hospital-based nursing staff to home care nursing staff etc. While the clinician's activities are limited to solving medical problems, the breast nurse performs all coordinating tasks to create a programme that runs smoothly. The patient is the key figure in the process. In a one-hour consultation, following the preoperative diagnosis, the patient is informed by the breast nurse about all aspects 
Table 1. Key recommendations of the study guideline to enable ultra short stay

for breast cancer surgery. The complete guideline contains 29 recommendations.

The participating breast nurses and surgeons from the study groups rated all

recommendations and decided upon which recommendations would be defined as 'key'

recommendations.

The treatment of all breast cancer patients is planned in a weekly

multidisciplinary meeting.

The interval between referral and first visit to the breast unit is 5 working days or less.

The interval between diagnostic tests and informing patients about their results is

5 working days or less.

The interval between the decision to operate and surgery is 15 working days or less.

The number of preoperative hospital visits is minimised.

The general practitioner is informed about diagnosis, treatment plan and potential side-effects prior to surgery.

Patients planned for day care treatment are postoperatively given the choice between continuation of admission and discharge.

Information given to patients about discharge is supported by written information.

Decisions on patient discharge are based on clear guidelines.

Specialised home care* for patients in the period following surgery is facilitated.

The breast nurse stays in contact with the patient during the postoperative period.

At least one night of hospital admission is planned for patients with co-morbidity and/or insufficient postoperative supervision.

The breast nurse informs the patient about the need for informal care

in the home situation.

of surgery (preparation, day of surgery, medication etc.). A checklist is used for this consultation and all oral information is supported by written information. Parts of this information (e.g. information on home care nursing and what to do in case of problems) are repeated on the morning of surgery, and at the moment of discharge.

\section{Implementation strategy}

The first step in the implementation process concerns the assessment of the guideline recommendations by consensus among experts, who define the complete set of recommendations $(\mathrm{n}=29)$ as well as a set of key recommendations (Table 1 ).

A so-called diagnostic analysis assesses the usual care, and explores factors that impede or facilitate the bridging of the gap between usual care and the programme to be implemented. Information for the diagnostics analysis will be retrieved from interviews during outreach visits, meetings, and telephone and e-mail conferences. The results of the assessment of usual care in the participating hospitals are compared to the standards 
of the innovative care programme. Information on perceived barriers and facilitators for implementation of the ultra short stay programme will be collected during outreach visits to the hospitals. These visits will be conducted in the recruitment and preparation phase. They will be aimed at preparation of the actual implementation and listing of the barriers and facilitators that were perceived by the participants for implementation of the care programme. This set of barriers and facilitators will be described on different levels: study guideline, care provider, patient, colleague, organization, and financial resources and reimbursement ${ }^{23}$.

Subsequently, a hospital-specific strategy is applied to implement a hospital-tailored version of the comprehensive care programme. This strategy is aimed at overcoming the barriers. Multi-faceted implementation strategies are used, providing insight, inducing change and acceptance, and feedback to maintain changes. These strategies are based on several components: 1 ) The promise that each early adopter makes to the project leader ( $\mathrm{MvM})$ to appoint a breast nurse fully available for coordination for the programme; 2 ) High-frequency outreach visits and study group meetings representing all disciplines involved in breast cancer care, provide the forum in which all steps for implementation

\section{Outcome indicators}

Final type of admission

\begin{tabular}{l}
\hline Readmission rate \\
\hline Complication rate \\
\hline Quality of care from the patients' perspective \\
\hline Cost-effectiveness of the ultra short stay programme \\
Process indicators \\
Cost-effectiveness of the implementation strategy \\
\hline Involvement of home care nursing \\
\hline Performance of professionals according to the protocol \\
\hline Reasons why patients were not treated according to ultra short stay protocol
\end{tabular}

are prepared, and issues are discussed and resolved. This local working party is also responsible for the communication of progress of implementation and of the findings within the hospital, to patients, and to other involved parties.; 3) The care process is measured through indicators mentioned in the Case Record Forms that are scored within the hospital, followed by feedback on performance by the researchers.

\section{Measurements and timing of measurements (Figure 1)}

- Information on the achievement of the targets of the implementation strategy is collected through Case Record Forms.

Quality of care is measured from the patient's perspective through the QUOTEbreast cancer, a questionnaire that was developed by and for breast cancer patients and concerns those aspects that breast cancer patients perceive as most 
important when assessing quality of care ${ }^{24,25}$. The QUOTE-breast cancer questionnaire is filled out six weeks after surgery.

- Information on the performance of professionals is gained through Case Record Forms. The performance indicators have been developed by means of a consensus procedure in the MUMC project group.

Patients fill out EuroQol questionnaires at baseline (one day before surgery) and at $24 \mathrm{~h}$, one week and six weeks after surgery.

When patients sign informed consent and receive the questionnaires, a stamped envelope is given to them which can be used to return the set of questionnaires.

Information on societal costs are retrieved from hospital information systems and through a prospective cost book that is filled out by patients during six weeks from the moment of discharge. The day before surgery, patients are asked to fill out a retrospective cost book to assess the patients' health-care related costs for a period of two weeks prior to surgery.

Policy cost-effectiveness of implementation of the ultra short stay programme versus 'doing nothing' is expressed as incremental costs per Quality Adjusted Life Year (QALY). Costs of the implementation strategy is measured through cost forms that participants in the study groups fill out, through scoring by a

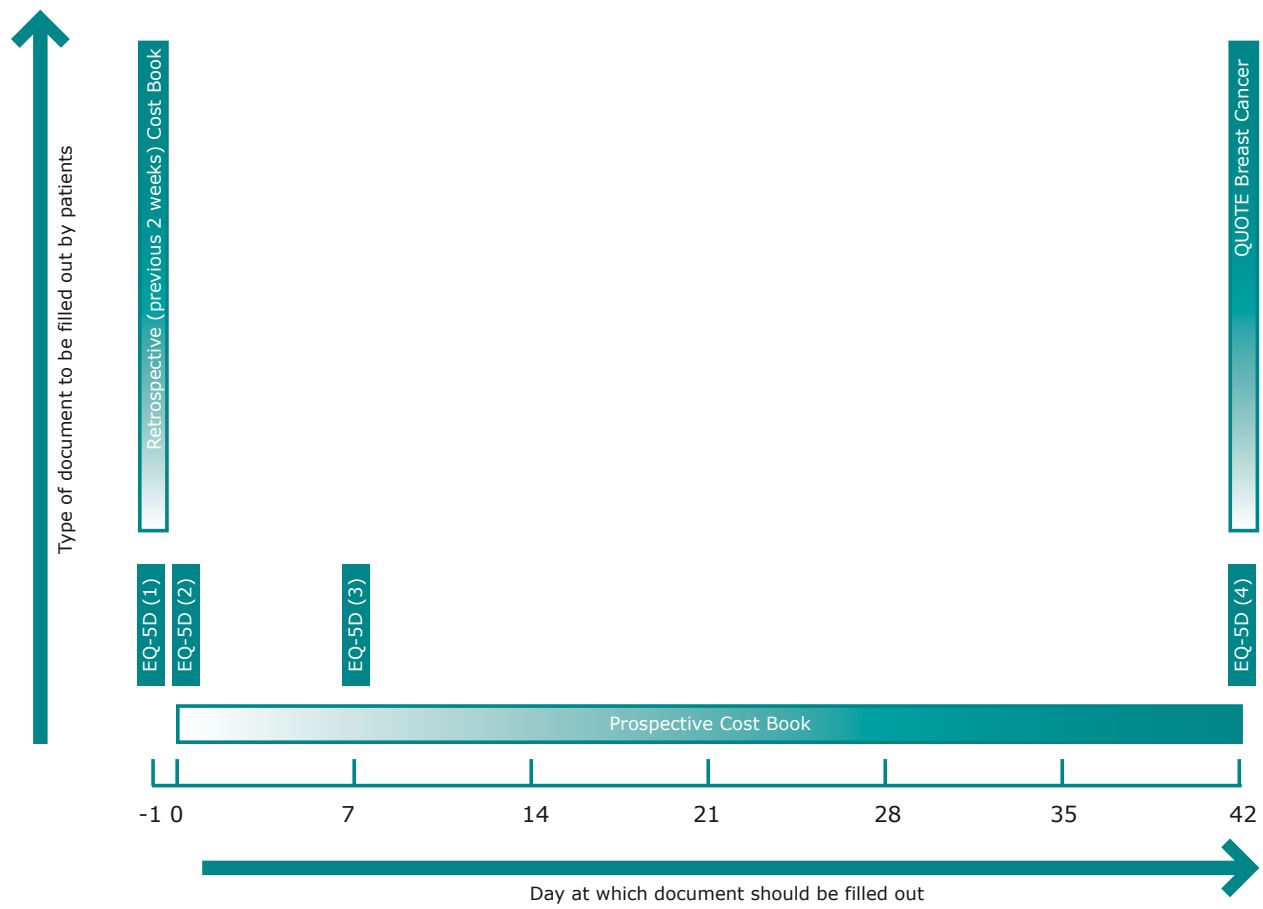

Figure 1. Overview of the type of questionnaires that are offered to patients and the time at which these questionnaires should be filled out 
researcher (MdK) of all other costs (e.g. times, materials, travel costs) in a data sheet. Effectiveness of the implementation strategy is measured through Case Record Forms containing treatment information. More details on programme cost-effectiveness and policy cost-effectiveness can be found in the section 'Economic evaluation'.

Programme cost-effectiveness (as compared to care as usual) consists of the two components costs and effectiveness, and is expressed as incremental costs per Quality Adjusted Life Year (QALY) of the ultra short stay programme versus care as usual. Incremental costs are expressed as the difference in costs between the ultra short stay programme and care as usual. Costs are calculated by multiplying the volumes with the appropriate cost prices. Information on (societal) costs are retrieved from hospital information systems and through a prospective cost book that is filled out by patients during six weeks from the moment of discharge. Effectiveness of the programme is determined through the measurement of safety (number of complications, number of visits to the emergency unit, number of re-admissions etc.; information gained from the Case Record Forms) and generic health-related Quality of Life. Generic health-related Quality of Life is recorded through the EuroQol-5D (EQ-5D) ${ }^{26}$, which is completed at baseline, $24 \mathrm{~h}$ after surgery, 1 week after surgery and 6 weeks after surgery. QALYs will be determined in two ways; from a societal perspective using the Dolan score, and from an individual perspective using the VAS score of the EuroQol. The multiple imputation method will be used for missing data analysis ${ }^{27}$.

\section{Time schedule for the study}

The study lasts three years. The first year of the study will be spent on the analysis of the breast cancer care processes in the different hospitals and the development of the measurement instruments. The following six months are used for baseline measurements, and preparation of the implementation of the new programme by the members of the local study groups.

Recruitment of patients will be performed by breast nurses and advanced practice nurses working at the breast units. Then, six months are used for implementation and running of the actual programme, followed by six months of measurements 'after implementation'.

\section{Statistical analyses}

Intention to treat will be used for data analyses, and analyses will be performed using the SPSS package, version 12.0.1 ® for Windows (SPSS INC 1989-2003). P values $<0.05$ will be defined as statistically significant. The pre and post comparison of the interval scaled outcome variables will be analysed with a multivariate linear regression model. 
Apart from the independent variable hospital, other independent variables included in this model are type of surgery, age, informal care at home, involvement of home care nursing and starting time of surgery. Furthermore, correlation of data within a hospital are accounted for by clustered data analysis.

\section{Economic evaluation}

In the economic evaluation, programme cost-effectiveness will be combined with costeffectiveness of the implementation strategy, to determine policy cost-effectiveness.

\section{Programme cost-effectiveness}

The time horizon of six weeks seems appropriate as patients may receive additional treatment after surgery (e.g. radiotherapy, chemotherapy or hormone replacement therapy). Therefore, we expect that only short-term quality-of-life effects and costs can be attributed to the ultra short stay programme. Cost analysis includes healthcare costs and costs outside healthcare such as out-of-pocket costs or productivity costs due to reduction in paid work and/or domestic activities. Healthcare costs refer to hospital and other healthcare facilities costs. Hospital costs consist of personnel, material, capacity costs, and overhead, associated with the diagnosis, surgical treatment, hospital stay and follow-up. Other healthcare costs include costs of visits to the general practitioner, medication, home care etc.

Healthcare costs are estimated by multiplying the resource utilization with the cost price per unit. Most of these costs are estimated by using existing resource registration systems and available cost prices through the financial departments of the participating centres. If true cost prices are not available in the participating centres, 1) existing cost prices of the MUMC or 2) official directive prices are used ${ }^{28}$. Healthcare costs incurred outside the hospital and costs outside healthcare are partly estimated through a structured cost book that is kept by all participating breast cancer patients during the period of six weeks following discharge. Productivity losses due to absence from work are estimated through the friction cost method ${ }^{28,29}$. To perform the cost-effectiveness analysis, costs and effects of patients treated according to care as usual (before implementation) will be compared to costs and effects of patients treated according to the ultra short stay programme (after implementation).

\section{Cost-effectiveness of implementation}

In each centre, the costs of the implementation process are calculated based on time and materials invested during the different phases of implementation. The diagnostic 
analysis may be looked upon as intervention. Its costs should be included in the costs of implementation. To determine cost-effectiveness of implementation, the costs of implementation will be weighed against the proportion of patients that is treated according to the ultra short stay programme.

\section{Policy cost-effectiveness}

The cost-effectiveness of implementation, that is the extra cost per patient treated according to the ultra short stay programme, will be combined with the cost-effectiveness of the breast cancer care programme to determine policy costeffectiveness, using Mason's model ${ }^{9,30}$. In this model, the duration of the effects of implementation is crucial for the cost-effectiveness of implementation, which will be investigated explicitly in this study. The incremental cost-effectiveness ratio of implementation of the ultra short stay programme versus 'doing nothing' will be expressed as the incremental cost per QALY.

\section{DISCUSSION}

Breast cancer surgery on an inpatient basis is a burden on the healthcare budget. Although previous studies have shown that ambulatory surgery is feasible for breast cancer patients, this has not been widely recognised in Europe. This is, to our knowledge, the first study that systematically evaluates the impact of an implementation strategy on patient and professional outcomes, patient experiences, costs, barriers and facilitators for change, for ultra short stay after breast cancer surgery. A randomized controlled trial is usually preferred over any other design. However, for several reasons a randomized controlled trial was not regarded as feasible. The first reason concerns the expected lack of willingness on the part of hospitals to be allocated to the control condition as they would get nothing in return for their efforts had we chosen a design with a concurrent control group. The number of participating hospitals in the study is too small to allow a controlled study design. A controlled study would have led to an unacceptable rise in study costs and the study period was too short to construct a waiting list control group. However, we think that the numbers of patients from the four participating hospitals provide enough power to draw conclusions on the estimation of change.

Random allocation at patient level was not considered for legal and organizational reasons; patients always have the right to go home whenever they want, making randomization for early or late discharge rather meaningless. Moreover, it is unethical to have one patient discharged the day of surgery while her neighbour is allowed to stay for another day or two. The extent of organizational changes to implement short 
stay within the existing processes of care are of such a scale that it is hardly feasible nor acceptable to allow different admission periods at the same time within one hospital. We are aware that the decision for a pre-post design instead of a randomized controlled trial cannot rule out the influence of developments and ongoing changes in healthcare, including reductions in lengths of hospital stays. This aspect will, therefore, be taken into account when conclusions are drawn based on the results of the study. In line with the most recent insights in implementation science a diagnostic analysis will be performed with the intention to tailor the implementation strategies to the needs of each hospital. However, this analysis will encompass a lot of time, energy, and costs, while there is no evidence as yet that such an analysis will assure a positive effect of implementation.

Since we wittingly selected merely early adopters, the external validity may be limited with regard to the smoothness of implementation. However, we think that although not every hospital can be labeled an 'early adopter', every hospital willing to participate in an implementation study must be eager to make the study a success, regardless of the degree of novelty at that time.

Although diagnostic analysis explores the willingness to implement as well as the opportunities for implementation, the number of perceived barriers and facilitators will be underestimated, or at least not overestimated. A thorough exploration of actual barriers and facilitators must, therefore, be performed during the actual implementation process.

There is a risk of contamination of the baseline measurement by socially desirable behaviour because the outreach visits for preparation of the study have taken place before and during the baseline measurement period. However, fixed moments to actually start with the innovative programme, are scheduled within each hospital and agreed upon. Feedback is given by the researchers if they suspect that hospitals may start the programme earlier than planned. Therefore, we think this influence is limited. A cost-effectiveness analysis is performed on the ultra short stay programme itself, and on the implementation strategy used. The goal of this study is to implement the ultra short stay programme for breast cancer surgery aiming at improved patient information, improved organization of care, a high degree of quality of care, and a reduction in mean hospital stay which results in a reduction of healthcare costs. 


\section{REFERENCES}

1. Blamey RW, Cataliotti L. EUSOMA accreditation of breast units. Eur J Cancer 2006;42(10): 1331-1337.

2. Baum M, Cassileth BR, Daniel R, Ernst E, Filshie J, Nagel GA, Horneber M, Kohn M, Lejeune S, Maher J, Terje R, Smith WB. The role of complementary and alternative medicine in the management of early breast cancer: recommendations of the European Society of Mastology (EUSOMA). Eur J Cancer 2006;42(12): 1711-1714.

3. Blamey RW. Guidelines on endocrine therapy of breast cancer EUSOMA. Eur J Cancer 2002;38(5): 615-634.

4. Perry NM. Quality assurance in the diagnosis of breast disease. EUSOMA Working Party. Eur J Cancer 2001;37(2): 159-172.

5. Rutgers EJ. Quality control in the locoregional treatment of breast cancer. Eur J Cancer 2001;37(4): 447-453.

6. Bartelink H, Garavaglia G, Johansson KA, Mijnheer BJ, Van den Bogaert W, van Tienhoven G, Yarnold J. Quality assurance in conservative treatment of early breast cancer. Report on a consensus meeting of the EORTC Radiotherapy and Breast Cancer Cooperative Groups and the EUSOMA (European Society of Mastology). Radiother Oncol 1991;22(4): 323-326.

7. Ray-Coquard I, Philip T, de Laroche G, Froger X, Suchaud JP, Voloch A, MathieuDaude $H$, Lurkin A, Farsi F, Bertrand P, Chauvin F. Persistence of medical change at implementation of clinical guidelines on medical practice: a controlled study in a cancer network. J Clin Oncol 2005;23(19): 4414-4423.

8. Ottevanger PB, De Mulder PH, Grol RP, van Lier H, Beex LV. Adherence to the guidelines of the CCCE in the treatment of node-positive breast cancer patients. Eur J Cancer 2004;40(2): 198-204.

9. Mason J, Freemantle N, Nazareth I, Eccles M, Haines A, Drummond M. When is it cost-effective to change the behavior of health professionals? Jama $2001 ; \mathbf{2 8 6}(23)$ : 2988-2992.

10. Will BP, Berthelot JM, Le Petit C, Tomiak EM, Verma S, Evans WK. Estimates of the lifetime costs of breast cancer treatment in Canada. Eur J Cancer 2000;36(6): 724735.

11. Dooley WC. Ambulatory mastectomy. Am J Surg 2002;184(6): 545-548; discussion 548-549.

12. Margolese RG, Lasry JC. Ambulatory surgery for breast cancer patients. Ann Surg Oncol 2000;7(3): 181-187.

13. Warren JL, Riley GF, Potosky AL, Klabunde CN, Richter E, Ballard-Barbash R. Trends and outcomes of outpatient mastectomy in elderly women. J Natl Cancer Inst 1998;90(11): 833-840.

14. McManus SA, Topp DA, Hopkins C. Advantages of outpatient breast surgery. Am Surg 1994;60(12): 967-970.

15. Goodman AA, Mendez AL. Definitive surgery for breast cancer performed on an outpatient basis. Arch Surg 1993;128(10): 1149-1152.

16. Purushotham AD, McLatchie E, Young D, George WD, Stallard S, Doughty J, Brown DC, Farish C, Walker A, Millar K, Murray G. Randomized clinical trial of no wound drains and early discharge in the treatment of women with breast cancer. $\mathrm{Br} J$ Surg 2002;89(3): 286-292.

17. Bundred N, Maguire P, Reynolds J, Grimshaw J, Morris J, Thomson L, Barr L, Baildam A. Randomised controlled trial of effects of early discharge after surgery for breast cancer. Bmj 1998;317(7168): 1275-1279. 
18. Bonnema J, van Wersch AM, van Geel AN, Pruyn JF, Schmitz PI, Uyl-de Groot CA, Wiggers T. Cost of care in a randomised trial of early hospital discharge after surgery for breast cancer. Eur J Cancer 1998;34(13): 2015-2020.

19. Rutgers EJ, Nortier JW, Tuut MK, van Tienhoven G, Struikmans H, Bontenbal M, von Meyenfeldt MF, Vreugdenhil G, Benraadt T, Garssen B, Peterse JL. Dutch Institute for Healthcare Improvement guideline, "Treatment of breast cancer" (in Dutch). Ned Tijdschr Geneeskd 2002;146(45): 2144-2151.

20. Grol R. Personal paper. Beliefs and evidence in changing clinical practice. Bmj 1997;315(7105): 418-421.

21. Rogers EM. Diffusion of Innovations (5th edn). Free Press: New York, 2003; xxi, $551 \mathrm{p}$.

22. Cohen J. A power primer. Psychological Bulletin 1992;112(1): 155-159.

23. Grol R, Cluzeau FA, Burgers JS. Clinical practice guidelines: towards better quality guidelines and increased international collaboration. Br J Cancer 2003;89 Suppl 1: S4-8.

24. de Kok M, Scholte RW, Sixma HJ, van der Weijden T, Spijkers KF, van de Velde CJH, Roukema JA, van der Ent FW, Bell AVRJ, von Meyenfeldt MF. The patient's perspective of the quality of breast cancer care. The development of an instrument to measure quality of care through focus groups and concept mapping with breast cancer patients. Eur J Cancer 2007;43(8): 1257-1264.

25. de Kok M, Sixma HJ, Scholte RW, Spijkers KF, van de Velde CJ, Roukema JA, van der Ent FW, Bell AV, von Meyenfeldt MF. What is important in breast cancer care? The patients' perspective after surgery. Eur J Surg Oncol 2006;32 (1): S78.

26. EuroQol--a new facility for the measurement of health-related quality of life. The EuroQol Group. Health Policy 1990;16(3): 199-208.

27. Rubin DB, Schenker N. Multiple imputation in health-care databases: an overview and some applications. Stat Med 1991;10(4): 585-598.

28. Oostenbrink JB, Bouwmans CAM, Koopmanschap MA, Rutten FFH. Manual for costing research (in Dutch). Healthcare Insurance Board: Amstelveen, The Netherlands, $2004 ; 172$.

29. Koopmanschap MA, Rutten FF, van Ineveld BM, van Roijen L. The friction cost method for measuring indirect costs of disease. J Health Econ 1995;14(2): 171-189.

30. Severens JL. Value for money of changing healthcare services? Economic evaluation of quality improvement. Qual Saf Healthcare 2003;12(5): 366-371. 



\section{Part Two Development of a Questionnaire on Quality of Care}




\section{Chapter 3}

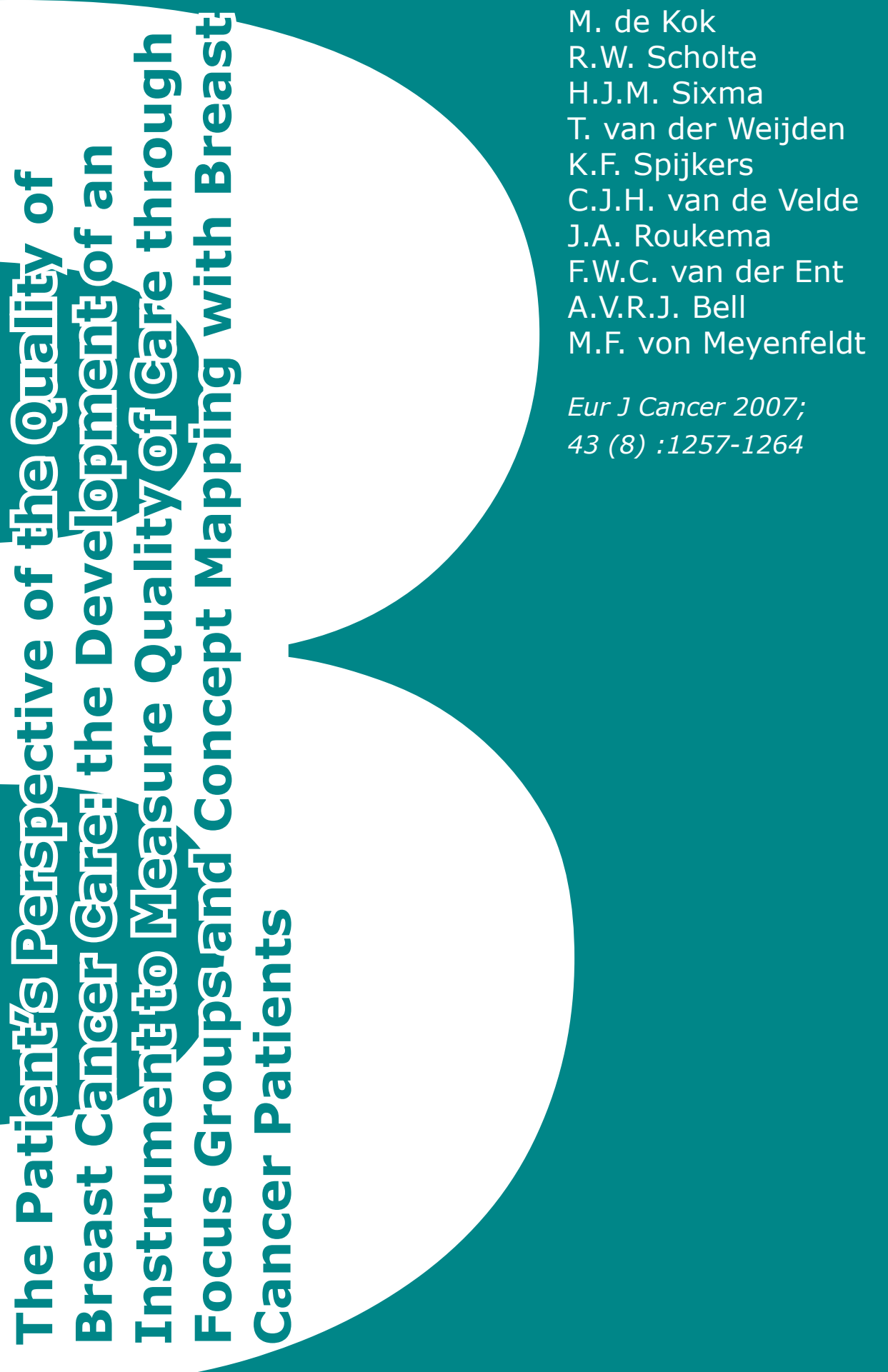




\section{ABSTRACT}

\section{Background}

Quality of care is often described by professionals. However, in this study breast cancer patients participated in developing an instrument that reflects quality of care from the patient's perspective.

\section{Methods}

Through focus groups and concept mapping patients' ideas on determinants of good quality of care were generated and categorised according to similarity and importance.

\section{Results}

Information from eight focus group interviews with a total of 72 participants yielded 221 quality of care aspects. Following reduction, 81 aspects were used for categorisation during six concept mapping sessions with 67 participants. After analysis, 55 aspects remained grouped into six clusters.

\section{Conclusion}

This study was conducted with a large number of breast cancer patients, undergoing the full range of treatment modalities, in different hospitals, in different areas in the Netherlands. Therefore, this set of quality of care indicators can be considered valid and suitable for the evaluation of breast cancer care as experienced by patients. 


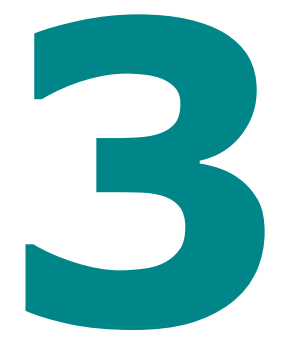

\section{INTRODUCTION}

Quality of care has become increasingly important in the evaluation of healthcare ${ }^{1-3}$. In addition, the patient's perspective in the assessment of quality of breast cancer care has been recognised ${ }^{4-7}$. To our knowledge, however, no publication has focussed on an instrument that corresponds with the needs, opinions, and wishes of breast cancer patients and provides reliable data on all aspects of breast cancer care.

First, most existing questionnaires on quality of breast cancer care have been developed by managers, insurance companies, policy makers, and healthcare professionals ${ }^{8,9}$. As these groups often entertain views on quality of care that are different from those held by patients ${ }^{10}$, the validity of these questionnaires to measure quality of care from the patients' perspective is questionable. Second, overall (generic) quality of care is usually evaluated instead of disease or category specific aspects that may differ among specific patient groups ${ }^{11}$.

Satisfaction questionnaires have often been used to ask for patients' opinions. Existing patient satisfaction questionnaires often provide highly skewed scores (75-90\% typically satisfied $)^{3}$ and produce results in absolute scores which do not give information about the reasons behind satisfaction or dissatisfaction ${ }^{12,13}$. Furthermore, satisfaction questionnaires have rarely been developed through systematic interviews with patients ${ }^{14}$, yielding direct insight into their opinions.

To deal with these disadvantages, Sixma and colleagues ${ }^{15}$ published the theoretical concept for a questionnaire that takes into account patients' expectations and experiences and measures quality of healthcare services from their perspective. They used focus groups (FGs), in combination with concept mapping (CM) for the generation and structuring of data on quality of healthcare for specific patient groups.

Kleeberg and colleagues constructed a questionnaire based on FGs with cancer patients ${ }^{12}$. This oncology questionnaire was sent to women with breast cancer as well as to women with other types of cancer. The results of the questionnaire were 
compared between the two groups, yet the FGs were not organised with breast cancer patients specifically. Therefore, the results of the comparison do not provide breast cancer specific aspects on quality of care. Gray published results from FG research with breast cancer patients derived from only one single FG with 11 patients ${ }^{16}$. The external validity of his observations is therefore limited. Other publications concerning FGs with breast cancer patients described specific categories of patients, such as older breast cancer patients and their opinions about chemotherapy ${ }^{17}$ or women who had received a risk assessment for familial breast cancer ${ }^{18}$.

The aim of the current study was to develop a questionnaire that is readily available, reliable and valid for assessment of quality of care by patients who have been operated on for breast cancer ${ }^{19}$.

\section{PATIENTS AND METHODS}

Data for analysis on quality of care for breast cancer patients were retrieved through a qualitative approach with FGs ${ }^{15,20}$ and CM, a method that combines qualitative methods (brain-storming sessions) and quantitative methods ${ }^{21}$. Concept mapping aims to produce visual representations (concept maps) of relationships between ideas generated during the qualitative phase of the process.

\section{Ethical aspects}

The study was approved by the Committees for Ethics in the participating hospitals. From five hospitals all patients, aged 18 years or older, who had been operated on with curative intent in the previous 15 months because of any (pre)clinical form of breast cancer $(n=387)$ were invited to participate in the FGs during the period of August 2004 until June 2005. Lists with patients eligible for recruitment were obtained from the breast nurses in the participating hospitals.

Similar eligibility criteria were used for the recruitment of participants in the FGs and in the CM, except for the period in which patients had undergone their primary treatment. Because fewer participants were needed in the CM meetings than in the FGs, this period was reduced to 12 months. As analyses of the FGs took four months, CM sessions were held four months after the FGs had been conducted. Both time-related methodological aspects resulted in a (partly) new cohort of people. For the CM 296 breast cancer patients were invited.

An invitation letter (explaining the aim and content of the study) and an application form were sent by mail to the people who met the eligibility criteria for participation 2 weeks before the FGs and CM sessions. Patients could indicate on the application form whether they wished to stay informed about the results of the study and whether they wished to participate. The people who applied received a confirmation letter and an 
informed consent form by mail. Signed informed consent forms were obtained from all participants before the start of the FGs.

\section{Focus groups}

The diversity of breast cancer treatment regimens within and between hospitals is great. Potential local hospital-related opinions and experiences may raise different issues for different patients. To overcome differences between hospitals and to increase the external validity of the instrument, eight FGs consisting of six to a maximum of 12 patients each ${ }^{22}$ were planned. Grouping of the FGs was dependent on the location in the Netherlands. A flow chart describing the development process of the study is shown in Figure 1.

A fixed scenario (Appendix) was used to chair the $\mathrm{FGs}^{23}$. The discussion was structured by the chair if needed but neither the chair nor the secretary played an active role in the discussion. An open-ended question was asked at the end of each meeting to identify areas of breast cancer care that had not been covered during the meetings. The FGs were tape-recorded and transcribed anonymously.

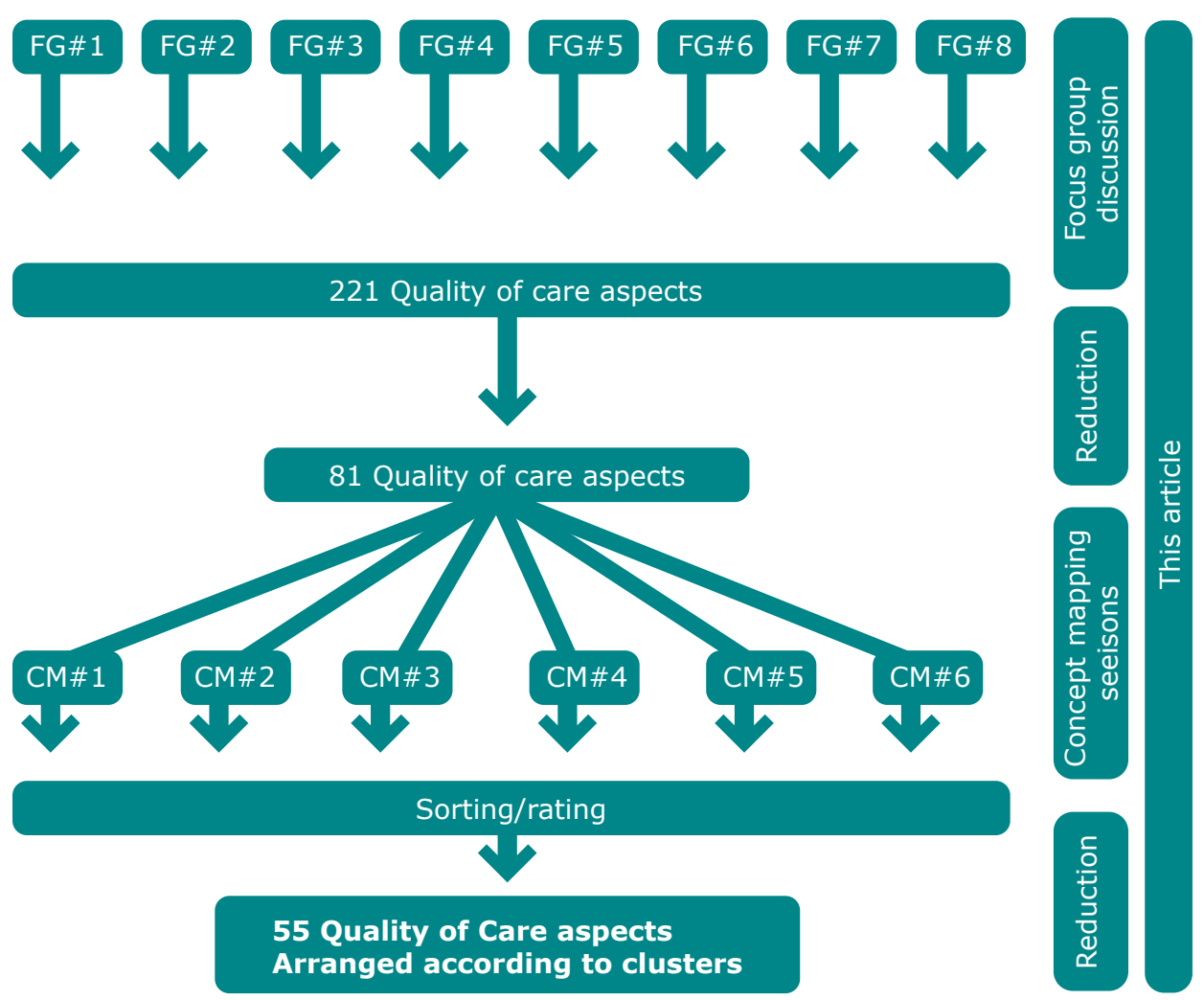

Figure 1. Flow chart showing the first part of the development process of the new instrument on quality of care for breast cancer 
A: From focus groups to concept mapping

1. Aspect is sensitive to change.

2. Aspect is an objective opinion.

3. The major part of the target population is able to judge the aspect.

4. In case of several specific aspects describing one subject, only the aspect that is applicable to most respondents, is preserved.

5. In case of several aspects describing in different words the same experience, only the aspect that describes the aspect most clearly, is preserved.

6. Aspects that are mentioned in several FGs have preference above aspects that are mentioned less frequently.

B: From concept mapping to final set

1. In case of several aspects describing a certain aspect of care, only the aspect that describes the aspect most specifically, is preserved.

2. Aspect is applicable to most respondents.

3. Aspect is not ambiguous.

4. An aspect that is rated relatively high on importance has preference above an aspect that is rated relatively low.

Figure 2. Reduction criteria used during the development process of the final set of aspect

\section{Analysis of focus groups}

Nvivo (Version 2.0, QSR International Pty Ltd., Melbourne, Australia, 1999-2002) was used by two researchers for the coding of the texts. In case of discrepancy, consensus was reached through discussion. Parts of the texts were abstracted into aspects of quality of care. The number of aspects was reduced to a feasible number by using reduction criteria (Fig. 2A) that were predetermined by two of the authors (MdK, HS).

\section{Concept mapping}

After application of the reduction criteria to the results of the FGs, participants in the CM grouped the aspects that were left, according to similarity. Each aspect was also ranked by the participants according to importance ${ }^{24}$ on a scale from one (relatively unimportant) to five (extremely important).

\section{Analysis of concept mapping}

The software programme Ariadne (NcGv/Talcott, Utrecht, the Netherlands, 1995) based on multidimensional scaling and hierarchical cluster analysis, was used for analysis of the CM data. This resulted in visual displays ('concept maps') depicting relationships in clusters between the aspects that had been grouped by the participants. Furthermore, a list of aspects of care arranged according to importance on the basis of the participants' 
data was obtained.

Reduction of the number of aspects in both steps of the process was performed by two of the authors (MdK, HS), and was aimed at a set that covered the maximum scope of care with a minimum number of aspects. This set of aspects should be suitable for a questionnaire used to describe quality of care through the eyes of breast cancer patients. Reduction criteria B were used for determination of the appropriateness of inclusion in the final set of aspects (Figure 2). Grouping aspects according to similarity resulted in general clusters of aspects that address a particular topic.

\section{RESULTS}

The overall response rate for the FGs was 25\% (95/387), which exceeded the planned maximum number of participants. Consequently, 23 over-recruited patients were randomly excluded from participation. A total of 72 participants (mean age (SD); 56.7 (10.6) joined in one of the eight FGs. The number of participants (mean age (SD);

Table 1. Sociodemographic and illness characteristics of participants

\begin{tabular}{|c|c|c|c|}
\hline Variable & & $\begin{array}{l}\text { Focus groups } \\
(\mathrm{N}=72)\end{array}$ & $\begin{array}{l}\text { Concept mapping } \\
(\mathrm{N}=67)\end{array}$ \\
\hline Gender & Female & $100(100 \%)$ & $100(100 \%)$ \\
\hline \multirow[t]{4}{*}{ Civil status } & Married & $54(75 \%)$ & $54(81 \%)$ \\
\hline & Not married & $8(11 \%)$ & $7(10 \%)$ \\
\hline & Divorced & $2(3 \%)$ & $2(3 \%)$ \\
\hline & Widowed & $8(11 \%)$ & $4(6 \%)$ \\
\hline \multirow[t]{4}{*}{ Education } & Primary school & $3(4 \%)$ & $2(3 \%)$ \\
\hline & Secondary school & $38(53 \%)$ & $42(64 \%)$ \\
\hline & College & $28(39 \%)$ & $16(24 \%)$ \\
\hline & University & $3(4 \%)$ & $6(9 \%)$ \\
\hline \multirow{2}{*}{$\begin{array}{l}\text { (Mod. Rad.) } \\
\text { Mastectomy }\end{array}$} & Yes & $37(51 \%)$ & $36(54 \%)$ \\
\hline & No & $35(49 \%)$ & $31(46 \%)$ \\
\hline \multirow[t]{2}{*}{ Lumpectomy } & Yes & $48(67 \%)$ & $34(51 \%)$ \\
\hline & No & $24(33 \%)$ & $33(49 \%)$ \\
\hline \multirow[t]{2}{*}{ Radiotherapy } & Yes & $37(51 \%)$ & $38(57 \%)$ \\
\hline & No & $35(49 \%)$ & $29(43 \%)$ \\
\hline \multirow[t]{2}{*}{ Chemotherapy } & Yes & $27(38 \%)$ & $32(48 \%)$ \\
\hline & No & $45(62 \%)$ & $35(52 \%)$ \\
\hline \multirow[t]{2}{*}{ Hormonal therapy } & Yes & $8(11 \%)$ & $9(13 \%)$ \\
\hline & No & $64(89 \%)$ & $58(87 \%)$ \\
\hline
\end{tabular}


54.4 (10.0) in the six CM meetings was 67 (response: 70/296 (=24\%). Reasons for not participating despite application concerned transportation problems $(n=1)$, emotional problems $(n=1)$, and problems with the details of the exercises $(n=1)$. For both the FGs and the CM the response rate was comparable among hospitals. Both groups were representative of the Dutch breast cancer population ${ }^{25}$. All meetings lasted between 1.5 and $2 \mathrm{~h}$. Characteristics of the participants in the FGs and CM are shown in Table 1.

\section{Focus groups}

The diversity in experiences between the participants gave rise to interactive meetings and lively discussions. Opinions differed on how care should be provided to breast cancer patients, on group level as well as on hospital level. Sharing experiences sometimes led to unexpected emotional reactions. Patients learned from each other and responded well to each other.

One FG needed more guidance than the other, and in some groups there was time for joking (e.g. showing each other wigs and mentioning anecdotes on forgetting the prosthesis). The patient approach and the wish to be treated less as a number and more as an individual person, was a core theme throughout all FGs.

Data from the FGs were abstracted into 221 aspects on quality of care and arranged into 19 general dimensions of care. The dimensions most commonly addressed were patient education (37 aspects, e.g. 'breast nurse provides me with information on reconstructive surgery'), involvement in decision making (26 aspects, e.g. 'in case of a trainee I am asked for permission regarding his/her presence'), skills of caregivers (22 aspects, e.g. 'physician reads my file before he enters the room') and a patient centred approach (20 aspects, e.g. 'on the day of surgery I am given a choice between going home or staying overnight'). Aspects of involvement in decisions and patient approach were mentioned in most sessions (mean: 3.0 and 2.9 times per aspect respectively). All transcripts of the eight FGs contained conversations on education, involvement in decision making, skills of caregivers, continuity of care, psychological aspects and waiting times.

When patients were asked which aspects of care they would improve if they could, aspects relating to waiting times as well as the wish for a postoperative visit by the breast nurse were most frequently mentioned. Other areas for improvement concerned communication between clinicians and general practitioners and more flexible scheduling at the department of radiotherapy. Few patients felt that the quality of breast cancer care was optimal.

Application of reduction criteria to the 221 aspects derived from the FGs resulted in 81 aspects to be included in the CM sessions. The largest part of the reduction was performed on the basis of the criteria 'content similarity of aspects' and 'frequency with which aspects were mentioned ${ }^{26}$ (Fig. 2A: criteria 5 and 6 respectively). 


\section{Concept mapping}

Patients reported to have more problems with the similarity assignment than with the importance assignment. Some meetings lasted the maximum $2 \mathrm{~h}$ that were planned. The rating of aspects according to importance on a scale from one (relatively unimportant) to five (extremely important) led to mean scores that ranged from 1.4 ('my physician provides me with information about the existence of patient support groups') to 4.7 ('direct referral by the GP to the hospital when a suspicious lesion is found'). Following the grouping according to similarity, two researchers reviewed the different cluster solutions. Over six clusters, the division of aspects into the different clusters became inconsistent with the interpretations obtained from the FG transcripts and the cluster labels that were given by the participants. Under six clusters, aspects clung together into very broad non-specific groups. Therefore, it was decided that a six-cluster solution fitted best (Figure 3). In this figure, the distance between the aspects illustrates the degree of similarity between the aspects; those aspects that were arranged together by more participants appear closer to each other than other aspects. For example, aspect 22 ('on the day of surgery I am operated on within $3 \mathrm{~h}$ after my operation was scheduled') and aspect 49 ('within $2 \mathrm{~h}$ after surgery the surgeon comes to see me') were considered related by participants, whereas aspect 71 ('results of diagnostic tests are given by the surgeon that I have seen before') and aspect 3 ('during diagnostic tests caregivers tell me what they do and see') were felt by the participants to be less related to one another.

Consensus was achieved about adding aspects 11 ('nurses give practical advice for the home situation on wound care and exercises') and 15 ('nurses give clear instructions about what I can and cannot do after surgery') to the cluster 'continuity of care' (cluster 2 in Figure 3). The researchers also agreed that aspect number 5 ('caregivers ensure that all results are available when I have an appointment with them for that reason') and aspect number 71 ('results of diagnostic tests are given by the surgeon that I have seen before') were added to the cluster 'focus on the patient' (cluster 6 in Figure 3), instead of the cluster 'continuity of care' (cluster 2 in Figure 3). Moreover, cluster Y was split into two separate clusters: 'period of admission' (top part of cluster 5 until aspect number 60 ) and 'time schedule' (bottom part of cluster 5 below aspect number 60). In a seven -cluster solution this division would have been included with a different cut-off point. In the following reduction process (Figure 2B), the majority of reduction was performed on the basis of the criteria 'content specificity of aspects' and 'mean importance scores of aspects' (Figure 2B: criteria 1 and 4 respectively). 'Professionals take into account my agenda when planning appointments' is an example of an aspect that was rated relatively low as compared to other aspects. Most aspects that were not included in 

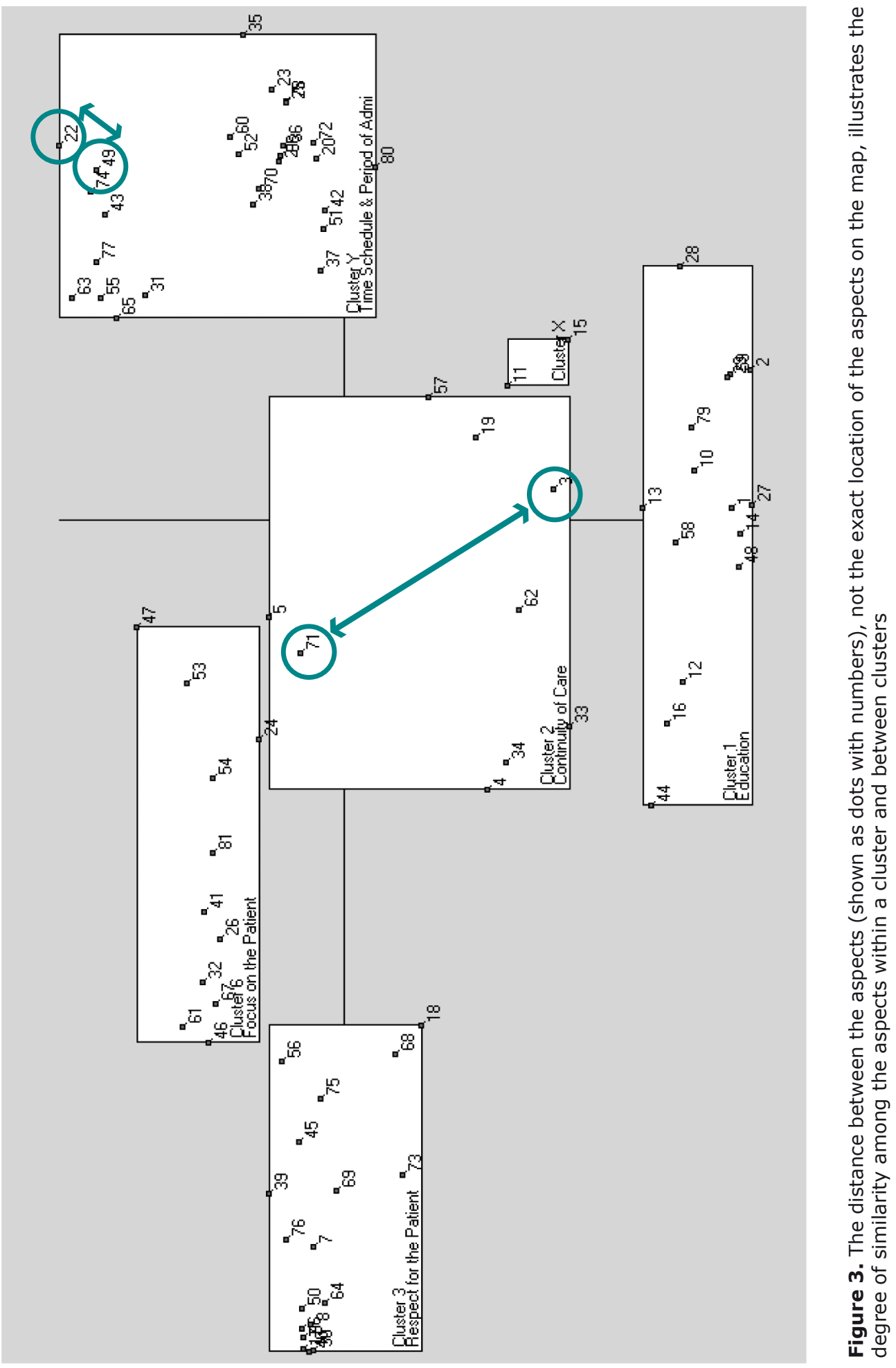
Figure 4. Final list of aspects after concept mapping and analysis. Participants ranked the aspects according to importance on a scale form one (relatively unimportant) to five (extremely important).

No Aspects / Cluster

Mean Mean

Item Cluster

Impor- Impor-

tance tance

score Score

Cluster no 1 Education

$\begin{array}{llll}\text { 1. Clear information about the risks of the treatment I have chosen } & 4.2 & 3.63\end{array}$

2. Adequate information about possible side effects of the treatment I 4.0 have chosen

3. Clear information about different treatment options 4.0

4. Doctor gives clear information about diagnostic tests 3.9

5. The caregiver explains exactly about the content of the treatment 3.8 that I have chosen

6. Openness about my current status at each moment that I ask for it 3.4

\begin{tabular}{ll}
\hline 7. Clear information on the period of admission & 2.9
\end{tabular}

8. Good information about a possible drain and/or prosthesis 2.8

Cluster no 2 Continuity of Care

1. Mutual communication on relevant information about me by the $\quad \begin{array}{lll}3.7 & 3.14\end{array}$ different caregivers

2. Openness by the doctor about the length of the waiting times (for 3.6 outpatient clinic, results, surgery)

3. $\quad$ During diagnostic tests a caregiver tells me what he/she sees and 3.5 does

4. The caregivers give me tips on what to do with the consequences of 3.5 the adjuvant treatment (e.g. tiredness, baldness, swollen arm)

5. Clear instructions about what I may and may not do after surgery 3.3

6. Follow-up by the doctor/breast nurse after hospital treatment 3.2

7. Clarity about which person to turn to with questions during my 3.0 treatment

\begin{tabular}{lll}
\hline 8. A breast nurse that is always available for questions & 2.6
\end{tabular}

9. Caregivers give me instruction about exercises and wound care for 2.5 the period after surgery

10. Caregivers provide me with practical information on wound care for 2.5 the home situation

Cluster no 3 Respect for the Patient

1. During treatment nurses and doctors listen with close attention to $3.5 \quad 3.13$ me

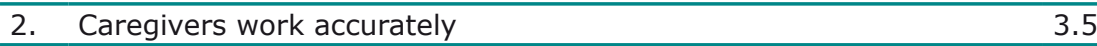

3. $\quad$ During treatment caregivers take enough time for me 3.4

4. Caregivers know about my general health status 3.3

$\begin{array}{ll}\text { 5. Caregivers take me seriously } & 3.3\end{array}$

6. Caregivers are prepared for a consultation and do not prepare dur- 3.2 ing my consultation

7. The doctor pays attention to the fear that waiting (for surgery and 3.2 the results) encompasses

8. There is room to give my opinion 3.0

9. Carefulness with personal data 2.9 
10. The doctor can always be reached for questions, either in person or 2.8 by phone

11. During treatment caregivers approach me in a respectful manner

2.8

12. Caregivers approach me equally

2.7

Cluster no 4 Time Schedule

1. Direct referral by the GP to the hospital when a suspicious lesion

$4.7 \quad 3.89$ was found

2. Caregivers offer me a follow-up consultation six months after sur- 4.3 gery

3. The result of the biopsy is known within a week 4.3

4. The results of X-ray, ultrasound and biopsy are known within a day 4.2

5. Within a week after referral from my GP I have a first consultation 4.2 at the Breast Unit

6. Within two weeks after the results I am operated on 4.1

\begin{tabular}{ll}
7. & All diagnostic tests take place at the same day \\
\hline 8.0
\end{tabular}

8. In case of worries on my side I am able to come to the Breast Unit 3.6 within a day

9. Within three weeks after surgery I receive an announcement for 3.3 adjuvant treatment

10. Caregivers engage home care nursing before discharge if needed 2.2

Cluster no 5 Period of Admission

1. On the day of surgery I am operated on within three hours after I $\begin{array}{lll}3.2 & 2.72\end{array}$ was told

2. Within two hours after surgery the surgeon comes to see me 3.2

3. As soon as I am awake, the department nurse comes to see me 2.9

4. There is a possibility to stay in the hospital until I feel well enough 2.6 to go home

5. Caregivers leave the choice up to me whether I go home on the day 2.2 of surgery or not

6. At discharge caregivers take into account my situation at home $\quad 2.2$

Cluster no 6 Focus on the Patient

1. Caregivers take care that all results are available when I come to $4.4 \quad 3.36$ the hospital to hear them

2. $\quad$ During treatment I see the same doctor every time 4.1

3. The surgeon leaves the choice up to me whether I undergo breast 3.9 conserving surgery or a breast amputation

4. I can take part in the decision about my treatment 3.6

5. My attending doctor operates on me 3.5

6. My attending doctor provides me with the results of diagnostic tests 3.3

7. Caregivers take into account my preference for a certain doctor 2.8

8. Within two hours after surgery the breast nurse comes to see me 2.5

9. The caregivers do not let me wait in the waiting room for more than 2.1 15 minutes 
the final list addressed quality aspects in the cluster 'Focus on the Patient'. A final list of 55 aspects was established, divided into six general clusters. Figure 4 shows these aspects with their mean item importance scores in the third column. For example, direct referral by the general practitioner (Cluster 'Time Schedule') was considered the most important aspect whereas a waiting time of less than 15 min (Cluster 'Focus on the Patient') was perceived less important by the participants when they assessed quality of breast cancer care. The cluster 'Time Schedule' contained the highest mean cluster score (3.89) as opposed to 'Period of Admission' (2.70), the cluster with the lowest mean cluster importance score (Figure 4: fourth column).

\section{DISCUSSION}

In this study a set of breast cancer specific indicators was developed that reflects quality of care from the patient's perspective, using a combination of FGs and CM meetings. A recognised difficulty in planning FGs is the number of participants to recruit and the number of sessions to hold ${ }^{22}$. Exploring quality of care and collecting brief opinions on this complex topic was more important to us than collecting long stories from participants. Therefore, we planned FGs with large numbers of participants. The FGs resulted in a wealth of data, concerning many aspects of breast cancer care, ranging from the breast screening programme to home care nursing after surgery. After six or seven FGs it became more difficult to gather new information and we observed the point of 'theoretical saturation'; more FGs would not yield new information ${ }^{27}$. We believe that concerning this complex subject the number of eight FGs was appropriate and that the greater part of the subject was covered.

Several aspects play a role in the external validity of the data. The study was undertaken in five hospitals throughout the Netherlands and the age range of the participants corresponded well to that of the Dutch breast cancer population in 2003. The study population was therefore a representative sample of the Dutch breast cancer population. Furthermore, as not all participants had experienced the same therapies, the variety of treatment regimens enhanced the brainstorming process and led to few dimensions of breast cancer treatment remaining untouched. On the other hand, a homogeneous sample of participants was achieved by inviting only people who had experienced breast cancer treatment. As a result, comparison between the different groups was facilitated ${ }^{28}$. The final aspect that contributed to the external validity was the large number of participants in both the FGs and the CM.

In our opinion, CM provides an elegant tool to differentiate between aspects on the basis of importance scores and similarity scores and making qualitative data quantifiable. In reaching the optimum set of aspects, we made some adjustments to the concept map 
solutions as provided by Ariadne. These adjustments addressed aspects that either led to more specific clusters or were on the periphery of the original clusters, indicating that they did not play an important role within the original clusters.

Kleeberg and colleagues ${ }^{29}$ presented data suggesting that breast cancer patients showed a need for more information on, for example, effects of treatment on sexual life and therapy-related side effects. Although the latter aspect was addressed in both the FGs as well as the CM part of our study, the former aspect was not mentioned in any of our eight FGs. This may be explained by the fact that Kleeberg conducted FGs with patients with different types of cancer and applied the results to breast cancer patients illustrating that his study was not breast cancer specific.

In seven out of eight FGs the importance of patients' support groups was mentioned, consistent with other research ${ }^{30}$. The support groups were included in an aspect during CM. However, CM analysis showed that the aspect had been given a relatively low importance score (1.4 on a scale from one to five) compared to other aspects. Therefore, it was not included in the final list of items (Figure 4), in which items are shown that best describe quality of care according to breast cancer patients. This difference supports our idea that a combination of several FGs and CM sessions increases the validity of the results.

According to the response to the open-ended questions, content validity of the data have would have improved if the role of the partner had been more extensively discussed. This suggestion will be included in the following steps of development of the questionnaire. The next step is to pilot these aspects and develop a final questionnaire that could be validated internationally. 
Appendix. Supplementary data

Fixed scenario used for the focus groups. All 'heading topics' are discussed and start with a question by the chairman on what quality of care on the concerning topic is, according to the participants. The subjects indicated by bullet points serve as a guideline for the chairman to lead the discussion on the topic as mentioned in the heading, rather than discussing all subjects in a chronological order. Whether or not the subjects indicated by bullet points are all discussed depends on the amount of information that participants have to share with each other. At the end of the discussion of each topic, participants are asked which information they would like to add to complete the information about quality of care concerning that topic.

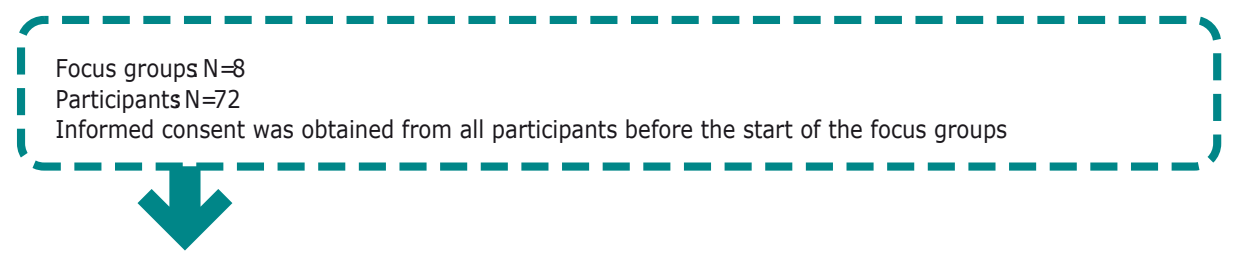

Preparation

- provision of coffee, tea, cakes and water

- provision of paper\& pens (in case participantsshould wish to make notes)

Introduction

- chairman and secretary introduce themselves

- participants are given the opportunity to tell something about themselves in a few sentences

(e g name, why they were treated, which treatments they had received)

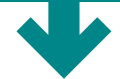

The study

- chairman explains

- goal of the study

- aim of the meeting discuss the meaning and aspects of quality of breast cancer care

- eligibility criteria for invitation

- chairman emphasizes that participants are experts in the field of quality of breast cancer care, and

encourages participants to sharetheir views in the meetings, in order to optimise the outcome of the focus group

Course of the meeting

- chairman outlines

- length of the meeting $(1,5-2 \mathrm{~h})$

- what aspects are to be discussed

- chronological order of discussion of the aspects

- open atmosphere, i.e. everybody is free to respond whenever they want, without denying others the

opportunity to discuss their opinion on quality of care

- audio taped character of the meeting(as mentioned in the information letter)

- chairman asks to switch off mobile phones

- secretary starts audio taping 


\section{Diagnostic phase}

- discovery of breast cancer national screening programme/ GP/own finding

- referral to the breast unit

- oral/written information about breast unit prior to hospital visit

- explanation about the organisation of the breast unit during the first visit

- diagnostic tests mammography, breast ultrasound, fine-needle biopsy, core biopsy, MRI

- consultations with surgeons and breast nurses

- intake, physical examination

- information about: results of diagnostic tests, therapeutic optionşside effects, medicine use, survival rates, positive and negative aspects of different treatment options, possible complications, information about the day of surgery

- communication between health care professionals

- organisation of the diagnostic phase in general

- preoperative screeningat department of anesthesiology

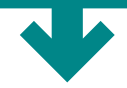

\section{Surgery period}

- positive /negative aspects about the day of surgery

- information about

- information about going home the surgical procedure

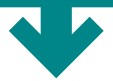

Results of surgery

provision of information moment:content
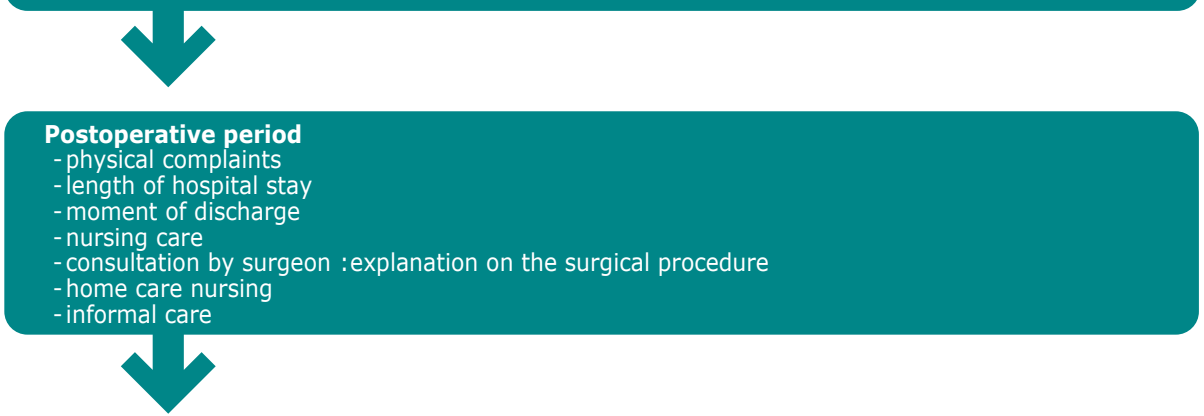

\section{Drain \& wound care}

- period

- visits to breast unit

-body image

- information by health care professionals

-home care nursing

-informal care

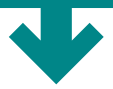

Adjuvant treatment(s)

-type

- course

- planning

- positive/negative aspects

- home care nursing

-informal care 
Healthcare givers' communication skills

- courtesy

-kindness

- understandable language

- dealing with questions

- taking the patient seriously

- understanding

-trust

-emotional support

- provision of information

-time management

-keeping appointments

- meeting/living up to the patient's expectations

- leaving room for the patient to take part in decisions

- advice

-knowledge about innovative methods

- explanation on medication, goalside effects etc

-accessibility (by phone)

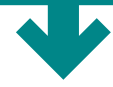

\section{Organisation in general}

-waiting times

- process times

- multidisciplinary decisions

- professional behaviour

- positive/negative experiences

-handling of complaints

- confidentiality

-replacement of staff in case of disease, holidays.etc

- continuity of caregivers

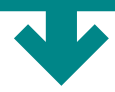

\section{Accommodation}

\section{-hospital}

- adjuvant therapy

- accessibility

- transportation

-hygiene

-waiting rooms, consultation rooms, examination rooms

- privacy

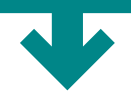

Current stage of disease

- success of treatment (and adjuvant treatment(s)) 
Follow-up period

- goal

- experiences

- usefulness

- consultation(s) with breast nurse

- mammography

- physical examination

- roomfor questions

-information on prosthesis

-information on heredity

- information on risk of recurrence

- information on benefits and side effects of treatment

- continuity of caregivers

- frequency of check-ups

- accessibility

\section{Patient support groups}

- need for

- accessibility

- usefulness

Improvement advice

-suggestions for nurses

-suggestions for doctors

-suggestions for organisation in general

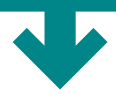

Summary

-other important aspects that have not been discussed

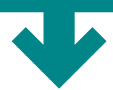

End of session; chairman

-... ends the audio-taping

-... explains the next steps in the study

-... thanks all participants for coming

-... provides reimbursement form for transportation and parking costs 


\section{REFERENCES}

1. Richards T. Patients' priorities. Bmj 1999; 318(7179):277.

2. Groenewegen PP, Kerssens JJ, Sixma HJ, et al. What is important in evaluating healthcare quality? An international comparison of user views. BMC Health Serv Res 2005; 5(1):16.

3. Avis $M$, Bond $M$, Arthur A. Satisfying solutions? A review of some unresolved issues in the measurement of patient satisfaction. J Adv Nurs 1995; 22(2):316-22.

4. Bitar R, Bezjak A, Mah K, et al. Does tumor status influence cancer patients' satisfaction with the doctor-patient interaction? Support Care Cancer 2004; 12(1):34-40.

5. de Bock GH, Bonnema J, Zwaan RE, et al. Patient's needs and preferences in routine follow-up after treatment for breast cancer. Br J Cancer 2004; 90(6):114450.

6. Gould J, Grassau P, Manthorne J, et al. 'Nothing fit me': nationwide consultations with young women with breast cancer. Health Expect 2006; 9(2):158-73.

7. Saares $P$, Suominen $T$. Experiences and resources of breast cancer patients in short-stay surgery. Eur J Cancer Care 2005; 14(1):43-52.

8. Rutgers EJ. Guidelines to assure quality in breast cancer surgery. Eur J Surg Oncol 2005; 31(6):568-76.

9. Birido N, Geraghty JG. Quality control in breast cancer surgery. Eur J Surg Oncol 2005; 31(6):577-86.

10. van der Eijk I, Sixma H, Smeets $\mathrm{T}$, et al. Quality of healthcare in inflammatory bowel disease: development of a reliable questionnaire (QUOTE-IBD) and first results. Am J Gastroenterol 2001; 96(12):3329-36.

11. van Campen C, Sixma HJ, Kerssens JJ, et al. Assessing patients' priorities and perceptions of the quality of healthcare: the development of the QUOTERheumatic-Patients instrument. Br J Rheumatol 1998; 37(4):362-8.

12. Kleeberg UR, Behrens MS, Heiden I. Patient satisfaction in breast cancer careresults from the patients satisfaction and quality in oncological care study (PASQOC 2004). Presented at the 28th San Antonio Breast Cancer Symposium. San Antonio, Tx, December 8-11 2005.

13. van Campen C, Sixma HJ, Kerssens JJ, Peters L. Assessing noninstitutionalized asthma and COPD patients' priorities and perceptions of quality of healthcare: the development of the QUOTE-CNSLD instrument. J Asthma 1997; 34(6):531-8.

14. van Campen C, Sixma H, Friele RD, et al. Quality of care and patient satisfaction: a review of measuring instruments. Med Care Res Rev 1995; 52(1):109-33.

15. Sixma HJ, Kerssens JJ, Campen CV, Peters L. Quality of care from the patients' perspective: from theoretical concept to a new measuring instrument. Health Expect 1998; 1(2):82-95.

16. Gray BS. Focus group feedback from breast cancer patients. J Healthc Qual 1997; 19(5):32-6.

17. Kreling B, Figueiredo MI, Sheppard VL, Mandelblatt JS. A qualitative study of factors affecting chemotherapy use in older women with breast cancer: barriers, promoters, and implications for intervention. Psychooncology 2006; 15(12):106576.

18. Rapport $F$, Iredale $R$, Jones $W$, et al. Decision aids for familial breast cancer: exploring women's views using focus groups. Health Expect 2006; 9(3):232-44. 
19. Bickell NA, Chassin MR. Determining the quality of breast cancer care: do tumor registries measure up? Ann Intern Med 2000; 132(9):705-10.

20. Kitzinger J. Qualitative research. Introducing focus groups. Bmj 1995; 311(7000):299-302.

21. Burke JG, O'Campo $\mathrm{P}$, Peak GL, et al. An introduction to concept mapping as a participatory public health research method. Qual Health Res 2005; 15(10):1392410.

22. Morgan DL, Krueger RA. Focus group kit. Thousand Oaks, Calif.: Sage Publication, 1998.

23. Gilmore GD, Campbell MD. Group Participation Process: Focus Group. Needs and Capacity Assessment Strategies for Health Promotion and Health Education: Jones and Bartlett Publishers, 2005. pp. 98-100.

24. Trochim WM, Linton R. Conceptualization for planning and evaluation. Eval Program Plann 1986; 9(4):289-308.

25. Dutch Cancer Registration (in Dutch) year 2003: Incidence of all patients with breast cancer. http://www.ikcnet.nl/cijfers. [11 September 2006].

26. Duggleby W. What about focus group interaction data? Qual Health Res 2005; 15(6):832-40.

27. Glaser BG, Strauss AL. The discovery of grounded theory; strategies for qualitative research. Chicago: Aldine Pub. Co., 1967.

28. Kitzinger J, Barbour RS. Developing focus group research : politics, theory, and practice. London ; Thousand Oaks: SAGE Publications, 1999.

29. Kleeberg UR, Tews JT, Ruprecht T, et al. Patient satisfaction and quality of life in cancer outpatients: results of the PASQOC study. Support Care Cancer 2005; 13(5):303-10.

30. The patient's point of view. Results of the Working Group on Socio-Psychological Implications of Follow-up. 1995; 6 Suppl 2:65-8. 


\section{Chapter 4}

M. de Kok

H.J.M. Sixma

T. van der Weijden

A.G.H. Kessels

C.D. Dirksen

K.F.J. Spijkers

C.J.H. van de Velde

J.A. Roukema

F.W.C. van der Ent

C. Finaly-Marais

M.F. von Meyenfeldt

Qual Saf Health Care,

In Press, 2010 


\section{ABSTRACT}

\section{Background}

In several breast cancer research environments, there was a need to develop a questionnaire that would 1) provide data on how breast cancer patients experience healthcare services, 2) address issues corresponding with patients' needs and expectations and 3) produce useful data for quality assessment and improvement projects aimed at breast cancer care. This article describes the first part of the quantitative process of item selection, instrument construction and optimisation based on the results of a pilot questionnaire.

\section{Methods}

Based on qualitative research, a pilot questionnaire with items formulated as "performance" and "importance" statements was developed and sent to all breast cancer patients operated on in the previous 3 to 15 months in five participating hospitals. Reduction criteria, exploratory factor analysis, and reliability analysis were used as part of the process of instrument optimisation.

\section{Results}

Of the 637 questionnaires sent out, 299 (47\%) were returned, and 276 (43\%) were used for analyses. Out of the 72 quality items included in the pilot questionnaire, 42 items did not meet the inclusion criteria for the revised version. The remaining items refer to the factors patient education regarding aspects related to postoperative treatment, services by the breast nurse, services by the surgeon, patient education regarding activities at home and patient education regarding aspects related to preoperative treatment (Cronbach $\alpha: 0.70-0.89$ ).

\section{Conclusions}

In this study, the number of items to be included in the self-administered questionnaire was reduced. The resulting set of items that determines patients' perceptions on quality of breast cancer care is easy to complete, and enables anonymous responses. Further research can be aimed at establishing the reliability of the current questionnaire. 


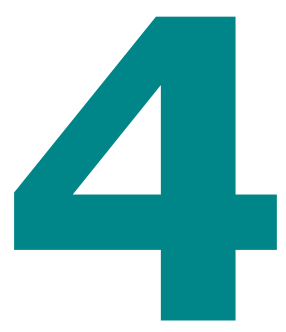

\section{INTRODUCTION}

The quality of breast cancer care has been the subject of many studies. However, these studies rarely included patient preference data ${ }^{1}$. Furthermore, they did not provide information suitable for designing interventions to improve the quality of care ${ }^{2}$, and they usually focused on one or a few separate dimensions of breast cancer care, such as informational needs ${ }^{3}$. In most studies, patients were not involved in the development of the tool, although patient judgements on breast cancer care are of fundamental importance for the assessment of quality of care. Therefore, patients should be involved in the development of an instrument that measures the quality of care.

Quality of care has traditionally been assessed using patient satisfaction measures ${ }^{4}$. In this context, patient satisfaction assessed patients' needs as perceived by healthcare professionals who often develop the questionnaires ${ }^{5-7}$. This may not coincide with what patients consider important. Therefore, patients' experiences may not reflect their view on quality of care, making the relevance of such studies, for "expert" assessment of quality of care concerning a specific disease, limited.

Outcome measures in patient satisfaction studies are often provided as skewed scores with satisfaction rates correlating positively with age ${ }^{8}$. In addition, outcome measures and the actual performance of healthcare systems are only partly related to differences in patient satisfaction scores 9 . Moreover, most researchers are primarily concerned with the outcome of patient (dis)satisfaction and not with the two basic elements: needs and experiences ${ }^{10}$. Another disadvantage of the majority of existing quality-of-care instruments is that they focus on general quality of care, and do not take into account disease-related or procedure-related factors ${ }^{11}$, such as the need for information about potential fatigue during adjuvant treatment in the management of breast cancer ${ }^{12}$. The Netherlands Institute for Health Services Research developed a theoretical 
framework ${ }^{11}$ for questionnaires measuring Quality of Care Through the Patient's Eyes (QUOTE) which overcomes the disadvantages mentioned above. It is based on the SERVQUAL model, which focuses on expectations and experiences ${ }^{13}$. QUOTE instruments have been developed for a number of diseases ${ }^{14,15}$. The instruments address three specific characteristics: the weight that patients attach to various care items (importance), the experiences concerning the functioning of medical practices and healthcare workers for each care item (performance), and the combined effect of importance and performance (quality impact). The questionnaires contain a set of disease-specific questions and a set of generic items that are applicable to all kinds of diseases. The self-administrative character of the questionnaires prevents interviewers' bias.

In several research contexts in the Netherlands, the need was felt to assess quality of breast cancer care as perceived by patients with an instrument that would result in tangible points for improvement. Based on the framework suggested by Sixma and colleagues $^{11}$, QUOTE Breast Cancer was developed to measure quality of breast cancer care. This instrument covers the most important aspects of care, from diagnostic tests until the beginning of adjuvant treatment. The development process started with qualitative research methods ${ }^{16}$. This paper describes the quantitative part of the process of selection of items, instrument construction, and optimisation, based on the results of a pilot questionnaire.

\section{METHODS}

\section{Design, patients and settings}

Participants were breast cancer patients, recruited from five hospitals throughout the Netherlands. Criteria for participation were experience with any type of surgery for breast cancer 3 to 15 months before the start of the study, aged older than 17 years and mental competence as judged by the breast nurse. For privacy reasons, the breast nurses from the participating hospitals provided only names, ages, and types of experienced (breast cancer) surgical procedures of all patients who met these criteria. These patients received the pilot questionnaire and information on the study objectives and procedures by mail. Prepaid envelopes and a letter guaranteeing patient confidentiality were enclosed. No reminder was sent. Data collection was performed from December 2005 through February 2006. 


\section{Scoring and use of the pilot questionnaire}

Based on the qualitative phase ${ }^{16}$, a pilot questionnaire was developed, consisting of four sections and 72 quality items. In Section A, patients were asked to rate perceived performance of the healthcare professionals /services on each of the items (e.g., "how often did the healthcare professionals provide you with clear information on wound care for the home situation?"). Four-point Likert type (1=never; 2=sometimes; 3=usually; $4=$ always) scales were used for most questions and for a set of items binary (yes, no) answering categories were applied. The response option 'not applicable/ I do not know' was added to 11 of the 72 questions in section $A$.

For example, the item 'health professionals informed me well about a possible prosthesis' did not apply to patients who underwent lumpectomy. The performance score represented the proportion of respondents that had experienced the item as (usually/always/yes) accomplished by professionals or institutions ${ }^{17}$.

In Section B, patients were asked to rate the relative importance of the healthcare items. (e.g., "healthcare professionals should provide me with clear information on wound care for the home situation") on ordinal 4-point Likert type scales (not important, fairly important, important, extremely important $)^{14}$.

Questions on patient characteristics (e.g. age, type of treatment ) were included in Section C. Section D allowed for assessment of the pilot questionnaire on use of vocabulary, response options, diversity in dimensions, design and length, and provided room for comments. Moreover, respondents were asked to indicate which other dimensions of care should be included to give a more comprehensive representation of breast cancer care.

\section{Quality impact scores}

While the aim of this study was to find items for improvement for the cohort under study, quality impact (QI) scores are represented in this paper to illustrate the usefulness of the questionnaire. QI scores represent the relative scores of performance $(\mathrm{P})$ and importance (I) on the different items. In general, satisfaction questionnaires show that about $90 \%$ of a population evaluate items of provided care as good, that is they are satisfied with the quality of care provided. Consequently, if $10 \%$ evaluate these items as poor, that is they are not satisfied with the quality of care provided, this implies that the non-performance score $(\mathrm{Pn})$ is .10 . When this non-performance score is combined with a maximum importance score of 4 indicating that patients consider an item extremely important, it leads to a benchmark of .40 above which improvement of quality of care may be needed. Thus, a mean QI score (QI= Pn x I) above .40 means that more than the 
standard $10 \%$ of a population evaluate that item as poor, that is the more the QI score is above .40 , the greater the suitability of the item for improvement.

\section{Statistical Analysis}

Analyses were performed with the SPSS package, version 17.0 ® for Windows (SPSS

INC 2009). Identification of the optimal set of quality of care items started with reduction to a viable number of items. This was done through a set of criteria (Figure 1) decided upon before start of the analysis by two of the authors (MdK and HS).

\section{Taxonomy of the instrument}

To explore the taxonomy of the new instrument, exploratory factor analysis (i.e. principal axis factoring) was performed for the performance items that met the criteria mentioned above. Oblique rotation was used to search for principal factors that were not correlated to each other. This resulted in eigenvalues representing the variance explained by each of the possible factors, and giving useful information concerning the total number of different groups with similar questions (=factors) within the data file. Significant factors underlying the grouping were identified using both the scree test, and eigenvalues $>1.0$ as criterions. Instead of reporting only factor loadings above a certain threshold, all factor loadings are reported ${ }^{18}$.

\section{Reliability testing}

Subsequently, reliability analysis was applied on the performance items to test the internal consistency of the subscales resulting from factor analysis. Corrected item-total correlations represented the correlation between each item in a scale and the total scale score. A score $\geq .40$ was perceived as satisfactory for the internal reliability of the items ${ }^{19}$. Cronbach $\alpha$ was used to determine to what extent different items in a scale measured the same concept. We considered an $\alpha$ of .70 acceptable $^{20}$. The analyses described above resulted in the current version of the questionnaire.

\section{Subgroup analyses}

Bi-variate analyses were performed to explore potential differences between subgroups of respondents. Relations between scale items were calculated through inter-item correlations with .30 benchmarking the minimum ${ }^{21}$. 


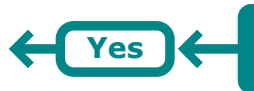

More than $10 \%$ of the values are missing on the performance component ${ }^{19}$

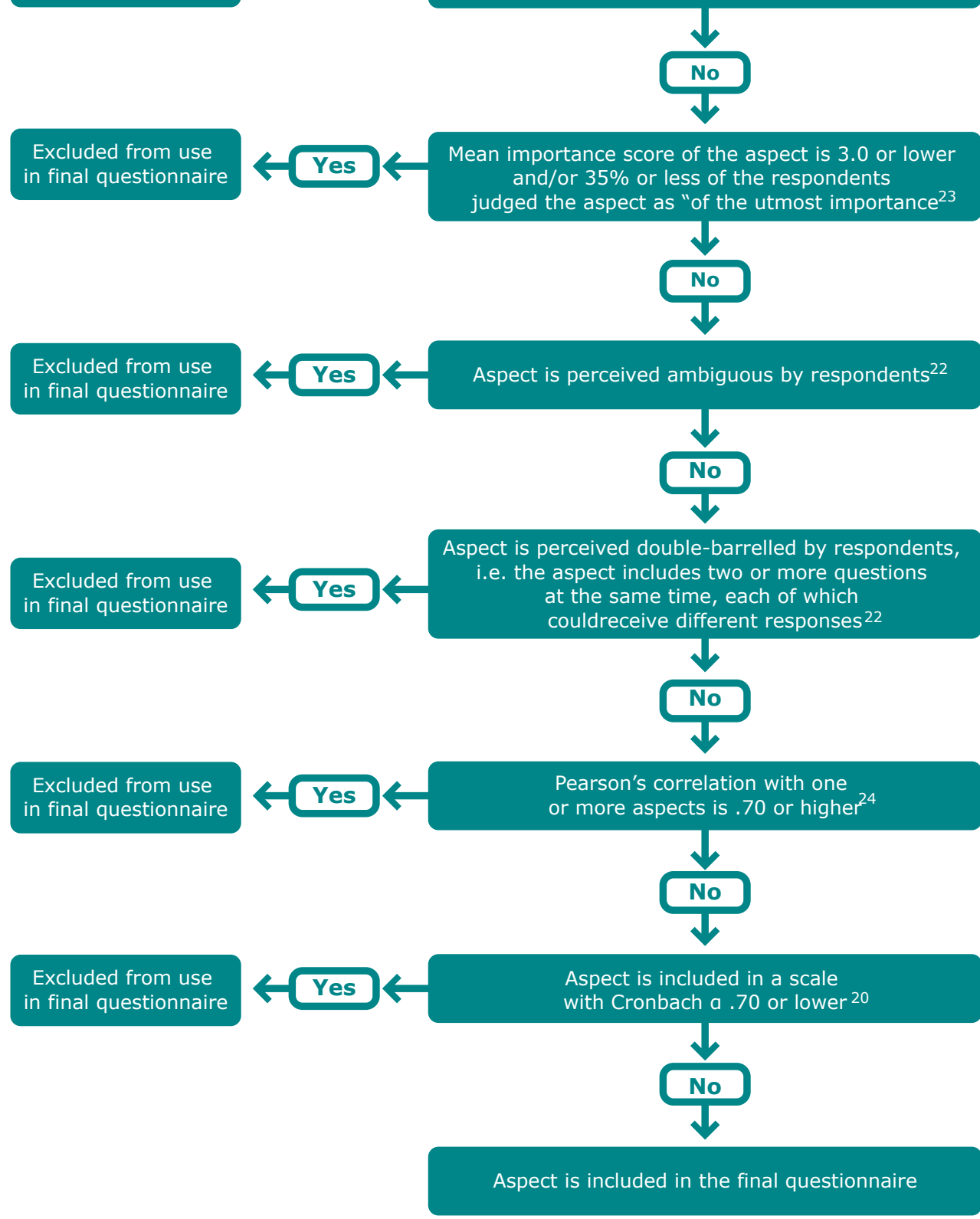

Figure 1. Criteria based on which aspects from the pilot questionnaire were not processed into the final questionnaire 


\section{RESULTS}

\section{Response rates and patient demographics}

Of the 637 questionnaires sent out, 299 were returned (47\%), of which 276 questionnaires (43\% of sent questionnaires) were deemed suitable for further analyses and 23 (8\% of returned questionnaires) were not used for analysis; 2 were returned after analyses had been performed, six patients did not meet the inclusion criteria (e.g. period between surgery and inclusion was 16 instead of the maximum 15 months), 14 were empty, and as only 1 male patient responded, his results were not included to retain homogeneity of the sample. The mean age of the respondents was 57 years (SD: 11.3 years; range: 32-85 years). Of the respondents, 150 (54\%) had experienced a lumpectomy, 144 (52\%) a (modified) radical mastectomy, 137 (50\%) radiotherapy and 105 (38\%) had undergone chemotherapy. Other respondents' characteristics are shown in Table 1.

Table 1. Pilot questionnaire: respondents' sociodemographic and illness characteristics $(\mathrm{N}=276)$

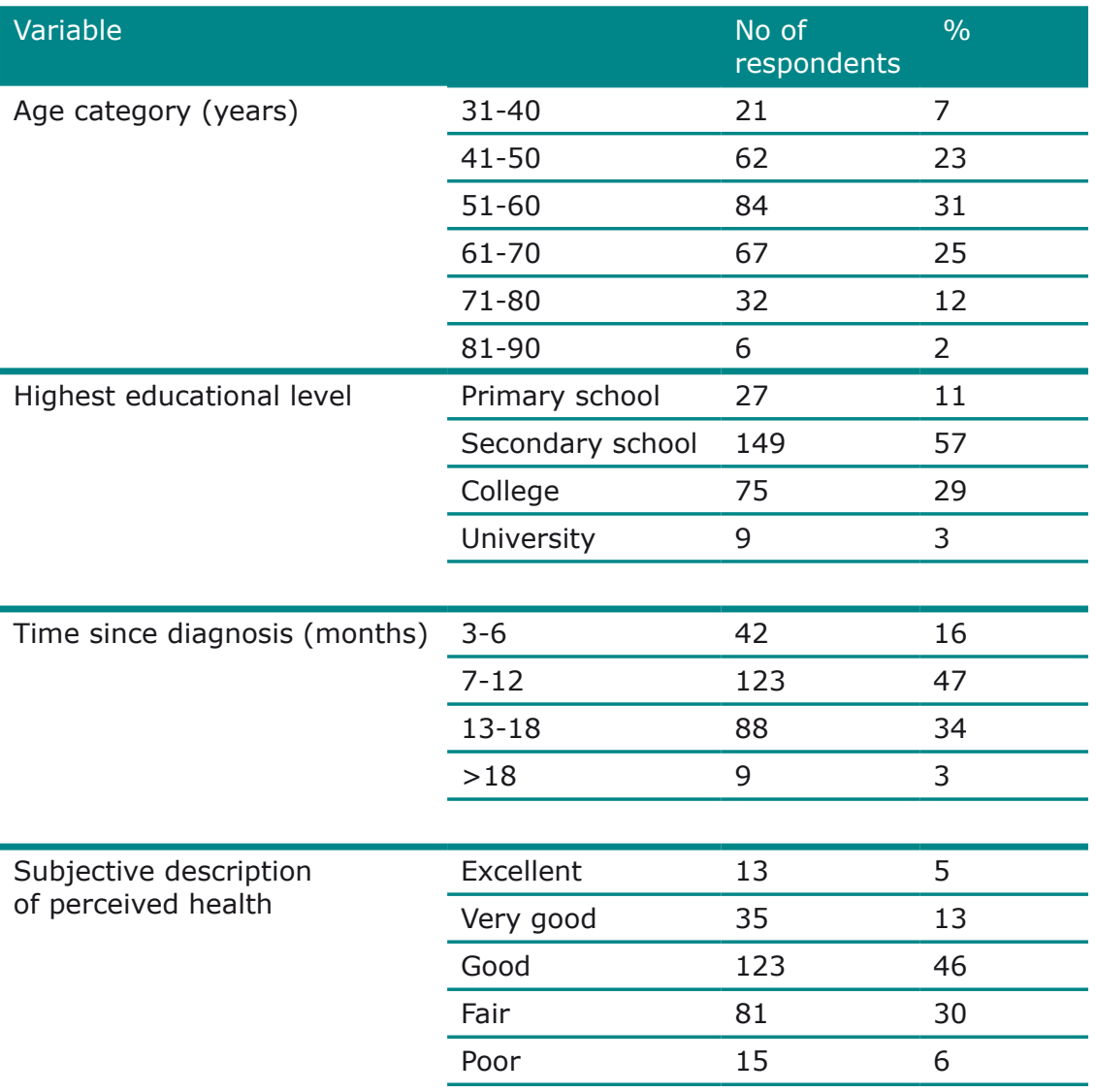


Table 2. Oblique rotation loadings for the six-factor solution

\begin{tabular}{lrrrrrrr}
\multicolumn{3}{c}{ Factor } & & & & \\
& 1 & 2 & 3 & 4 & 5 & 6 \\
$\begin{array}{l}\text { Health professionals informed me well about } \\
\text { survival rates that were known about my } \\
\text { type of breast cancer }\end{array}$ & -0.04 & 0.06 & 0.02 & 0.13 & -0.07 & -0.62 \\
\hline
\end{tabular}

\begin{tabular}{lllllll}
\hline $\begin{array}{l}\text { Health professionals informed me well about } \\
\text { different treatment options }\end{array}$ & -0.04 & -0.01 & 0.13 & 0.10 & 0.05 & -0.66 \\
\hline $\begin{array}{l}\text { Health professionals informed me clearly } \\
\text { about risks of different treatment options }\end{array}$ & -0.06 & -0.03 & 0.00 & 0.02 & 0.06 & -0.69 \\
\hline $\begin{array}{l}\text { Health professionals provided me with good } \\
\text { information about what the chosen treatment } \\
\text { consisted of }\end{array}$ & 0.24 & -0.08 & -0.01 & -0.11 & -0.00 & -0.67 \\
\hline
\end{tabular}

$\begin{array}{lllllll}\text { Health professionals informed me well about } & 0.47 & -0.09 & 0.13 & -0.16 & -0.06 & -0.43\end{array}$ possible side effects of the treatment

\begin{tabular}{lcccccc}
\hline $\begin{array}{l}\text { Health professionals informed me well about } \\
\text { a possible drain or prosthesis }\end{array}$ & 0.35 & 0.09 & -0.09 & 0.24 & -0.04 & -0.37 \\
\hline $\begin{array}{l}\text { Health professionals informed me well about } \\
\text { wound care in the home situation }\end{array}$ & 0.01 & -0.15 & -0.05 & 0.58 & 0.01 & -0.11 \\
\hline $\begin{array}{l}\text { Health professionals informed me clearly } \\
\text { about what I should and should not do after } \\
\text { surgery }\end{array}$ & 0.07 & -0.12 & 0.01 & 0.65 & -0.04 & -0.04 \\
\hline
\end{tabular}

\begin{tabular}{lllllll}
\hline $\begin{array}{l}\text { Health professionals informed me well about } \\
\text { exercises for the period after surgery }\end{array}$ & 0.34 & 0.05 & 0.02 & 0.61 & 0.04 & -0.02 \\
\hline $\begin{array}{l}\text { Health professionals concerned with adjuvant } \\
\text { treatment informed me clearly about possible } \\
\text { side effects of adjuvant treatment(s) }\end{array}$ & 0.71 & 0.00 & 0.10 & 0.15 & 0.07 & -0.10 \\
\hline $\begin{array}{l}\text { Health professionals concerned with adjuvant } \\
\text { treatment informed me clearly about the } \\
\text { start of adjuvant treatment(s) }\end{array}$ & 0.66 & 0.01 & 0.06 & 0.06 & 0.00 & -0.10 \\
\hline
\end{tabular}

\begin{tabular}{lllllll}
\hline $\begin{array}{l}\text { Health professionals concerned with adjuvant } \\
\text { treatment informed me clearly about the } \\
\text { consequences of adjuvant treatment (e.g. }\end{array}$ & 0.73 & -0.02 & -0.06 & 0.09 & 0.09 & -0.01 \\
tiredness, boldness, swollen arm) & & & & & & \\
\hline
\end{tabular}

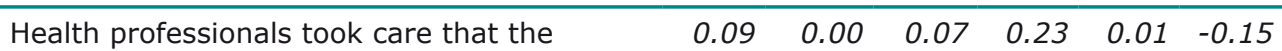
various caregivers coordinated patient education

\begin{tabular}{|c|c|c|c|c|c|c|}
\hline $\begin{array}{l}\text { Health professionals had results available } \\
\text { when I had an appointment with (one of) } \\
\text { them for that reason }\end{array}$ & 0.22 & -0.06 & 0.26 & 0.16 & -0.07 & 0.16 \\
\hline The breast nurse listened to me attentively & 0.08 & -0.87 & 0.10 & 0.09 & -0.06 & 0.04 \\
\hline The breast nurse treated me as an equal & -0.07 & -0.83 & 0.10 & 0.10 & 0.08 & -0.04 \\
\hline The breast nurse took me seriously & -0.02 & -0.96 & 0.06 & 0.05 & -0.02 & 0.05 \\
\hline $\begin{array}{l}\text { The breast nurse spent enough time on my } \\
\text { consultation }\end{array}$ & 0.02 & -0.75 & 0.07 & 0.01 & 0.01 & -0.00 \\
\hline
\end{tabular}




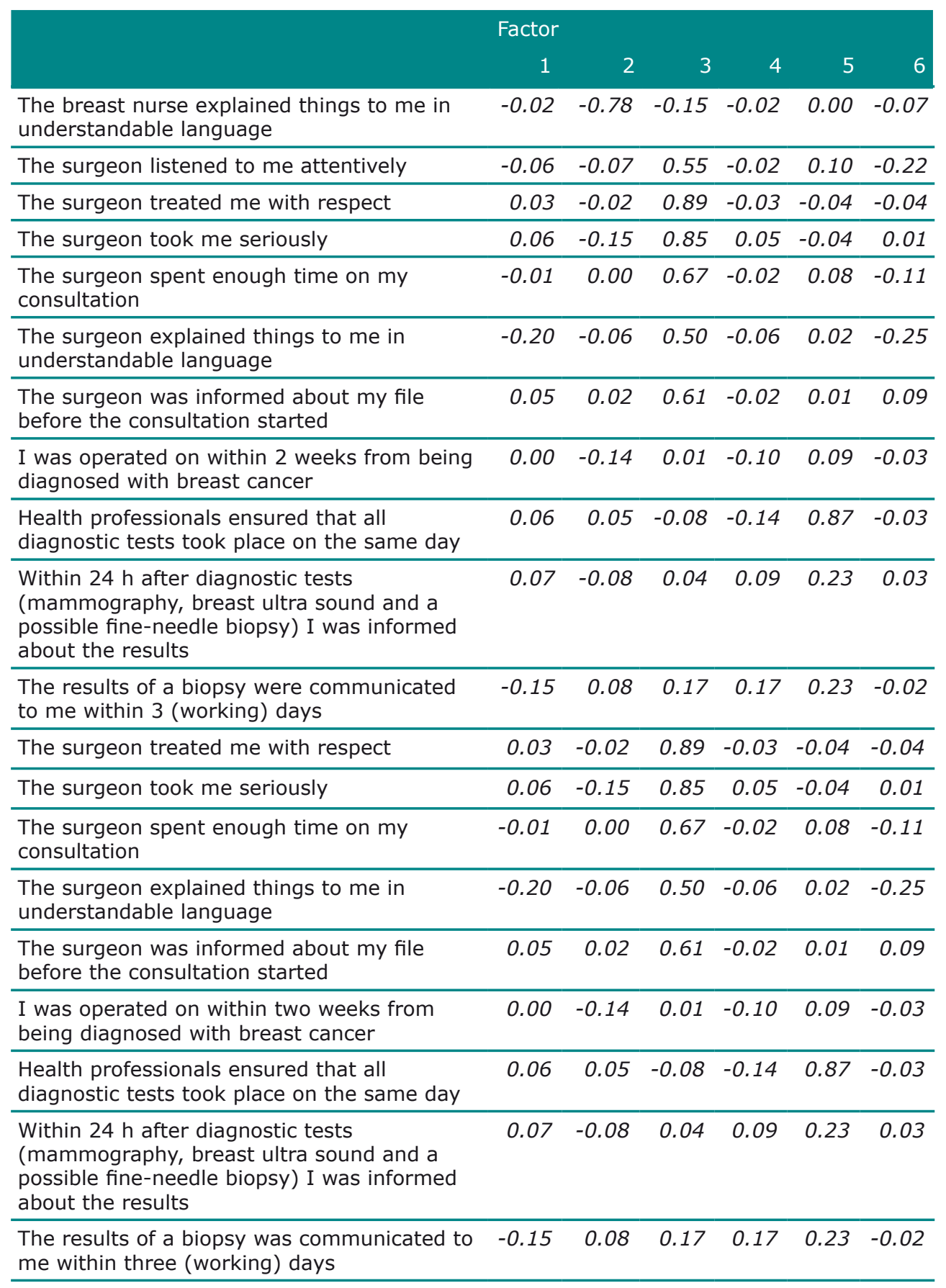


Table 3. Patient scores on quality of breast cancer care as evaluated $(\mathrm{N}=276)$ by the pilot version of the QUOTE- breast cancer.
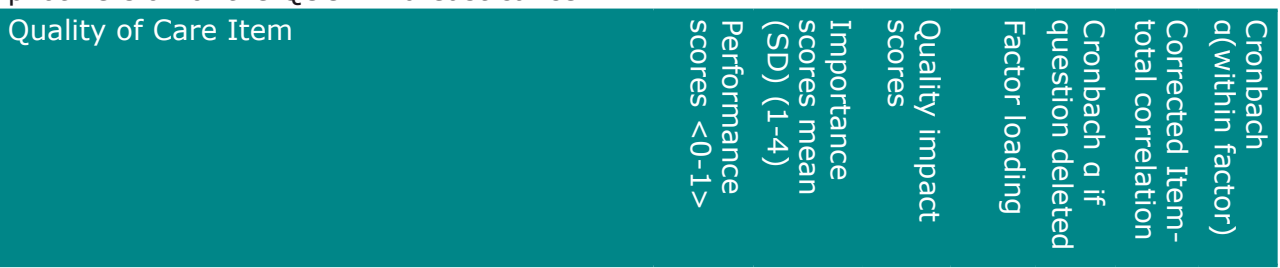

Factor 1: Patient education regarding aspects related to postoperative treatment

\begin{tabular}{|c|c|c|c|c|c|c|}
\hline \multicolumn{7}{|l|}{ Health professionals ... } \\
\hline $\begin{array}{l}\text {... informed me well about possible side } \\
\text { effects of the treatment }\end{array}$ & .85 & $\begin{array}{l}3.61 \\
(.51)\end{array}$ & .54 & .47 & .82 & .54 \\
\hline ... informed me well about a possible drain & .84 & $\begin{array}{l}3.49 \\
(.54)\end{array}$ & .56 & .35 & .82 & .51 \\
\hline $\begin{array}{l}\text {... informed me well about a possible } \\
\text { prosthesis }\end{array}$ & \multicolumn{6}{|c|}{$\begin{array}{l}\text { As items on prosthesis and drain were } \\
\text { combined into one item in the pilot, results } \\
\text { are shown for one item only. }\end{array}$} \\
\hline $\begin{array}{l}\text {... concerned with adjuvant treatment } \\
\text { informed me clearly about possible side } \\
\text { effects of adjuvant treatment(s) }\end{array}$ & .77 & $\begin{array}{l}3.56 \\
(.50)\end{array}$ & .82 & .71 & .77 & .71 \\
\hline $\begin{array}{l}\text {... concerned with adjuvant treatment } \\
\text { informed me clearly about the start of } \\
\text { adjuvant treatment(s) }\end{array}$ & .78 & $\begin{array}{l}3.42 \\
(.52)\end{array}$ & .75 & .66 & .79 & .65 \\
\hline $\begin{array}{l}\text {... concerned with adjuvant treatment } \\
\text { informed me clearly about the consequences } \\
\text { of adjuvant treatment (e.g. tiredness, } \\
\text { boldness, swollen arm) }\end{array}$ & .82 & $\begin{array}{l}3.59 \\
(.52)\end{array}$ & .65 & .73 & .77 & .72 \\
\hline
\end{tabular}

\section{Factor 2: Services by the breast nurse}

The breast nurse ...

\begin{tabular}{|c|c|c|c|c|c|c|c|}
\hline ... listened to me attentively & .97 & $\begin{array}{l}3.45 \\
(.58)\end{array}$ & .10 & -.87 & .86 & .80 & .89 \\
\hline ... treated me as an equal & .98 & $\begin{array}{l}3.33 \\
(.57)\end{array}$ & .07 & -.83 & .88 & .71 & \\
\hline ... took me seriously & .98 & $\begin{array}{l}3.45 \\
(.55)\end{array}$ & .07 & -.96 & $.8 \mathrm{t} 6$ & .82 & \\
\hline ... spent enough time on my consultation & .97 & $\begin{array}{l}3.43 \\
(.57)\end{array}$ & .10 & -.75 & .86 & .78 & \\
\hline $\begin{array}{l}\text {... explained things to me } \\
\text { in understandable language }\end{array}$ & .98 & $\begin{array}{l}3.51 \\
(.56)\end{array}$ & .07 & -.78 & .90 & .62 & \\
\hline \multicolumn{8}{|l|}{ Factor 3: Services by the surgeon } \\
\hline \multicolumn{8}{|l|}{ The surgeon ... } \\
\hline ... listened to me attentively & .96 & $\begin{array}{l}3.51 \\
(.50)\end{array}$ & .14 & .55 & .82 & .63 & .85 \\
\hline ... treated me with respect & .99 & $\begin{array}{l}3.39 \\
(.53)\end{array}$ & .03 & .89 & .81 & .74 & \\
\hline ... took me seriously & .98 & $\begin{array}{l}3.61 \\
(.49)\end{array}$ & .07 & .85 & .81 & .73 & \\
\hline ... spent enough time on my consultation & .94 & $\begin{array}{l}3.46 \\
(.55)\end{array}$ & .21 & .67 & .80 & .70 & \\
\hline $\begin{array}{l}\text {... explained things to me } \\
\text { in understandable language }\end{array}$ & .96 & $\begin{array}{l}3.55 \\
(.51)\end{array}$ & .14 & .50 & .83 & .59 & \\
\hline $\begin{array}{l}\text {... was informed about my file } \\
\text { before the consultation started }\end{array}$ & .92 & $\begin{array}{l}3.50 \\
(.53)\end{array}$ & .28 & .61 & .85 & .53 & \\
\hline
\end{tabular}




\begin{tabular}{|c|c|c|c|c|c|}
\hline \multicolumn{6}{|l|}{ Health professionals ... } \\
\hline $\begin{array}{l}\ldots \text { informed me well about wound care } \\
\text { in the home situation }\end{array}$ & .90 & $\begin{array}{l}3.52 \\
(.53)\end{array}$ & .35 & .58 & .67 .48 \\
\hline $\begin{array}{l}\text {... informed me clearly about what } \\
\text { I should and should not do after surgery }\end{array}$ & .81 & $\begin{array}{l}3.44 \\
(.53)\end{array}$ & .65 & .65 & $.51 \quad .60$ \\
\hline $\begin{array}{l}\ldots \text { informed me well about exercises } \\
\text { for the period after surgery }\end{array}$ & .72 & $\begin{array}{l}3.42 \\
(.54)\end{array}$ & .96 & .61 & .65 \\
\hline \multicolumn{6}{|c|}{ Factor 5: Patient education regarding aspects related to preoperative treatment } \\
\hline \multicolumn{6}{|c|}{ Health professionals ... } \\
\hline $\begin{array}{l}\text {... informed me well about survival rates that } \\
\text { were known about my type of breast cancer }\end{array}$ & .72 & $\begin{array}{l}3.73 \\
(.54)\end{array}$ & 1.04 & -.62 & $.81 \quad .54$ \\
\hline $\begin{array}{l}\text {... informed me well about different } \\
\text { treatment options }\end{array}$ & .88 & $\begin{array}{l}3.74 \\
(.46)\end{array}$ & .45 & -.66 & .73 .69 \\
\hline $\begin{array}{l}\text {... informed me clearly about risks of } \\
\text { different treatment options }\end{array}$ & .78 & $\begin{array}{l}3.66 \\
(.49)\end{array}$ & .81 & -.69 & $.74 \quad .67$ \\
\hline $\begin{array}{l}\text {... provided me with good information about } \\
\text { what the chosen treatment consisted of }\end{array}$ & .91 & $\begin{array}{l}3.64 \\
(.49)\end{array}$ & .33 & -.67 & .64 \\
\hline \multicolumn{6}{|l|}{ Separate items } \\
\hline $\begin{array}{l}\text { Health professionals took care that the } \\
\text { various caregivers coordinated patient } \\
\text { education }\end{array}$ & .82 & $\begin{array}{l}3.49 \\
(.56)\end{array}$ & .63 & B & $\begin{array}{l}\text { Reason for } \\
\text { inclusion } \\
\text { in the final } \\
\text { questionnaire }^{\text {a }}\end{array}$ \\
\hline $\begin{array}{l}\text { Health professionals had results available } \\
\text { when I had an appointment with (one of) } \\
\text { them for that reason }\end{array}$ & .91 & $\begin{array}{l}3.61 \\
(.53)\end{array}$ & .32 & B & \\
\hline $\begin{array}{l}\text { I was operated on within two weeks from } \\
\text { being diagnosed with breast cancer }\end{array}$ & .47 & $\begin{array}{l}3.63 \\
(.64)\end{array}$ & 1.92 & A & \\
\hline $\begin{array}{l}\text { Health professionals ensured that all } \\
\text { diagnostic tests took place on the same day }\end{array}$ & .59 & $\begin{array}{l}3.55 \\
(.59)\end{array}$ & 1.46 & A & \\
\hline $\begin{array}{l}\text { Within } 24 \mathrm{~h} \text { after diagnostic tests } \\
\text { (mammography, breast ultra sound and a } \\
\text { possible fine-needle biopsy) I was informed } \\
\text { about the results }\end{array}$ & .26 & $\begin{array}{l}3.52 \\
(.65)\end{array}$ & 2.60 & A & \\
\hline $\begin{array}{l}\text { The results of a biopsy was communicated to } \\
\text { me within three (working) days }\end{array}$ & .82 & $\begin{array}{l}3.67 \\
(.54)\end{array}$ & .67 & B & \\
\hline $\begin{array}{l}\text { Health professionals concerned with adjuvant } \\
\text { treatment paid me personal attention }\end{array}$ & Not & plicable & & C & \\
\hline $\begin{array}{l}\text { Health professionals concerned with adjuvant } \\
\text { treatment were helpful }\end{array}$ & Not & plicable & & C & \\
\hline $\begin{array}{l}\text { Health professionals concerned with adjuvant } \\
\text { treatment kept appointments punctually }\end{array}$ & Not & plicab & & C & \\
\hline
\end{tabular}

For items that loaded at least .35 onto a factor, evaluation of the taxonomy and reliability of their corresponding subscales are shown through factor loadings (5th column), information on internal consistency (Cronbach a; 6th and 8th column), and corrected item-total correlations (7th column) are shown.

${ }^{a}$ Reason for inclusion: A) despite exclusion according to factor analysis: a low mean performance score on pilot questionnaire; B) despite exclusion according to factor analysis: a high mean importance score during concept mapping; C) patients' responses to open questions asking for missing items in pilot questionnaire. 


\section{Items not included in the current questionnaire}

Compared with the pilot version of the questionnaire, four items were not processed to the next version of the questionnaire because more than $10 \%$ of the values were missing: 11 items were not included because, as compared with other items, they were valued low in importance. Seven items were not incorporated because of ambiguity (e.g. patients commented that they were not able to judge whether "the surgeon worked carefully"). As indicated by patients' responses, two items each contained two or more questions, each of which could receive different responses ${ }^{22}$. Two items regarding courtesy ("the breast nurse treated me with respect" and "the breast nurse treated me as an equal") were highly correlated (Pearson correlation coefficient 0.79 ). To prevent the risk of a bloated specific factor, the first item was not processed. Finally, 17 items were removed from the pilot version as a result of factor- and reliability analyses.

\section{Items included in the current questionnaire}

Table 2 shows the results of the factor analysis. Table 3 shows the respondents' performance and importance ratings for the 33 items that remained in the Optimized QUOTE Breast Cancer questionnaire. The second column represents the mean scores on perceived performance by healthcare professionals and mean scores on time-related items. For instance, the perceived performance on the item "within $24 \mathrm{~h}$ after diagnostic tests I should be informed about the results" was $26 \%$. This score indicates that, on average, $26 \%$ of the respondents received information about the results within $24 \mathrm{~h}$. Mean importance scores for the different components of care can be deducted from the third column, showing that patients rated information about different treatment options (importance score: 3.74) and information about survival rates that are known (importance score: 3.73 ) relatively as the two most important items.

The computed quality impact scores ((1-performance score) $\mathrm{x}$ importance score) are depicted in the fourth column. The performance score of the first item from the fifth factor implied that $72 \%$ of patients perceived to be well informed about survival rates. This item was valued as 3.73 on the importance component. The product of a relatively high non-performance score $(1-0.72=0.28)$ and a high importance score results in a relatively high quality impact score of 1.04. Based on the results of these patients, quality improvement is needed concerning this item.

\section{Taxonomy of the instrument}

The point of inflexion displayed by the scree test was congruent with an eigenvalue 


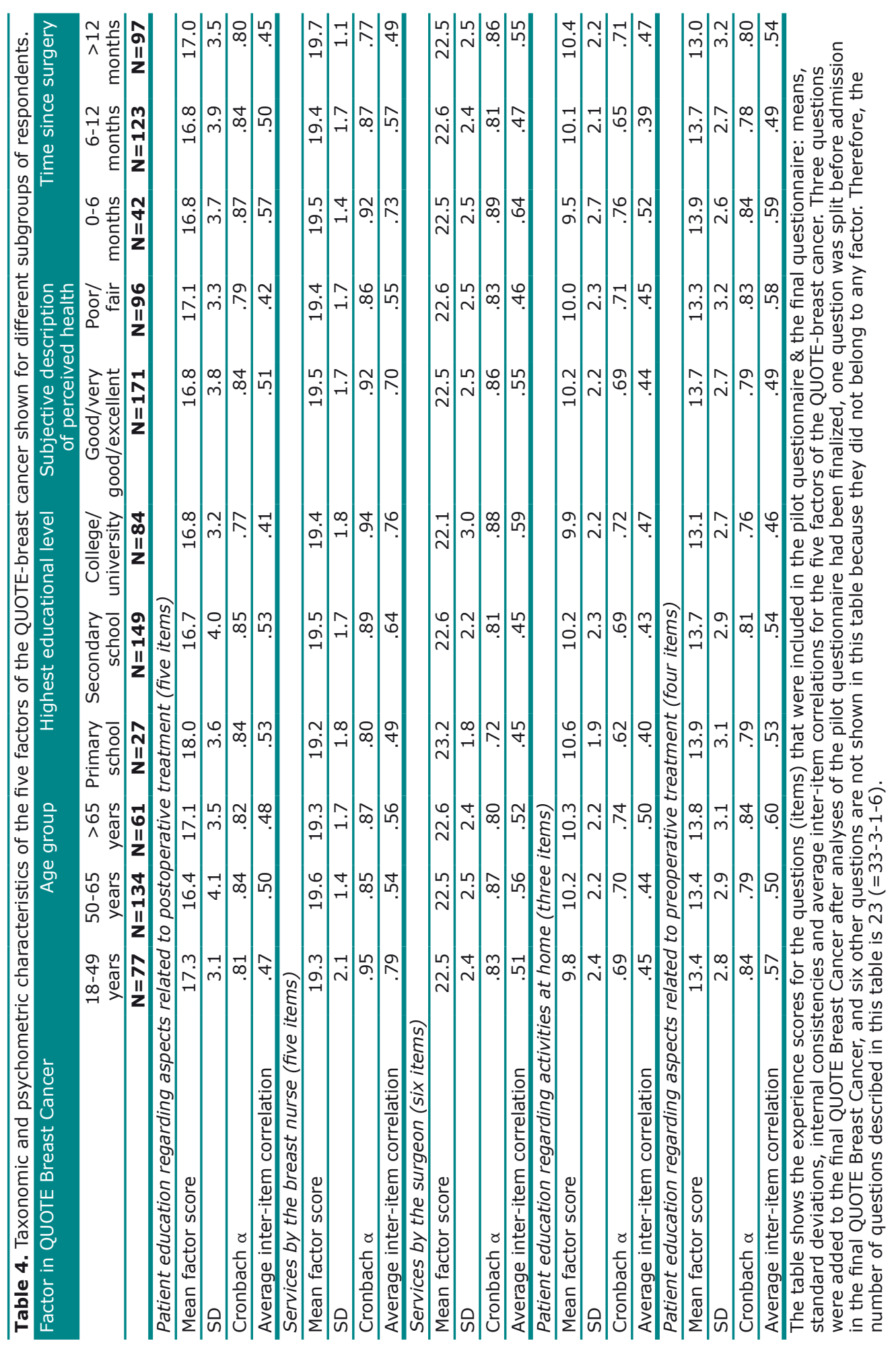


of $>1.0$ for the different factors. The discriminative character of the items is shown through the corrected item-total correlations which were all greater than 0.48 . All presented scales showed to be reliable for separate assessment. For six items, factor and reliability analyses did not provide one solid scale. Therefore, these items were assessed separately. The five resulting factors concern patient education regarding aspects related to postoperative treatment, services by the breast nurse, services by the surgeon, patient education regarding activities at home and patient education regarding aspects related to preoperative treatment.

Most respondents (80\%) declared that no aspects of breast cancer care were missing in the questionnaire. Items that were mentioned as 'missing' refer to adjuvant treatment (mentioned by 18 respondents). As a consequence, three new items on adjuvant treatment were processed in the next version (Table 3). The other reasons for inclusion were low mean performance scores on the pilot questionnaire $(n=3)$ and high mean importance scores during concept mapping $(n=2)$. In the next questionnaire, 33 items on quality of care are incorporated. Items are referred to as performance and importance statements and address healthcare professionals in general, the breast nurse, the surgeon, professionals concerned with adjuvant treatment and the time schedule of the care process.

\section{Subgroup analyses}

The taxonomy and psychometric characteristics of the instrument were further explored by looking at the results for different subgroups of respondents (Table 4). No striking differences were found for the subgroups on mean factor scores, SD, Cronbach $\alpha$, and average inter-item correlation. 


\section{DISCUSSION}

The aim of this study was to test a pilot instrument aimed towards assessment of professionals' performance and patients' needs in the care process from the perspective of breast cancer patients, and to reduce the number of items to a feasible set. We aimed for an instrument that would, when applied in a breast cancer care setting result in clear, well-defined items suitable for improvement of the breast cancer care process.

\section{Analyses}

As part of the process of scale optimization, a large number of quality items from the test version are not included in the current version of the instrument. In general, a more extensive questionnaire might increase validity and provide room for improvement items. However, we perceived the minimisation of the number of items and the inclusion of items that were rated as relatively important to be more relevant and thus aimed at an appropriate balance between importance and number of items. Therefore, we did not include items with lower importance ratings than other items (e.g. "the healthcare worker should call me into his room within 15 min after appointment" (importance score (SD): 2.90 (0 .80)), although these were present in previously published questionnaires ${ }^{17,25}$ The percentages of missing values for the four removed items being high is explained by the fact that these items did not apply to most patients, who therefore were not able to judge them. To maintain applicability of this questionnaire for the majority of patients undergoing breast cancer surgery, these items were not processed.

\section{Strengths of the study}

Patients participated in the instrument development from the beginning. Incorporated were those items considered relevant by breast cancer patients. Users played an important role in the current content of the questionnaire, in a qualitative and a quantitative way, thus increasing face validity of the questionnaire.

As we focused on describing items specific to breast cancer as performance and importance dimensions, we avoided familiar problems related to existing quality of care instruments, such as outcomes that are positively related to age, as described by Hall $\&$ Dornan $^{8}$. In addition, the important role that was assigned to breast cancer patients circumvented problems associated with the mismatch between professionals' and patients' opinions on what quality of care entails and which items should be included in a questionnaire. 
Striving for a relatively large study population, we chose a large time frame since surgery as our eligibility criterion. Subgroup analysis on time since surgery showed that the means and SD did not increase or decrease with an increase in age, in contrast to previous studies with similar types of subgroups ${ }^{26,27}$. This may suggest that the instrument is independent of age.

The resulting set of items provides information on how important patients value and assess performance by professionals and institutions, and it also provides specific information about the relative need for improvement for each of these items.

\section{Limitations of the study}

The study was performed in a limited number of hospitals that are representative of most hospitals in the Netherlands. The study was performed with patients who had been operated for breast cancer. Although items concerning adjuvant treatment are included, we think that the instrument is applied best several weeks after surgery or just after the beginning of adjuvant treatment.

A flaw in the study concerns the non-response analysis. We knew the age of the total sample of invited patients beforehand and the type of breast cancer surgical procedures related to breast cancer that they had experienced; however, we did not, for anonymity reasons, have data on the people who did not respond. Neither did we ask people who did not fill out the pilot questionnaire to return the questionnaire, nor did we ask for their motivation for not participating. The most important disadvantage of this was that we were not able to send out a reminder that is known to be of additional value to increase the response. These aspects possibly introduced selection bias. Although we acknowledge that the response was relatively low, the respondents were comparable to the female Dutch breast cancer population with regard to age and type of treatment, and the non-respondents were comparable with regard to age $\mathrm{e}^{28-30}$. Also, the percentage of patients who underwent ablative surgery or breast-conserving surgery alone did not significantly differ between the respondents and the total sample of invited patients. Therefore, we assume that the results are representative of the opinion of the female Dutch breast cancer population.

\section{Implications for research}

Based on the results of the pilot questionnaire, we used the factor and reliability analyses to reduce the number of items to be included in the following version of the questionnaire. As the number of items from the pilot questionnaire was dramatically 
reduced, we are not able to draw conclusions on the characteristics (factor loading, internal consistency etc.) of these items in their new scales. Therefore, the current 33- item questionnaire should be empirically tested for validity and reliability. At present, the current version of the questionnaire is used in a multi-centre study in the Netherlands. In this study, taxonomy of the instrument that we have developed will be tested.

\section{Implications for current practice: quality impact scores}

Based on the results of our study, 15 out of the 28 QI scores shown need improvement, and the quality item with the highest need for improvement concerns the process time between diagnostic tests and test results. QI scores can be compared within and between services and might facilitate the identification of quality improvement targets.

\section{CONCLUSION}

This study resulted in the final version of an instrument that combines experiences and needs of breast cancer patients into outcome measures, and offers specific information about the quality of breast cancer care and the need for improvement. 


\section{REFERENCES}

1. Mandelblatt J, Armetta C, Yabroff KR, Liang W, Lawrence W. Descriptive review of the literature on breast cancer outcomes: 1990 through 2000. J Natl Cancer Inst Monogr 2004;(33): 8-44.

2. Galloway S, Graydon J, Harrison D, Evans-Boyden B, Palmer-Wickham S, BurleinHall S, et al. Informational needs of women with a recent diagnosis of breast cancer: development and initial testing of a tool. J Adv Nurs 1997;25(6):1175-83.

3. Raupach JC, Hiller JE. Information and support for women following the primary treatment of breast cancer. Health Expect 2002;5(4):289-301.

4. Zastowny TR, Roghmann KJ, Hengst A. Satisfaction with medical care: replications and theoretic reevaluation. Med Care 1983;21(3):294-322.

5. Bruera E, Willey JS, Palmer JL, Rosales M. Treatment decisions for breast carcinoma: patient preferences and physician perceptions. Cancer 2002;94(7):2076-80.

6. Malin JL, Schuster MA, Kahn KA, Brook RH. Quality of breast cancer care: what do we know? J Clin Oncol 2002;20(21):4381-93.

7. Bickell NA, McEvoy MD. Physicians' reasons for failing to deliver effective breast cancer care: a framework for underuse. Med Care 2003;41(3):442-6.

8. Hall JA, Dornan MC. Patient sociodemographic characteristics as predictors of satisfaction with medical care: a meta-analysis. Soc Sci Med 1990;30(7):811-8.

9. Pezner RD, Patterson MP, Hill LR, Vora N, Desai KR, Archambeau JO, et al. Breast retraction assessment: an objective evaluation of cosmetic results of patients treated conservatively for breast cancer. Int J Radiat Oncol Biol Phys 1985;11(3):575-8.

10. Fitzpatrick $R$, Hopkins A. Problems in the conceptual framework of patient satisfaction research: an empirical exploration. Sociol Health Illn 1983;5(3):297-311.

11. Sixma HJ, Kerssens JJ, Campen CV, Peters L. Quality of care from the patients' perspective: from theoretical concept to a new measuring instrument. Health Expect $1998 ; 1(2): 82-95$.

12. Yates $\mathrm{P}$, Aranda S, Hargraves M, Mirolo B, Clavarino A, McLachlan S, et al. Randomized controlled trial of an educational intervention for managing fatigue in women receiving adjuvant chemotherapy for early-stage breast cancer. J Clin Oncol 2005;23(25):6027-36.

13. Parasuraman A, ZeithamI VA, Berry LL, Tregear AEJL. A conceptual model of service quality and its implications for future research. Journal of Marketing 1985;49:4150.

14. Pieterse A, van Dulmen S, Ausems M, Schoemaker A, Beemer F, Bensing J. QUOTEgene(ca): development of a counselee-centered instrument to measure needs and preferences in genetic counseling for hereditary cancer. Psychooncology 2005;14(5):361-75.

15. Hekkink CF, Sixma HJ, Wigersma L, Yzermans CJ, Van Der Meer JT, Bindels PJ, et al. QUOTE-HIV: an instrument for assessing quality of HIV care from the patients' perspective. Qual Saf Health Care 2003;12(3):188-93.

16. de Kok M, Scholte RW, Sixma HJ, van der Weijden T, Spijkers KF, van de Velde CJ, et al. The patient's perspective of the quality of breast cancer care. The development of an instrument to measure quality of care through focus groups and concept mapping with breast cancer patients. Eur J Cancer 2007;43(8):1257-64.

17. Nijkamp MD, Sixma HJ, Afman H, Hiddema F, Koopmans SA, van den Borne B, et al. Quality of care from the perspective of the cataract patient: the reliability and validity of the QUOTE-cataract. Br J Ophthalmol 2002;86(8):840-2. 
18. Stevens J. Exploratory and confirmatory factor analysis. In Applied multivariate statistics for the social sciences. pp 385-393. 4th ed. Mahwah, N.J.: Lawrence Erlbaum Associates; 2001.

19. McHorney CA, Ware JE, Jr., Lu JF, Sherbourne CD. The MOS 36-item Short-Form Health Survey (SF-36): III. Tests of data quality, scaling assumptions, and reliability across diverse patient groups. Med Care 1994;32(1):40-66.

20. Nunnally JC, Bernstein I.H. Psychometric theory (3rd edition) New York: McGrawHill; 1994.

21. Eisen M, Ware JE, Jr., Donald CA, Brook RH. Measuring components of children's health status. Med Care 1979;17(9):902-21.

22. Streiner DL, Norman GR. Selecting the items. In: Health measurement scales : a practical guide to their development and use. pp 61-79. Oxford: Oxford University Press; 2003.

23. Temmink D, Hutten JB, Francke AL, Abu-Saad HH, van der Zee J. Quality and continuity of care in Dutch nurse clinics for people with rheumatic diseases. Int J Qual Health Care 2000;12(2):89-95.

24. Thewes B, Butow P, Girgis A, Pendlebury S. The psychosocial needs of breast cancer survivors; a qualitative study of the shared and unique needs of younger versus older survivors. Psychooncology 2004;13(3):177-89.

25. King MT, Kenny P, Shiell A, Hall J, Boyages J. Quality of life three months and one year after first treatment for early stage breast cancer: influence of treatment and patient characteristics. Qual Life Res 2000;9(7):789-800.

26. Dutch Cancer Registration (in Dutch) year 2003: Incidence of all patients with breast cancer. In: http://www.ikcnet.nl/cijfers; 2006 [25 November 2007].

27. Siesling S, van de Poll-Franse LV, Jobsen JJ, Repelaer van Driel OJ, Voogd AC. Explanatory factors for variation in the use of breast conserving surgery and radiotherapy in the Netherlands, 1990-2001. Breast 2007;16:606-614. 



\section{Part three}

Perceived barriers

and facilitators

before implementation

of the programme 


\section{Chapter 5}

M. de Kok

T. van der Weijden

A.G.H. Kessels

C.D. Dirksen

C.J.H. van de Velde

J.A. Roukema

A.V.R.J. Bell

F.W.C. van der Ent

M.F. von Meyenfeldt

World J Surg 2008;

32 (12): 2541-2548 


\section{ABSTRACT}

\section{Background}

The objective of this study was to identify barriers and facilitators that professionals see when implementing a programme incorporating ultra short hospital admission in the treatment of breast cancer. Such an intervention is an essential step when designing a strategy for implementation of a care programme that is different from established daily routines.

\section{Methods}

In a prospective quasi-experimental study qualitative data were collected from four hospitals in the Netherlands between January 2005 and July 2006. Potential barriers and facilitators for successful implementation were extracted from detailed notes of all contacts between the researchers and each participating hospital. Subsequently, these items were categorised according to themes.

\section{Results}

Over 40 items were identified. Most barriers concerned organisational and programmerelated aspects, whereas the most common facilitators addressed organisational issues. Six of the 29 study recommendations were perceived as impeding or facilitating. Thirty of the 40 barriers were mentioned in one hospital only. Several key factors were found that determine the success of implementation of an ultra short stay programme. Provision of care in the home situation should be assured. Policy makers and insurance companies should acknowledge that multidisciplinary care teams, and teams integrating primary and secondary care, fulfil important roles in delivering continuity of care. Specific strategies should be set out to convince everybody in the organisation about the new ideas, particularly the minority of people that does not agree with the plans.

\section{Conclusions}

A set of barriers and facilitators for implementation of the programme was described that may be used by any professional preparing to perform breast cancer surgery in ultra short stay. The systematic approach that led to this set may be used by any healthcare professional concerned with implementation and consolidation of innovation programmes in healthcare in order to enhance the effectiveness of the chosen strategy. 


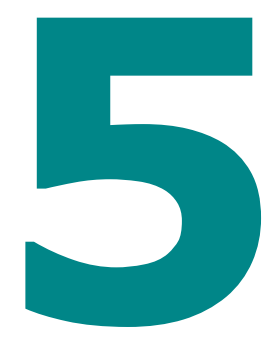

\section{BACKGROUND}

Early discharge after breast cancer surgery is increasingly advocated because of the potential to reduce wound pain $^{1}$, facilitate shoulder movement ${ }^{1}$, and improve informal support ${ }^{2}$ without affecting the number of complications or the psychosocial situation of the patient ${ }^{1,3-5}$. In addition, early discharge has the potential to reduce healthcare costs without affecting the quality of the care process ${ }^{2,6-8}$, and decrease costs resulting from loss of labour9. In 2002, a short stay programme for breast cancer surgery was successfully implemented at the Maastricht University Medical Centre (MUMC). Subsequently, a detailed guideline for an ultra-short stay (day care or $24 \mathrm{~h}$ hospital admission) programme for breast cancer surgery was defined, partly based on existing guidelines ${ }^{10-15}$. In contrast to several other studies ${ }^{16,17}$ type of surgery was not a selection criterion for participation in the programme.

Publications on breast surgery in a short stay setting are numerous. However, no study reports results of provision of surgical care to patients of all ages undergoing all types of surgical interventions, including major ablative surgical resections. Neither did we find any study in which emphasis was placed on multi-institutional implementation of a multi-faceted programme following breast cancer surgery, incorporating for example important roles for home care nursing and informal caregivers, and a drug protocol tailor-made for short stay admission purposes.

While acknowledging that healthcare professionals tend to stick to their routines ${ }^{18}$ and that hospitals differ in the way they are organised ${ }^{7,19}$, the MUMC developed a strategy for large- scale implementation of the short-stay programme in 2004.

During any implementation process, different impeding and stimulating factors may play a role in each step in the process and in the size of the success of the implementation. Insight into these 'barriers' and 'facilitators' is essential to adequately design implementation strategies for different settings and gain information on the kind of activities to be developed ${ }^{20}$. Professionals should not only focus on factors that arise during actual implementation but systematically explore and try to resolve those (often 
unexpected) barriers and facilitators that are perceived by the target group before the true start of the implementation. Thus, the risk can be reduced of interventions being ineffective or implementation activities focussing on aspects of patient care that are not crucial. We did not come across a study in which attention was paid to impeding and stimulating factors for adoption of a comprehensive care programme. Although ultrashort stay admission may have been adopted in different ways in different settings, this does not imply that all breast cancer patients in these settings are actually treated in ultra-short stay. Compliance numbers concerning ultra-short stay admission differ between institutions, countries, or even continents. Yet, most of these results can be improved or optimized if healthcare professionals pay careful attention to factors that may impede or stimulate the success rate of an ultra-short stay programme. This regards healthcare professionals who have already implemented short stay in their settings, as well as those working in an environment where the socioeconomic situation allows only for improvement of certain aspects of such a programme.

To our knowledge, no previous study has entailed implementation of such a multifaceted programme in four hospitals at the same time, nor have barriers and facilitators for implementation of an ultra-short stay programme after breast cancer surgery been explored systematically. The aim of this study was to systematically describe the identification of a set of potential barriers and facilitators for implementation of an ultra-short stay programme after breast cancer surgery. This set should be considered by healthcare professionals in preparing for implementation of such a programme. In addition, the methods and results described in this paper may also serve as an example when implementing changes in healthcare organisations.

\section{MATERIALS AND METHODS}

\section{Study design and Setting}

This quasi-experimental study was part of a large prospective study concerning the implementation of ultra-short stay after breast cancer surgery in four hospitals in the Netherlands that were known to be interested ${ }^{21}$, and was performed before the actual implementation of the ultra-short stay programme, between January 2005 and July 2006. Participants in the hospitals were healthcare professionals associated with breast cancer care. Approval for this study was obtained from the Medical Ethical Committees of all participating hospitals.

\section{Procedures and Data Collection}

Qualitative data regarding facilitating and impeding factors for implementation of the programme were derived from extensive notes of all contacts with each hospital: 
audio-taped project-group meetings, interviews during outreach visits (MdK), telephone conferences, and e-mails. The minutes were taken by one of the authors (MdK). All stakeholders of the implementation programme were present at the projectgroup sessions: surgeons, breast nurses, ward nurses, managers, anaesthesiologists, anaesthesiology nurses, and sometimes a nurse of the home care company, a representative of a patient support group, or a nurse responsible for communication with the home care nursing team. Project-group meetings were tape-recorded, minutes were taken by one of the authors $(\mathrm{MdK})$ and approved by the participants.

Outreach visits to the different hospitals were performed on a regular basis by a physician (MdK) and a nurse to prepare each hospital for the actual change through the provision of information, instruction and support, and to provide them with feedback on current practice. During these outreach visits, semi-structured interviews with one or more participants were arranged at their convenience (before or after their shifts or at other times). The interviews lasted 10 to $90 \mathrm{~min}$. Focus of the interviews was the professionals' perceptions towards the barriers and facilitators for the implementation of the guideline for the ultra-short stay programme.

The number of e-mails and telephone calls between the researchers and healthcare providers at the hospitals was not registered. Only reports that contained possible barriers and facilitators were archived.

\section{Analysis}

Minutes, notes, reports and e-mails were analysed by two of the authors (MdK, TvdW). Potential barriers and facilitators for successful implementation of the ultra-short stay programme were extracted, and arranged according to the following themes: programme, care provider, patient, colleagues, organisation and financial resources \& reimbursement. Frameworks for this categorisation had been suggested by $\mathrm{Grol}^{20}$ and Cabana $^{20,22}$. Differences in opinion were solved through consensus. Subsequently, the set of barriers and facilitators was shown to the participants. Based on their comments, the set was adapted and the definitive set was approved by the participants.

\begin{tabular}{llll}
\hline $\begin{array}{l}\text { Table 1. Methods and numbers of data collecting moments in the different hospitals } \\
\text { Hospital number }\end{array}$ & $\begin{array}{l}\text { N Monthly Meetings } \\
\text { (Dec 05 -June 06) }\end{array}$ & $\begin{array}{l}\text { N Outreach Visits } \\
\text { (Dec 04- June 06) }\end{array}$ & N Barriers \& Facilitators \\
1 & 5 & 18 & 18 \\
\hline 2 & 5 & 17 & 17 \\
\hline 3 & 5 & 12 & 13 \\
\hline 4 & 1 & 12 & 14 \\
\hline a For confidentiality purposes, the names of the hospitals are not shown. \\
\hline
\end{tabular}




\section{RESULTS}

The patient outcome measures "quality of care" and "quality of life" were essential characteristics of the study according to several care providers, and triggered them to participate in the study. Other reasons for participation were related to positive publicity, acknowledgements in scientific papers, curiosity, personal challenges, possibility to take part in important decisions, and previous positive experiences with similar studies.

Nearly 15 outreach visits per hospital (mean 14.8; SD 3.2) were conducted from January 05 until July 06. On average, four project-group meetings (SD 2.0) were held per hospital from February 06 until July 06 (Table 1). In one hospital, professionals were not prepared to participate in more than one meeting as they did not perceive any gap between actual care in their hospital and the short stay programme. All participants actually approved the set of barriers and facilitators as it is shown in this chapter. Well-known general resistance to change was observed, such as reluctance (especially by the long-stay wards) to give up the well-established current practice. For six of the 29 recommendations in the guideline of the programme, impeding and facilitating factors were perceived to influence adherence to the guideline (Table 2). Barriers and facilitators related to other aspects are shown in Tables $3 \& 4$. Most barriers and facilitators $(n=30)$ seemed rather specific, as they were mentioned in one hospital only. One barrier was specifically related to the hospital organisation; healthcare workers of the university hospital felt that the more 'complex' disease presentations and corresponding treatments at their hospital, as compared to the other participating hospitals, were related to longer durations of stay.

\section{Barriers \& Facilitators related to the Programme (Table 2)}

Many professionals showed a negative attitude towards the recommendations regarding planning of surgeries, treatment of nausea and pain, and postoperative visits by healthcare workers. Moreover, negative attitudes towards home care seemed to play an important role; some ward nurses found it difficult to accept that wound and psychological care could also be provided by home care nurses or given by the patients' proxy rather than solely by the ward nurses themselves.

Five programme-related aspects were identified as facilitators: the lymphoscintigraphy for the Sentinel Node Procedure performed in an ambulatory setting, the planning of breast cancer surgeries early in the morning, pre- and postoperative medication aimed at ultra-short stay and drain removal before discharge. 
Table 2. Perceived barriers and facilitators to implementation of ultra short stay admission for breast cancer surgery related to the recommendations of the programme

Recommendation:

"Optimal use of staff, occupation of beds and operation rooms for breast cancer surgery in day care"

\section{Barriers}

-Surgeon's preference for "major" non-breast before breast surgery which may result in a low \% of day care admission

-Goal is to perform as much as we can in $24 \mathrm{~h}$ admission

\section{Facilitators}

- Possibility to perform first part of Sentinel Node Procedure or wire localisation at the morning of surgery

-Reservation of two "places" for SNP breast cancer patient planned for day care surgery

-Intention to perform breast surgery early in the morning which may increase $\%$ of day care surgery

Recommendation: "Breast nurse informs the patient about the need for informal care in the home situation"

\section{Barrier}

-Doubt whether family members have enough time to take care of the patient

Recommendation: "Removal of drain at discharge"

\section{Facilitator}

-Intention to remove the drain before discharge

Recommendation: "Decisions on patient discharge are based on clear guidelines"

\section{Barriers}

-Postoperative visits by specialist only with admissions periods longer than $24 \mathrm{~h}$

-Postoperative visits by breast nurse only with admissions periods longer than $24 \mathrm{~h}$

Recommendation: "The prescription of opiates is minimised"

\section{Barrier}

-Opiates with postoperative pain are often provided which may result in a low \% of day care surgery (some hospitals: contra-indication for day care surgery)

\section{Facilitator}

-Non-opiates used as pain medication

Recommendation: "Specialised home carea for patients in the period following surgery is facilitated"

\section{Barriers}

·Home care nursing offered only to total amputations and axillary node clearance patients

-Indication for home care nursing can not be given anymore before surgery (before: yes)

-Difficult to get an indication (=fee) for psychosocial support from home care nursing 
Table 3. Perceived barriers and facilitators to implementation of ultra short stay admission for breast cancer surgery related to the individual care provider's own motivation for change, the care provider's view on the patient's motivation or the care provider's view on colleague(s).

\begin{tabular}{ll} 
- Unwillingness to discharge patients on the day of surgery & 2 \\
\hline - Patients' unwillingness to visit the hospital for wound care & 1 \\
\hline $\begin{array}{l}\text { - Patients' unwillingness to pay an income-dependent fee } \\
\text { for home care nursing }\end{array}$ & 2 \\
\hline $\begin{array}{l}\text { - Insufficient communication about admission plans for patients } \\
\text { between anaesthesiologists and surgeons }\end{array}$ & 1 \\
\hline $\begin{array}{l}\text { Facilitators } \\
\text { - Participation in national trends (decrease admission time, cost } \\
\text { effectiveness, effective use of hospital's capacity) }\end{array}$ & 1 \\
\hline $\begin{array}{l}\text { - Opportunity to start trans-mural home care } \\
\text { - Inform patients preoperatively about opiates and their contra indication } \\
\text { for day care surgery }\end{array}$ & 1 \\
\hline $\begin{array}{l}\text { - Patients expected only } 45 \text { min before surgery so no-one is admitted the } \\
\text { day before surgery }\end{array}$ & 1 \\
\hline Signed prescriptions for recipes needed at discharge available & 3 \\
\hline
\end{tabular}

\section{Barriers \& Facilitators related to the Individual Care Provider, Patient or Colleague (Table 3)}

Some professionals were concerned about the acceptability of the programme for the patients. On the other hand, eagerness to participate in innovation programmes in healthcare, such as short stay surgery or a cooperation between intramural and extramural care professionals, increased their motivation for change.

Patients' income-dependent out of pocket costs for home care, and their foreseen unwillingness to visit the hospital for wound care were the only perceived barriers related to patients. Informing patients before surgery about the effects of opiates on the possibility of day care surgery and providing the ward with signed prescriptions for medications to prevent patients from waiting for physicians to prescribe the medications were viewed as important facilitating factors.

Previous poor experiences with home care resulting in lack of trust in the home care company, and lack of communication between colleagues were barriers that were perceived on the level of colleagues.

\section{Barriers \& Facilitators related to the Organisation and Finances (Table 4)}

Of the organisation-related barriers, the majority described issues related to the type of ward at which the patients would be located; the combination of "short stay patients" and "long stay patients" in one ward was perceived as a problem for both departments. 
Table 4. Perceived barriers and facilitators to implementation of ultra short stay admission for breast cancer surgery related to the organisation and finances

- Selection of specific patients for difficult breast cancer surgery leads to 1 increase in admission time

\begin{tabular}{ll}
\hline Short stay and long stay combined into one ward & 1 \\
\hline Short stay open until 2000 hrs \& discharge until 2000 hrs & 1 \\
\hline $\begin{array}{l}<5-10 \% \text { patients admitted at long stay departments (only) in case of } \\
\text { shortage in day care capacity }\end{array}$ & 2 \\
\hline $\begin{array}{l}\text { ICT system does not allow correspondence of information between care- } \\
\text { givers about patients }\end{array}$ & 1 \\
\hline $\begin{array}{l}\text { - Inconsistent use of written and digital notes which increases the chance } \\
\text { of incomplete files }\end{array}$ & 1 \\
\hline $\begin{array}{l}\text { - New building without day care operation room which might cause a low } \\
\% \text { of day care surgery (if other surgeries take longer than planned) }\end{array}$ & 1 \\
\hline $\begin{array}{l}\text { near of the hospital staff to be responsible for the work by the home care } \\
\text { nurses }\end{array}$ & 1 \\
\hline $\begin{array}{l}\text { Surgeons expect less income with day care as compared } \\
\text { to the clinical setting }\end{array}$ & 1 \\
\hline
\end{tabular}

- The hospital expects less income with day care as compared

to the clinical setting

Facilitators

- Patients can be admitted in the morning (unless blood parameters 1 needed )

\begin{tabular}{ll}
\hline - Recovery and Short stay combined into one ward & 1 \\
\hline - Breast cancer patients will be admitted on one day care ward instead of & 1 \\
different wards & \\
\hline
\end{tabular}

\begin{tabular}{ll}
\hline - Short stay open $24 \mathrm{~h} /$ day & 1 \\
\hline - Discharge from short stay possible until 2100 hrs & 2 \\
\hline - Home care nurses receive clinical lectures from hospital nurses & 2 \\
\hline $\begin{array}{l}\text { - Decrease in postoperative checks the day after surgery which makes day } \\
\text { care more acceptable }\end{array}$ & 1 \\
\hline
\end{tabular}

\begin{tabular}{ll}
\hline -Surgeons: "hospital payment is independent of the admission period" & 1 \\
\hline - Increase in working hrs for breast nurse is cost effective & 2
\end{tabular}

Therefore, caregivers at those different departments aimed at different admission periods for their patients, which would be confusing for patients. Other barriers were caused by use of different communication aids that caused confusion about the patients' treatment plans (e.g. an ICT system that did not allow nurses and anaesthesiologists to look at the surgeon's considerations for a certain admission period). Examples of perceived facilitators related to the organisation were not admitting patients before the morning of surgery, placement of all breast cancer patients in one ward, all-week 
possibility of discharge, and abolition of a time-consuming blood check that had not been proven to be cost effective.

Financial-system barriers involved the surgeons' fear for loss of income for day care surgery compared to standard admission, and the insurance declaration system in the Netherlands that does not trigger healthcare workers to promote ultra-short stay. In contrast, other participants identified two facilitators on the financial level. First, they had perceived an intention of insurance companies to pay hospitals for breast cancer surgery independent of the admission time. Second, the payment of extra hours of breast nurse care was perceived to be cost-effective; although patients are offered more consultations after ultra-short stay surgery which leads to an increase in consultation costs, admission costs decrease at a relatively higher rate.

\section{DISCUSSION}

In this chapter we have outlined a set of relevant factors potentially influencing the success and smoothness of implementation of an ultra-short stay programme for breast cancer surgery, and its consolidation. Programme, care provider, patient and system related factors were perceived to play a role in supporting and impeding the implementation of ultra-short stay after breast cancer surgery.

Surgeons and breast nurses were the stakeholders who perceived most barriers. This may be explained by the coordinating role that these two types of professionals have in the current organisation of breast cancer care. A striking outcome, in our opinion, is that (together with the surgeons) the ward nurses perceived most facilitating factors for the programme; we expected the nurses to be most reluctant towards the introduction of a programme encompassing shorter and less intensive contacts between the nurses and the patients. The nurses acknowledged to regret the decrease in time they could spend with the patients but anticipated other challenges in tasks because of the shift from traditional to ultra-short stay admission.

All stakeholders expected more or about as many facilitators as barriers, except for some of the participating anaesthesiologists who expected mostly barriers. Extra attention should be paid to those people's opinions on the overall programme for negative attitudes of only one or a few persons can be decisive in the (un)successful process of implementation.

Our study confirmed the importance of several factors as published by others such as drain removal before discharge ${ }^{23,24}$ and support at home ${ }^{1,2}$. However, it also provides additional factors that, to our knowledge, have not been described before in the literature. 


\section{Key barriers}

Barriers concerning the use of home care are important to consider for they may influence the success of the programme if a hospital decides to involve home care nursing for wound care during the first days following surgery. In our opinion, wound care should be given to the patient within the first $48 \mathrm{~h}$ after surgery, either by the home care team or by the breast nurse. If expert wound care can not be guaranteed professionals should strongly consider $24 \mathrm{~h}$ admission for breast cancer patients who could otherwise be discharged. Depending on the patient's wish, wound care given by home care nurses could be followed by extra wound care visits to the breast nurses. Hospital professionals and home care institutions should reach clear agreements on expectations, responsibilities and financing of the care provided to this group of patients. Moreover, policy makers and insurance companies should acknowledge the supplementary role multidisciplinary and multi setting (integrating primary and secondary care) care teams can fulfil in the provision of continuity of care. However, the current payment structure does not stimulate this change at all, at least not in the Netherlands. On the contrary, it even discourages cooperation between different settings.

Secondly, communication on all levels of the organisation proved to be crucial for successful implementation, as shown by others ${ }^{25,26}$. This study confirms that communication needs to be streamlined on all healthcare levels including communication between leaders from different hospitals. A multidisciplinary meeting ensures that different specialists become acquainted with, and can discuss each other's plans with patients on different aspects such as type of admission and type of treatment. Finally, despite decisions on hospital management level aimed at decreasing the number of written notes and increasing the use of one standard electronic patient record, management teams should consider that not all professionals are willing to give up their trusted paper notes. They should use a strategy to motivate these people to act according to newly implemented rules. If this problem is not solved, it will result in professionals who are misinformed by colleagues about what will happen to patients, which unnecessarily leads to a lower standard of quality of care than could be achieved.

\section{Strengths and Weaknesses}

The data collection was generally based on high contact frequency between the MUMC researchers and the hospitals. Furthermore, we covered different types of surgical departments, and provided member checks on the final results. Therefore, we think that very few barriers and facilitators within the participating hospitals remained unidentified. Since our primary goal was to identify facilitators and barriers rather than to quantify relative importance we do not think that the qualitative design of the 
study limits our ability to draw conclusions on the topic of barriers and facilitators for implementation of the programme.

Although this study was performed in one country only, we believe the results are useful for those countries with comparable organisations of breast cancer care (e.g. organisations where the breast nurse plays a central role in the care process).

\section{CONCLUSIONS}

We have described a set of barriers and facilitators that may influence the effectiveness of implementation of a programme of ultra-short stay after breast cancer surgery. This set can be used by any healthcare professional who intends to start with ultra-short stay after breast cancer surgery in order to aid in a swift and successful implementation of such a programme and by any healthcare professional who has already adopted breast cancer care in an ultra short-stay setting and aims to improve the compliance numbers and support consolidation of the adopted programme. In addition, we think that the methods of data collection and (several of) the results can be helpful and serve as an example for those healthcare professionals who are planning to implement changes in their healthcare system. 


\section{REFERENCES}

1. Bundred N, Maguire P, Reynolds J, Grimshaw J, Morris J, Thomson L, Barr L, Baildam A. Randomised controlled trial of effects of early discharge after surgery for breast cancer. Bmj 1998;317(7168): 1275-1279.

2. Bonnema J, van Wersch AM, van Geel AN, Pruyn JF, Schmitz PI, Uyl-de Groot CA, Wiggers T. Cost of care in a randomised trial of early hospital discharge after surgery for breast cancer. Eur J Cancer 1998;34(13): 2015-2020.

3. Goodman AA, Mendez AL. Definitive surgery for breast cancer performed on an outpatient basis. Arch Surg 1993;128(10): 1149-1152.

4. McManus SA, Topp DA, Hopkins C. Advantages of outpatient breast surgery. Am Surg 1994;60(12): 967-970.

5. Margolese RG, Lasry JC. Ambulatory surgery for breast cancer patients. Ann Surg Oncol 2000;7(3): 181-187.

6. Horgan K, Benson EA, Miller A, Robertson A. Early discharge with drain in situ following axillary lymphadenectomy for breast cancer. Breast 2000;9(2): 90-92.

7. Davis C, Williams $\mathrm{P}$, Redman S. Early discharge following breast surgery: assessing care, support, and informational needs of women with early breast cancer in Australia. Aust N Z J Surg 2000;70(8): 569-572.

8. Holcombe C, West N, Mansel RE, Horgan K. The satisfaction and savings of early discharge with drain in situ following axillary lymphadenectomy in the treatment of breast cancer. Eur J Surg Oncol 1995;21(6): 604-606.

9. Lindqvist $R$, Stenbeck M, Diderichsen $F$. Does hospital discharge policy influence sick-leave patterns in the case of female breast cancer? Health Policy 2005;72(1): 65-71.

10. The requirements of a specialist breast unit. Eur J Cancer 2000;36(18): 22882293.

11. Perry NM. Quality assurance in the diagnosis of breast disease. EUSOMA Working Party. Eur J Cancer 2001;37(2): 159-172.

12. Bartelink H, Garavaglia G, Johansson KA, Mijnheer BJ, Van den Bogaert W, van Tienhoven G, Yarnold J. Quality assurance in conservative treatment of early breast cancer. Report on a consensus meeting of the EORTC Radiotherapy and Breast Cancer Cooperative Groups and the EUSOMA (European Society of Mastology). Radiother Oncol 1991;22(4): 323-326.

13. Rutgers EJ. Quality control in the locoregional treatment of breast cancer. Eur J Cancer 2001;37(4): 447-453.

14. NABON. Nationaal Borstkanker Overleg Nederland (NABON). Richtlijn mammacarcinoom: screening en diagnostiek. Utrecht. Kwaliteitsinstituut voor de Gezondheidszorg СВО 2000.

15. Blamey RW. The British Association of Surgical Oncology Guidelines for surgeons in the management of symptomatic breast disease in the UK (1998 revision). BASO Breast Specialty Group. Eur J Surg Oncol 1998;24(6): 464-476.

16. Athey N, Gilliam AD, Sinha P, Kurup VJ, Hennessey C, Leaper DJ. Day-case breast cancer axillary surgery. Ann R Coll Surg Engl 2005;87(2): 96-98.

17. Marchal F, Dravet F, Classe JM, Campion L, Francois T, Labbe D, Robard S, Theard $\mathrm{JL}$, Pioud R. Post-operative care and patient satisfaction after ambulatory surgery for breast cancer patients. Eur J Surg Oncol 2005;31(5): 495-499.

18. Ottevanger PB, De Mulder PH, Grol RP, van Lier H, Beex LV. Adherence to the guidelines of the CCCE in the treatment of node-positive breast cancer patients. Eur J Cancer 2004;40(2): 198-204. 
19. Chassin MR, Kosecoff J, Park RE, Winslow CM, Kahn KL, Merrick NJ, Keesey J, Fink A, Solomon DH, Brook RH. Does inappropriate use explain geographic variations in the use of health care services? A study of three procedures. Jama 1987;258(18): 2533-2537.

20. Grol R, Wensing M, Eccles M. Improving patient care. The implementation of change in clinical practice. Butterworth-Heinemann: Toronto, 2005.

21. de Kok M, Scholte RW, Sixma HJ, van der Weijden T, Spijkers KF, van de Velde $\mathrm{CJH}$, Roukema JA, van der Ent FW, Bell AVRJ, von Meyenfeldt MF. The patient's perspective of the quality of breast cancer care. The development of an instrument to measure quality of care through focus groups and concept mapping with breast cancer patients. Eur J Cancer 2007;43(8): 1257-1264.

22. Cabana MD, Rand CS, Powe NR, Wu AW, Wilson MH, Abboud PA, Rubin HR. Why don't physicians follow clinical practice guidelines? A framework for improvement. Jama 1999;282(15): 1458-1465.

23. Wells M, Harrow A, Donnan P, Davey P, Devereux S, Little G, McKenna E, Wood R, Chen R, Thompson A. Patient, carer and health service outcomes of nurse-led early discharge after breast cancer surgery: a randomised controlled trial. $\mathrm{Br} \mathrm{J}$ Cancer 2004;91(4): 651-658.

24. Purushotham AD, McLatchie E, Young D, George WD, Stallard S, Doughty J, Brown DC, Farish C, Walker A, Millar K, Murray G. Randomized clinical trial of no wound drains and early discharge in the treatment of women with breast cancer. Br J Surg 2002;89(3): 286-292.

25. Pedersen $\mathrm{SH}$, Douville LM, Eberlein TJ. Accelerated surgical stay programs. A mechanism to reduce health care costs. Ann Surg 1994;219(4): 374-381.

26. de Kok M, Sixma HJ, Scholte RW, Spijkers KF, van de Velde CJ, Roukema JA, van der Ent FW, Bell AV, von Meyenfeldt MF. What is important in breast cancer care? The patients' perspective after surgery. Eur J Surg Oncol 2006;32 (1): S78.

27. Donabedian A. The quality of medical care: a concept in search of a definition. $J$ Fam Pract 1979;9(2): 277-284. 

Part four

Results of the study on implementation of the short stay programme following breast cancer surgery

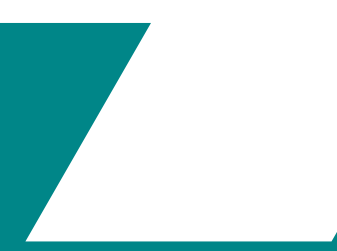




\section{Chapter 6}

M. de Kok

T. van der Weijden

A.C. Voogd

C.D. Dirksen

C.J.H. van de Velde

J.A. Roukema

C. Finaly-Marais

F.W.C. van der Ent

M.F. von Meyenfeldt

Br J Surg, 2010; 97(2):

189-194 


\section{ABSTRACT}

\section{Background}

Short-stay breast cancer surgery ( $24 \mathrm{~h}$ or day case) is not common practice in Europe. This before-after comparative study was carried out to test the feasibility of systematically implementing a care programme incorporating short-stay admission using strategies tailored to individual hospital needs, and to assess safety and facilitating factors.

\section{Methods}

Patients with breast cancer from four Dutch hospitals participated. The intervention concerned the programme developed by the Maastricht University Medical Centre. This was implemented through local multidisciplinary meetings and educational outreach visits.

\section{Results}

Of 421 eligible patients, 324 (77.0 per cent) gave consent to participate. The proportion of patients who had short-stay treatment increased from 45.3 per cent before to 82.2 per cent after implementation of the programme $(\mathrm{P}<0.001)$. No increase was observed in the rate of complications, readmissions, reoperations or number of visits to the emergency department. Factors associated with an increased chance of short-stay treatment were: breast-conserving surgery, having children and being employed. Being aged over 64 years showed a trend towards a decreased chance.

\section{Conclusion}

Introducing a care programme incorporating short stay following breast cancer surgery in four hospitals was feasible and safe. 


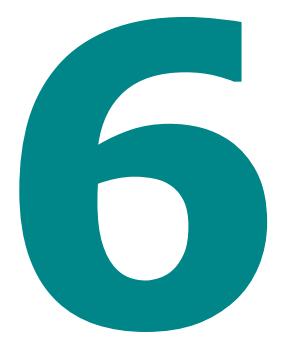

\section{INTRODUCTION}

Previous studies have demonstrated that major breast cancer surgery can be carried out with a hospital stay of less than $24 \mathrm{~h}$ in well defined patient groups, without increasing adverse effects ${ }^{1-3}$. Benefits have been described for patients (faster recovery, less wound pain) $)^{4,5}$, their relatives (strong family interactions) ${ }^{6}$, hospitals (less workload on staff, savings on hospital charges) $)^{1,4}$ and society (reduction in waiting lists, shift from expensive hospital care to cheaper home care).

As early as the 1990s, innovators on this subject reported day-case surgery, not only for breast-conserving procedures but also for radical mastectomy in North America ${ }^{7,8}$. This caused public debate, as concerns were expressed that gains in healthcare savings were at the expense of quality of healthcare. Legislative procedures were initiated to mandate a minimum hospital stay following mastectomy ${ }^{9}$. However, the results of the study by Warren and colleagues ${ }^{8}$ showed no statistical differences between outpatient and inpatient mastectomy with respect to complications, readmissions or mortality. Another study showed that outpatient treatment was possible for all subtypes of mastectomy and lumpectomy ${ }^{10}$. A major influencing factor on type of admission was type of insurance. Co-morbidity, metastases or breast reconstruction were negatively correlated with treatment in an outpatient setting. However, these three factors were retrieved with some methodological flaws. Premenopausal age did not have an influence. A pilot study at Maastricht University Medical Centre, performed from 2001 to 2002, showed that the proportion of patients with breast cancer treated as a day case or with one overnight stay increased from 13 to 84 per cent after consolidation of the short-stay care programme (C. N. A. Frotscher, M. H. Hebly, G. L. Beets and M. F. von Meyenfeldt, unpublished data). This pilot study provided targets for implementation of short stay following all types of breast cancer surgery, such as the establishment of interdisciplinary meetings between the anaesthetic and surgical teams. In the programme, emphasis was placed on patient-centred treatment such as active 
participation in decisions about discharge and the type of postoperative care ${ }^{11}$. Short stay after breast cancer surgery is not common practice in every part of Europe. Therefore, an implementation study was conducted, starting with a problem analysis ${ }^{12}$. In this analysis, generic and hospital-specific barriers and facilitators were explored, along with facilitators that might play a role in the success of introducing short stay in a hospital. The implementation strategy was tailored to the needs of the four hospitals participating in this implementation study ${ }^{11}$.

The hypothesis of the present study was that the proportion of patients discharged within $24 \mathrm{~h}$ would increase by at least 30 per cent after implementation, without a negative effect on patient outcomes and quality of care ${ }^{11}$.

\section{METHODS}

Data for this multicentre study were collected from December 2005 until July 2007, after approval by the medical ethics committees of all participating hospitals. The study entailed two measurement periods (before and after implementation of the short-stay programme) of 6 months each, with 6 months of actual implementation in between. The aim was to include 40 patients in each hospital during each measurement interval in order to detect a statistically significant increase of at least 30 per cent in short-stay admissions $(\alpha<0.05 ; \beta>0.90)$.

Four hospitals were invited by the project leader based on the assumption that they would participate in the study as early adopters ${ }^{13}$. At least three-quarters of the invitational meetings in each hospital were attended by surgeons, breast nurses, department managers, department nurses, team leaders, and a researcher, as well as representatives from other departments involved in the breast cancer care process.

\section{Patients}

All patients aged 18 years and older scheduled for all types of elective breast cancer surgery were eligible to participate. They were asked to give informed consent 3-5 working days after diagnosis. Patients eligible for study participation were not allowed to be treated in short stay if: contraindications were present related to the physiology (such as need for intravenous medication, severe chest or heart disease), informal care at home could not be guaranteed during the first $24 \mathrm{~h}$ after surgery, the situation at home did not allow an undisturbed physical and psychological recovery, or they lived more than $100 \mathrm{~km}$ from the hospital.

A comprehensive short-stay care programme was implemented for patients who had surgery for breast cancer. A key aspect of the programme was an additional checklistguided consultation between patient and breast nurse in which the patient was 
informed about the day of surgery. Information was also provided in a leaflet, and was repeated on the morning of surgery and the morning of discharge (if this was the day after surgery). The patient was given a say in the final decision about discharge. A detailed description of the study protocol can be found elsewhere ${ }^{11}$.

\section{Implementation strategies}

Five main strategies were applied to all hospitals. They were generally derived from a mixture of theoretical and empirical background knowledge $\mathrm{e}^{14}$ and pragmatic considerations. The strategies were: dissemination of the guideline; outreach visits with the local team or with the breast nurse, based on problem analysis per hospital; clinical lectures given by an experienced breast nurse from the Maastricht University Medical Centre to the local home-care nursing teams (concerning wound, drain and psychosocial care) and to nurses on the ward (explaining the shift from inpatient to outpatient care); audit and feedback on performance on outcome measures during implementation; and incentives (for example breast nurses received registration for the European Breast Cancer Conference). The outreach visits had several functions: to achieve goodwill for participation and influence attitudes, to educate, to create local solutions for local problems, and to remind people about the plans that had been made. Plenary meetings with the local teams were organized within each hospital during both baseline (problem analysis) and implementation intervals ${ }^{15}$. All stakeholders from each hospital were invited for the 60-90-min sessions which were used as a forum for discussion on interdisciplinary communication. Barriers that arose during the preintervention diagnostic analysis and during the plenary meetings were translated into improvement targets ${ }^{15}$.

\section{Outcome measures and data collection}

Primary outcome variables were the proportion of patients treated in short stay including admission, surgery and discharge the same day (day-case admission) or within $24 \mathrm{~h}$ (also referred to as overnight stay) ${ }^{16}$, and the duration of hospital admission. Secondary outcome variables were related to safety and included complication rate, readmission rate, reoperation rate, and number of visits to the emergency unit for problems related to breast cancer surgery for up to 6 weeks after operation.

For each participating patient, hospital data were collected prospectively through case record forms with items in closed or open response format relevant to assessment of the success of implementation. A distinction was made between breast-conserving treatment (wide local excision with, or without sentinel node biopsy; wide local excision with axillary clearance or axillary clearance by itself) and ablative procedures (ablative surgery with or without sentinel node biopsy; modified radical mastectomy). 
Data related to recovery outside the hospital were obtained from prospectively collected data forms filled out by patients; for example, number of visits by a home care nurse.

\section{Statistical analysis}

The analyses of primary outcome measures tested for significant differences between patients from the cohorts treated before and after implementation of the short-stay programme. Proportions of patients treated in short stay in both intervals were compared using $\mathrm{X}^{2}$ tests, and mean length of stay was compared using the MannWhitney U test. Multivariable logistic regression analyses were performed for the group treated after implementation of the programme, using postimplementation values

\begin{tabular}{|c|c|c|c|}
\hline & $\begin{array}{l}\text { Before implementation } \\
(n=161)\end{array}$ & $\begin{array}{l}\text { After implementation } \\
(\mathrm{n}=163)\end{array}$ & P* \\
\hline $\begin{array}{l}\text { Age (years) } \\
<50 \\
50-64 \\
65 \\
\text { Mean(SD) }\end{array}$ & $\begin{array}{l}57(35.4) \\
70(43.5) \\
34(21.1) \\
55.3(11.5)\end{array}$ & $\begin{array}{l}40(24.5) \\
89(54.6) \\
34(20.9) \\
56.8(10.8)\end{array}$ & 0.073 \\
\hline $\begin{array}{l}\text { Hospital } \\
1 \\
2 \\
3 \\
4\end{array}$ & $\begin{array}{l}39(24.2) \\
33(20.5) \\
49(30.4) \\
40(24.9)\end{array}$ & $\begin{array}{l}50(30.7) \\
34(20.9) \\
40(24.5) \\
39(23.9)\end{array}$ & 0.515 \\
\hline $\begin{array}{l}\text { Civil status } \\
\text { Married } \\
\text { Not married } \\
\text { Widowed } \\
\text { Divorced } \\
\text { Not known }\end{array}$ & $\begin{array}{l}101(71.6) \\
22(15.6) \\
13(9.2) \\
5(3.5) \\
20\end{array}$ & $\begin{array}{l}109(73.6) \\
16(10.8) \\
17(11.5) \\
6(4.1) \\
15\end{array}$ & 0.781 \\
\hline $\begin{array}{l}\text { Household } \\
\text { Living alone } \\
\text { Living with others } \\
\text { Not known }\end{array}$ & $\begin{array}{l}25(18.1) \\
113(81.9) \\
23\end{array}$ & $\begin{array}{l}20(14.4) \\
119(85.6) \\
24\end{array}$ & 0.400 \\
\hline $\begin{array}{l}\text { Highest educational level } \\
\text { Primary school } \\
\text { Secondary school } \\
\text { College } \\
\text { University } \\
\text { Not known }\end{array}$ & $\begin{array}{l}9(6.4) \\
99(70.7) \\
26(18.6) \\
6(4.3) \\
21\end{array}$ & $\begin{array}{l}4(2.7) \\
116(78.9) \\
22(15.0) \\
5(3.4) \\
16\end{array}$ & 0.318 \\
\hline $\begin{array}{l}\text { Current employment status } \\
\text { Full or part time } \\
\text { Not working } \\
\text { Not known }\end{array}$ & $\begin{array}{l}79(49.4) \\
81(50.6) \\
1\end{array}$ & $\begin{array}{l}87(54.7) \\
72(45.3) \\
4\end{array}$ & 0.340 \\
\hline $\begin{array}{l}\text { Has children } \\
\text { Yes } \\
\text { No } \\
\text { Not known }\end{array}$ & $\begin{array}{l}116(82.9) \\
24(17.1) \\
21\end{array}$ & $\begin{array}{l}126(85.7) \\
21(14.4) \\
16\end{array}$ & 0.506 \\
\hline
\end{tabular}

Values in parentheses are percentages unless indicated otherwise.

$* X^{2}$ test or Fisher's exact test, depending on the expected number of frequencies. 
to search for patient and healthcare-related determinants of treatment in short stay. Variables tested were type of surgery, involvement of home-care nursing, availability of informal care givers, age, type of household, level of education, having children, civil status and employment status. $\mathrm{P}<0.050$ was considered statistically significant for all tests.

\section{RESULTS}

Three hundred and twenty-four patients were included in the study. In both intervals two hospitals did not reach the planned number of 40 participants. All eligible patients were women. There were no obvious imbalances between the patients included in the two intervals with respect to sociodemographic characteristics, such as mean age, distribution between the four hospitals, level of education and employment status (Table 1). A non-response analysis showed a significantly higher mean age for the eligible patients who declined to participate compared with the participants (mean(SD) 61.6(14.9) versus 56.0(11.1) years; $\mathrm{P}=0.001)$.

\section{Implementation strategies}

Because of the differences in needs between hospitals, the frequency of outreach visits varied per hospital. It was 35, 27, 18 and 22 for hospitals 1, 2, 3 and 4, of which nine, seven, two and nine respectively were plenary meetings. Patients were educated about the programme through newly developed patient information leaflets and through hospital websites.

\section{Feasibility and safety of short stay}

Before implementation of the programme, the proportions of patients who had shortstay surgery in each of the hospitals were: hospital 1, two of 39; hospital 2, nine of 33; hospital 3, 47 of 49; and hospital 4, 15 of 40. After implementation these changed to: hospital 1, 37 of 50; hospital 2, 25 of 34; hospital 3, 38 of 40; and hospital 4, 34 of 39. Taking all four hospitals together, the mean proportion of patients treated in short stay increased significantly from 45.3 to 82.2 per cent $(\mathrm{P}<0.001)$. No increase was observed in the risk of complications, readmissions or reoperations after implementation of the programme (Table 2).

Complications that occurred in the interval before implementation were postoperative haemorrhage (seven, 4.3 per cent), wound dehiscence (five, 3.1 per cent), haematoma and/or seroma (14, 8.7 per cent), wound infection/abscess (13, 8.1 per cent) and other (one, 0.6 per cent). After implementation, complications included postoperative haemorrhage (five, 3.1 per cent), wound dehiscence (seven, 4.3 per cent), haematoma 


\begin{tabular}{|c|c|c|c|}
\hline & $\begin{array}{l}\text { Before implementation } \\
(\mathrm{n}=161)\end{array}$ & $\begin{array}{l}\text { After implementation } \\
(n=163)\end{array}$ & P* \\
\hline $\begin{array}{l}\text { Duration of hospital admission } \\
\text { (days) } \\
0 \\
1 \\
2 \\
3 \\
>3\end{array}$ & $\begin{array}{l}27(16.8) \\
46(28.6) \\
43(26.7) \\
17(10.6) \\
28(17.4)\end{array}$ & $\begin{array}{l}54(33.1) \\
80(49.1) \\
22(13.5) \\
2(1.2) \\
5(3.1)\end{array}$ & $<0.001$ \\
\hline $\begin{array}{l}\text { Short stay ( } \leq 1 \text { day) } \\
\text { Yes } \\
\text { No }\end{array}$ & $\begin{array}{l}73(45.3) \\
88(54.7)\end{array}$ & $\begin{array}{l}134(82.2) \\
29(17.8)\end{array}$ & $<0.001$ \\
\hline $\begin{array}{l}\text { Type of surgery } \\
\text { Breast conserving } \\
\text { Mastectomy }\end{array}$ & $\begin{array}{l}88(54.7) \\
73(45.3)\end{array}$ & $\begin{array}{l}109(66.9) \\
54(33.1)\end{array}$ & 0.024 \\
\hline $\begin{array}{l}\text { No. of visits to emergency } \\
\text { department } \\
0 \\
1 \\
2\end{array}$ & $\begin{array}{l}136(84.5) \\
20(12.4) \\
5(3.1)\end{array}$ & $\begin{array}{l}150(92.0) \\
9(5.5) \\
4(2.5)\end{array}$ & 0.085 \\
\hline $\begin{array}{l}\text { No. of complications } \\
0 \\
1 \\
2\end{array}$ & $\begin{array}{l}127(78.9) \\
30(18.6) \\
4(2.5)\end{array}$ & $\begin{array}{l}134(82.2) \\
28(17.2) \\
1(0.6)\end{array}$ & 0.404 \\
\hline $\begin{array}{l}\text { No. of readmissions owing to } \\
\text { complications } \\
0 \\
1 \\
2\end{array}$ & $\begin{array}{l}152(94.4) \\
7(4.3) \\
2(1.2)\end{array}$ & $\begin{array}{l}150(92.0) \\
9(5.5) \\
4(2.5)\end{array}$ & 0.626 \\
\hline $\begin{array}{l}\text { No. of reoperations owing to } \\
\text { complications } \\
0 \\
1 \\
2\end{array}$ & $\begin{array}{l}152(94.4) \\
9(5.6) \\
0(0)\end{array}$ & $\begin{array}{l}153(93.9) \\
8(4.9) \\
2(1.2)\end{array}$ & 0.665 \\
\hline
\end{tabular}

\footnotetext{
Values in parentheses are percentages.

$* X^{2}$ test or Fisher's exact test, depending on the expected number of frequencies.
}

and/or seroma (11, 6.7 per cent), wound infection/abscess (eight, 4.9 per cent), sentinel node procedure performed without removal of the sentinel node (one, 0.6 per cent) and other (one, 0.6 per cent). The number of infections was similar in patients treated in short stay compared with inpatients. The number of readmissions and reoperations owing to complications were similar in patients treated before and after implementation of the programme. Twenty-eight of 73 mastectomies were carried out with an overnight admission before implementation. This proportion almost doubled to 36 of 54 after implementation. The percentage of patients undergoing breast-conserving surgery was significantly higher after implementation. 


\section{Predictors of treatment in short stay}

Hospital 3 already applied short stay before the intervention. Thus, the change from inpatient to outpatient admission seemed more hospital-related than patient-related. For this reason, emphasis was placed on the interval after implementation to determine which patient and healthcare-related factors were associated with treatment in short stay.

Logistic regression analysis showed that undergoing breast-conserving surgery (odds ratio (OR) 5.45 (95 per cent confidence interval 2.06 to 16.04); $\mathrm{P}<0.001$ ), being employed full or part time (OR 2.83 (1.05 to 7.65); $\mathrm{P}=0.040$ ) and having children (3.93 (1.06 to 14.62$) ; \mathrm{P}=0.041$ ) were independently associated with a higher probability of short admission after implementation of the programme. Additionally, patients older than 64 years were less likely to be treated in a short admission (0.28 (0.07 to 1.06); $\mathrm{P}=$ $0.061)$.

\section{DISCUSSION}

This study showed that short-stay hospital admissions were achieved in hospitals that were invited to participate in an implementation study, without a negative effect on the number of readmissions and complications. Therefore, if patients are selected using guidelines presented in this chapter, short hospital admission following breast cancer surgery is feasible and safe. Having a full- or part-time job, having children, undergoing breast-conserving surgery and younger age were predictors of successful short-stay treatment.

Institutional differences in uptake of the protocol were observed. Although the number of hospitals and the study design did not allow conclusions to be drawn, the number of outreach visits was related to the proportional increase of patients treated with an overnight stay. In some hospitals the head of the department played a pivotal role in reaching consensus, and creating a basis for implementation ${ }^{17,18}$.

The proportion of patients planned for treatment in short stay did not increase further for various reasons. Apart from protocol restrictions, the most common reasons were difficulty in changing daily routines, tumour wire localization the day before surgery, the patient's preference for being in hospital and older age. Reasons for failure to achieve a planned short stay were nausea, excessive drain fluid production (in a hospital where patients were not allowed to be discharged with drains in place), secondary haemorrhage, emotional problems, anaphylactic shock, surgical delay because of incorrect use of contrast medium during the sentinel node procedure, and surgery performed late in the afternoon.

The present study had some limitations. As in other studies, eligible patients who 
did not participate were significantly older than those who consented ${ }^{19,20}$. The age difference may have led to an overestimation of the probability of being treated in short stay, as older people are more likely to be admitted for longer ${ }^{21}$. However, the age distribution was similar in both intervals, and was almost identical to the age distribution of all women with newly diagnosed breast cancer in the Netherlands. The proportion of women who underwent breast-conserving surgery was significantly higher after implementation of the programme. This difference was not responserelated, nor could it be explained at a hospital level. It may be the result of a general trend away from breast ablative surgery towards breast-conserving surgery. The question of whether the change to short stay has influenced the choice of breastconserving surgery remains unanswered. It is increasingly recognized that patients should be involved in this decision, and encouraged to express their preference for the type of surgery ${ }^{22}$. Although involving patients has been demonstrated to increase the rate of breast-conserving therapy ${ }^{23}$, this rise is smaller than the increase found in the present study.

The non-randomized and non-controlled character of the study means that external influences on its findings cannot be excluded ${ }^{11}$. There has been a general tendency to a reduction in mean length of hospital stay in the past few years ${ }^{22-24}$, which possibly contributed to the positive results.

Short stay was already common practice in one hospital at start of the implementation phase. This had not been foreseen by the project leader when he contacted the hospital for participation. Possibly, the project leader's experience with short stay, and his plans to perform a study on this subject may have stimulated healthcare givers of this hospital to explore their own capacities in implementing short stay following breast cancer surgery. However, this was not a strong enough stimulus to explain the magnitude of the increase in short stay in the other hospitals (37 per cent) in the relatively short period between the two intervals in which no selection with respect to type of surgery was made ${ }^{25}$. Therefore, results from this hospital were included in the analyses. The findings of this study can be used to optimize selection of patients for short admission in a health improvement and efficiency programme. Anaesthesia and pain protocols should be developed. Day-care and home-care nursing staff should be trained specifically for the short-stay programme, so that patients are among others with similar severity of disease while they receive personalized care by trained and dedicated staff in a relatively short period of time within the hospital, and thereafter at home. Informal caregivers should be educated on wound care, and drain care if applicable. 


\section{REFERENCES}

1. Bonnema J, van Wersch AM, van Geel AN, Pruyn JF, Schmitz PI, Uyl-de Groot CA, Wiggers $\mathrm{T}$. Cost of care in a randomised trial of early hospital discharge after surgery for breast cancer. Eur J Cancer 1998;34(13): 2015-2020.

2. Bundred N, Maguire P, Reynolds J, Grimshaw J, Morris J, Thomson L, Barr L, Baildam A. Randomised controlled trial of effects of early discharge after surgery for breast cancer. Bmj 1998;317(7168): 1275-1279.

3. Purushotham AD, McLatchie E, Young D, George WD, Stallard S, Doughty J, Brown DC, Farish C, Walker A, Millar K, Murray G. Randomized clinical trial of no wound drains and early discharge in the treatment of women with breast cancer. $\mathrm{Br} J$ Surg 2002;89(3): 286-292.

4. Cole BO, Hislop WS. A grading system in day surgery: effective utilization of theatre time. J R Coll Surg Edinb 1998;43(2): 87-88.

5. Margolese RG, Lasry JC. Ambulatory surgery for breast cancer patients. Ann Surg Oncol 2000; 7(3): 181-187.

6. Kambouris A. Physical, psychological, and economic advantages of accelerated discharge after surgical treatment for breast cancer. Am Surg 1996;62(2): 123127.

7. Tan LR, Guenther JM. Outpatient definitive breast cancer surgery. Am Surg 1997;63(10): 865-867.

8. Warren JL, Riley GF, Potosky AL, Klabunde CN, Richter E, Ballard-Barbash R. Trends and outcomes of outpatient mastectomy in elderly women. J Natl Cancer Inst 1998;90(11): 833-840.

9. Stauffner M. Issue Brief: Mastectomies. In: National Conference of State Legislatures; 1998; Washington, DC: Health Policy Tracking Service; 1998.

10. Case C, Johantgen M, Steiner C. Outpatient mastectomy: clinical, payer, and geographic influences. Health Serv Res 2001;36(5): 869-884.

11. de Kok M, Frotscher CN, van der Weijden T, Kessels AG, Dirksen CD, van de Velde CJ, Roukema JA, Bell AV, van der Ent FW, von Meyenfeldt MF. Introduction of a breast cancer care programme including ultra short hospital stay in 4 early adopter centres: framework for an implementation study. BMC Cancer 2007;7(1): 117.

12. Grol R. Personal paper. Beliefs and evidence in changing clinical practice. $B m j$ 1997;315(7105): 418-421.

13. Rogers EM. Diffusion of innovations (5th edn). Free Press: New York, 2003; xxi, 551 p.

14. Grol R, Wensing M, Eccles M. Improving patient care. The implementation of change in clinical practice. Butterworth-Heinemann: Toronto, 2005.

15. de Kok M, van der Weijden T, Kessels A, Dirksen C, van de Velde C, Roukema J, van der Ent F, Bell A, von Meyenfeldt M. Implementation of an Ultra-short-stay Program After Breast Cancer Surgery in Four Hospitals: Perceived Barriers and Facilitators. World J Surg 2008; 32 (12):2541-2548.

16. (IAAS) IAfAS. Day surgery: Development and practice, 2006; 346.

17. Ham C. Improving the performance of health services: the role of clinical leadership. Lancet 2003;361(9373): 1978-1980.

18. Grimshaw JM, Eccles MP, Greener J, Maclennan G, Ibbotson T, Kahan JP, Sullivan F. Is the involvement of opinion leaders in the implementation of research findings a feasible strategy? Implement Sci 2006;1: 3. 
19. Ellis PM, Butow PN, Tattersall MH, Dunn SM, Houssami N. Randomized clinical trials in oncology: understanding and attitudes predict willingness to participate. J Clin Oncol 2001;19(15): 3554-3561.

20. Kemeny MM, Peterson BL, Kornblith AB, Muss HB, Wheeler J, Levine $E$, Bartlett $N$, Fleming $\mathrm{G}$, Cohen $\mathrm{HJ}$. Barriers to clinical trial participation by older women with breast cancer. J Clin Oncol 2003;21(12): 2268-2275.

21. Dutch National Institute for Public Health and the Environment (RIVM). Breast Cancer. 2009; http//www.rivm.nl/vtv/object_document/o4564n17276.html. [8 June 2009].

22. Molenaar S, Sprangers MA, Rutgers EJ, Luiten EJ, Mulder J, Bossuyt PM, van Everdingen JJ, Oosterveld $\mathrm{P}$, de Haes HC. Decision support for patients with earlystage breast cancer: effects of an interactive breast cancer CDROM on treatment decision, satisfaction, and quality of life. J Clin Oncol 2001;19(6): 1676-1687.

23. Waljee JF, Rogers MA, Alderman AK. Decision aids and breast cancer: do they influence choice for surgery and knowledge of treatment options? J Clin Oncol 2007;25(9): 1067-1073.

24. Marrazzo A, Taormina P, David M, Riili I, Lo Gerfo D, Casa L, Noto A, Mercadante S. Surgical treatment of early breast cancer in day surgery. Chir Ital 2007;59(5): 687691.

25. McCannon CJ, Berwick DM, Massoud MR. The science of large-scale change in global health. Jama 2007;298(16): 1937-1939. 


\section{Chapter 7}

M. de Kok

T. van der Weijden

A.G.H. Kessels

C.D. Dirksen

H.J.M. Sixma

C.J.H. van de Velde J.A. Roukema

C. Finaly-Marais

F.W.C. van der Ent M.F. von Meyenfeldt

Breast,

In Press, 2010 


\section{ABSTRACT}

\section{Background}

Aim was to assess breast cancer patients' opinions on quality of care before and after implementation of a short stay protocol, and to formulate patient inspired targets for further quality improvement.

\section{Methods}

Patients were asked to complete the QUOTE (Quality of Care Through the Patients' Eyes) breast cancer instrument, a self-administered validated questionnaire on quality of breast cancer care six weeks after in four Dutch hospitals between December 2005 and June 2007. A quality impact score indicated the need for improvement for each aspect.

\section{Results}

Among 324 patients who had signed consent for the study, 282 (87\%) completed the questionnaire. Quality of patient education regarding activities at home was in need of improvement in both measurements. Quality of services delivered by the surgeon improved somewhat after implementation. Although quality of waiting and process times improved after implementation, there was still room for further improvement on these aspects.

\section{Conclusion}

A breast cancer care programme in short stay was introduced while, on average, preserving quality of care as perceived by the patient. However, aspects regarding education on drains, prosthesis, exercises after surgery, survival rates, and waiting and process times require continuing attention to enhance patients' assessment of quality of care. 


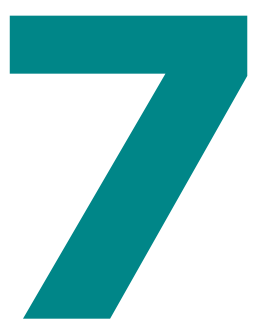

\section{INTRODUCTION}

The importance of assessment of quality of care is increasingly emphasized in healthcare research. In relation to this, it is well accepted that patients should be involved in the assessment of quality of healthcare. The QUOTE breast cancer instrument provides a tool to meet these requirements: it measures quality of care from the breast cancer patients' perspective ${ }^{1}$.

Day case or $24 \mathrm{~h}$ admission following breast cancer surgery is increasingly common. One element plays a decisive role in turning short hospital admission into a success; patients who are to be discharged need to be confident about their own and their relatives' capacity to provide sufficient care during the recovery process in the home situation. To achieve this, hospital care in the short stay setting should be at least similar to quality of care in the traditional inpatient admission setting. In a pilot study, a short stay (i.e. admission and discharge the same day or within 24 h) programme for breast cancer surgery was introduced at the Maastricht University Medical Centre (MUMC). Key figures in this programme are the multidisciplinary team, the breast nurse, and the patient. Following the preoperative diagnosis, the patient is extensively informed about all aspects of surgery (pre-, peri-, and postoperative period) in a one $\mathrm{h}$ consultation. In the programme, emphasis is placed on education, especially concerning the perioperative period. This is achieved by frequent repetition of the information as well as by supporting the oral information with a written format. After successful introduction at the MUMC, a study was performed in which the short stay programme was implemented in four Dutch hospitals. Patients treated according to the short stay programme (SSP), that is after implementation, were compared with patients treated in care as usual (CAU), that is before implementation. The proportion of patients treated in short stay increased from 45 per cent before to 82 per cent after implementation of the programme. Outcomes on patient level such as complications have been published recently². 
Alongside the implementation study, an evaluation was performed on quality of care from the patients' perspective. Our hypothesis was that restructuring of the care process as a result of the introduction of the short stay programme would result in equal scores on quality of care or even improvement of specific aspects such as patient education and waiting times in SSP compared with CAU. We wished to assess the patients' view on quality aspects that should be improved, as indicated by their experiences after implementation of the short stay programme.

\section{METHODS}

\section{Study design}

A before $\&$ after multi-centre study was performed, aimed at implementation of a short stay programme following breast cancer surgery ${ }^{2}$. Patients were included six months before and six months after an implementation period, which itself also lasted six months.

\section{Patients, settings, and procedure}

Four Dutch hospitals representing each of four different organizational formats (university hospital, large training hospital, small training hospital, non-training hospital) were invited to participate. All eligible 421 patients who had been scheduled for surgery with curative intent for any type of breast cancer during the two measurement periods (Dec '05 to June '06; Dec '06 to June '07), were invited to participate in the study. Eligibility criteria included being aged 18 years or older, having been diagnosed with breast cancer, and being scheduled for surgery for that reason. Excluded were patients who were not able to complete treatment in the hospital within a period of three months. The breast nurse at the breast unit invited patients to participate during the visit following that in which the diagnosis had been communicated. After being given oral and written information on the study, patients were asked to sign informed consent. Consenters were asked to fill out the QUOTE breast cancer questionnaire six weeks after surgery, and to return it by prepaid envelope. A six-week period was chosen to ensure the majority of patients had undergone most contact moments related to surgical admission (e.g. readmissions, outpatient department visits). Patients who had not returned the questionnaire were reminded by telephone or by letter if they could not be reached by phone. The study was approved by the Medical Ethical Committee of each participating hospital.

The QUOTE (Quality of Care Through the Patients' Eyes) breast cancer instrument QUOTE instruments ${ }^{3}$ provide information about the patients' perspective on the quality 
of healthcare services provided, and have been developed for various diseases and care organisations $\mathrm{s}^{4-6}$. They are appropriate for studies comparing situations before and after an intervention as they provide weight for aspects most suitable for inclusion in healthcare improvement programmes. The QUOTE-breast cancer was developed based on extensive focus group studies with breast cancer patients ${ }^{2}$. The instrument had been pilot tested among 276 breast cancer patients.

The results presented in this chapter refer to a previous version of the questionnaire containing 32 items. The Optimized QUOTE instrument which has recently been published $^{1}$ contains one additional item ("healthcare professionals provided me with good information about what the chosen treatment consisted of'), and aspects are divided under the headings 'Patient education regarding aspects related to postoperative treatment' (six items), 'Services by the breast nurse' (five items), 'Services by the surgeon' (six items), 'Patient education regarding activities at home' (three items), 'Patient education regarding aspects related to preoperative treatment' (four items), and 'Miscellaneous' (nine items). Items were formulated in two ways. First, patients were asked whether they received care as defined in the items, the so-called performance questions. Answers could be given in a binary (yes/no) format or in four -point Likert scales (never/ sometimes/ usually/ always ). Second, patients were asked to rate the importance they attached to each of the items, the so-called importance questions. The response format was of a four-point Likert-type (not important/ fairly important/ important/ extremely important).

Internal consistency of the items in the questionnaire was assessed through Cronbach $\alpha$ of non-performance scores with values of .70 and higher indicating reliable scales ${ }^{7}$. Scores were compared to those resulting from analyses of the pilot questionnaire ${ }^{1}$. Internal consistency of the full factor-based scales indicated substantial reliability, with Cronbach $\alpha$ ranging from .84 to .93 . A deviation of .02 to .14 from the scores presented previously was observed.

\section{Analyses}

The independent samples t-test was used to test for differences in mean age and response rates between the SSP and CAU study cohorts. The global chi-squared $\left(\mathrm{X}^{2}\right)$ statistic was used to test for differences in other sociodemographic characteristics between the measurements, and for differences between response and type of surgery or type of hospital. To explore discrepancies in scores between both measurements, scores were explored for all (domains of) aspects in the QUOTE breast cancer. Performance aspects with four-point answering categories were dichotomized; the responses 'never' and 'sometimes' were combined into "not-performed" scores $\left(\mathrm{P}_{\mathrm{n}}\right)$, and 'usually' and 'always' were combined into "was performed" scores $(\mathrm{P})^{8}$. Consecutively, 
so-called "quality impact scores" were computed per quality of care aspect by multiplication of the mean proportion of $\mathrm{P}_{\mathrm{n}}$ score for an aspect with the mean importance score for that aspect.

Usually, about $85-90 \%$ of respondents to satisfaction instruments assess quality of care aspects to be present or good ${ }^{9,10}$. Therefore, if $10 \%$ evaluates them as non-present or poor, this would imply a non-performance score of .10. If combined with a maximum importance score of 4 on a four-point Likert scale, it results in a benchmark of .40. We therefore interpret mean quality impact scores of .40 or above as indicative for a need for quality improvement whereas scores below .40 indicate adequate quality of care $\mathrm{e}^{2.3}$. Thus, quality impact scores are positively related to the need for improvement. Differences in non-performance scores between both measurements for each of the aspects were analyzed through the global chi-squared $\left(\mathrm{X}^{2}\right)$ statistic for the (dichotomized) response categories with $\mathrm{P}<0.05$ considered statistically significant. Mann-Whitney tests were applied to explore differences in importance scores between both measurements.

Logistic and linear regression analyses were executed for non-performance and importance scores respectively to adjust for a relation between outcomes and measuring moment, patients' age, type of surgery, or the hospital. As quality impact scores were constructed scores, they were only used for comparisons of the opinions on quality of care of large groups of patients, and were not used in further statistical analyses. Statistical analyses were performed using the SPSS package, version 12.0.1 ${ }^{\circ}$ for Windows (SPSS INC 1989-2003).

\section{RESULTS}

Of the 324 questionnaires given to patients who had signed informed consent (SSP: $\mathrm{n}=163$; CAU: $\mathrm{n}=161), 302$ (93\%) were returned and 282 (87\%) were completed (SSP: $\mathrm{n}=144$; CAU: $\mathrm{n}=138)$. Response rates were comparable in both measurements $(\mathrm{p}=.394)$, and between hospitals for SSP $\left(\mathrm{X}^{2}(3)=2.175, \mathrm{p}=.537\right)$ and for $\operatorname{CAU}(\mathrm{X} 2(3)=0.799, \mathrm{p}=.850)$. Significantly fewer patients underwent ablative surgery in SSP compared with CAU $(\mathrm{p}=.039)$.

Reasons for not returning the questionnaire despite a reminder were: patients felt results would be biased by other surgeries during the six week time period $(n=5)$, too much work $(n=1)$, too many things on their mind $(n=6)$, forgotten $(n=1)$, moved away $(n=1)$, partner deceased $(n=2)$, unknown $(n=5)$, and holiday $(n=1)$. Patients' age was comparable in both measurements (SSP: Mean (SD): 55 (11) years; CAU: Mean (SD): 55 (12) years, $\mathrm{p}=.343$. All participants were female. Respondents' characteristics are displayed in Table 1. 


\begin{tabular}{|c|c|c|c|}
\hline Variable & $\begin{array}{l}\text { Before implementation } \\
(n=138)\end{array}$ & $\begin{array}{l}\text { After implementation } \\
(\mathrm{n}=144)\end{array}$ & $P$ \\
\hline \multicolumn{4}{|l|}{ Age (years) } \\
\hline$<50$ & $50(36.2)$ & $38(26.4)$ & 0.126 \\
\hline $50-64$ & $58(42.0)$ & $77(53.5)$ & \\
\hline$>64$ & $29(21.0)$ & $29(20.1)$ & \\
\hline Not known & 1 & & \\
\hline Means (SD) & $55.2(11.6)$ & $56.5(11.0)$ & 0.342 \\
\hline \multicolumn{4}{|l|}{ Civil status } \\
\hline Married & $97(70.3)$ & $106(73.6)$ & 0.551 \\
\hline Not married & $20(14.5)$ & $13(9.0)$ & \\
\hline Divorced & $5(3.6)$ & $6(4.2)$ & \\
\hline Widowed & $16(11.6)$ & $19(13.2)$ & \\
\hline \multicolumn{4}{|l|}{ Highest educational level } \\
\hline Primary school & $9(6.5)$ & $2(1.4)$ & 0.079 \\
\hline Secondary school & $96(69.6)$ & $116(80.6)$ & \\
\hline College & $26(18.8)$ & $21(14.6)$ & \\
\hline University & $6(4.3)$ & $5(3.5)$ & \\
\hline Not known & 1 & & \\
\hline \multicolumn{4}{|l|}{ Daily activities $*$} \\
\hline$>30 \mathrm{hrs} / \mathrm{wk}$ paid work & $23(16.7)$ & $26(18.1)$ & 0.766 \\
\hline$<30 \mathrm{hrs} / \mathrm{wk}$ paid work & $37(26.8)$ & $33(22.9)$ & \\
\hline At home & $40(29.0)$ & $50(34.7)$ & \\
\hline $\begin{array}{l}\text { Physically impaired in daily } \\
\text { functioning }\end{array}$ & $11(8.0)$ & $9(6.3)$ & \\
\hline Unemployed & $4(2.9)$ & $1(0.7)$ & \\
\hline Voluntary work & $2(1.4)$ & $1(0.7)$ & \\
\hline (Early) retired & $18(13.0)$ & $21(14.6)$ & \\
\hline Studying & $2(1.4)$ & $3(2.1)$ & \\
\hline Not known & 1 & & \\
\hline \multicolumn{4}{|c|}{ Subjective description of perceived health } \\
\hline Excellent & $4(2.9)$ & $3(2.1)$ & 0.823 \\
\hline Very good & $9(6.5)$ & $11(7.6)$ & \\
\hline Good & $69(50.0)$ & $68(47.2)$ & \\
\hline Fair & $46(33.3)$ & $54(37.5)$ & \\
\hline Poor & $8(5.8)$ & $6(4.2)$ & \\
\hline Not known & 2 & 2 & \\
\hline \multicolumn{4}{|l|}{ Type of admission } \\
\hline Inpatient (> $24 \mathrm{~h})$ & $78(56.5)$ & $25(17.5)$ & 0.000 \\
\hline 24-hours & $28(20.3)$ & $67(46.9)$ & \\
\hline Day care & $31(22.5)$ & $51(35.7)$ & \\
\hline Not known & 1 & & \\
\hline \multicolumn{4}{|l|}{ Experienced treatment(s) } \\
\hline Breast conserving surgery & $67(48.6)$ & $84(58.3)$ & 0.076 \\
\hline Radiotherapy & $58(42.0)$ & $57(39.6)$ & 0.749 \\
\hline Chemotherapy & $48(34.8)$ & $45(31.3)$ & 0.584 \\
\hline Hormonal therapy & $36(26.1)$ & 2618.1 & 0.119 \\
\hline
\end{tabular}


Limited data were available of the patients who did not consent or who consented but did not respond. Within the total sample of eligible patients, the patients who did not sign informed consent were significantly older (62; SD 15 years) than those who did sign informed consent (56; SD 11 years), $\mathrm{p}=.000$. Within the total sample of patients who signed informed consent, there was no significant relation between age and filling out the questionnaire. Within this same sample, type of surgery tended to have an influence on response with patients with breast conserving surgery responding more often (than ablative surgery), but this was not significant $\left(\mathrm{X}^{2}(1)=0.246, \mathrm{p}=.062\right)$.

For all aspects, quality impact scores are presented in Table 2 for all hospitals and for both measurements. Neither Mann-Whitney tests nor regression analyses showed any significant changes in non-performance or importance scores on comparison of the two measurement periods.

Overall quality impact concerning education on postoperative treatment was below 0.40 indicating no need for improvement for both measurements although there was variation between, and within, hospitals. When aspects within the scale were assessed separately, two aspects were in need of improvement after implementation of the programme. Services by the breast nurse were looked upon as optimal in both measurements, on aspect and scale level. Mean quality impact for the "surgeon" scale and for each aspect separately had improved, and was below the .40 benchmark for both measurements indicating satisfactory overall quality of care. Patient education regarding activities at home showed a need for improvement in both measurements, specifically information on exercises after surgery. This need was even higher in SSP than in CAU. Concerning patient education on aspects of preoperative treatment, provision of information on survival rates is mostly in need of improvement. As hypothesized, most of aspects relating to waiting times had improved between the two measurements. However, aiming for a decrease in waiting times (between diagnostic tests (and results); between test results and surgery) should still receive attention in nearly all hospitals. In SSP, the number of aspects suitable for quality improvement was slightly higher than in CAU (eight aspects vs. six aspects). However, of the six aspects suitable for quality improvement in CAU, three had improved in the interim.

Despite extra attention paid to patient education in SSP, patients treated in SSP 


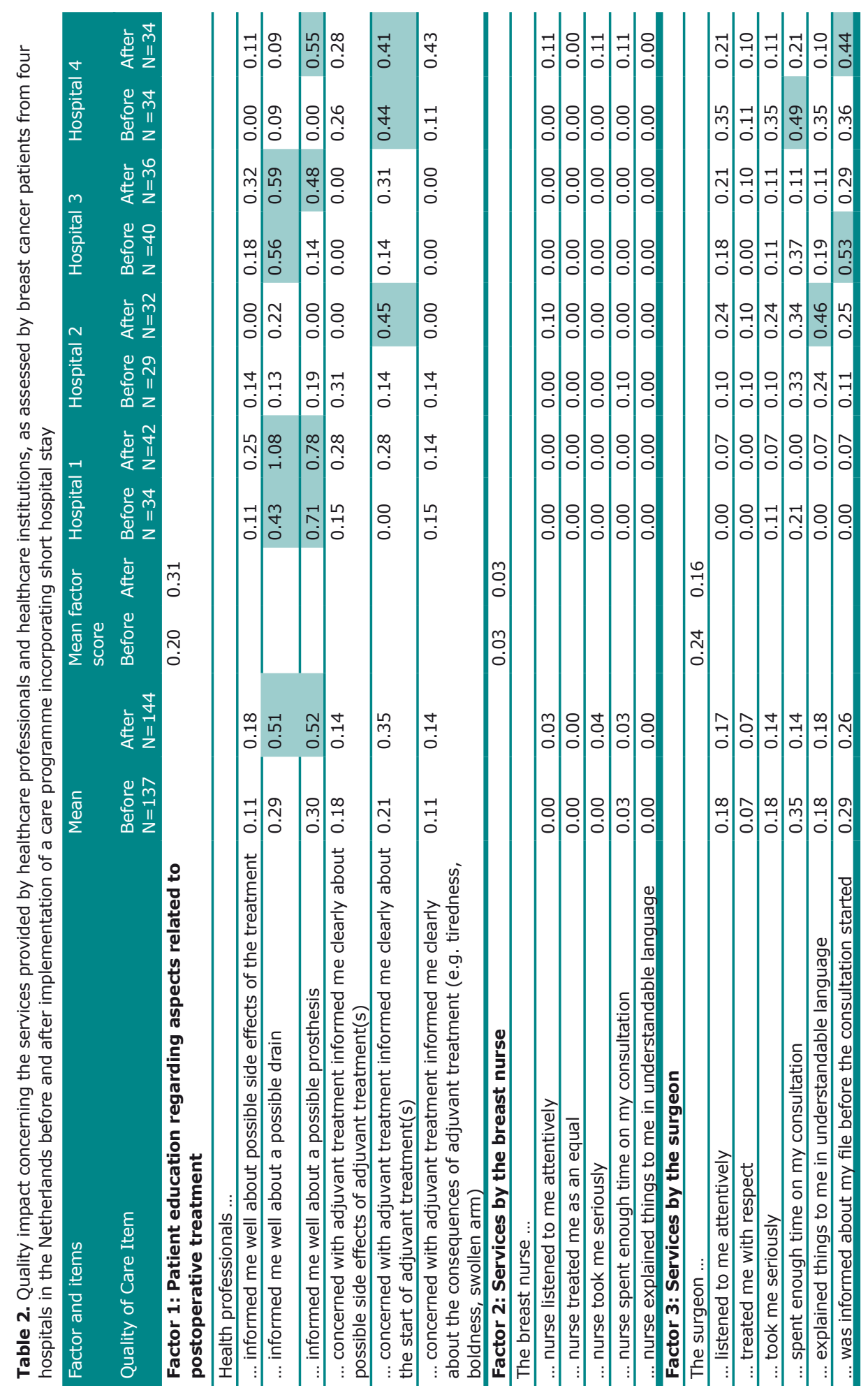




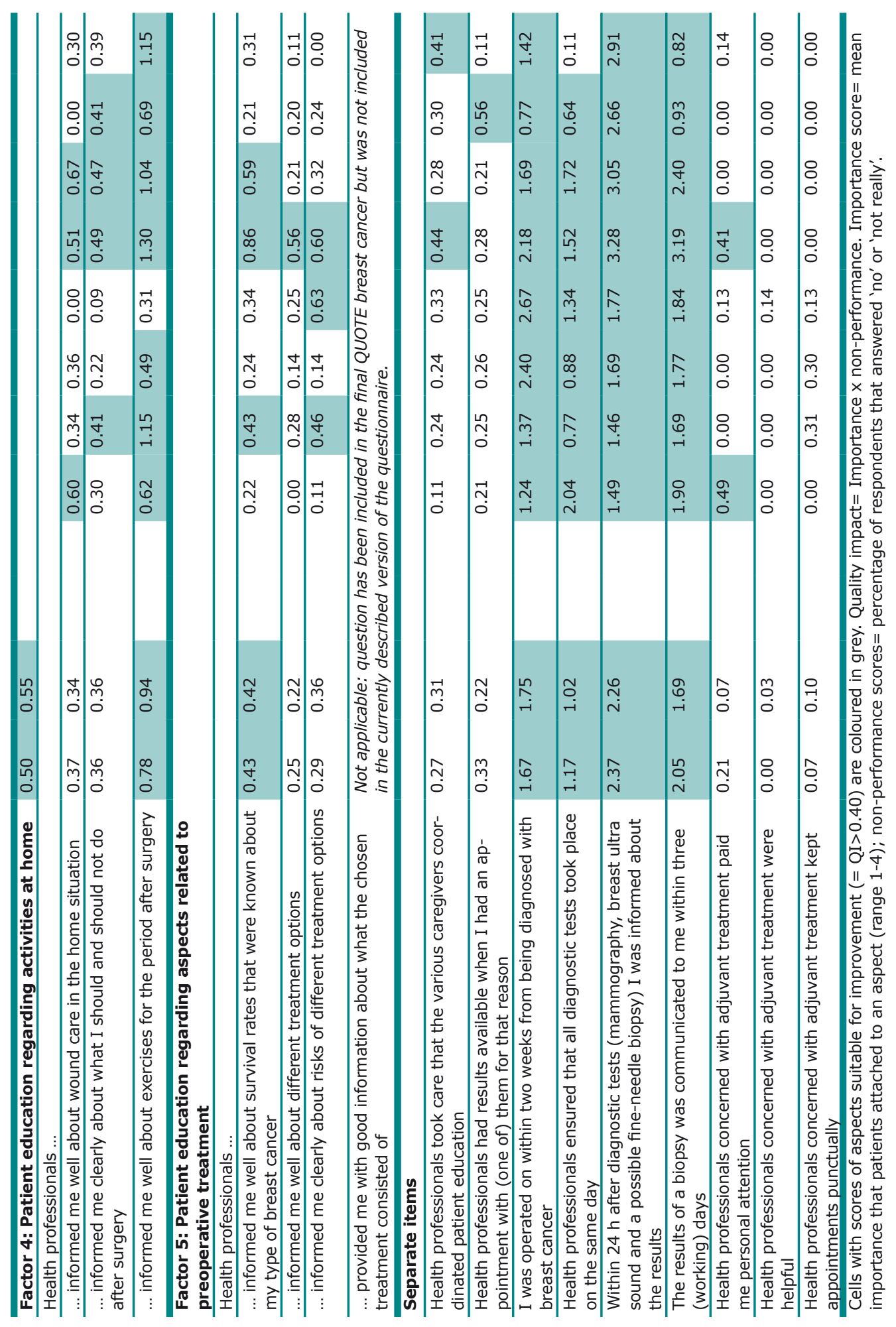


perceived a larger gap in the information they wished to receive, and the information they actually received, compared with CAU. The gap could be clarified by both an increase in non-performance as well as an increase in importance. In other words, healthcare professionals performed slightly less than before but patients, in going home earlier, also attached more value to the information on, for example, drains. This was not congruent with our assumption that information about possible drains, prostheses, and exercises after surgery were precisely the aspects that should be given extra attention when changing from an inpatient to an outpatient setting according to the short stay programme; we expected patients would rate education on these aspects as of higher quality in SSP than in CAU.

\section{DISCUSSION}

Overall, before and after implementation of the short stay programme breast cancer patients assessed quality of care as sufficient. Targets for further quality improvement concerned predominantly aspects that could be enhanced by improving information transfer.

In contrast to our expectations, we did not find that most aspects concerning patient education had improved from CAU to SSP. This was mainly explained by both a decreased/stable non-performance rate and an increase in importance rate. Possibly, the roughly stable scores can be explained by the fact that we did not only change the type of education (e.g. more written information) but also the care process as a whole. In CAU, patients were not informed about care in the home situation because all care needed was provided on an inpatient basis. In this situation, patients did not have to worry about the home situation. In contrast, in SSP, patients were well informed about care in the home situation, were required to consider and participate in many things but went home earlier, and were not dissatisfied with that. Another explanation is that the groups were comparable in general, but showed differences on patient characteristics such as education and unemployment although these differences were not statistically significant. The proportion of patients who had a low level of education or were unemployed was lower after implementation of the short stay programme than before, which may have resulted in more critical patients with higher information needs after compared with before implementation.

\section{Strengths of the study}

Although only four hospitals participated, each of the four different hospital organisational settings that prevail in the Netherlands was represented in the study. We think, therefore, that general applicability to the rest of the Netherlands was relatively 
good. For countries with (partially) comparable breast care organisations, results may be useful in identifying barriers or targets for improvement.

Previous research showed that the (development of the) instrument was valid and reliable. In addition, reliability of the questionnaire was confirmed in this study. Social desirability response bias ${ }^{11}$ was minimized as patients could fill out the questionnaire anonymously, and data collection and evaluation were performed by an independent researcher $(\mathrm{MdK})$. Therefore, we think that we have collected a data set representative of female breast cancer patients in the Netherlands.

\section{Weaknesses}

A randomized controlled trial was not feasible for budgetary reasons, in addition to which professionals' willingness to participate was estimated as low. The before \& after design allowed us to compare quality of care over time. We do not have indications that patients with breast cancer have gone through a sudden change in appreciation of the programme due to specific attention for breast cancer in mass media or society in general. Although the response rate was high ${ }^{11}$, we can not rule out the influence of consent and response bias; study participants were significantly younger than nonparticipants. For the patients who have given consent, no significant age difference was found between questionnaire returnees and non-returnees.

In our study, the timing of administration of the questionnaire was at six weeks after surgery. Therefore, some patients had started adjuvant treatment whereas other patients would start adjuvant treatment after administration of the questionnaire ${ }^{12}$. Although this may blur results, the time-point was chosen on purpose to maximize the perception of quality of care related to short admission, and to minimize recall bias ${ }^{13}$. As a consequence, it is possible that patients filled out their questionnaires either more positively or more negatively than they would have done at an earlier or later moment (and thus more patients would have started their adjuvant treatment). As the effect could work in both ways, we are confident we have collected fairly representative data.

\section{Generalizability of the results}

As we invited breast cancer patients undergoing different types of surgical treatment, validity of our results may seem limited as this increased diversity within groups. However, the SSP and CAU study cohorts as well as the pilot study cohort were fairly comparable. Therefore, we do not believe a difference in results can be explained by the study population. 


\section{Relation to other studies}

Marchal and colleagues compared patient satisfaction among groups of breast cancer patients treated in ambulatory or inpatient settings. However, patient satisfaction was captured in 1 mean score on a 1-10 for each group scale representing patient satisfaction ${ }^{14}$. They did not present data on how patients rated different aspects in the traditional hospital admission as compared to the short stay setting as presented extensively in this chapter through performance and importance scores. Bergenmar and colleagues studied quality of care before and after implementation of an improved healthcare programme, and presented the results through easily interpretable quality impact scores ${ }^{15}$. However, their study only focussed on the outpatient contacts of breast cancer patients. Besides, the questionnaire was formulated based on different papers, and pilot tested among a small $(\mathrm{n}=10)$ number of patients instead of item selection performed by the target group followed by a large pilot study.

Patients' opinions in the assessment of quality of breast cancer care have gained popularity in recent years. However, these opinions are rarely included in questionnaires on quality of care. Even when quality assessment is performed based on different dimensions, e.g. outcome, process, and structure indicators, patients' opinions in the assessment of quality of care are omitted ${ }^{16}$. In our study, these three types of indicators are combined with patients' assessment on quality of breast cancer care. Although other research findings show patients' wish to be better informed about potential side effects of adjuvant therapy, and information about chances of cure and spread of disease, this did not become clear from our study ${ }^{17,18}$. This may be explained by the fact that the questionnaire was generated by patients themselves and involved a care programme designed for appropriate and thorough information of patients.

\section{CONCLUSIONS AND RECOMMENDATIONS}

Patients are in general experiencing sufficient quality of care, both in care as usual as in the short-stay situation. However, institutions changing from inpatient admission towards day care or $24 \mathrm{~h}$ admission for breast cancer surgery should pay extra attention to information on prostheses, drains, and exercises after surgery in order to improve self-confidence of the patients recovering in their home situation. In addition, a decrease in waiting and process times should continue to receive attention in any breast cancer care process 


\section{REFERENCES}

1. de Kok M, Sixma HJ, van der Weijden T, Kessels AGH, Dirksen CD, Spijkers KFJ, van de Velde $\mathrm{CJH}$, Roukema JA, van der Ent FW, Finaly-Marais C, von Meyenfeldt MF. A patient-centred instrument for assessment of quality of breast-cancer care: results of a pilot questionnaire. Qual Saf Health Care, 2010, in press.

2. de Kok M, Scholte RW, Sixma HJ, van der Weijden T, Spijkers KF, van de Velde $\mathrm{CJ}$, Roukema JA, van der Ent FW, Bell AV, von Meyenfeldt MF. The patient's perspective of the quality of breast cancer care. The development of an instrument to measure quality of care through focus groups and concept mapping with breast cancer patients. Eur J Cancer 2007;43(8): 1257-1264.

3. Sixma HJ, Kerssens JJ, Campen CV, Peters L. Quality of care from the patients' perspective: from theoretical concept to a new measuring instrument. Health Expect 1998;1(2): 82-95.

4. Harmsen JA, Bernsen RM, Bruijnzeels MA, Meeuwesen LL. Patients' evaluation of quality of care in general practice: What are the cultural and linguistic barriers? Patient Educ Couns 2008.

5. Sixma HJ, van Campen C, Kerssens JJ, Peters L. Quality of care from the perspective of elderly people: the QUOTE-elderly instrument. Age Ageing 2000;29(2): 173178.

6. Van der Linde H, Hofstad CJ, Geertzen JH, Postema K, Van Limbeek J. From satisfaction to expectation: the patient's perspective in lower limb prosthetic care. Disabil Rehabil 2007;29(13): 1049-1055.

7. Nunnally JC, Bernstein IH. Psychometric theory (3rd edn).McGraw-Hill, 1994.

8. Nijkamp MD, Sixma HJ, Afman H, Hiddema F, Koopmans SA, van den Borne B, Hendrikse F, Nuijts RM. Quality of care from the perspective of the cataract patient. QUOTE cataract questionnaire. J Cataract Refract Surg 2002;28(11): 1924-1931.

9. Williams B. Patient satisfaction: a valid concept? Soc Sci Med 1994;38(4): 509516.

10. Lebow JL. Research assessing consumer satisfaction with mental health treatment: a review of findings. Eval Program Plann 1983;6(3-4): 211-236.

11. Sitzia J, Wood N. Response rate in patient satisfaction research: an analysis of 210 published studies. Int J Qual Health Care 1998;10(4): 311-317.

12. Vrieling C, Collette L, Fourquet A, Hoogenraad WJ, Horiot JC, Jager JJ, Bing Oei $S$, Peterse HL, Pierart M, Poortmans PM, Struikmans H, Van den Bogaert W, Bartelink $\mathrm{H}$. Can patient-, treatment- and pathology-related characteristics explain the high local recurrence rate following breast-conserving therapy in young patients? Eur J Cancer 2003;39(7): 932-944.

13. Coughlin SS. Recall bias in epidemiologic studies. J Clin Epidemiol 1990;43(1): 87-91.

14. Marchal F, Dravet F, Classe JM, Campion L, Francois T, Labbe D, Robard S, Theard $\mathrm{JL}$, Pioud R. Post-operative care and patient satisfaction after ambulatory surgery for breast cancer patients. Eur J Surg Oncol 2005;31(5): 495-499.

15. Bergenmar M, Nylen U, Lidbrink E, Bergh J, Brandberg Y. Improvements in patient satisfaction at an outpatient clinic for patients with breast cancer. Acta Oncol 2006;45(5): 550-558.

16. Kaufman CS. Validating quality breast care: three new validation programs for 2007. Am J Surg 2007;194(4): 515-517. 
17. Degner LF, Kristjanson LJ, Bowman D, Sloan JA, Carriere KC, O'Neil J, Bilodeau B, Watson $\mathrm{P}$, Mueller B. Information needs and decisional preferences in women with breast cancer. Jama 1997;277(18): 1485-1492.

18. McGurk R, Fallowfield $L$, Winters $Z$. Information provision for patients by breast cancer teams about the side-effects of hormone treatments. Eur J Cancer 2006;42(12): 1760-1767. 


\section{Chapter 8}

M. de Kok

C.D. Dirksen

A.G.H. Kessels

T. van der Weijden

C.J.H. van de Velde J.A. Roukema

A.V.R.J. Bell

F.W.C. van der Ent

M.F. von Meyenfeldt

Acta Oncol,

In Press, 2010 


\section{ABSTRACT}

\section{Background}

Short stay (admission, surgery, and discharge the same day or within $24 \mathrm{~h}$ ) following breast cancer surgery is part of an established care protocol but as yet not well implemented in Europe. Alongside a before-after multi-centre implementation study, an economic evaluation was performed exploring the cost-effectiveness of a short stay programme (SSP) versus care as usual (CAU).

\section{Methods}

In the implementation study, 324 patients were included. In the economic evaluation a societal perspective was applied with a six week time horizon. Cost data were obtained from Case Record Forms and cost diaries. Effectiveness was assessed by calculating Quality Adjusted Life Years (QALYs), using the EuroQol-5D. Cost-effectiveness was expressed as the incremental costs per QALY.

\section{Results}

Mean societal costs decreased by $€ 955$,- (95\% CI $€$ - 2104,- to $€ 157,-)$ for patients in SSP $(\mathrm{n}=127)$ compared with CAU $(\mathrm{n}=135)$. Mean healthcare costs differed $€ 883,-(95 \% \mathrm{CI}$ $€-1560$,- to $€-870,-)$ in favour of SSP. The incremental cost-effectiveness ratio could not be calculated due to similar effectiveness for both groups, that is the difference in QALYs was zero. The cost-effectiveness acceptability curves showed that the probability that SSP was more cost-effective than CAU was over $90 \%$ in the base-case analysis.

\section{Conclusions}

A short stay programme as implemented is cost-effective compared with care as usual. In achieving good and more efficient quality of care, larger scale implementation is warranted. 


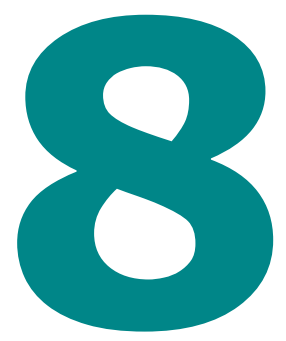

\section{INTRODUCTION}

Breast cancer is the most common malignancy in women worldwide ${ }^{1}$. One of every eight Dutch women will be diagnosed with breast cancer at some moment in her life 2 . The proportion of breast cancer related hospital admissions in Dutch women increased with 13\% from 1995-2004. In 2005, breast cancer-related costs comprised $0.4 \%$ of the Dutch national healthcare budget, of which $54 \%$ were hospital-related costs ${ }^{3}$. With an ageing population and an increasing breast cancer incidence, a rise of breast cancerrelated healthcare costs is expected. Therefore, efficient treatment regimens ensuring good quality of breast cancer care are important to continue to answer to every patient's needs.

A short hospital stay following breast cancer surgery provides the opportunity to reduce the burden on the healthcare budget, and allows recovery in the familiar home situation. In three RCT's on breast cancer surgery no significant increase in side effects was found comparing early discharge (two to four days) with traditional admission (five to 10 days $)^{4-6}$. Several studies on reduction of mean admission periods following breast cancer surgery showed cost reductions due to savings on admissions ${ }^{7-9}$. At the Maastricht University Medical Centre (MUMC), a short stay programme following breast cancer surgery was successfully introduced during a pilot study. Results (unpublished data) pointed towards a cost saving of about $€ 500$,- per patient. However, costs outside the hospital were not available including potential additional costs (e.g. due to increased use of informal care), and possible savings (e.g. due to reduction of productivity losses). As the programme was primarily expected to have an effect on quality of care, and not on quality of life, only safety and satisfaction were explored in the pilot study. However, the national breast cancer union expressed concerns regarding the effects on short-term quality of life. To convince the breast cancer union and facilitate introduction of the programme, quality of life research seemed warranted. 
Although all studies indicate that reduced hospital stay after breast cancer surgery is feasible and safe, no formal economic evaluation has yet been performed on this issue, including an assessment of societal costs and quality of life.

Following successful introduction of the programme in the MUMC, an implementation study evaluated the multi-centre introduction of the programme ${ }^{10}$. Alongside this study an economic evaluation was performed from a societal perspective exploring the costeffectiveness of the short stay programme (SSP) versus care as usual (CAU).

\section{MATERIAL AND METHODS}

\section{Study design}

The economic evaluation was performed in four Dutch hospitals from December 2005 until July 2007. The implementation study consisted of three phases each lasting six months; a prospective assessment of CAU, the implementation phase, and a prospective assessment of SSP. A time horizon of six weeks (44 days exactly) was used. The incremental cost-effectiveness ratio (ICER) was computed as the difference in societal costs divided by the difference in Quality Adjusted Life Years (QALYs) between SSP and CAU.

\section{Interventions}

In CAU, stakeholders were not informed about the set of activities needed to introduce the programme. In other words, the admission lasted as long as deemed necessary by the surgeons without making arrangements for early recovery at home. In SSP, activities were performed to assess whether each individual patient's situation was suitable for short hospital admission. If suitable, patients were scheduled for short stay ${ }^{10}$. Patients scheduled for day care admission were discharged as planned, unless their medical condition demanded overnight stay.

\section{Effectiveness}

Effectiveness was assessed through a generic health-related quality of life instrument, the EuroQol (EQ-5D) ${ }^{11}$. This instrument has proven validity and reliability, and is commonly used in cost-effectiveness studies ${ }^{12}$. The descriptive system of the EQ$5 \mathrm{D}$ consists of five dimensions (mobility, self-care, daily activities, pain/discomfort, depression/anxiety). Each dimension has three response options (no problems, some problems, severe problems), leading to 243 possible health states. For each health state, a utility score (US) can be computed, based on preferences from a general UK population, that is the UK tariff ${ }^{13}$. The EQ-5D was administered at baseline (one day before first surgery), one day postoperatively, one week postoperatively, and six weeks 
postoperatively. Utility scores were used to calculate QALYs using the following formula ${ }^{14}$.

QALY $=(((($ US baseline + US one day postoperatively/ 2)*3) $+((($ US one day postoperatively + US one week postoperatively $\left.) / 2)^{*} 7\right)+((($ US one week postoperatively + US six weeks postoperatively)/2)*34))/365. With a 44-day time horizon, a maximum of $44 / 365=0.12$ QALYs can be obtained.

\section{Cost analysis}

The cost analysis was performed according to the Dutch guidelines for cost calculations in healthcare ${ }^{15}$. Direct healthcare-related costs, direct costs outside healthcare, indirect costs, and out-of-pocket costs were included. Hospital visits concerning adjuvant treatment were excluded from analysis, as 1) patients may start adjuvant therapy shortly after discharge causing potentially biased results, and 2) most costs related to surgical treatment are made within weeks after first hospital discharge. A detailed inventory and measurement of consumed resources is termed micro-costing ${ }^{16}$, which allows others to explore how results compare to their own organizational and financial situation. Resource use was obtained through Case Record Forms (hospital costs) and through prospective cost diaries filled out by patients (all other costs). Only data indicated by patients as 'breast cancer related' were analyzed. Costs were expressed in 2008 euros $(€ 1=\text { US \$0.64) })^{17}$. If necessary, cost prices were actualized to 2008 using the Dutch Consumer Price Index ${ }^{18}$. Healthcare-related cost prices were obtained from published guidelines ${ }^{15}$, internet databases ${ }^{19}$, and financial departments of the participating hospitals. Hospital unit prices included 35\% general overhead and $10 \%$ housing costs ${ }^{15}$. Prices for personnel included 38\% social charges added to the gross salary. If cost prices differed between hospitals, an average price was calculated. If different cost prices were available within and between hospitals for a procedure (e.g. fine needle biopsies can be X-ray or ultra-sound guided), a weighed estimate was calculated. If cost prices were unavailable, as for multidisciplinary meetings, an integral cost price was calculated based on costs per hour per type of personnel involved, including materials, capacity, traveling and parking costs, added with overhead and housing. Productivity losses due to sick leave were calculated using the friction costs method, in which production losses are confined to the period needed to replace a sick worker: the friction period ${ }^{15}$.

\section{Statistical analysis}

Analysis was performed based on intention to treat. Multiple imputation was used to replace missing values with plausible estimates, and generated five data sets ${ }^{20}$. Results were provided as pooled estimates of these sets.

Bootstrapping was performed to determine 95\% confidence intervals (CI) around cost- 
differences between SSP and CAU and to quantify the uncertainty around the ICER. It is an appropriate method compared with traditional parametric and non-parametric tests to analyze skewed cost distributions and to yield information about the joint distribution of cost and effect differences ${ }^{21}$. It estimates the sampling distribution of a statistic through 1000 simulations, based on sampling with replacement from the original data. Results are plotted in an incremental cost-effectiveness plane in which the horizontal axis represents the incremental effects, and the vertical axis represents the incremental costs between SSP and CAU. This results in four quadrants: 1) southeast quadrant (SE): SSP is less costly and more effective than CAU meaning that SSP is dominant; 2) northwest quadrant (NW): SSP is more costly and less effective than CAU meaning that SSP is inferior; 3) southwest quadrant (SW): SSP is less costly and less effective than CAU meaning that the cost-effectiveness of SSP depends on the minimum amount of money society is willing to accept for loss of effectiveness and; 4) northeast quadrant (NE): SSP is more costly and more effective than CAU meaning that the cost-effectiveness of SSP depends on the maximum amount of money society is willing to pay for a gain in effectiveness.

The probability that SSP is cost-effective varies according to the ceiling ratio, that is the maximum amount society is willing to pay for a health gain or the minimum society is willing to accept for a health loss. The bootstrapped ICERs are plotted in a cost-effectiveness acceptability curve showing the probability that SSP is cost-effective using a range of ceiling ratio's22. Bootstrapping was performed using Excel 2000. Other analyses were performed using the SPSS package, version $17.0{ }^{\circledR}$ for Windows (SPSS INC 2009).

\section{Secondary analyses}

Sensitivity analyses were performed to explore the robustness of the results, that is the impact of changing (a) parameter(s) on the ICER. An analysis was performed on the only cost item that showed a substantial difference between SSP and CAU, for which a change in unit price might have an influence on the ICER; the cost price of an admission day was calculated using respectively the lowest and highest value. Next, analyses were performed from the patient's and healthcare perspective. Then, the Dutch EQ-5D tariff was used instead of the more commonly used UK tariff to calculate utilities $^{23}$. In the Dutch tariff the anxiety/depression dimension 'weighs' more than in the UK tariff. As anxiety plays an important role with (breast) cancer we expected that the Dutch tariff might have an effect on the outcomes.

Subsequently, subgroup analyses were performed, starting with analyses on hospital level from a societal and healthcare perspective. Next, types of surgeries (breast conserving/ablative) were compared. Then, a per-protocol analysis was performed, 
comparing the subgroup of patients in which surgery in short stay in SSP really succeeded, to the subgroup of patients in CAU that underwent surgery in long stay (that is hospital stay longer than $24 \mathrm{~h}$ ). The outcome of this analysis provides an 'optimal' estimate of cost-effectiveness of the programme compared to CAU (sometimes referred to as treatment cost-effectiveness), assuming that patients in CAU are always admitted longer than $24 \mathrm{~h}$, and patients treated in the SSP are always treated within $24 \mathrm{~h}$.

\section{RESULTS}

\section{Participants}

A total of 262 of the 324 patients participating in the implementation study returned filled out EQ-5D questionnaires. As data on health-related quality of life were necessary for the cost-effectiveness analysis, patients' data were not analyzed if all EQ-5D data were missing $(n=62)$. Of 35 of these 62 patients cost diaries and a questionnaire on baseline characteristics were also missing. The proportion of values missing at random on the EQ-5D for the remaining 262 patients was 0.03 . These values and missing values on cost diary data were imputed. Logistic regression analysis showed that the 262 patients included in the economic evaluation were not statistically different from the 62 excluded patients with respect to age, hospital, and type of surgery (breast conserving/ ablative).

Patients in SSP and CAU were comparable on socio-economic characteristics (Table 1). The proportion of patients actually treated in short admission was 0.81 (103/127) in SSP and $0.45(61 / 135)$ in CAU ( $\mathrm{p}=0.000)$. Groups were comparable regarding safety items ${ }^{10}$. During the study no mortality was recorded.

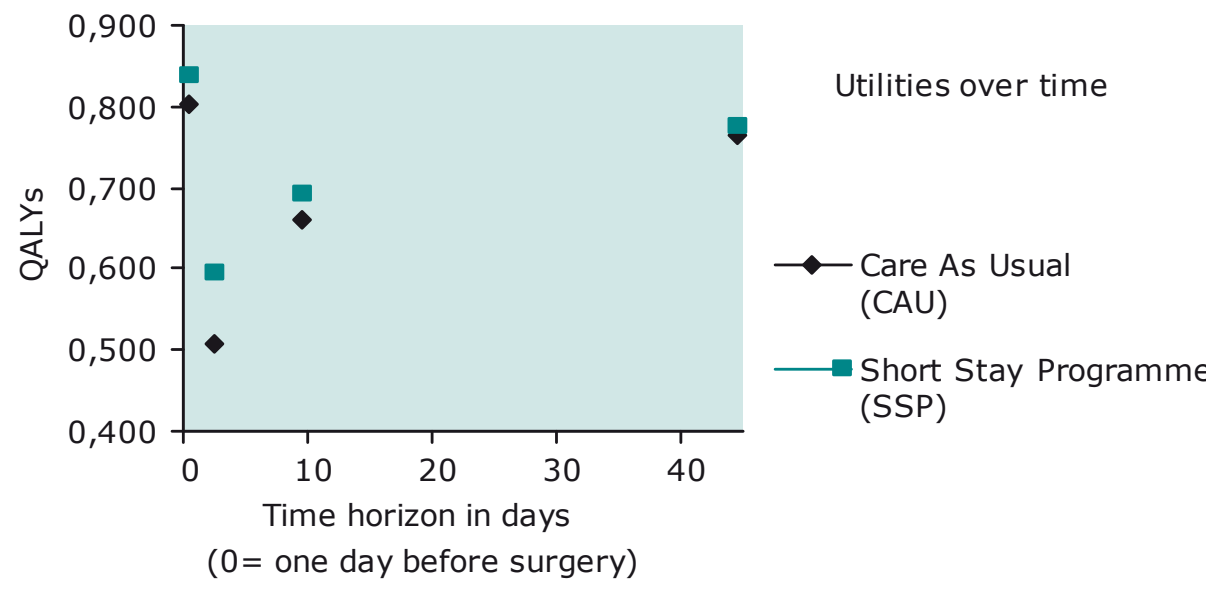

Figure 1. Utilities at thew four consecutive time points. The graph shows a timeline difference between the two groups in favour of SSP. 


\begin{tabular}{|c|c|c|c|c|c|}
\hline \multirow[t]{2}{*}{ Characteristic } & \multicolumn{2}{|c|}{$\begin{array}{l}\text { SSP v } \\
(n=127)\end{array}$} & \multicolumn{2}{|c|}{$\begin{array}{l}\text { CAU } \\
(n=135)\end{array}$} & P-value \\
\hline & \multicolumn{2}{|c|}{ Mean (SD) [range] } & \multicolumn{2}{|c|}{ Mean (SD) [range] } & \\
\hline \multirow[t]{2}{*}{ Age (years) } & \multicolumn{2}{|c|}{$56.1(10.8)[33-89]$} & \multicolumn{2}{|c|}{$55.3(11.6)[26-88]$} & \multirow[t]{2}{*}{0.577} \\
\hline & $\mathbf{n}$ & $\%$ & $\mathbf{n}$ & $\%$ & \\
\hline Marital status & & & & & 0.770 \\
\hline Married & 95 & 74.8 & 97 & 71.9 & \\
\hline Not married & 9 & 7.2 & 13 & 9.6 & \\
\hline Living together & 5 & 3.9 & 9 & 6.7 & \\
\hline Widowed & 13 & 10.2 & 11 & 8.1 & \\
\hline Divorced & 5 & 3.9 & 5 & 3.7 & \\
\hline Highest educational degree & & & & & 0.329 \\
\hline Primary school & 4 & 3.1 & 10 & 7.4 & \\
\hline Secondary school & 98 & 77.2 & 93 & 68.9 & \\
\hline College & 19 & 15.0 & 25 & 18.5 & \\
\hline University & 5 & 3.9 & 7 & 5.2 & \\
\hline Information missing & 1 & 0.8 & - & - & \\
\hline Paid work & & & & & 0.924 \\
\hline Yes & 55 & 43.3 & 59 & 43.7 & \\
\hline Mean hours per week & & 10.4 & & 10.5 & \\
\hline Performing housekeeping task & & & & & 0.246 \\
\hline Yes & 72 & 56.7 & 48 & 35.6 & \\
\hline Information missing & 1 & 0.8 & 1 & 0.7 & \\
\hline Having a housekeeper & & & & & 0.887 \\
\hline Yes & 26 & 20.5 & 31 & 23 & \\
\hline Information missing & 1 & 0.8 & 1 & 0.7 & \\
\hline Volunteer work & & & & & 0.828 \\
\hline Yes & 21 & 16.5 & 21 & 15.6 & \\
\hline Information missing & 1 & 0.8 & 1 & 0.7 & \\
\hline Household & & & & & 0.223 \\
\hline Living alone & 15 & 11.8 & 24 & 17.8 & \\
\hline Living with others & 104 & 81.9 & 108 & 80.0 & \\
\hline Information missing & 8 & 6.3 & 3 & 2.2 & \\
\hline Having children & & & & & 0.816 \\
\hline Yes & 108 & 85.0 & 111 & 82.2 & \\
\hline No & 18 & 14.2 & 23 & 17.1 & \\
\hline Information missing & 1 & 0.8 & 1 & 0.7 & \\
\hline \multicolumn{6}{|c|}{ Utilities (before Delta-adjustment) } \\
\hline 1 day before surgery & 0.84 & 0.02 & 0.80 & 0.02 & \\
\hline \multicolumn{6}{|c|}{ Utilities (after Delta-adjustment) } \\
\hline 1 day before surgery & 0.80 & 0.02 & 0.80 & 0.02 & \\
\hline
\end{tabular}

Table 1. Socio-economic characteristics of participants at baseline and mean scores for the EQ-5D in the care as usual group (CAU), and for patients treated according to the short stay programme (SSP) 


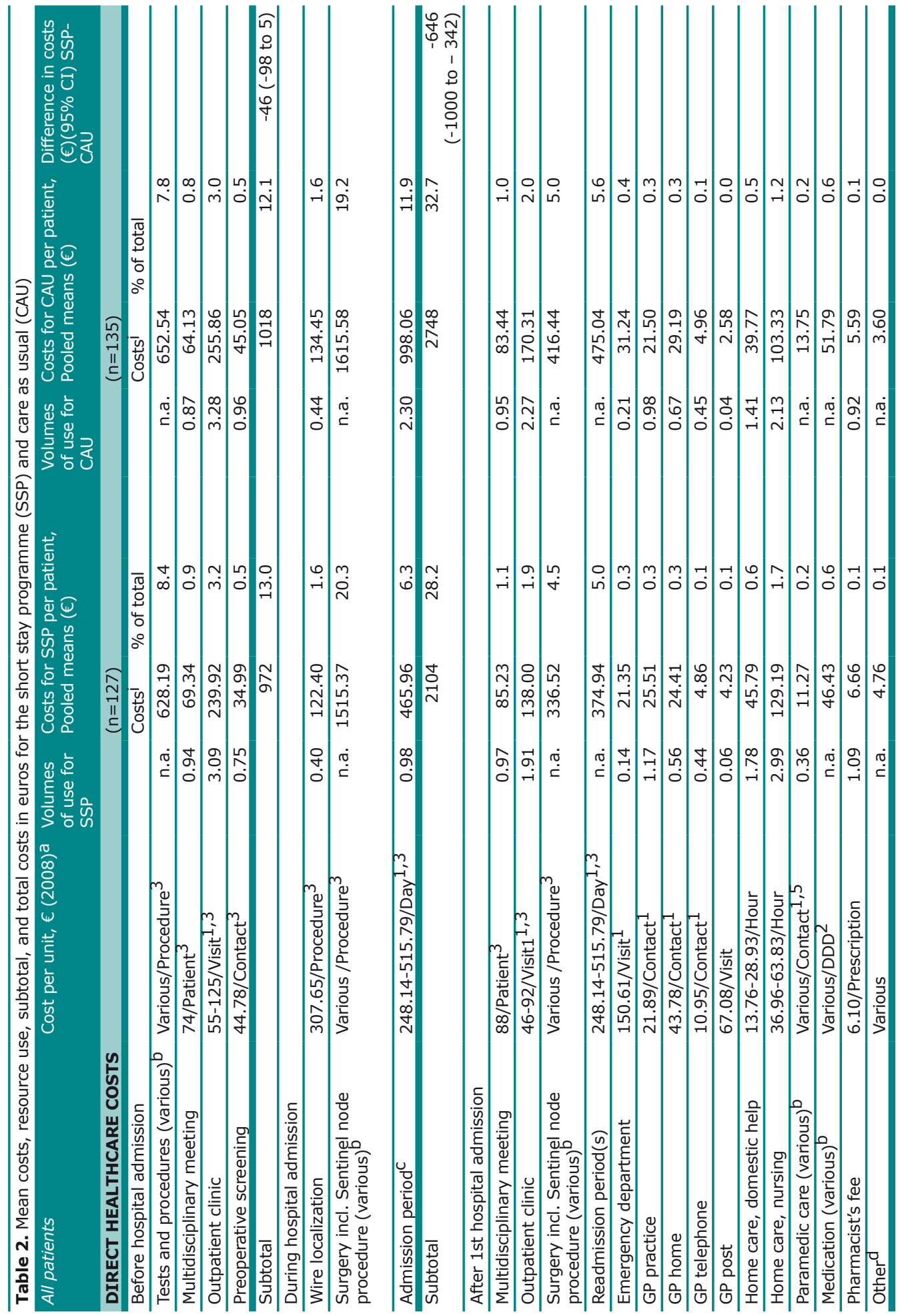




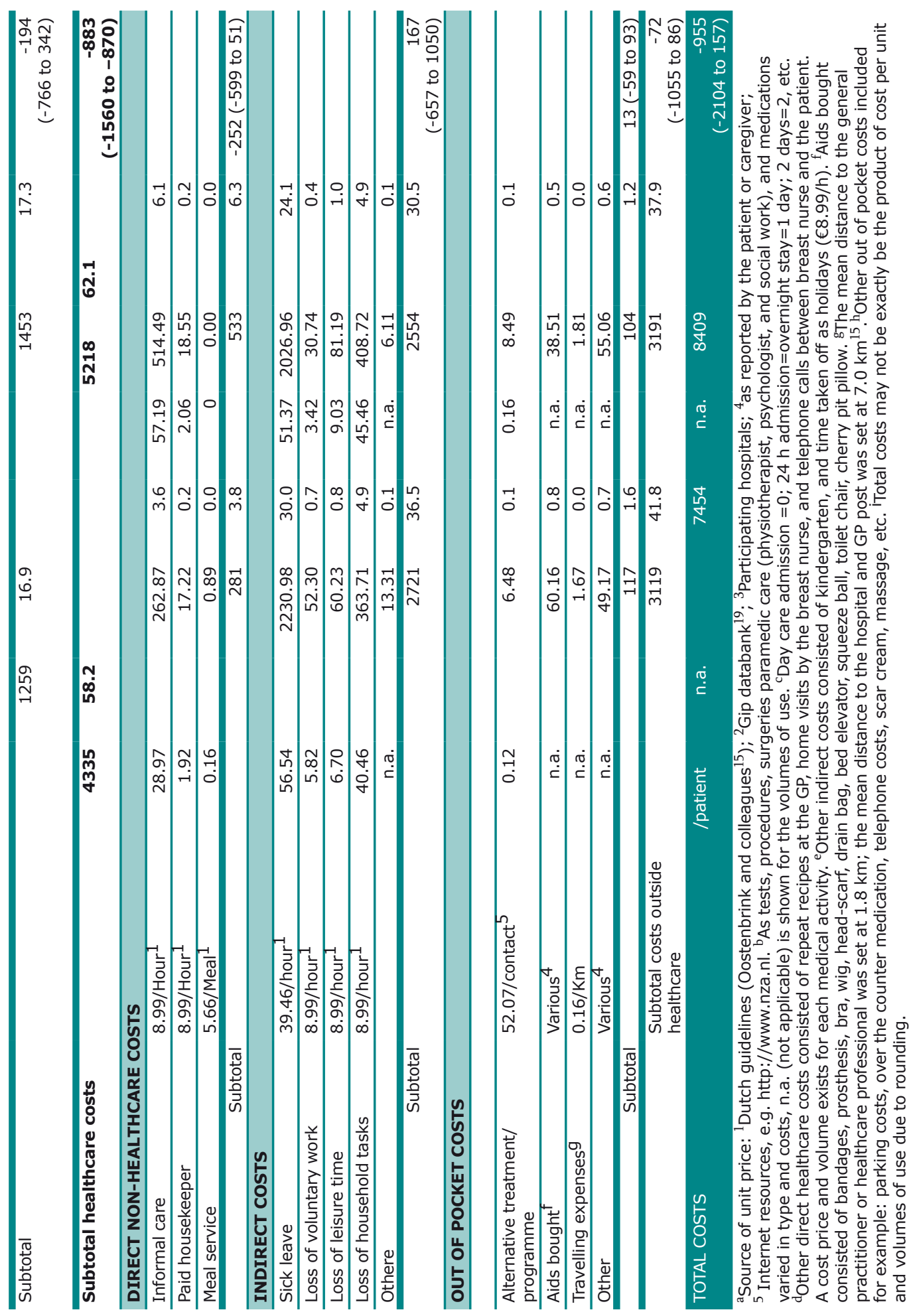




\section{Effectiveness}

Baseline utility was slightly (0.03) higher in SSP than in CAU. Values at the follow-up measurements were also slightly and consistently higher in SSP (Figure 1). Calculation of QALYs based on uncorrected data would lead to an outcome in favour of SSP, which would not be attributable to SSP. Using a conservative approach, a Delta-adjustment was performed to correct for the baseline utility difference ${ }^{24}$. The 0.03 difference was subtracted from the values at all measurements in SSP, as shown for the baseline measurement in Table 1.

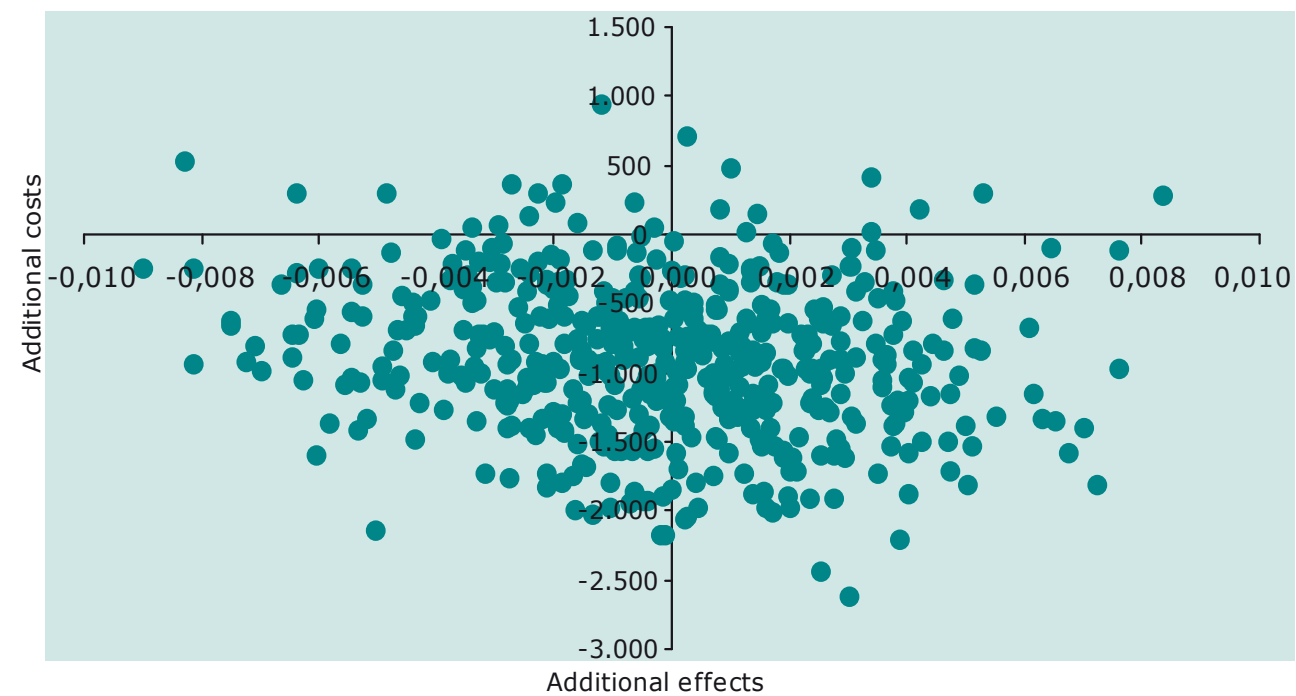

Figure 2. Cost-effectiveness plane for the Short Stay Programme (SSP) compared with Care As Usual (CAU). Effects (QALY); Costs $(€)$.

\section{Cost analysis}

Pooled total societal costs per patient differed $€ 955$,- in favour of SSP though not significantly. Total healthcare costs were significantly lower for SSP compared with CAU. This was mainly due to significantly lower costs of first admission for SSP compared with CAU. Although not significant, costs of informal care were lower for SSP, whereas productivity costs due to sick leave were higher for SSP than for CAU (Table 2).

\section{Cost-effectiveness}

Calculation of the point estimate of the ICER was impossible due to the fact that the difference in QALYs between SSP and CAU was zero. However, bootstrap analyses showed that SSP was cost-saving and more effective (dominant) in $47 \%$ of the bootstrap replicates (southeast quadrant) and cost-saving and less effective in $48 \%$ (southwest quadrant) (Figure 2). These results point towards the conclusion that SSP is cost-saving 
and equally effective compared to CAU. The cost-effectiveness acceptability curve illustrates that the probability that SSP is cost-effective compared with CAU is over $90 \%$, irrespective of the ceiling ratio (Figure 3 ).

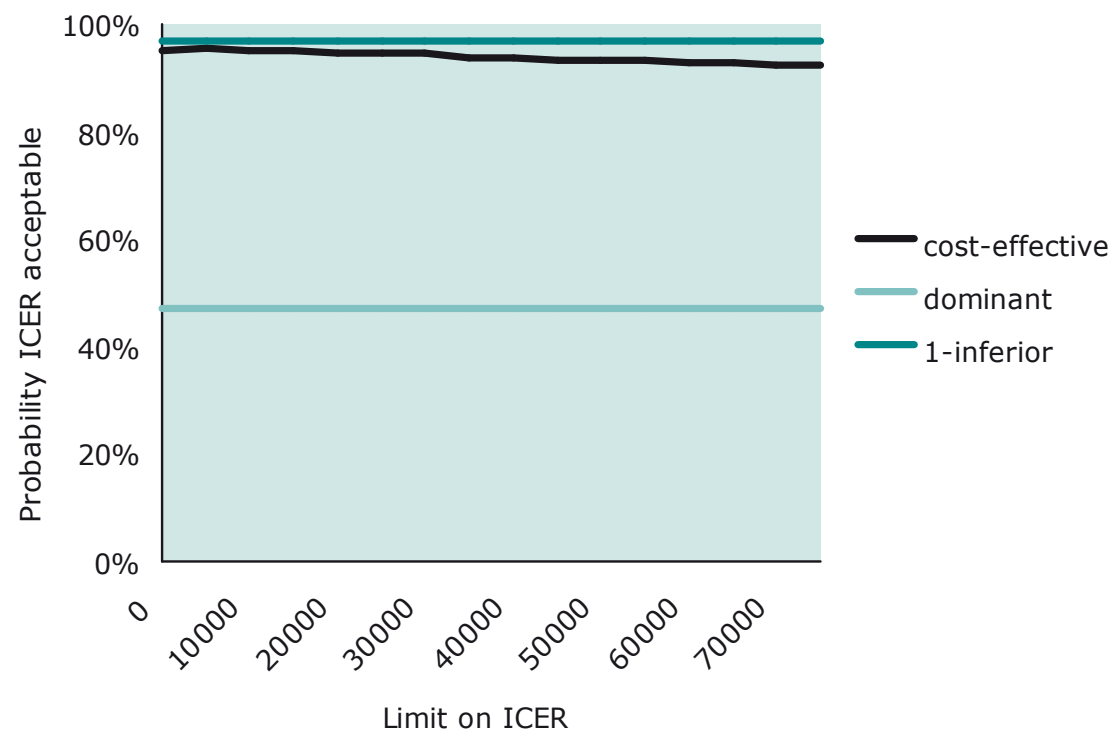

Figure 3. Cost-effectiveness acceptability curve for base-case analysis

\section{Secondary analyses (Table 3 )}

All but one secondary analyses revealed that SSP was either cost saving or dominant compared with CAU, which was also confirmed by bootstrap analyses. Only in hospital four, SSP was more costly than CAU from a societal perspective, confirmed by low probabilities for SSP being cost-effective (18\%-28\%). This was explained by higher costs of informal care and productivity losses in the SSP group.

Although the point estimate of the analysis from a patient perspective indicated that SSP is cost-saving, the uncertainty around the point estimates (54-57\%) suggests that SSP and CAU have almost equal chances of being cost-effective. This stands to reason as this perspective consisted only of costs outside healthcare, which were not different between groups. 
Table 3. Mean (pooled) costs, effects, and incremental cost-effectiveness ratio of the Short Stay Programme (SSP) compared with Care As Usual (CAU); results from base-case analyses and secondary analyses.

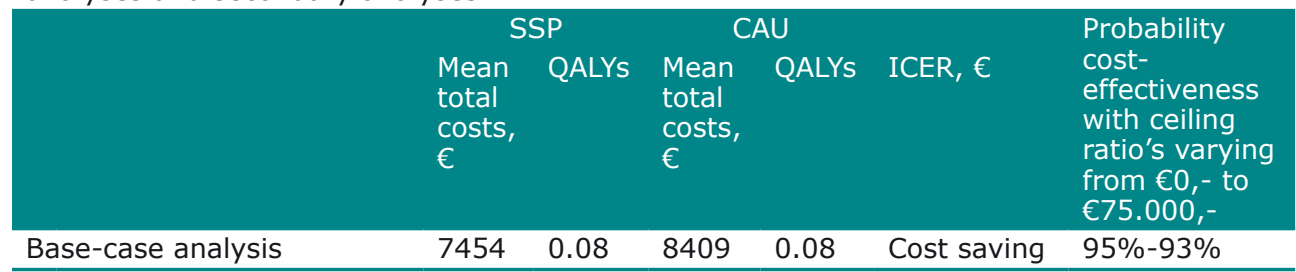

Resource use of hospital

admission days

\begin{tabular}{|c|c|c|c|c|c|c|}
\hline Low estimate: $€ 248,14$ & 7132 & 0.08 & 7807 & 0.08 & Cost saving & $89 \%-87 \%$ \\
\hline High estimate: $€ 515,79$ & 7692 & 0.08 & 8746 & 0.08 & Cost saving & $96 \%-95 \%$ \\
\hline $\begin{array}{l}\text { Analysis from patient } \\
\text { perspective }^{\mathrm{a}}\end{array}$ & 623 & 0.08 & 646 & 0.08 & Cost saving & $54 \%-57 \%$ \\
\hline $\begin{array}{l}\text { Analysis from healthcare } \\
\text { perspective }^{\mathrm{b}}\end{array}$ & 4335 & 0.08 & 5218 & 0.08 & Cost saving & $99 \%-98 \%$ \\
\hline $\begin{array}{l}\text { Dutch EQ tariff (after Delta- } \\
\text { adjustment) }\end{array}$ & 7454 & 0.09 & 8409 & 0.09 & Cost saving & $94 \%-91 \%$ \\
\hline
\end{tabular}

Type of hospital

Hospital $1(n=72)$

\begin{tabular}{lllllll}
\hline Societal perspective & 8025 & 0.08 & 8669 & 0.08 & Cost-saving & $68-59 \%$ \\
\hline Healthcare perspective & 5006 & 0.08 & 6536 & 0.08 & Cost-saving & $98-81 \%$ \\
\hline $\begin{array}{l}\text { \% Patients treated in } \\
\text { short stay }\end{array}$ & $77 \%$ & & $6 \%$ & & & \\
\hline
\end{tabular}

\section{Hospital 2 ( $n=54)$}

\begin{tabular}{lllllll}
\hline Societal perspective & 6436 & 0.09 & 9841 & 0.08 & Dominant & $100 \%-100 \%$ \\
\hline Healthcare perspective & 4009 & 0.09 & 5801 & 0.08 & Dominant & $100 \%-99 \%$ \\
\hline $\begin{array}{l}\text { \% Patients treated in } \\
\text { short stay }\end{array}$ & $67 \%$ & & $30 \%$ & & & \\
\hline
\end{tabular}

\section{Hospital $3(n=69)$}

\begin{tabular}{|c|c|c|c|c|c|c|}
\hline Societal perspective & 5965 & 0.09 & 7512 & 0.09 & Cost-saving & $95 \%-93 \%$ \\
\hline Healthcare perspective & 3235 & 0.09 & 3611 & 0.09 & Cost-saving & $93 \%-82 \%$ \\
\hline $\begin{array}{l}\text { \% Patients treated in } \\
\text { short stay }\end{array}$ & $93 \%$ & & $100 \%$ & & & \\
\hline \multicolumn{7}{|l|}{ Hospital $4(n=67)$} \\
\hline Societal perspective & 8833 & 0.08 & 7908 & 0.08 & $\begin{array}{l}\text { Cost- } \\
\text { increasing }\end{array}$ & $18-28 \%$ \\
\hline Healthcare perspective & 4767 & 0.08 & 5270 & 0.08 & Cost-saving & $87 \%-85 \%$ \\
\hline $\begin{array}{l}\text { \% Patients treated in } \\
\text { short stay }\end{array}$ & $85 \%$ & & $33 \%$ & & & \\
\hline \multicolumn{7}{|l|}{ Type of surgery } \\
\hline $\begin{array}{l}\text { Breast conserving } \\
(n=157)\end{array}$ & 7213 & 0.09 & 7826 & 0.09 & Cost saving & $82 \%-71 \%$ \\
\hline Ablative $(n=105)$ & 7864 & 0.08 & 9183 & 0.08 & Cost saving & $91 \%-91 \%$ \\
\hline \multicolumn{7}{|l|}{ Type of admission ${ }^{C}$} \\
\hline Short stay & 7129 & 0.09 & 7603 & 0.09 & n.a. & n.a. \\
\hline Long stay & 8851 & 0.07 & 9073 & 0.08 & n.a. & n.a. \\
\hline
\end{tabular}

apaid housekeeper, meal service, loss of voluntary work, loss of leisure time, loss of household tasks, other indirect costs, costs of alternative treatment, aids bought, traveling expenses.

beneral practitioner, home care nursing, paramedic care, hospital care.

comparing patients in short stay in SSP with patients in long stay in CAU would lead to dominance

for SSP due to lower costs and higher effectiveness. 


\section{DISCUSSION}

To our knowledge, this is the first formal economic evaluation comparing SSP with CAU for breast cancer surgery from a societal perspective.

This study revealed that SSP is cost-effective compared to CAU. Although societal costs were not significantly lower for SSP compared to CAU and the difference in QALYs was zero, bootstrap results showed a very high probability of SSP being cost-effective from a societal perspective and even more pronounced from a healthcare perspective. Secondary analyses showed that cost-effectiveness results were robust. Only the analysis on hospital level revealed that in hospital four SSP was cost-increasing from a societal perspective, confirmed by bootstrap results showing a very low probability of SSP being cost-effective. Detailed analysis showed that an increased use of informal care was reported in SSP, which was four times as high as in CAU. This was mainly due to one patient reporting the maximum amount of informal care during the time horizon of the study. Furthermore, costs due productivity losses and informal care increased to a level that SSP became cost-increasing compared with CAU. This could be explained by a pre-existent difference in marital status, full-time employed patients, and type of household within hospital four between SSP and CAU (not in table). This difference was not observed at comparison of the whole group in SSP and CAU.

It is difficult to compare our results with other studies, since the RCT's did not report QALYs or indirect costs such as costs due to productivity losses ${ }^{6,7}$. Although Purushotham reported costs outside healthcare generally, no explicit cost calculations were provided. In contrast to Bonnema and colleagues ${ }^{7}$, and in contrast with our expectations, overall the use of informal care decreased in SSP compared with CAU. In SSP, patients and informal caregivers are informed extensively about needs at home and they know exactly (except from unforeseen changes) when the patient is discharged. Possibly, this makes tasks and time frames for caregivers clearer than in CAU, allowing them to use their time more efficiently. Regarding costs due to productivity losses, no comparison with other studies can be made, but our results suggest that strategies to stimulate work rehabilitation may be worthwhile.

A strength of our study compared with published RCTs is that it was performed multi-centric, which increases the generalizability of the results. Moreover, our results confirm that SSP is safe and cost-saving, and add to the literature that from both a societal and healthcare perspective SSP is cost-effective compared to CAU. Ideally, a 'gold standard' RCT would be performed. However, this is often not feasible with an organizational change; caregivers are not likely to change behaviour based on randomization for a guideline, especially when internal motivation is the strongest 
driver for change. In such cases, logical alternatives are a before-after study or a study comparing different geographical area's. Since patient populations and routines may differ between hospitals, a before-after design seemed the 'purest'. As both groups were comparable on socio-economic characteristics, we believe that the design did not compromise our study findings.

It can be argued that our time horizon is too short to provide a valid estimate of costeffectiveness. However, most costs and effects relating to the surgical period take place in the first weeks after discharge. Moreover, after this period, results are likely to be biased due to other interventions.

As it was impossible to calculate ICERs due to equal effectiveness, one may suggest that a cost-minimization approach would have been better. However, as the implementation study was not specifically designed to show equivalence in effectiveness between SSP and CAU, such an approach would be inappropriate. Nevertheless, a post-hoc power calculation showed that, with at least 127 patients per group, our study was powered at $73 \%$ to reject a minimally important difference of 0.074 or greater in mean QALY between both groups ${ }^{25}$. Moreover, in this case a cost-minimization approach would have led to the same conclusions, as bootstrap results confirmed equal effectiveness between SSP and CAU.

Our results support the decision to substitute CAU with SSP. Especially when a hospital perspective is taken, our results point towards significant cost-savings when changing form CAU to SSP, and we state that the programme can be transferred to other settings. Our micro-costing results can be used to assess one's own situation, and to predict the success of the programme in terms of costs. In line with this, it is important to assess costs related to such an implementation.

In conclusion, we advise broad implementation of the short stay programme with special attention for strategies to stimulate work rehabilitation. The results of this multi-centre study should be used to improve quality of care for breast cancer patients. Nevertheless, individual decisions are not only based on cost-effectiveness arguments but also on patients' acceptance of the increasingly important role of home care and informal caregivers in exchange for hospital admission. 


\section{REFERENCES}

1. Parkin DM, Bray F, Ferlay J, Pisani P. Global cancer statistics, 2002. CA Cancer J Clin 2005;55(2): 74-108.

2. Comprehensive Cancer Centres (IKCNET).2006; http://www.ikcnet.nl. [30 September 2009].

3. Dutch National Institute for Public Health and the Environment (RIVM). 2009; http:// www.rivm.nl. [30 September 2009].

4. Bonnema J, van Wersch AM, van Geel AN, Pruyn JF, Schmitz PI, Paul MA, Wiggers T. Medical and psychosocial effects of early discharge after surgery for breast cancer: randomised trial. Bmj 1998;316(7140): 1267-1271.

5. Bundred N, Maguire P, Reynolds J, Grimshaw J, Morris J, Thomson L, Barr L, Baildam A. Randomised controlled trial of effects of early discharge after surgery for breast cancer. Bmj 1998;317(7168): 1275-1279.

6. Purushotham AD, McLatchie E, Young D, George WD, Stallard S, Doughty J, Brown DC, Farish C, Walker A, Millar K, Murray G. Randomized clinical trial of no wound drains and early discharge in the treatment of women with breast cancer. $\mathrm{Br} J$ Surg 2002;89(3): 286-292.

7. Bonnema J, van Wersch AM, van Geel AN, Pruyn JF, Schmitz PI, Uyl-de Groot CA, Wiggers $T$. Cost of care in a randomised trial of early hospital discharge after surgery for breast cancer. Eur J Cancer 1998;34(13): 2015-2020.

8. Evans WK, Will BP, Berthelot JM, Logan DM, Mirsky DJ, Kelly N. Breast cancer: better care for less cost. Is it possible? Int J Technol Assess Health Care 2000;16(4): 11681178.

9. Edwards MJ, Broadwater JR, Bell JL, Ames FC, Balch CM. Economic impact of reducing hospitalization for mastectomy patients. Ann Surg 1988;208(3): 330-336.

10. de Kok M, Frotscher CN, van der Weijden T, Kessels AG, Dirksen CD, van de Velde $\mathrm{CJ}$, Roukema JA, Bell AV, van der Ent FW, von Meyenfeldt MF. Introduction of a breast cancer care programme including ultra short hospital stay in 4 early adopter centres: framework for an implementation study. BMC Cancer 2007;7(1): 117.

11. EuroQol--a new facility for the measurement of health-related quality of life. The EuroQol Group. Health Policy 1990;16(3): 199-208.

12. Brooks R. EuroQol: the current state of play. Health Policy 1996;37(1): 53-72.

13. Dolan $\mathrm{P}$, Roberts J. Modelling valuations for Eq-5d health states: an alternative model using differences in valuations. Med Care 2002;40(5): 442-446.

14. Koopmanschap MA, Rutten FF. Berekening van kosten van zorg; vaak onderschat in economische evaluaties. Nederlands Tijdschrift voor gezondheidswetenschappen (in Dutch) 1998;76: 83-88.

15. Oostenbrink JB, Bouwmans CAM, Koopmanschap MA, Rutten FFH. Handleiding voor kostenonderzoek: Methoden en standaard kostprijzen voor economische evaluaties in de gezondheidszorg. College voor zorgverzekeringen. Geactualiseerde versie: Rotterdam, 2004.

16. Gold MR, Siegel JR, Russell LB, Weinstein MC. Cost-Effectiveness in Health and Medicine Oxford University Press: New York 1996.

17. Board of Governors of the Federal Reserve System. http://www.federalreserve.gov. [1 September 2009].

18. Statistics Netherlands (CBS). http://www.cbs.nl. [22 June 2009].

19. The Genees-en hulpmiddelen Informatie Project databank (GIP-databank). http:// www.gipdatabank.nl. [30 September 2009]. 
20. Schafer JL, Graham JW. Missing data: our view of the state of the art. Psychol Methods 2002;7(2): 147-177.

21. Briggs $A H$, Wonderling DE, Mooney CZ. Pulling cost-effectiveness analysis up by its bootstraps: a non-parametric approach to confidence interval estimation. Health Econ 1997;6(4): 327-340.

22. van Hout BA, Al MJ, Gordon GS, Rutten FF. Costs, effects and C/E-ratios alongside a clinical trial. Health Econ 1994;3(5): 309-319.

23. Lamers LM, Stalmeier PF, McDonnell J, Krabbe PF, van Busschbach JJ. [Measuring the quality of life in economic evaluations: the Dutch EQ-5D tariff]. Ned Tijdschr Geneeskd 2005;149(28): 1574-1578.

24. Richardson G, Manca A. Calculation of quality adjusted life years in the published literature: a review of methodology and transparency. Health Econ 2004;13(12): 1203-1210.

25. Walters SJ, Brazier JE. Comparison of the minimally important difference for two health state utility measures: EQ-5D and SF-6D. Qual Life Res 2005;14(6): 15231532. 


\section{ABSTRACT}

\section{Background}

Study aim was to examine the policy cost-effectiveness of a short hospital stay programme following breast cancer surgery after implementing the programme in four Dutch hospitals. Costs and effects of a short stay programme were combined with costs and effects of a hospital-tailored multi-faceted implementation strategy to calculate policy cost-effectiveness.

\section{Methods}

The analysis was performed alongside a multi-center implementation study and took a societal perspective with a time horizon of five years. Effectiveness of implementation was defined as the uptake of short stay admission. Costs for development and execution of the implementation strategy were obtained from healthcare professionals, and were added to costs of the short stay programme to calculate total policy costs. Policy costeffectiveness of the short stay programme versus care as usual was expressed as the incremental costs per Quality Adjusted Life Year (QALY).

\section{Results}

The mean increase in uptake of short stay admission compared with baseline amounted to $36 \%$. Implementation costs were $€ 23$,- per patient. As QALY differences were marginally small, an ICER could not be calculated. Bootstrap analysis revealed that the short stay programme had a probability over $88 \%$ of being cost-effective irrespective of the ceiling ratio.

\section{Conclusions}

Taking costs and effects of implementation into account, the short stay programme was cost-effective from a policy point of view. Based on the results of this study, large- scale implementation of the programme is recommended. 


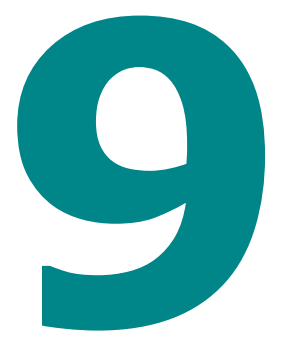

\section{BACKGROUND}

It is well established that implementation strategies are generally an effective means to actively change healthcare services through changing behaviour, as important research findings or clinical guidelines often do not translate automatically into routine practice. The efficiency of these strategies depends both on the degree of change achieved following implementation, and on the efforts and costs associated with implementation. The cost-effectiveness of an implementation strategy is combined with the cost-effectiveness of a guideline to estimate the overall policy cost-effectiveness of a guideline ${ }^{1}$. For example, if an implementation strategy is not cost-effective, that is due to substantial implementation costs and/or a low degree of change compared with another implementation strategy or 'doing nothing', then the cost-effectiveness of the guideline itself may be overridden. On the other hand, not including costs and effects related to implementation of a guideline may produce biased and overestimated cost-effectiveness results. In general, policy cost-effectiveness is less attractive than treatment cost-effectiveness.

Information on costs and effects associated with implementation of a guideline is important for policymakers such as hospital managers and, at a higher level, ministers of health, especially regarding institutions where development and dissemination of an innovation have not yet taken place. This information helps policymakers to judge the value of a specific implementation strategy relative to other spending options ${ }^{2}$. Whereas the number of reports on implementation strategies in healthcare have dramatically increased in the past decennia, economic evaluations related to these strategies, performed according to well-established criteria ${ }^{1,3}$ are still $\mathrm{few}^{4-9}$.

Recently, a study was performed regarding multi-center implementation of a short hospital stay programme following breast cancer surgery ${ }^{10}$. The programme was aimed at improving patient education, providing more standardized and better organized care, reducing hospital stay, and high quality of care as assessed by patients. It incorporates for example anesthesia dedicated to short hospital stay ${ }^{11}$. 
Following an analysis of potential barriers and facilitators for change in each hospital ${ }^{12}$, a multi-faceted implementation strategy ${ }^{13}$ was developed. The strategy was hospitaltailored to address the specific circumstances in each of the hospitals. Alongside the implementation study, an economic evaluation was performed comparing the costs and effectiveness of the short stay programme (SSP; after implementation) with costs and effectiveness of care as usual (CAU; before implementation). This economic evaluation was the first concerning short stay following breast cancer surgery in which all societal costs were considered, and in which Quality Adjusted Life Years (QALYs) were calculated as measure of effectiveness ${ }^{14}$. Results of the economic evaluation revealed that the short stay programme was cost-effective, both from a societal and healthcare point of view.

In the current chapter, the policy cost-effectiveness of the short stay programme following breast cancer surgery will be calculated, by combining the costs and effects of the short stay programme with costs and effects of an active implementation strategy using the framework as described by Mason and colleagues ${ }^{1}$. To our knowledge, evidence regarding the efforts and costs of a hospital-tailored strategy concerning implementation of a short stay programme has not yet been published. Detailed information is provided on activities regarding multi-centre hospital-tailored implementation of innovation, and costs related to these activities.

\section{METHODS}

\section{Policy cost-effectiveness}

Mason and colleagues ${ }^{1}$ provided a useful framework for calculation of policy costeffectiveness. According to this framework, the policy cost-effectiveness of SSP versus CAU is dependent on four aspects; 1) the cost-effectiveness of SSP compared with CAU, also termed 'treatment cost-effectiveness', 2) the level at which short stay admission is already common practice, 3 ) the costs of the implementation strategy, and 4) the effectiveness of the implementation strategy in terms of uptake of short stay admission. Aspects 2-4 denote the 'implementation cost-effectiveness', indicating the implementation costs per extra patient treated in short stay admission of a hospitaltailored implementation strategy versus 'doing nothing' (no implementation). In calculating the cost-effectiveness of SSP versus CAU, of which results are summarized in Table 1, costs and effects of all patients after implementation of the programme (of which $81 \%$ were treated in short stay and $19 \%$ in long stay) had been compared to costs and effects of all patients before implementation of the programme (of which $45 \%$ were treated in short stay and $55 \%$ in long stay) ${ }^{14}$. This means that the 
Table 1. Summary of costs, effects, and cost-effectiveness of treatment according to the short stay programme (SSP) compared with care as usual (CAU) following breast cancer surgery for the base-case analysis with a time horizon of six weeks.

\begin{tabular}{lccccccccccc} 
& \multicolumn{2}{c}{ Total } & Hospital 1 & Hospital 2 & Hospital 3 & Hospital 4 \\
\hline & SSP & CAU & SSP & CAU & SSP & CAU & SSP & CAU & SSP & CAU \\
\hline $\begin{array}{l}\text { Patients treated in } \\
\text { short stay }\end{array}$ & $81 \%$ & $45 \%$ & $77 \%$ & $6 \%$ & $67 \%$ & $30 \%$ & $93 \%$ & $100 \%$ & $85 \%$ & $33 \%$ \\
\hline Mean pooled QALYs & 0.08 & 0.08 & 0.08 & 0.08 & 0.09 & 0.08 & 0.09 & 0.09 & 0.08 & 0.08 \\
\hline $\begin{array}{l}\text { Mean pooled costs ( } €) \\
\text { per patient (societal } \\
\text { perspective) }\end{array}$ & 7454 & 8409 & 8025 & 8669 & 6436 & 9841 & 5965 & 7512 & 8833 & 7908 \\
\hline $\begin{array}{l}\text { Incremental cost- } \\
\text { effectiveness ratio } \\
\text { (ICER) }\end{array}$ & Cost-saving & Cost-saving & Dominant & Cost-saving & $\begin{array}{l}\text { Cost- } \\
\text { increasing }\end{array}$ \\
\hline
\end{tabular}

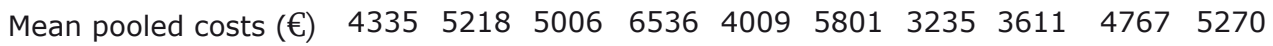
per patient (healthcare perspective)

Incremental cost- Cost-saving Cost-saving Dominant
effectiveness ratio
(ICER)

The difference in pooled QALYs between SSP and CAU was only observed on the fifth decimal level in the base-case analysis (SSP: 0.08281; CAU: 0.08285), which is far below the minimally important difference reported in the literature 29 . The QALY data are presented at the two decimal level.

cost-effectiveness calculation already included the effectiveness of the implementation strategy as denoted in aspects 2 and 4 described above. Results on effectiveness of the implementation strategy will be reported in this chapter. However, for calculation of policy cost-effectiveness of SSP versus CAU, only the implementation costs were added to the mean societal costs per patient as calculated in the cost-effectiveness calculations of the programme.

The policy cost-effectiveness analysis was performed alongside the implementation study in four Dutch hospitals from December 2004 until December 2007 ${ }^{11}$. The analysis was performed from a societal perspective with a time horizon of five years, and was expressed as the incremental cost per QALY of SSP versus CAU.

\section{The implementation strategy}

The strategy incorporated five main facets of implementation ${ }^{15}$ : dissemination of the guideline for the short stay programme among healthcare professionals concerned with breast cancer care in the hospitals, outreach visits performed by a researcher with the local team (plenary multidisciplinary team meetings) or with the breast nurses, clinical lectures given by an experienced breast nurse from the Maastricht University Medical 
Centre (MUMC) to the home care nursing teams and to nurses on the ward, audit and feedback given on performance and on outcome measures such as patients' experiences in the outreach visits during the implementation period, and provision of incentives. In the first plenary local team meeting, the guideline was explained and discussed. The following meetings were used to identify barriers and facilitators for the implementation of the short stay programme, to adjust the protocol to the needs and wishes of each hospital, to discuss problems that had arisen, and to provide feedback on current performance; professionals learned to what extent they adhered to the short stay programme guideline, and how patients perceived quality of care. Each plenary local team meeting was summarized in a set of notes.

For the organization and content of the meetings, the researcher was supported by an expert team at the MUMC, consisting of the project leader (oncologic surgeon), an implementation expert, a cost-effectiveness expert, and a statistician. During these meetings, important issues were discussed: steps and decisions taken previously by the researcher, the exploration of barriers and facilitators as part of the problem analysis for implementation, and the implementation strategy.

\section{Implementation costs}

Micro-costing, that is identifying costs per individual resource unit ${ }^{16}$, was applied to make a detailed inventory and measurement of consumed resources for each implementation-related activity. Data on implementation costs were collected prospectively through scoring forms from all healthcare professionals participating in the plenary local team meetings in each of the hospitals and from participating experts at the MUMC. Implementation costs were calculated by multiplying resource use with a cost-price per unit of resource use. Healthcare professionals' time costs were calculated based on the staff member's gross salary per hour ${ }^{17}$, including $38 \%$ social charges and $10 \%$ housing costs multiplied by the number of hours.

Implementation costs were divided into costs for development of the strategy to implement the short stay programme (developmental costs) and costs for execution of the strategy (execution costs) ${ }^{18}$. The former were related to, for example, plenary multidisciplinary team meetings at the participating hospitals, and information meetings for GPs, and the latter were attributed to, for example, outreach visits by the researcher to the hospital, and travels.

The total yearly number of breast cancer patients operated on in all four hospitals added to 660 patients for 2006/2007. According to Mason and colleagues ${ }^{1}$, mean implementation costs were assessed as costs spent per patient. In the base-case analysis, costs of implementation were calculated for a period of five years as care would have changed so much after five years that new guidelines would have been implemented. 
Discounting was not applied as all implementation costs were fixed, that is unrelated to the (future) number of patients treated according to the short stay protocol, and are not dispersed over time. To calculate mean implementation costs, the total implementation costs were therefore divided by 3300 (660 x 5). These costs were added to the mean societal costs per patient as calculated in the cost-effectiveness calculations of the short stay programme. Costs were expressed as 2008 euros $(€)$. As only costs were included that would arise if the intervention was implemented in a non-research setting, research-related costs (e.g. time spent on writing scientific papers) were excluded from the analysis.

\section{Effectiveness}

Effectiveness of the hospital-tailored implementation strategy was defined in terms of uptake of short stay admission and calculated as the proportion of patients treated in short stay admission after implementation of the short stay programme minus the proportion of patients treated in short stay admission before implementation.

\section{Statistical analysis}

Bootstrap simulations, appropriate for analyses of skewed data, were performed on the base-case analysis to determine $95 \%$ confidence intervals (CI) around the total policy costs, based on the $2.5^{\text {th }}$ and $97.5^{\text {th }}$ percentiles, and to quantify uncertainty around the policy incremental cost-effectiveness ratio (ICER), that is the difference in policy costs divided by the difference in policy effectiveness ${ }^{19}$. The bootstrap method estimates the sampling distribution of a statistic through 1000 simulations, based on sampling with replacement from the original data. Bootstrapped results were plotted in an incremental cost-effectiveness plane in which the horizontal axis represents the difference in policy effectiveness between SSP and CAU, and the vertical axis represents the difference in policy costs.

Following, the bootstrapped ICERs were plotted in a cost-effectiveness acceptability curve. This quantifies and visualizes the probability that SSP is cost-effective using a range of ceiling ratio's, which are maximum values that policymakers may be willing to pay for a unit of improvement in outcome ${ }^{20}$. The bootstrap analyses were performed using Excel 2000. All other analyses were performed using the SPSS package, version 17.0 ® for Windows (SPSS INC 2009).

\section{Secondary analyses}

Sensitivity analyses were used to assess the robustness of the results, that is whether changing (a) parameter(s) had an effect on the policy ICER. One-way sensitivity analyses were performed, changing the perspective and time horizon during which 
the implementation was expected to have effects. Next, although the study funding of $€ 400.000$,- was, for the larger part, spent on research activities, it was included in a sensitivity analysis to provide an upper estimate of the total implementation costs. For this purpose, the full amount of the study funding was added to the local implementation costs reported at the four hospitals. In addition, a two-way sensitivity analysis was performed reflecting the worst case scenario in which both the $€ 400.000$,was included and simultaneously a one year societal perspective was applied.

Subsequently, subgroup analyses were performed on hospital level, both from a societal and healthcare perspective.

\section{RESULTS}

\section{Implementation activities and costs}

Surgeons, breast nurses, department heads, department nurses, team leaders, home care nurses, and the researcher were represented in most of the plenary multidisciplinary team meetings. Participants present in lower frequency were staff advisors, research nurses, division managers, financial advisors, anaesthesiologists, anaesthesiology nurses, liaison nurses, secretaries, social workers, and the MUMC project leader. Most hours on implementation activities were spent by breast nurses (283 h), department nurses (208 h), the researcher (196 h), home care nurses (158 h), and surgeons (120 h). In Table 2 the costs of implementation activities are presented as totals and per hospital. The three largest cost components of the total implementation costs were plenary multidisciplinary team meetings, small meetings (on average consisting of less than three persons), and clinical lectures. All participants from all hospitals accounted for a total of 450 hours spent on plenary multidisciplinary team meetings. A fair proportion of costs related to these meetings was made at the MUMC on preparation and summarization, the latter serving as reminders concerning plans that had been made, and assignments regarding implementation activities for each participant in the meeting (e.g. the breast nurse developing flyers, and the surgeon corresponding with hospital managers).

In hospital one, the highest mean number of participants in the plenary multidisciplinary team meetings was recorded and the highest implementation costs were reported (more than twice as high as in the other hospitals). In hospital three, implementation costs were the lowest. Total implementation costs in the four hospitals added up to $€ 75.597,-$. Assessed for 660 patients treated per year with a time horizon of five years, this resulted in mean implementation costs of $€ 23,-(75.597 / 3300)$ per patient. 


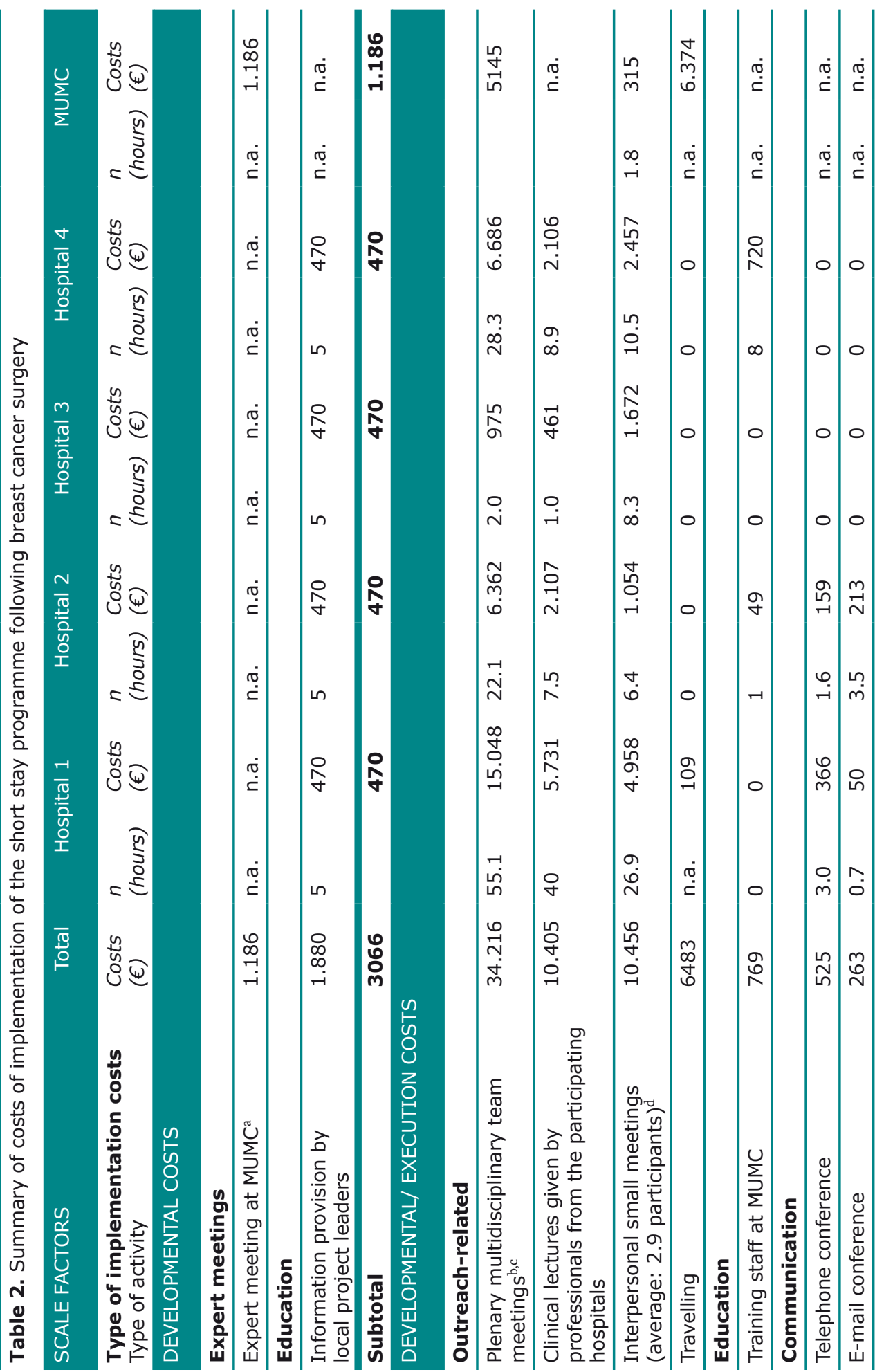




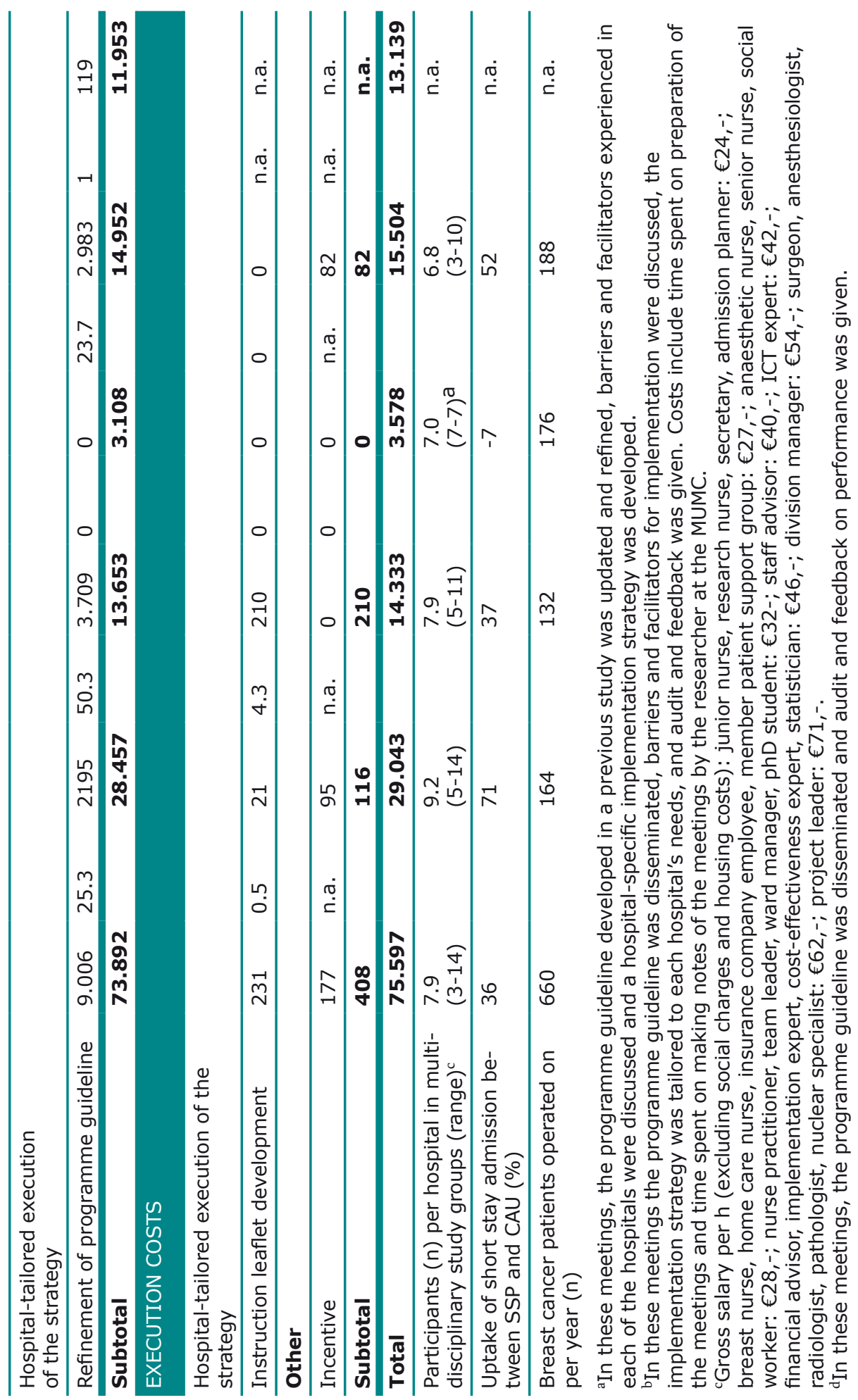




\section{Effectiveness}

The overall mean increase in uptake of the short stay programme in the four participating hospitals was $36 \%$ compared with baseline. The highest uptake was observed in hospital one, and the lowest was observed in hospital three due to a high percentage of patients already treated in short hospital admission in the CAU period. The uptake of short stay admission during the course of the implementation study is shown in Figure 1 for illustrative purposes only, to highlight the increase of the percentage of patients treated in short stay while simultaneously implementation activities were performed (until December 2006). The variation in percentages was the largest in the beginning of the implementation period. The figure shows that there is some room for additional uptake at the end of the study period, although limited.

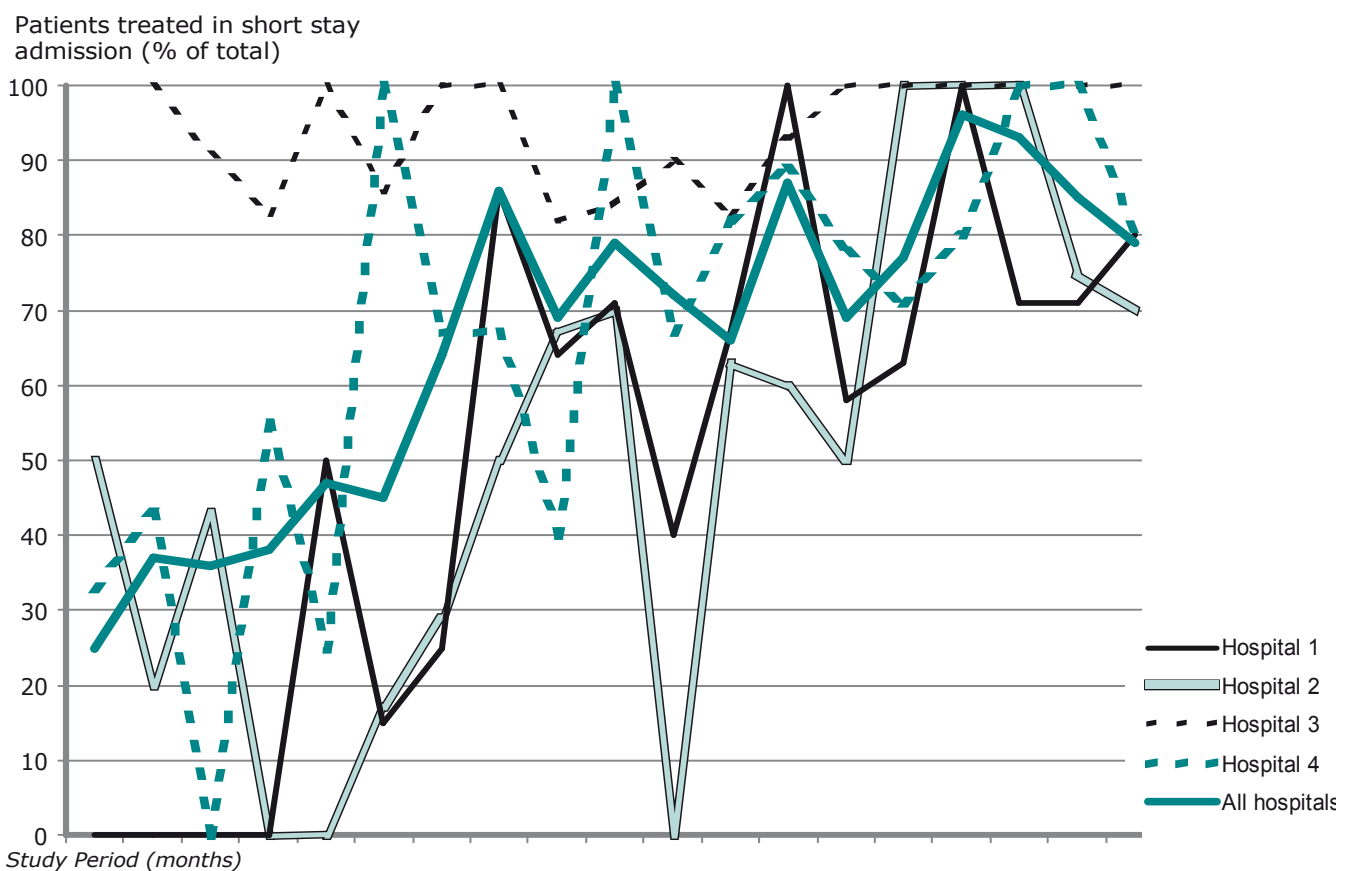

Study Period (months)

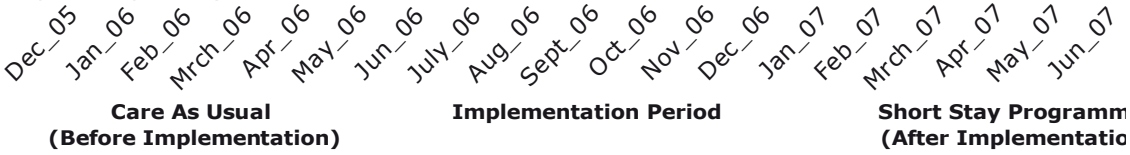

Figure 1. Patients treated in short stay admission over time. On average, eight patients were operated on for breast cancer per hospital per month

\section{Policy cost-effectiveness}

Calculation of the point estimate of the policy ICER was impossible as the difference in QALYs was zero (Table 1). In Figure 2 the distribution of differences in costs and effects is presented for the base-case analysis, that is the results of the bootstrap simulation. Each point on the graph represents a single replication in the bootstrap 
simulation. Bootstrap results indicated that the incremental costs associated with the implementation strategy compared with 'doing nothing' (€23,-) were well recovered through cost savings due to the short stay programme itself; even with incorporation of the implementation costs, SSP was cost saving and marginally more effective than CAU (dominant) in $47 \%$ of the bootstrap replicates and cost-saving and marginally less effective in $46 \%$. These results point towards the conclusion that SSP is cost-saving and equally effective compared to CAU, also when implementation costs are included in the cost calculation. Figure 3 shows the same data as policy cost-effectiveness acceptability curves, illustrating that the probability that SSP is cost-effective compared with CAU is over $88 \%$, irrespective of the ceiling ratio.

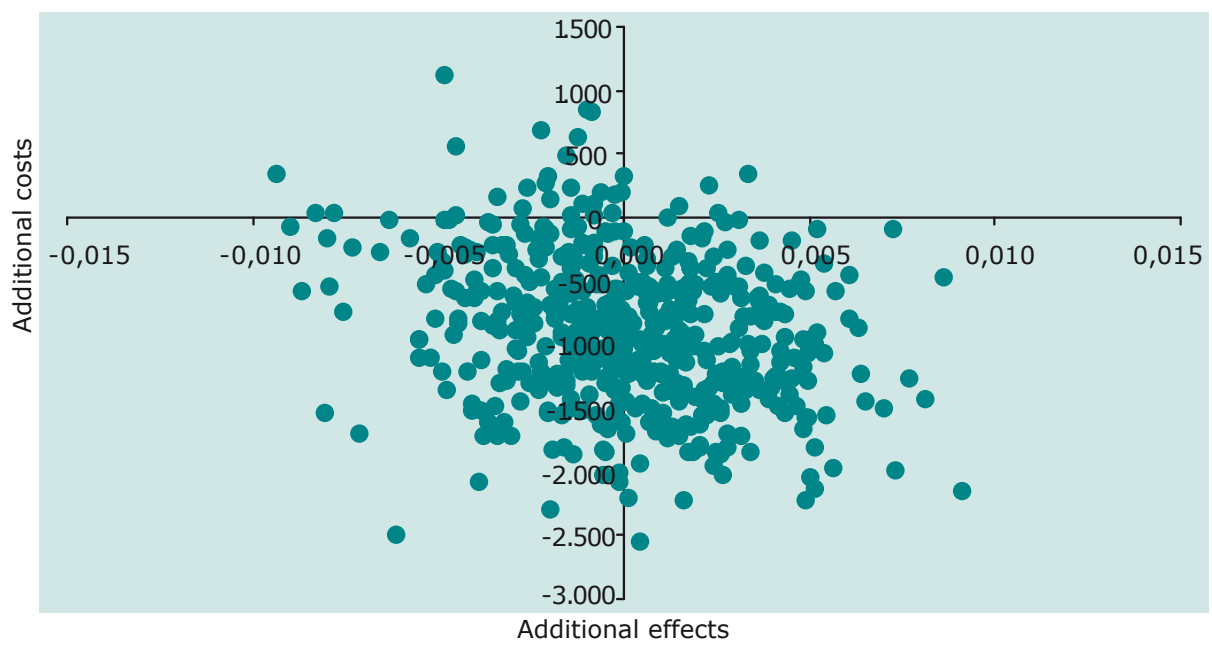

Figure 2. Incremental policy cost-effectiveness plane for the Short Stay Programme (SSP) compared with Care As Usual (CAU) for the base-case analysis. Effects (QALY); Costs $(€)$.

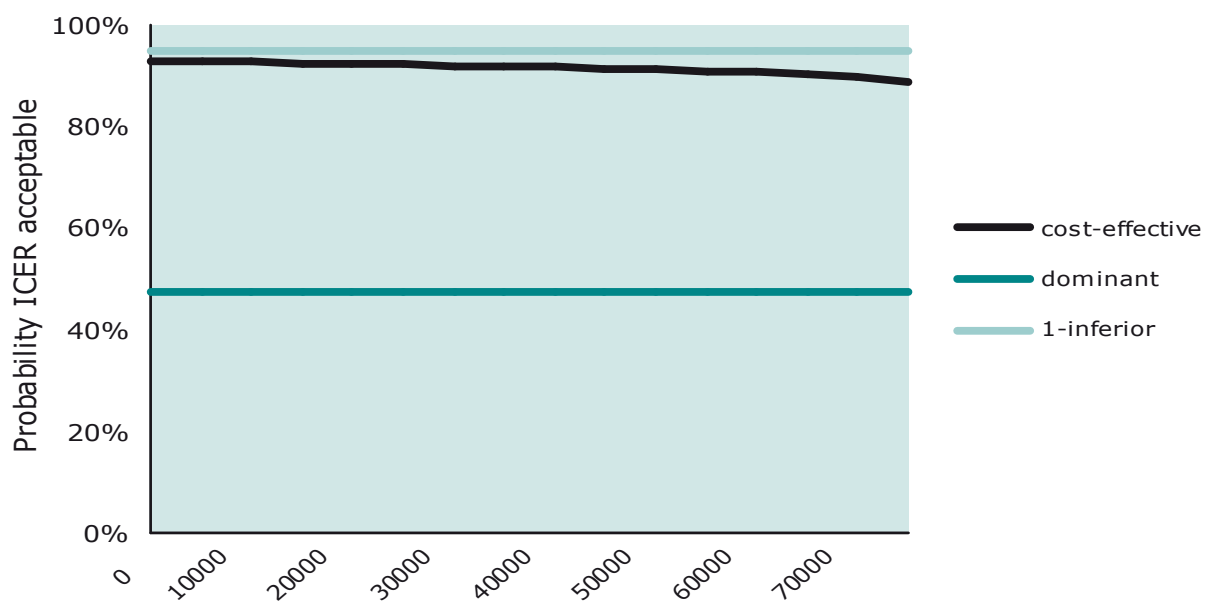

Limit on ICER

Figure 3. Policy cost-effectiveness acceptability curve for the base-case analysis showing the probability that SSP is cost-effective over a range of ceiling ratio's regarding costs per QALY. 


\section{Secondary analyses (Table 3)}

As for the base-case, calculation of the point estimate of the policy ICER was impossible in secondary analyses due to a negligibly small QALY difference. The policy ICER was insensitive for changing the perspective and/or inclusion of the study funding. SSP remained cost-effective from a policy point of view, irrespective of changes in parameters or subgroup analyses (apart from one), which was confirmed by bootstrap analyses. From the healthcare perspective, SSP was significantly cost saving with uncertainties around the point estimates varying from $99 \%$ to $96 \%$. Due to higher indirect costs for SSP than for CAU at calculation of cost-effectiveness of the programme in hospital four, the ICER appeared less favourable for the societal perspective with low probabilities for SSP being cost-effective (15-23\%) in this hospital. Inclusion of the total research funding only marginally decreased the probability of SSP being cost-effective, as did reduction of the time horizon to a period of one year. The probability that SSP had an acceptable ICER remained above 77\% for most acceptability thresholds with the exception of results from the two-way sensitivity analysis (67-67\%), and results from the societal perspective in hospitals one (66-52\%) and four (15-23\%).

Table 3. Mean (pooled) costs, effects, and policy incremental cost-effectiveness ratio of the Short Stay Programme (SSP) compared with Care As Usual (CAU); results from base-case analyses and secondary analyses.

\begin{tabular}{|c|c|c|c|c|c|c|c|}
\hline & \multicolumn{2}{|c|}{ SSP } & \multicolumn{2}{|c|}{$\mathrm{CAU}$} & \multirow[b]{2}{*}{ 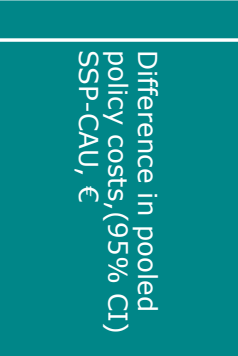 } & \multirow[b]{2}{*}{ 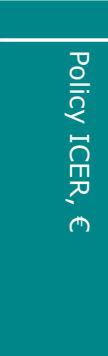 } & \multirow[b]{2}{*}{ 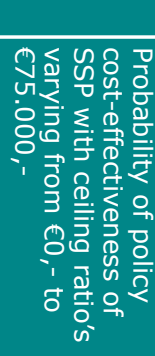 } \\
\hline & 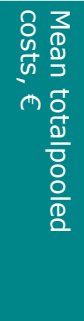 & 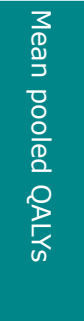 & 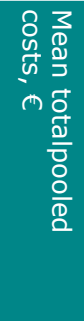 & 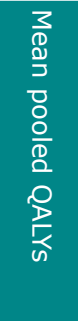 & & & \\
\hline $\begin{array}{l}\text { Base case policy cost- } \\
\text { effectiveness }^{\mathrm{a}}\end{array}$ & 7477 & 0.08 & 8409 & 0.08 & $\begin{array}{l}-932 \\
(-2083 ; 323)\end{array}$ & $\begin{array}{l}\text { Cost- } \\
\text { saving }\end{array}$ & $93 \%-89 \%$ \\
\hline Healthcare perspective & 4358 & 0.08 & 5218 & 0.08 & $\begin{array}{l}-860 \\
(-1562 ;-176)^{* *}\end{array}$ & $\begin{array}{l}\text { Cost- } \\
\text { saving }\end{array}$ & $99 \%-96 \%$ \\
\hline 1 year $^{b}$ & 7569 & 0.08 & 8409 & 0.08 & $\begin{array}{l}-840 \\
(-2017 ; 297)\end{array}$ & $\begin{array}{l}\text { Cost- } \\
\text { saving }\end{array}$ & $91 \%-89 \%$ \\
\hline \multicolumn{8}{|l|}{$\begin{array}{l}\text { Inclusion of study } \\
\text { funding }\end{array}$} \\
\hline Societal perspective & 7618 & 0.08 & 8409 & 0.08 & $\begin{array}{l}-791 \\
(-2023 ; 311)\end{array}$ & $\begin{array}{l}\text { Cost- } \\
\text { saving }\end{array}$ & $91 \%-88 \%$ \\
\hline Healthcare perspective & 4499 & 0.08 & 5218 & 0.08 & $\begin{array}{l}-719 \\
(-1422 ;-57) * *\end{array}$ & $\begin{array}{l}\text { Cost- } \\
\text { saving }\end{array}$ & $98 \%-94 \%$ \\
\hline $\begin{array}{l}\text { Two-way sensitivity } \\
\text { analysis: } 1 \text {-year } \\
\text { horizon from a societal } \\
\text { perspective \& inclusion } \\
\text { of study funding }\end{array}$ & 8155 & 0.08 & 8409 & 0.08 & $\begin{array}{l}-254 \\
(-1317 ; 914)\end{array}$ & $\begin{array}{l}\text { Cost- } \\
\text { saving }\end{array}$ & $67 \%-67 \%$ \\
\hline
\end{tabular}




\begin{tabular}{lllllllll}
\hline Type of hospital & & & & & & & \\
\hline Hospital 1 & $\begin{array}{l}\text { Societal } \\
\text { perspective }\end{array}$ & 8048 & 0.08 & 8669 & 0.08 & $\begin{array}{l}-621 \\
(-2019 ; 3263)\end{array}$ & $\begin{array}{l}\text { Cost- } \\
\text { saving }\end{array}$ & $66 \%-52 \%$ \\
\hline $\begin{array}{l}\text { Healthcare } \\
\text { perspective }\end{array}$ & 5029 & 0.08 & 6536 & 0.08 & $\begin{array}{l}-1507 \\
(-3711 ; 393)\end{array}$ & $\begin{array}{l}\text { Cost- } \\
\text { saving }\end{array}$ & $94 \%-80 \%$ \\
\hline Hospital 2 & $\begin{array}{l}\text { Societal } \\
\text { perspective }\end{array}$ & 6459 & 0.09 & 9841 & 0.08 & $\begin{array}{l}-3383 \\
(-5671 ;- \\
1202) * *\end{array}$ & Dominant & $\begin{array}{l}100 \%- \\
100 \%\end{array}$ \\
\hline & $\begin{array}{l}\text { Healthcare } \\
\text { perspective }\end{array}$ & 4032 & 0.09 & 5801 & 0.08 & $\begin{array}{l}-1769 \\
(-3217 ;-488) * *\end{array}$ & Dominant & $100 \%-99 \%$ \\
\hline Hospital 3 & $\begin{array}{l}\text { Societal } \\
\text { perspective }\end{array}$ & 5988 & 0.09 & 7512 & 0.09 & $\begin{array}{l}-1524 \\
(-3486 ; 522)\end{array}$ & $\begin{array}{l}\text { Cost- } \\
\text { saving }\end{array}$ & $93 \%-91 \%$ \\
\hline & $\begin{array}{l}\text { Healthcare } \\
\text { perspective }\end{array}$ & 3258 & 0.09 & 3611 & 0.09 & $\begin{array}{l}-353 \\
(-842 ; 141)\end{array}$ & $\begin{array}{l}\text { Cost- } \\
\text { saving }\end{array}$ & $93 \%-77 \%$ \\
\hline Hospital 4 & $\begin{array}{l}\text { Societal } \\
\text { perspective }\end{array}$ & 8856 & 0.08 & 7908 & 0.08 & $\begin{array}{l}948 \\
(-840 ; 3061)\end{array}$ & $\begin{array}{l}\text { Cost- } \\
\text { increasing }\end{array}$ & $15 \%-23 \%$ \\
\hline $\begin{array}{l}\text { Healthcare } \\
\text { perspective }\end{array}$ & 4790 & 0.08 & 5270 & 0.08 & $\begin{array}{l}-480 \\
(-1361 ; 490)\end{array}$ & $\begin{array}{l}\text { Cost- } \\
\text { saving }\end{array}$ & $85 \%-82 \%$ \\
\hline
\end{tabular}

${ }^{\mathrm{a} A}$ societal perspective was used for calculation of policy cost-effectiveness of SSP vs. CAU. Costs of the programme (SSP: €7454,-; CAU: $€ 8409,-$ ) were added with $€ 23$,- implementation costs for each patient treated in SSP. Programme costs were calculated until six weeks postoperatively.

bCosts of the programme (SSP: $€ 7454,-;$ CAU: $€ 8409,-$ ) were added with $€ 115$,- implementation costs for each patient treated in SSP.

'Costs of the programme (SSP: €7454,-; CAU: €8409,-) were added with €164,- implementation costs for all patients treated in SSP. This amount was based on $€ 400.000$ study funding added to local implementation costs made outside the MUMC (=€62.458).

** Difference in costs is statistically significant

\section{DISCUSSION}

In a multi-center study, we demonstrated that the policy cost-effectiveness of a short stay admission programme following breast cancer surgery was not compromised by incorporating the costs of a hospital-tailored multi-faceted implementation strategy ${ }^{1}$. The results were quite robust, even if the total research funding was included in the analyses or if the time horizon was set at one year only.

\section{Choice of the implementation strategy}

In this study, policy cost-effectiveness of SSP was based on applying a hospitaltailored multi-faceted implementation strategy. The added value of a tailor-made implementation strategy over any other strategy has been under debate among implementation researchers ${ }^{21-23}$, and it is unclear whether other strategies would have improved the outcomes on policy costs and effects. Besides, we cannot determine which facets of the multi-faceted strategy were most successful, and whether fewer facets would have led to similar effects, but at lower costs.

Notwithstanding, our results seem to favor the choice of a hospital-tailored implementation strategy, as an association was observed between the costs spent on implementation and uptake of short stay admission, although this could not be tested statistically. In hospital one, healthcare professionals showed more need of guiding 
by the MUMC than the other hospitals. Although twice as much money was spent on implementation in that hospital compared with hospital two, the uptake of short stay was also almost twice as high. We doubt whether similar results would have been achieved if, for example, the number of plenary multidisciplinary meetings had been the same for all hospitals.

Besides content, the duration of the implementation activities is important too. Before start of the study, the implementation period was set at six months. After implementation of the programme not all patients were treated in short stay admission. This was in line with our expectations as the short stay programme is designed to distinguish patients who are not suitable for treatment in short stay from those patients who are. Some patients will never fulfill the criteria for short stay and therefore the first group will always be represented ${ }^{11}$; in our study, about ten per cent of patients were not even scheduled for short stay admission preoperatively. We are not sure whether this remaining ten percent of patients had been treated in short stay if the implementation period had lasted longer. The curve representing the percentage of patients treated in short stay showed a slight flattening towards the end of the implementation period which persisted after implementation, suggesting that the maximum uptake had been reached with an implementation period of six months.

\section{Choice of the comparator}

In this study, the implementation strategy was compared with 'doing nothing', for which data before implementation of the short stay programme were used. The lack of a concurrent control group may be considered a weak aspect of this study, and may have inflated the results regarding the uptake of the short stay programme, as the majority of hospitals might have performed breast cancer surgery in short stay over time spontaneously. The effect of time on the size of the behavourial change should indeed not be played down ${ }^{1}$.

\section{Target group}

The study was performed in four hospitals recognized as early adopter hospitals ${ }^{24}$, that is hospitals active in changing and innovating healthcare, and that function as a reference group for most innovators. It can be argued that the target group is not representative for the Dutch hospitals. This idea is strengthened by the observation that the uptake of short stay admission seemed to have started already during the care as usual period, that is before the implementation (Figure 1). On the one hand, we expect that policy costs would have been higher had late majority hospitals (i.e. a group skeptic towards change ) had participated in the study. Then, additional efforts would have been put into changing professionals' ideas from skepticism towards enthusiasm. On the 
other hand, the uptake of short stay admission would also have been higher after implementation as baseline results would have been lower than they were with the early adopter hospitals in our study. Nevertheless, even a seven-fold increase in implementation costs in a sensitivity analysis did not affect our conclusions regarding the policy cost-effectiveness of SSP, which suggests that implementation of the programme in a less dedicated environment is still worthwhile and efficient. In hospital three a large proportion of patients was already treated in short stay before implementation of the short stay programme. Between approval for study participation and actual start of the study, some healthcare givers from hospital three had already visited the MUMC to learn about the programme. As a result, the implementation costs associated with this early adoption were not included in the study analysis. It can be argued that this may flatter our study findings. On the other hand, the uptake of short stay in hospital three also took place before start of the study, and did therefore not positively affect our measure of effectiveness. Exclusion of hospital three in the policy cost-effectiveness analysis did not influence our results in any way (data not shown).

\section{Measure of effectiveness}

In many implementation studies, 'guideline adherence' is used as measure of effectiveness $^{22,25-27}$. In this study, there were several difficulties that disabled us to report guideline adherence. The guideline was multi-factorial, that is it was targeted at different healthcare professionals and it focused on the entire breast cancer care process (until six weeks after surgery) instead of on one single item (e.g. 'short stay admission'). As a result, the guideline consisted of 29 recommendations. Apart from the difficulty in defining adherence, poor reporting by healthcare professionals was observed on several specific recommendations mentioned in the guideline (such as whether or not patients received an information leaflet on care at home before discharge). For the above mentioned reasons, effectiveness was assessed in terms of 'patients treated in short stay admission' instead of 'patients treated according to the guideline'.

According to Mason's framework, treatment cost-effectiveness is combined with implementation cost-effectiveness to calculate policy cost-effectiveness. In this study, no true distinction was made between treatment cost-effectiveness and implementation cost-effectiveness, as the programme cost-effectiveness already included effectiveness of implementation, that is the uptake of short stay admission. To calculate treatment costeffectiveness in the context of this study, the subgroup of patients treated in clinical admission before implementation (54\% of total) should have been compared with the subgroup of patients treated in short stay admission after implementation (81\% of total). Such calculation would have provided an optimal estimate of the cost-effectiveness of a short stay programme. Apart from the fact that this is not a 'real-world' comparison, 
treatment cost-effectiveness could not be calculated separately as both subgroups mentioned above were not comparable, leading to selection bias. Important to mention is that this approach does not influence our results of the policy cost-effectiveness analysis at all, as all aspects of Mason's framework have been properly addressed and incorporated in the calculations.

\section{Implementation costs}

An interesting issue which we would like to highlight, is the distinction between development and execution costs ${ }^{4}$ in the context of a hospital-tailored implementation strategy. In our empirical study, development of the strategy tailored to the needs of each of the hospitals was part of the strategy and consequently, developmental costs and execution costs could not be easily distinguished. For example, should a multidisciplinary plenary meeting, in which plans were made to implement a programme smoothly, be perceived as part of development of the strategy (for plans are actually developed) or be looked upon as execution of the strategy (for multidisciplinary meetings are used as one of potential implementation strategies)? A relatively small part of the total costs were therefore considered to be 'pure' developmental costs. Although the distinction between both types of costs is not relevant for calculation of total implementation costs and policy cost-effectiveness, it can be argued that it would be inappropriate to assign the development costs to each subsequent repetition of the implementation strategy. We recommend more research and clear guidelines on the difference in developmental costs and execution costs between different implementation strategies, as it may influence the generalizability of our and others' study findings.

A strong aspect of this study is that it involved a full economic evaluation performed according to generally accepted principles on economic evaluations of guideline implementation. The evaluation was based on empirical data, incorporated both a societal and healthcare perspective, included information on the comparator, the target group, the time frame, the measurement and assessment of costs and effects, and used one and two-way sensitivity analyses and bootstrap analyses to address the uncertainty of policy costs and effectiveness. In addition, programme-related costs were distinguished from implementation-related costs ${ }^{4}$. Frequently, implementation-related costs are not taken into account in economic evaluations on implementation of new programmes, let alone that a differentiation is made between the two types of costs. Our study boundaries are indirectly related to the trial-based design of our study. A way to address limitations regarding for example the choice and duration of the implementation strategy, the choice of the comparator and the target group, is by performing a model-based study in addition to and following data generated in this 
empirical study. In a model-based study, data are synthesized based on different data sources to predict costs and effects as truthfully as possible, and to gain a broader view on the cost-effectiveness of alternative choices. A model-based study also allows researchers to simultaneously study the efficiency of several combinations of treatment options and implementation strategies instead of doing so sequentially, the latter which was the case in this study ${ }^{28}$. However, little is yet known about the costs of different implementation strategies, which currently prohibits a proper synthesis of costing data. Furthermore, the effectiveness and costs of an implementation strategy are unquestionably associated with the acceptability and feasibility of a clinical guideline, which is also termed the "implementability" of a guideline ${ }^{28}$.

\section{CONCLUSIONS}

We provided an up to date example of how economic considerations can be integrated into implementation research. Based on our results regarding policy cost-effectiveness, we advise broad implementation of the short stay programme using a multi-faceted and hospital-tailored implementation strategy. We expect the largest implementation costs but also effects in settings where short stay following breast cancer surgery is still in it's infancy.

Further cost-effectiveness studies on implementation strategies are needed to bridge the gap between cost-effectiveness of an intervention and it's cost-effectiveness from a policy perspective. 


\section{REFERENCES}

1. Mason J, Freemantle N, Nazareth I, Eccles M, Haines A, Drummond M. When is it cost-effective to change the behavior of health professionals? Jama 2001;286(23): 2988-2992.

2. Smith MW, Barnett PG. The role of economics in the QUERI program: QUERI Series. Implement Sci 2008;3: 20.

3. Sculpher M. Evaluating the cost-effectiveness of interventions designed to increase the utilization of evidence-based guidelines. Fam Pract 2000;17 Suppl 1: S26-31.

4. Hoomans T, Evers SM, Ament AJ, Hubben MW, van der Weijden T, Grimshaw JM, Severens JL. The methodological quality of economic evaluations of guideline implementation into clinical practice: a systematic review of empiric studies. Value Health 2007;10(4): 305-316.

5. Akers L, Gordon JS, Andrews JA, Barckley M, Lichtenstein E, Severson HH. Cost effectiveness of changing health professionals' behavior: training dental hygienists in brief interventions for smokeless tobacco cessation. Prev Med 2006;43(6): 482487.

6. Hoeijenbos M, Bekkering T, Lamers L, Hendriks E, van Tulder M, Koopmanschap M. Cost-effectiveness of an active implementation strategy for the Dutch physiotherapy guideline for low back pain. Health Policy 2005;75(1): 85-98.

7. Dijkstra RF, Niessen LW, Braspenning JC, Adang E, Grol RT. Patient-centred and professional-directed implementation strategies for diabetes guidelines: a clusterrandomized trial-based cost-effectiveness analysis. Diabet Med 2006;23(2): 164170.

8. Scheeres K, Wensing M, Bleijenberg G, Severens JL. Implementing cognitive behavior therapy for chronic fatigue syndrome in mental health care: a costs and outcomes analysis. BMC Health Serv Res 2008;8: 175.

9. Verstappen WH, van Merode F, Grimshaw J, Dubois WI, Grol RP, van der Weijden T. Comparing cost effects of two quality strategies to improve test ordering in primary care: a randomized trial. Int J Qual Health Care 2004;16(5): 391-398.

10. de Kok M, van der Weijden T, Voogd AC, Dirksen CD, van de Velde CJH, Roukema JA, Finaly-Marais C, van der Ent FW, von Meyenfeldt MF. Implementation of a short-stay programme after breast cancer surgery. Br J Surg 2010;97(2): 189-194.

11. de Kok M, Frotscher CN, van der Weijden $T$, Kessels AG, Dirksen CD, van de Velde CJ, Roukema JA, Bell AV, van der Ent FW, von Meyenfeldt MF. Introduction of a breast cancer care programme including ultra short hospital stay in 4 early adopter centres: framework for an implementation study. BMC Cancer 2007;7(1): 117.

12. de Kok M, van der Weijden T, Kessels A, Dirksen C, van de Velde C, Roukema J, van der Ent F, Bell A, von Meyenfeldt M. Implementation of an Ultra-short-stay Program After Breast Cancer Surgery in Four Hospitals: Perceived Barriers and Facilitators. World J Surg 2008; 32(12); 2541-2548.

13. Grol R, Grimshaw J. From best evidence to best practice: effective implementation of change in patients' care. Lancet 2003;362(9391): 1225-1230.

14. de Kok $M$, Dirksen $C D$, Kessels $A G H$, van der Weijden $T$, van de Velde $C J H$, Roukema JA, Bell AVRJ, van der Ent FW, von Meyenfeldt MF. Cost-effectiveness of a short stay admission programme for breast cancer surgery. Acta Oncologica, 2010; in press.

15. Grol R, Wensing M, Eccles M. Improving patient care. The implementation of change in clinical practice. Butterworth-Heinemann: Toronto, 2005.

16. Gold MR, Siegel JR, Russell LB, Weinstein MC. Cost-Effectiveness in Health and Medicine Oxford University Press: New York 1996. 
17. CAO ziekenhuizen 2006-2008; http://www.fbz.nu/files. [16 November 2009].

18. Severens JL. Value for money of changing healthcare services? Economic evaluation of quality improvement. Qual Saf Health Care 2003;12(5): 366-371.

19. Efron B., R. T. Introduction to the Bootstrap. Chapman \& Hall: New York, USA, 1993.

20. van Hout BA, Al MJ, Gordon GS, Rutten FF. Costs, effects and C/E-ratios alongside a clinical trial. Health Econ 1994;3(5): 309-319.

21. Shaw B, Cheater F, Baker R, Gillies C, Hearnshaw H, Flottorp S, Robertson N. Tailored interventions to overcome identified barriers to change: effects on professional practice and health care outcomes. Cochrane Database Syst Rev 2005(3): CD005470.

22. Grimshaw JM, Thomas RE, MacLennan G, Fraser C, Ramsay CR, Vale L, Whitty P, Eccles MP, Matowe L, Shirran L, Wensing M, Dijkstra R, Donaldson C. Effectiveness and efficiency of guideline dissemination and implementation strategies. Health Technol Assess 2004;8(6): iii-iv, 1-72.

23. Bosch $M$, van der Weijden $T$, Wensing $M$, Grol R. Tailoring quality improvement interventions to identified barriers: a multiple case analysis. J Eval Clin Pract 2007;13(2): 161-168.

24. Rogers EM. Diffusion of Innovations (5th edn). Free Press: New York, 2003; xxi, $551 \mathrm{p}$.

25. Fritz JM, Cleland JA, Brennan GP. Does adherence to the guideline recommendation for active treatments improve the quality of care for patients with acute low back pain delivered by physical therapists? Med Care 2007;45(10): 973-980.

26. Menendez R, Reyes S, Martinez R, de la Cuadra P, Manuel Valles J, Vallterra J. Economic evaluation of adherence to treatment guidelines in nonintensive care pneumonia. Eur Respir J 2007;29(4): 751-756.

27. Hysong SJ, Best RG, Pugh JA. Clinical practice guideline implementation strategy patterns in Veterans Affairs primary care clinics. Health Serv Res 2007;42(1 Pt 1): 84-103.

28. Hoomans T, Severens JL, Evers SM, Ament AJ. Value for money in changing clinical practice: should decisions about guidelines and implementation strategies be made sequentially or simultaneously? Med Decis Making 2009;29(2): 207-216.

29. Walters SJ, Brazier JE. Comparison of the minimally important difference for two health state utility measures: EQ-5D and SF-6D. Qual Life Res 2005;14(6): 15231532. 

Part Five

General

Discussion 
Chapter 10

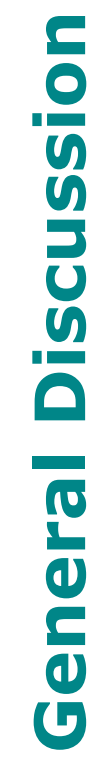




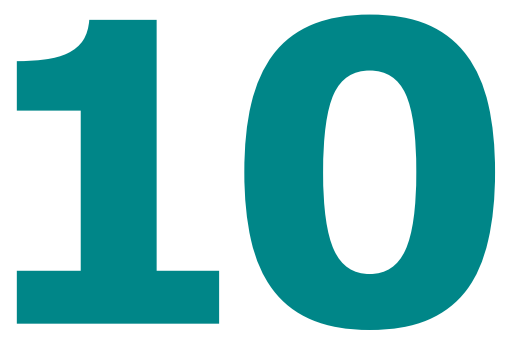

\section{Summary of main findings}

The comprehensive care programme that was implemented in the current study incorporated several key elements such as a structured care organisation (including adequate education and counselling options for patients and medical staff), dedicated anaesthesia, active patient participation in the decision to go home, home care nursing if requested, and written contact information in case of questions in the home situation. In this chapter, this multi-faceted programme is referred to as the short stay programme.

The aim of the study was to implement the short stay admission programme following breast cancer surgery, comparing costs, effects (in terms of quality of life and clinical outcomes), and quality of care, before and after implementation, and to evaluate barriers and facilitators for implementation.

Overall study results showed that the short stay programme was cost-saving, even when costs of the tailor-made multi-faceted implementation strategy were included in the economic evaluation. These results were achieved without a negative effect on quality of life or a loss of safety, while patients perceived similar quality of care.

Patients were more likely to be treated in short hospital admission if they underwent breast conserving surgery, had children, or were employed. Patients over 64 years of age were less likely to be treated in short hospital admission. The proportion of patients treated in short hospital admission was almost twice as high after implementation of the short stay programme (SSP) (82\%) compared with the care as usual period (CAU), that is before implementation (45\%). This could not just be explained by a parallel shift towards breast conserving therapy; the proportion of patients that underwent breast conserving surgery was only $12 \%$ higher in SSP than in CAU. Our observation was that breast conserving therapy is a predictive factor for treatment in short stay but not the most important factor. Thus, we conclude that short hospital admission following surgery can be achieved for the majority of breast cancer patients, also in case of major breast surgery. 
Short admission was not used for all patients that were scheduled for short admission at the outpatient clinic before surgery. Different reasons were given for a hospitalisation that was longer than planned. Some of these could have been prevented, such as postoperative nausea and vomiting that occurred due to non-dedicated anaesthesia. Other reasons were more difficult to control even in study circumstances, such as emotional stress among some patients. Furthermore, patients' relatives were often not prepared for the patient returning home so soon after surgery, despite preoperative education of informal caregivers. Either this had not been emphasized enough at the hospital, or it was related to the way people filter information. Nevertheless, these aspects of the programme need to be given more attention. To ensure that patients and their relatives took in the information provided, they should be asked to repeat the information back to the counsellor.

\section{Choice of the study design}

The design of the implementation study was of a non-controlled type, with a measurement before and after the implementation period. For several reasons, a randomised controlled trial was not regarded as feasible. Larger amounts of financial resources, and related to that, a longer study period, would have facilitated participation of more hospitals which again would have allowed for a controlled study design for the implementation study. Then, the control groups would have been promised that the successful methods of implementation would be handed over to them as an honorarium after the study finished. This type of design is also termed a waiting list design. Our study period was too short to construct a waiting list control group, and we did not have the financial resources for data collection in control hospitals. Random allocation at patient level was not considered for different reasons; patients always have the right to return home whenever they wish, making randomisation for early or late discharge rather meaningless. In addition, it is unethical to discharge one patient on the day of surgery while her neighbour is allowed to stay for another day or two. Furthermore, the extent of organisational changes to implement short stay within the existing processes of care is of such a scale, that it is hardly feasible or acceptable to allow different admission periods within one hospital at the same time.

The lack of a concurrent control group makes a causal inference of the effect of the implementation strategy impossible. However, reliable data on length of stay after breast cancer surgery in the Netherlands are available in existing registration databases, registered prospectively for the purpose of health services policy ${ }^{1}$. We therefore conclude that our observations are a true representation of the effect of the implementation of the short stay programme in an average breast cancer patient population in the Netherlands. 


\section{From pilot study to multi-centre study}

The implementation part of this study was based on the promising results of a pilot study performed at the Maastricht University Medical Centre (MUMC), in which an increase of $71 \%$ (from $13 \%$ to $84 \%$ ) was achieved of the proportion of patients treated in short hospital admission compared with usual care. Plausible reasons for the discrepancy between the $71 \%$ increase in the MUMC pilot study and the $45 \%$ increase found in this study are that, since the pilot study, increasing numbers of patients have been undergoing breast conserving surgery instead of ablative surgery, and that our study started three years after the pilot. Therefore, the room for improvement had already decreased. The effect of time cannot be ruled out, in different countries illustrated by an ongoing trend towards shorter admission periods ${ }^{2-4}$. The mean Dutch admission time following breast cancer surgery was 6.7 days at the start of the pilot study in 2001, 3.2 days at the start of the multi-centre study in 2005, and 2.6 days in 2007 when our multi-centre study ended ${ }^{1}$. Already in 2006, this number was 1.1 days for the four hospitals participating in our study, obviously less than the overall mean in the Netherlands. This indicates that the implementation strategy probably was effective. Aside from this assessment, we do not know whether the minimum admission period has yet been reached.

\section{Patients' eligibility and study participation}

Of the 421 eligible patients, 324 actually participated in the implementation study. The main reason for patients to decline study participation was the feeling that they already had too many things on their minds. The number of participants could have been higher if 20 eligible patients (5\%), who had not even been asked for participation by the breast nurse, would indeed have been asked. A perception and assumption that patients could not handle study participation was reported to have played an important role in this decision process by the breast nurse ${ }^{5,6}$. Strikingly, high age was only given once as a reason for not approaching a patient for informed consent, whereas this issue has been reported as one of the two main predictors for study participation ${ }^{6,7}$. Of 23 eligible patients (6\%), the reason for not participating in the study was unclear. Possibly, (a number of) these patients had also not been asked for enrollment in the study. Even though this was emphasized at the start of the study, continuing efforts should be put into registration of reasons for non-participation in patient related studies.

\section{Hospitals' representativeness}

Selection bias may have been introduced as only those hospitals were approached that belonged to the project leader's network. However, within each hospital all of the subsequently approached professionals confirmed participation. Furthermore, one 
additional hospital even requested participation after hearing about the study when the number of four participants had already been reached. A facilitating factor in hospital recruitment was that local project leaders were surgeons, as was the initiator of this implementation project at the MUMC.

Rogers developed a model for implementation processes in which a distinction was made between innovators, early adopters, early majority, late majority, and laggards ${ }^{8}$. In this model, the role of the innovator (in this study: MvM) who tries to influence the early adopters in his network, is emphasized. Subsequently, selection bias towards hospitals that are early adopters may have been introduced which is common in small scale implementation studies. We can imagine that results would have been less promising if the local project leaders had not been part of the innovator's network; they might have felt less committed to make the study a success compared with the surgeons in our study.

\section{Smoothness of implementation in the hospitals}

The ease of implementation differed per hospital. As the proportion of patients treated in short hospital admission was already large before the start of the implementation in hospital three, we noted a relative reluctance of healthcare professionals in this hospital to actively participate in the regularly planned plenary multidisciplinary team meetings. The need for stimulation and explanation in this hospital was evidently less than in the other hospitals as this hospital had already started to perform breast cancer surgery in short hospital admission before the actual start of the study. This led to only limited data of this hospital for comparison of the frequency, intensity, and content of the implementation activities. It is debatable whether hospital three should have been excluded from the study. However, these selection measures would have been precluded by both the intention to treat principle for analysis and the natural evolution of the care organization over time. In addition, there is a difference between merely treating patients in short hospital admission or treating patients according to a well defined short stay programme incorporating many specific care features e.g. patient education, patient participation in decision making, and home care nursing. Overall, participants of the plenary multidisciplinary team meetings in the hospitals felt responsible for their task of making the study a success although initially resistance from several caregivers was experienced ${ }^{9}$. Hospital one expressed a wish for guidance, more than the other hospitals. Consequently, the highest implementation costs were reported in that hospital. However, the efforts showed to be worthwhile as the largest uptake of short stay was also observed in that hospital. 


\section{Economic evaluation of the short stay programme and of the hospital-tailored multi-faceted implementation strategy}

The aim of our economic evaluation was twofold; first, to compare the costs and effects between patients treated according to the short stay programme with patients treated in care as usual, and second, to calculate policy cost-effectiveness by combining cost-effectiveness of the programme with costs and effects of the multi-faceted implementation strategy.

Through this combined evaluation, all aspects of policy cost-effectiveness were taken into account. Our study may serve as an example for other researchers planning to perform a cost-effectiveness analysis on implementation of a programme.

Quality adjusted life years (QALYs) were similar between SSP and CAU, unfortunately making it impossible for us to calculate the point estimate of the incremental costeffectiveness ratio (ICER). Although beforehand we did not have reason to expect that QALYs would differ between the measurements, this was the first study concerning short hospital stay following breast cancer surgery in which QALYs were actually assessed. We believe our results support the idea that further quality of life assessment is not of primary concern in comparable studies. However, a formal equivalence study with enough power to reject a clinically meaningful difference in quality of life should be performed to confirm this ${ }^{10}$.

From a societal perspective, the short stay programme was cost-saving although results were not statistically significant, mainly due to results regarding the indirect costs; in SSP costs for informal care were lower but costs due to sick leave were higher than in CAU. Sensitivity analyses revealed that results were quite robust and the probability that the programme was cost-effective was high. From the healthcare perspective, the short stay programme showed significant cost-savings.

In calculation of policy cost-effectiveness, mean implementation costs per patient were low and did not (by far) offset the cost-saving aspect of the programme itself. The point estimate of the incremental cost-effectiveness ratio indicated that from a policy point of view the short stay programme was cost-saving (i.e. less costly and equally effective), from both the societal perspective and the health care perspective, although bootstrapped costs indicated that societal costs were not statistically significantly different. Bootstrapped cost-effectiveness pairs showed that the programme had a very high probability of being cost-effective. Secondary analyses showed that our policy results were again quite robust.

The highly comparable results for the programme cost-effectiveness and policy costeffectiveness follow from the fact that implementation effects were already accounted for in calculation of the programme cost-effectiveness and that implementation costs were low. 


\section{The assessment of patients' opinions on breast cancer care}

A strong feature of the study is that an important part was devoted to the assessment of quality of care by patients. We started at the basis; through qualitative methods we gained insight into what breast cancer patients think quality of care entails. After a pilot version of the questionnaire, a definitive questionnaire was developed with various advantages. It is a self-assessment questionnaire, it reflects consumers' opinions, it requires minimal time and energy from research staff, and it yields quantifiable responses. The response rate to the questionnaire was comparable with other studies involving breast cancer patients ${ }^{11-13}$.

Measuring patients' experiences is important for quality assessment within institutions (i.e. internal quality assessment). Patient-based quality assessment tools are increasingly used to encourage consumers to compare the quality of healthcare professionals and select their preferred healthcare provider (i.e. external quality assessment) in the USA. The number of publications of Dutch origin on this subject is increasing ${ }^{14-16}$. The tools are used to provide consumers with useful information when choosing a health plan ${ }^{17,18}$. A so-called consumer quality index for breast cancer patients has been developed recently ${ }^{19}$. Although the development of that questionnaire roughly follows that of our questionnaire, it incorporates a number of flaws. First, the content of the questionnaire was influenced by stakeholders such as insurance companies, the Netherlands Health Care Inspectorate and the Dutch breast cancer union. These groups may have different interests in the type of questions incorporated in the questionnaire than breast cancer patients have themselves. For example, the insurance companies wished for information that would improve their room for negotiation with hospitals, and the Dutch breast cancer union as an important financial player had a considerable influence on the content of the questionnaire. Second, the recruitment procedures reported, introduced considerable selection bias as one section of the patients were recruited through advertisements, and another section was recruited through a database of an insurance company. We can imagine that educational level for example, plays a role in responding to advertisements or that an insurance company makes a selection in their patients appropriate for participation in study groups. Our questionnaire provides a true reflection of breast cancer patients' opinions on quality of care in the Netherlands, and has been developed while incurring minimal selection bias.

Our questionnaire on quality of breast cancer care was designed to distinguish between different healthcare providers. As shown in this study, results were not very different between hospitals. Possibly, this was influenced by the multi-faceted programme that had been implemented in the same way in the four hospitals during the study. Although implementation of the programme was hospital-tailored, the programme itself incorporated many similar quality of care aspects in the different hospitals, with 
a chance to obtain similar quality of care outcomes among the hospitals. It is not clear from this study whether the questionnaire can discriminate between professionals and hospitals that perform well and those that perform less well. Therefore, other studies with larger numbers of participating hospitals are needed.

Further, to evaluate changes in breast cancer care, the questionnaire needs to be reviewed and tested regularly. To determine whether the questionnaire corresponds with the needs and wishes in other healthcare environments (such as states and countries), inter-environmental validations are needed. Institution, culture or countryspecific items may be added or removed as they do or do not apply. This would require focus groups with specific categories of patients addressing these items combined with this QUOTE.

\section{Reflection on the implementation strategy}

For the process of implementation, we followed Grol's model for implementation in which professionals focus on locally perceived barriers and facilitators, and the implementation strategy was hospital-tailored to respond to those barriers ${ }^{20}$. We had purposefully decided not to use one specific theory or set of theories ${ }^{21,22}$ beforehand for explanation, approach, and evaluation of the process of change. Instead, we combined different types of theory-based implementation activities and applied a hospital-tailored implementation strategy. We have chosen to focus on potential problems based on our observational findings before implementation and during implementation, rather than following one pre-determined model. The question whether more favourable results could have been reached with a theory-based strategy instead of our pragmatic tailormade strategy yet remains unanswered ${ }^{23}$.

Advocates of a theory-based strategy emphasize the potential advantages (better understanding of the generalizability and replicability of research interventions) it may provide ${ }^{24}$. In contrast, others plead for pragmatic approaches including outcome measurement, and for less rather than more focus on theories ${ }^{25}$. Bhattacharryya and colleagues stressed the lack of empirical evidence that theory-based implementations are superior to non-theory-based interventions ${ }^{26}$. They suggested that the use of a theory in planning interventions should remain a personal judgement. Pragmatically tailored interventions are assumed to improve patient care and patient outcomes. However, a Cochrane review, based on 15 randomized clinical trials demonstrated that the effectiveness of tailored interventions is yet not clear, although it seems promising ${ }^{27}$. We are satisfied with the results achieved with the hospital-tailored strategy. In order to implement the short stay programme in other (Dutch) hospitals, or, in other words, large-scale national implementation, it seems wise to make use of the already existing infrastructure for health care improvement. The national Institute for 
Healthcare Improvement (CBO) runs a large programme for multidisciplinary guideline development, and has experience with concurrent large-scale implementation strategies such as the Breakthrough Series. The Breakthrough Series can roughly be regarded as similar to our implementation strategy, but the contact hours with the change agent are less intensive. Recently, a short stay programme for colon cancer patents was implemented in 26 hospitals in the Netherlands ${ }^{28}$. This collaborative incorporates the improvement of healthcare systems using the plan-do-study-act cycles of continuously implementing, measuring, and refining small, rapid changes at multiple, similar sites to create a large change that becomes standard practice instead of making a change throughout the system that requires years of implementation planning ${ }^{29}$. In these series, changes are guided by best evidence ${ }^{28}$. The real challenge of this type of large-scale implementation is to consolidate and sustain the changes that can be realized in the Breakthrough Series Initiatives.

To date, cost-effectiveness of these Breakthrough Series is not known. It would be interesting to compare the combined costs, effects, and cost-effectiveness of such a large scale, less time-consuming implementation strategy with our small scale, timeconsuming strategy. Our expectations are that the Breakthrough Series is possibly faster, cheaper and less intensive than our strategy but also less effective in the long term. This hypothesis provides a challenge for further research.

\section{Actual barriers and facilitators}

Apart from the perceived barriers described in Chapter five, a range of actual barriers was found. For example, initially the responsibility for care performed by the home care nursing teams was unclear in one hospital. It took several meetings and discussions to make home care nursing companies aware of their (and not the surgeons') responsibilities concerning the home care nursing teams, both verbally and in writing. Another example concerned the high turnover in surgeons and anaesthesiologists in training, who often did not know about the protocol when they started their training at the participating hospitals. This was solved by handing out the short stay guideline to doctors who were new in the hospital, and emphasizing its difference to other hospital guidelines that they may have been used to.

\section{The results in the light of findings by others}

The available evidence on breast cancer surgery in short hospital admission did not report on any (in-depth) implementation plan before the start of the studies apart from a study by Pederson and colleagues ${ }^{30}$. They introduced an accelerated surgical stay programme by using some aspects of our implementation study (e.g. a so-called multidisciplinary taskforce). However, the definition of the accelerated aspect of the 
programme (mean length of stay 2.6 days at that time) is, in our opinion, outdated. Bundred and colleagues performed a randomized trial on early discharge compared with traditional admission without any report on implementation activities ${ }^{31}$. They used the term 'early discharge' (that is discharge within $48 \mathrm{~h}$ ) for admission that would be assessed as usual care or inpatient admission in our study. In addition, in their study $39 \%$ of patients were excluded from participation for reasons that were not exclusion criteria in our study. In other words, had we performed our study according to their design, our positive results would probably have been even better.

The study by Purushotham and colleagues ${ }^{32}$ on wound drains and early discharge after breast cancer surgery reported benefits on healthcare costs. However, only exact numbers were provided concerning consumables in theatre whereas other relevant direct costs (e.g. visits to a physiotherapist, home care nursing) and indirect costs (e.g. costs due to sick leave or costs due to loss of leisure time) were not reported. This makes further comparison between our study and their study difficult.

\section{Role of the researcher}

An interesting aspect for anthropologists is the multimodal role of the researcher. Not only was she the implementer; she was also chairman of all plenary multidisciplinary team meetings, and the person who wrote papers on the results. This was a strength as it enhanced the success of the implementation and facilitated participatory process evaluation. At the same time, it was a weakness, making the evaluator too involved in the outcome. In this light, and based on a research diary she kept, the weekly expert meeting at the MUMC functioned as a type of reflection; a manner to discuss the steps made and decisions taken in the previous week, and therefore as a mechanism to minimize the conflict of interest of the thesis candidate.

The extent to which this double role influenced the study results is unclear. In our opinion, the double role was successful as participants in the plenary multidisciplinary team meetings were found increasingly responsible for the project; they wanted the study to be a success, not only for themselves but partly also for the researcher. Of course, the effect could have been the opposite, had there been no personal connection between the researcher and the other team members. In conclusion, we think the ability of continuous self reflection is important in this type of study.

\section{Recommendations for research}

Concerning broad implementation in the Netherlands, we do not think that performing yet another study on larger scale implementation of the programme will provide additional information. However, if researchers are interested in the costs, effects, and methods of international implementation of the short stay programme, a waiting- 
list design as described above seems appropriate. With comparable studies but on another subject, the use of other (additional) strategies provides more insight into the (cost)efficacy of different implementation strategies on this subject. Possibly, the effect of a theory based approach can be compared with the effect of a pragmatic tailor made approach as ours.

Regarding cost-effectiveness studies, it would be interesting to gain more insight into the costs, effects, and cost-effectiveness of Breakthrough Series Initiatives. If this information is known, it is recommendable to compare these results with those of small scale implementation studies as ours.

For future research projects using 'implementation project groups', we advise extra attention for participants who obviously need motivation to act according to newly implemented rules. If this is not done, it will result in professionals who are misinformed by colleagues about what will happen to patients, which unnecessarily leads to a lower standard of quality of care than could be achieved. It should be realized that these (few) persons can be decisive in determining the (lack of) success of the implementation. In addition, we recommend performing a simple survey first to gain insight into reasons why people are currently not treated in day care or $24 \mathrm{~h}$ admission. Perhaps, these reasons are simple to solve, and they provide a solid basis for the success of the implementation efforts.

Another suggestion for future research is to explore the potential of a hospital admission coach. Such a person would be responsible for a smooth coordination of activities regarding admission and discharge, and education of patients and their relatives regarding admission and discharge. The coach should be introduced already at the outpatient clinic preoperatively. Then, these coordinating tasks of the breast nurses decrease, and the breast nurses can focus more on other disease-related aspects. Such a coach would not only be useful for breast cancer care but for all types of care. It would be interesting to explore the effect of such a coach on length of stay, and compare it with 'usual care'.

\section{Recommendations for practice}

An important finding of the present thesis was that implementation of the short stay programme following breast cancer surgery was cost-saving, and had a high probability for being cost-effective, even when implementation costs were taken into account. Therefore, we recommend large-scale implementation of the programme. A strategy as used in the Breakthrough Series Initiative seems appropriate. Our results can be used by the Dutch Ministry of Health to diminish the burden that breast cancer care places on the healthcare budget. In the current market economy in the Dutch healthcare system, these results are useful for insurance companies in negotiation with hospitals 
on care to be delivered. Policy makers and insurance companies should acknowledge the supplementary role that multidisciplinary and multi setting (integrating primary and secondary care) care teams can fulfil in the provision of continuity of care, and we advise insurance companies to act upon that. Related to broad implementation, we do have to make an important remark. One cannot expect patients to be discharged the day of admission or the day after, if they are enrolled in a healthcare programme that is slow on most other time-related aspects. Therefore, we advise making sure that referral patterns, process times, and waiting times are as short as possible.

Another finding was that a thorough exploration of barriers and facilitators before the start of the implementation was associated with very positive results. If the programme is spread out on a large scale, this is an issue that deserves the attention of all healthcare professionals dedicated to breast cancer care. We recommend investing in such an exploration before start of implementation of the programme. In order to do so, a "change agent" is needed in each hospital, a person who is made responsible for preparing for and organising the change. This could e.g. be a dedicated specialized nurse, as mentioned in a model by Maessen ${ }^{33}$.

Related to this is the responsiveness of the system concerning home care nursing, that is whether the care provided by the healthcare professionals corresponds to the patients' needs. We expect that the importance of home care nursing teams will increase in the near future. The use of these teams will increase continuity of care and it is a challenge to integrate these facilities even better into the postoperative care process. In the Netherlands, the shift from inpatient care to home care nursing is not a fluent process, and extra attention to expectations, tasks, responsibilities, and finances between hospitals and home care nursing companies is needed in this respect. A solution would be to initiate a nationwide home care nursing company as is operational in Belgium ${ }^{34}$. In several other countries, however, home care nursing is not an option at all. In countries where home care nursing is not (yet) an option for patients, a start should be made by setting up home care nursing companies.

Institutions changing from inpatient admission towards day care or $24 \mathrm{~h}$ admission for breast cancer surgery should pay extra attention to information on prostheses, drains, and exercises after surgery in order to improve self-confidence of patients and their relatives. Patients and their relatives should be asked to repeat the information they receive back to the healthcare professional, to ensure that they have understood the information provided.

As having a full- or part-time job, having children, undergoing breast-conserving surgery and a younger age were predictors of successful short-stay treatment, these factors should be taken into account when scheduling a patient for hospital admission (Figure 1). 


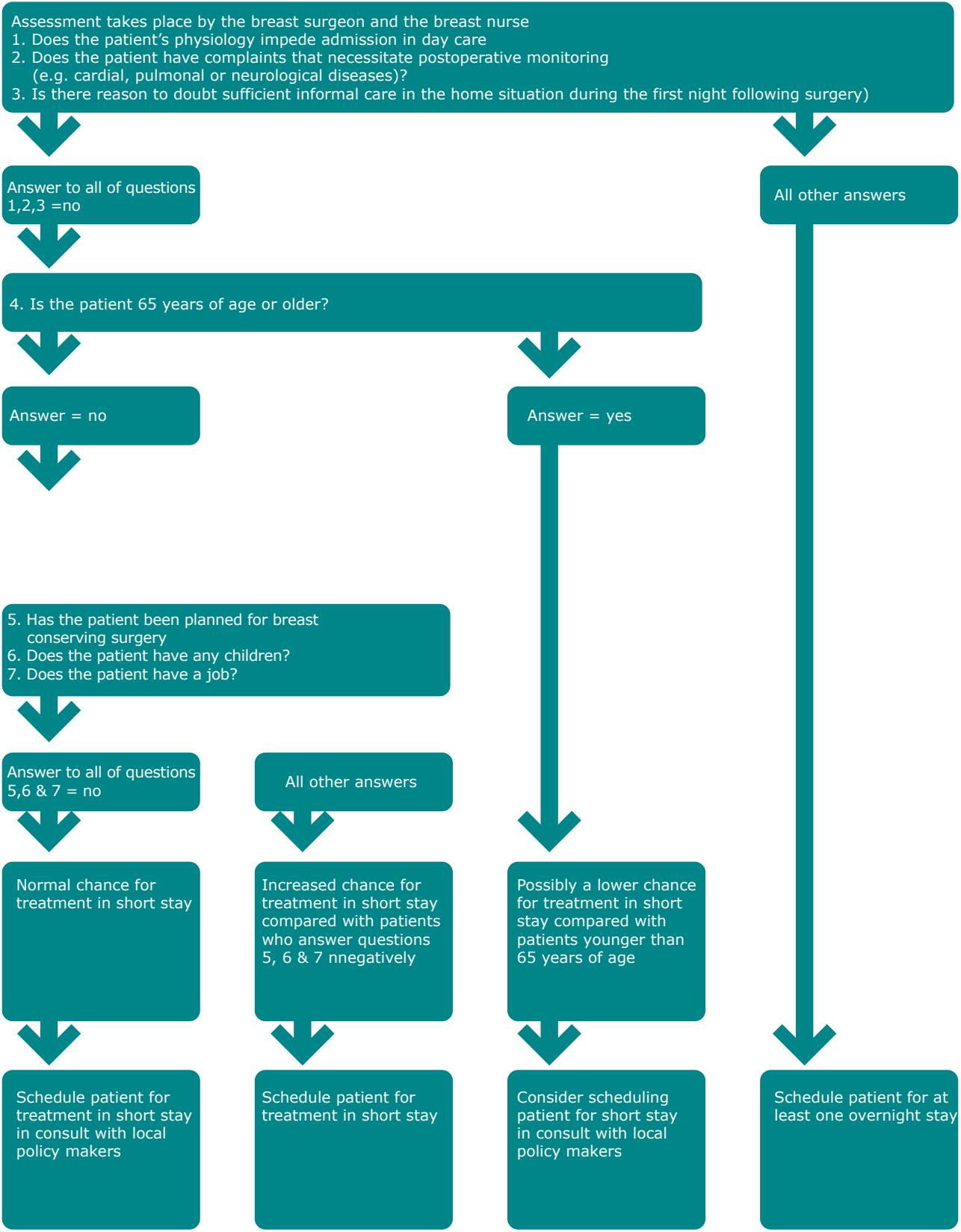

Figure 1. Flowchart for scheduling patients for breast cancer surgery 
Based on the reporting of higher costs due to productivity losses in SSP compared with CAU, we advise special attention for strategies to stimulate work rehabilitation. Our study provides level II-2 evidence on the costs and effects of a short stay programme. In the field of short stay admission, this is a sufficient level of evidence for a change of the Dutch guideline on breast cancer treatment ${ }^{35}$. By using our evidence on the safety of the short stay programme caregivers, and specifically surgeons, are stimulated to incorporate the programme in their medical profession in daily practice. In doing so, quality of care improves. Beforehand, our quality indicators should be assessed on validity and importance in order to draw conclusions on performance indicators in the guideline ${ }^{36,37}$. Once it's validated, we will advise that the entire guideline be assessed for inclusion in an international database focused on guideline development ${ }^{38}$.

This thesis shows that the programme incorporating short stay is cost-saving and costeffective, also when implementation costs are considered. Moreover, safety variables and quality of care are comparable after implementation of the programme compared with the period before implementation of the programme. In conclusion, we strongly encourage broad implementation of a short stay programme following breast cancer surgery. 


\section{REFERENCES}

1. Prismant, het kennis- en expertisecentrum voor de zorg (in Dutch), http://www. prismant.nl/Informatie-expertise/Thema's/Ziekenhuisstatistieken. [June 15 2009].

2. Marrazzo A, Taormina P, David M, Riili I, Lo Gerfo D, Casa L, Noto A, Mercadante S. Surgical treatment of early breast cancer in day surgery. Chir Ital 2007;59(5): 687691.

3. Case $C$, Johantgen $M$, Steiner $C$. Outpatient mastectomy: clinical, payer, and geographic influences. Health Serv Res 2001;36(5): 869-884.

4. Arnaud S, Houvenaeghel G, Julian-Reynier C, Protiere C, Moatti JP. [Women's preferences for early discharge after conservative breast surgery: feasibility, patient profile and satisfaction]. Ann Chir 2003;128(1): 26-33.

5. Ross S, Grant A, Counsell C, Gillespie W, Russell I, Prescott R. Barriers to participation in randomised controlled trials: a systematic review. J Clin Epidemiol 1999;52(12): 1143-1156.

6. Kemeny MM, Peterson BL, Kornblith $A B$, Muss $H B$, Wheeler J, Levine $E$, Bartlett $N$, Fleming $\mathrm{G}$, Cohen $\mathrm{HJ}$. Barriers to clinical trial participation by older women with breast cancer. J Clin Oncol 2003;21(12): 2268-2275.

7. Shamley DR, Barker K, Simonite V, Beardshaw A. Delayed versus immediate exercises following surgery for breast cancer: a systematic review. Breast Cancer Res Treat 2005;90(3): 263-271.

8. Rogers EM. Diffusion of Innovations (5th edn). Free Press: New York, 2003; xxi, $551 \mathrm{p}$.

9. de Kok M, van der Weijden T, Kessels A, Dirksen C, van de Velde C, Roukema J, van der Ent $F$, Bell A, von Meyenfeldt M. Implementation of an Ultra-short-stay Program After Breast Cancer Surgery in Four Hospitals: Perceived Barriers and Facilitators. World J Surg 2008; 32(12):2541-2548.

10. Briggs $\mathrm{AH}, \mathrm{O}^{\prime}$ Brien $\mathrm{BJ}$. The death of cost-minimization analysis? Health Econ 2001;10(2): 179-184.

11. Maslin A. A survey of the opinions on 'informed consent' of women currently involved in clinical trials within a breast unit. Eur J Cancer Care (Engl) 1994;3(4): 153-162.

12. Mancini J, Nogues C, Adenis C, Berthet P, Bonadona V, Chompret A, Coupier I, Eisinger F, Fricker JP, Gauthier-Villars M, Lasset C, Lortholary A, N'Guyen TD, Vennin $\mathrm{P}$, Sobol H, Stoppa-Lyonnet D, Julian-Reynier C. Impact of an information booklet on satisfaction and decision-making about BRCA genetic testing. Eur J Cancer 2006;42(7): 871-881.

13. Ellis PM, Butow PN, Tattersall MH. Informing breast cancer patients about clinical trials: a randomized clinical trial of an educational booklet. Ann Oncol 2002;13(9): 1414-1423.

14. Stubbe JH, Brouwer W, Delnoij DM. Patients' experiences with quality of hospital care: the Consumer Quality Index Cataract Questionnaire. BMC Ophthalmol 2007;7: 14.

15. Stubbe JH, Gelsema T, Delnoij DM. The Consumer Quality Index Hip Knee Questionnaire measuring patients' experiences with quality of care after a total hip or knee arthroplasty. BMC Health Serv Res 2007; 7: 60.

16. Zuidgeest M, Sixma H, Rademakers J. Measuring patients' experiences with rheumatic care: the consumer quality index rheumatoid arthritis. Rheumatol Int 2009. 
17. McGee J, Kanouse DE, Sofaer S, Hargraves JL, Hoy E, Kleimann S. Making survey results easy to report to consumers: how reporting needs guided survey design in CAHPS. Consumer Assessment of Health Plans Study. Med Care 1999;37(3 Suppl): MS32-40.

18. Delnoij DM, ten Asbroek G, Arah OA, de Koning JS, Stam P, Poll A, Vriens B, Schmidt $P$, Klazinga NS. Made in the USA: the import of American Consumer Assessment of Health Plan Surveys (CAHPS) into the Dutch social insurance system. Eur J Public Health 2006;16(6): 652-659.

19. Damman OC, Hendriks M, Sixma HJ. Towards more patient centred healthcare: A new Consumer Quality Index instrument to assess patients' experiences with breast care. Eur J Cancer 2009; 45(9): 1569-1577.

20. Grol R, Wensing M, Eccles M. Improving patient care. The implementation of change in clinical practice. Butterworth-Heinemann: Toronto, 2005.

21. Michie S, Johnston M, Abraham C, Lawton R, Parker D, Walker A. Making psychological theory useful for implementing evidence based practice: a consensus approach. Qual Saf Health Care 2005;14(1): 26-33.

22. Grol RP, Bosch MC, Hulscher ME, Eccles MP, Wensing M. Planning and studying improvement in patient care: the use of theoretical perspectives. Milbank $Q$ 2007;85(1): 93-138.

23. Bosch M, van der Weijden T, Wensing M, Grol R. Tailoring quality improvement interventions to identified barriers: a multiple case analysis. J Eval Clin Pract 2007;13(2): 161-168.

24. The Improved Clinical Effectiveness through Behavioural Research Group (ICEBeRG). Designing theoretically-informed implementation interventions. Implement Sci 2006;1: 4.

25. Oxman $A D$, Fretheim $A$, Flottorp $S$. The OFF theory of research utilization. $J$ Clin Epidemiol 2005;58(2): 113-116; discussion 117-120.

26. Bhattacharyya O, Reeves S, Garfinkel S, Zwarenstein M. Designing theoreticallyinformed implementation interventions: fine in theory, but evidence of effectiveness in practice is needed. Implement Sci 2006;1: 5.

27. Shaw B, Cheater F, Baker R, Gillies C, Hearnshaw H, Flottorp S, Robertson N. Tailored interventions to overcome identified barriers to change: effects on professional practice and health care outcomes. Cochrane Database Syst Rev 2005(3): CD005470.

28. Maessen JM, Hoff C, Jottard K, Kessels AG, Bremers AJ, Havenga K, Oostenbroek RJ, von Meyenfeldt MF, Dejong $\mathrm{CH}$. To eat or not to eat: facilitating early oral intake after elective colonic surgery in the Netherlands. Clin Nutr 2009;28(1): 29-33.

29. Kilo CM. A framework for collaborative improvement: lessons from the Institute for Healthcare Improvement's Breakthrough Series. Qual Manag Health Care 1998;6(4): $1-13$.

30. Pedersen SH, Douville LM, Eberlein TJ. Accelerated surgical stay programs. A mechanism to reduce health care costs. Ann Surg 1994;219(4): 374-381.

31. Bundred N, Maguire P, Reynolds J, Grimshaw J, Morris J, Thomson L, Barr L, Baildam A. Randomised controlled trial of effects of early discharge after surgery for breast cancer. Bmj 1998;317(7168): 1275-1279.

32. Purushotham AD, McLatchie E, Young D, George WD, Stallard S, Doughty J, Brown DC, Farish C, Walker A, Millar K, Murray G. Randomized clinical trial of no wound drains and early discharge in the treatment of women with breast cancer. $\mathrm{Br} J$ Surg 2002;89(3): 286-292.

33. Maessen JMC. Enhanced Recovery After Surgery Fact or Fiction? Maastricht: Maastricht University Medical Centre; 2009. 
34. Landelijke Thuiszorg (in Dutch); http://www.landelijkethuiszorg.be. [June 15 2009].

35. Dutch Institute for Healthcare Improvement, http://www.cbo.nl/. [June 15 2009].

36. Campbell SM, Braspenning J, Hutchinson A, Marshall MN. Research methods used in developing and applying quality indicators in primary care. Bmj 2003;326(7393): 816-819.

37. Wollersheim $H$, Hermens $R$, Hulscher $M$, Braspenning J, Ouwens $M$, Schouten J, Marres H, Dijkstra R, Grol R. Clinical indicators: development and applications. Neth J Med 2007;65(1): 15-22.

38. Guidelines International Network; http://www.g-i-n.net. [June 15 2009]. 
Chapter 11

$$
\frac{2}{E}
$$

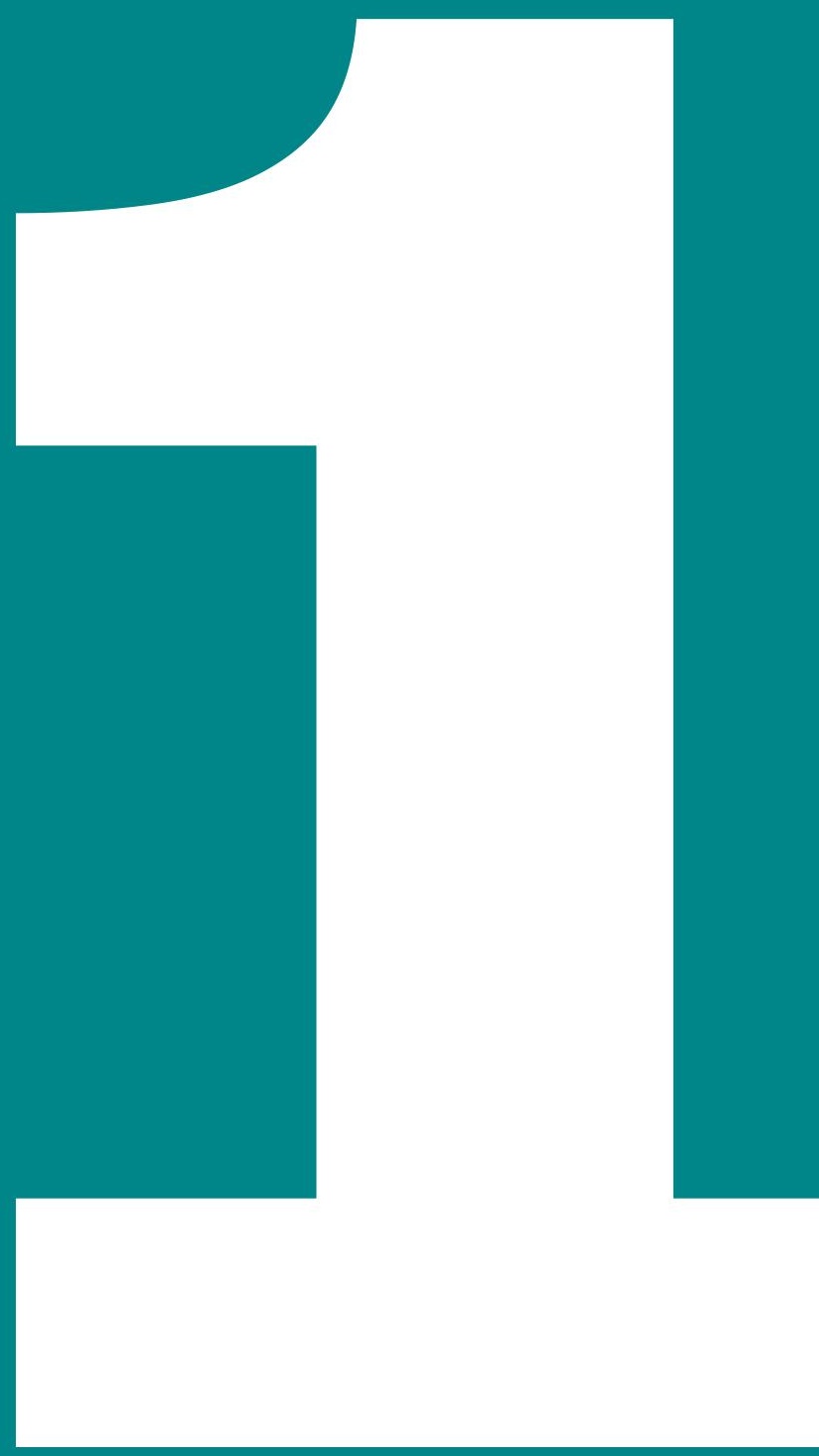



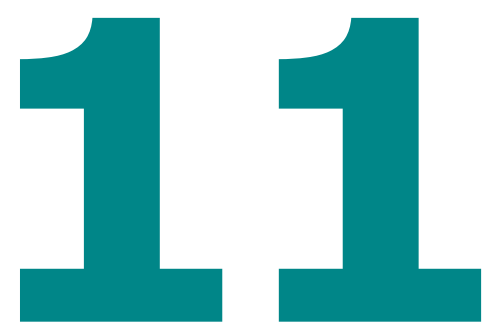

The change towards decreasing admission periods following breast cancer surgery has been taking place since the 1980s. There is culminating evidence that breast cancer surgery can be safely performed in day care admission. To date, no data have been published on the performance of all types of breast cancer surgery in day care admission or $24 \mathrm{~h}$ admission. This, combined with the lack of thoroughly performed multi-centre studies on this subject, was the basis for the implementation study presented in this thesis.

This thesis presents studies that systematically explore the implementation of a short stay programme in four hospitals in the Netherlands, and assesses the effect of the programme on patient outcomes such as length of hospital stay, complications, recurrent hospital admission, quality of care according to breast cancer patients, quality of care actually delivered, as well as programme and policy cost-effectiveness, the latter also comprising the costs and effects of implementation of the programme.

The introductory chapter (Chapter 1) provides an overview of the history of breast cancer treatment, the definition of postoperative recovery, and hospital admission following breast cancer surgery. Related to that, the short stay programme as developed at the Maastricht University Medical Centre (MUMC) is discussed. Key figures in this programme are the multidisciplinary team, the breast nurse, and the patient. Following the preoperative diagnosis, the patient is extensively informed about all aspects of surgery (pre-, peri-, and postoperative period) in a one $\mathrm{h}$ consultation. In the programme, emphasis is placed on education, especially concerning the perioperative period. This is achieved by frequent repetition of the information as well as by supporting the oral information with a written format.

Furthermore, the chapter considers potential effects of the programme on clinical outcomes, quality of care according to the patient's perspective, and costs of implementing such a programme. The concept of implementation is described, and the model that was used as a framework for implementation is introduced. At the end of the 
chapter, an outline of the thesis is presented with a flowchart of the study.

In Chapter $\mathbf{2}$ the study protocol is explained for the entire study, that is including the economic evaluations and the assessment of quality of care. The implementation study was a before \& after study performed in four hospitals in the Netherlands. The study entailed two measurement periods of six months each, with six months of implementation in between. Primary outcome measure of the study was the percentage of patients treated in short stay. Secondary endpoints included the quality of care from the patients' perspective, cost-effectiveness of the short stay programme, and policy cost-effectiveness including cost-effectiveness of the chosen implementation strategy. Based on an analysis of perceived barriers and facilitators for implementation, the strategy was tailored to the needs of each hospital, and used plenary multidisciplinary team meetings, clinical lectures, and small meetings as important means of implementation. In our study, quality of care was measured using the QUOTE breast cancer instrument. Cost-effectiveness of the short stay programme was calculated and policy cost-effectiveness of the programme was calculated combining the costs-effectiveness of the short stay programme with the costs-effectiveness of the implementation activities.

Chapter 3 elaborates on the development of a patient questionnaire on quality of breast cancer care. Often, the items of such questionnaires on quality of care are developed by healthcare professionals or healthcare researchers, without involvement of the target patients who are supposed to fill out these questionnaires. In this study, breast cancer patients participated in developing an instrument that describes quality of care from the patient's perspective. Seventy-two patients participated in eight focus group interviews in which the concept 'quality of breast cancer care' was discussed. These interviews yielded 221 aspects concerning quality of care. Reduction criteria were applied, resulting in a remaining set of 81 items. Six concept mapping meetings were then held, with 67 breast cancer patients to categorize these 81 of the 221 items according to similarity and importance. After analysis, 55 quality of care aspects remained, which were grouped into six clusters. These aspects were used for further development of the questionnaire.

Chapter 4 focuses on the quantitative part of development of the questionnaire. Based on the previous qualitative methods presented in Chapter 3, a pilot questionnaire was developed. Of the 55 items used in the concept mapping meetings, 11 were used for both the breast nurse and the surgeon, and six items were added based on open questions put to breast cancer patients, asking for missing elements. In the 
pilot questionnaire, 72 quality items were formulated as questions about importance and perceived performance. The pilot questionnaire was tested among 276 breast cancer patients operated on in the previous three to 15 months in the four hospitals participating in the implementation study, and in the Maastricht University Medical Centre. Instrument optimization incorporated the use of reduction criteria, exploratory factor analysis, and reliability analysis. The number of items in the final questionnaire is 33 , and the items refer to the factors 'patient education regarding aspects related to postoperative treatment, 'services by the breast nurse', 'services by the surgeon', 'patient education regarding activities at home', and 'patient education regarding aspects related to preoperative treatment. The strengths of the questionnaire are that it consists entirely of questions that are perceived as important by breast cancer patients, that it is self-administered and therefore social desirability response bias is minimized, that it enables anonymous responses, and that it is easy to complete.

Chapter 5 reports on the analysis of barriers and facilitators, performed with healthcare professionals on the subject of implementation of the short stay programme. The identification of impeding and facilitating factors that professionals perceive, is an essential step when a strategy is designed for implementation of a care programme which deviates from daily routines. Data were collected from the hospitals participating in the implementation study. Over forty potential barriers and facilitators for successful implementation were extracted from detailed notes of all contacts between researchers and each participating hospital. These items were then categorized according to themes. Most barriers aspects concerned the organization and the programme. The most common facilitators addressed organizational issues. Based on this study, the success of implementation of the short stay programme appeared to depend on the provision of postoperative care in the home situation, and on policy makers and insurance companies who must acknowledge that multidisciplinary teams, and teams integrating primary and secondary care, fulfil important roles in the delivery of continuity of care. Specific attention should be paid to the minority of people within the organization that disagrees with the plans. The resulting set of barriers and facilitators for implementation of the programme may inspire other professionals preparing to perform breast cancer surgery in short stay.

Chapter 6 evaluates the hospital-tailored implementation strategy regarding the effect on the proportion of patients treated in short stay (admission, surgery, and discharge the same day (day-case admission) or within $24 \mathrm{~h}$ (also referred to as overnight stay), on the duration of hospital admission, and on complication rate, readmission rate, reoperation rate, and number of visits to the emergency unit for 
problems related to breast cancer.

A before \& after design was used for this study. The intervention concerned the programme developed by the Maastricht University Medical Centre. The programme was implemented using a variety of implementation strategies such as plenary multidisciplinary team meetings and educational outreach visits. A total of 324 breast cancer patients participated in the study. The proportion of patients treated in short stay admission (i.e. admission, surgery, and discharge the same day or within $24 \mathrm{~h}$ ) increased significantly from $45 \%$ before, to $82 \%$ after implementation of the programme. The steep increase in short stay in our study was not accompanied by an increase in the rate of complications, readmissions, reoperations or number of visits to the emergency department. Factors associated with an increased chance of short-stay treatment were: breast-conserving surgery, having children and being employed. Being aged over 64 years showed a trend towards a decreased chance of being treated in short stay. In conclusion, this study demonstrates that introduction of the care programme incorporating short stay is feasible and safe.

Chapter 7 addresses the assessment of quality of care from the patient's perspective, before and after implementation of the short stay programme in four Dutch hospitals. Of the 324 participants in the implementation study, 282 patients returned a completed questionnaire ( $\mathrm{n}=138$ before implementation; $\mathrm{n}=144$ after implementation). Results showed that the quality of patient education, regarding activities in the home situation following discharge from the hospital, was in need of improvement. Quality of services by the surgeon somewhat improved and quality of services by the breast nurse roughly remained stable. Quality of patient education regarding aspects of preoperative treatment remained stable, and that of aspects relating to postoperative treatment was not in need of improvement in either measurement. Quality of waiting and process times had improved after implementation. However, there was still room for further improvement on these aspects. In conclusion, a short stay breast cancer care programme was introduced with, on average, comparable quality of care. However, specific patientinspired targets for further quality improvement concerned education on drains, prosthesis, exercises after surgery, survival rates, and waiting and process times.

In Chapter $\mathbf{8}$ costs and effects of the period after implementation of the short stay programme (SSP) are compared with those of the care as usual period (CAU), that is before implementation, and these are combined in a cost-effectiveness analysis, performed from both a societal and healthcare perspective. The outcome measure was defined as costs per quality adjusted life year (QALY) gained. Data of 262 participants were analyzed. SSP was less costly (€7454,-) than CAU (€8409,-) from the societal 
perspective and from the healthcare perspective (SSP: €4335,-; CAU: €5218,-). The incremental cost-effectiveness ratio could not be calculated due to similar effectiveness for both groups, that is the difference in QALYs was zero. Bootstrap analysis showed that a short stay programme as implemented has a high probability of being costeffective compared with care as usual.

Chapter 9 describes an economic evaluation in which costs and effects of a short stay programme were combined with costs and effects of a hospital-tailored multi-faceted implementation strategy to calculate policy cost-effectiveness. Costs for development and execution of the implementation strategy were obtained from healthcare professionals, and were added to costs of the short stay programme to calculate total policy costs. Total societal costs were calculated over a period of five years, and these were related to the measures of effectiveness: the uptake of short stay admission and QALYs. The mean absolute increase in uptake of short stay admission, compared with baseline, amounted to $36 \%$ for 262 patients analyzed in the economic evaluation. Implementation costs were $€ 23$,- per patient. As the QALY difference was zero, an incremental cost effectiveness ratio (ICER) could not be calculated. Bootstrap analysis revealed that the short stay programme had a high probability of being cost-effective. Taking costs and effects of implementation into account, the short stay programme was cost-effective from a policy point of view. Based on the results of this study, large-scale implementation of the programme is recommended.

In the final chapter, Chapter 10, the results are discussed and integrated. Furthermore, implications for research and practice, and recommendations are provided. 
Chapter 12
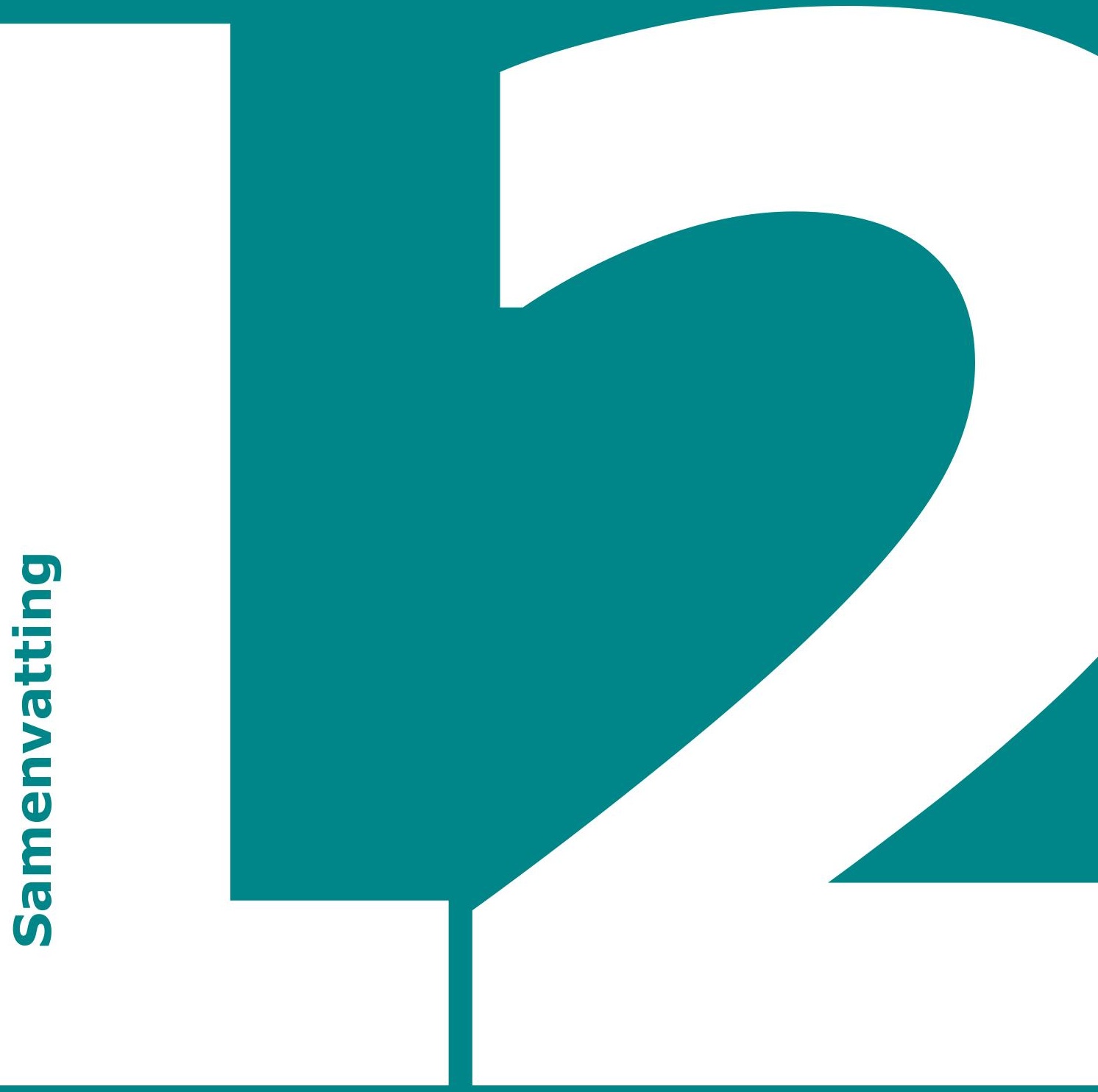

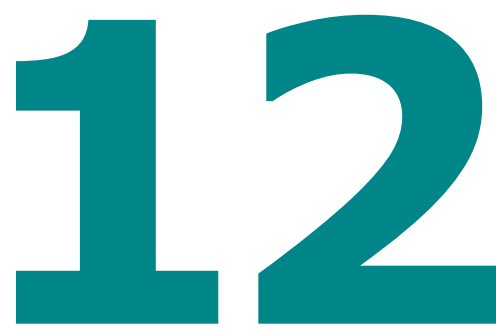

Sinds de jaren ' 80 is er een afname van de gemiddelde opnameduur na borstkankerchirurgie. Er is krachtig bewijs dat borstkankerchirurgie veilig uitgevoerd kan worden binnen dagopname. Tot op heden zijn er geen data gepubliceerd waarin alle typen borstkankerchirurgie in principe in dag- of 24-uursopname worden uitgevoerd. Gecombineerd met het ontbreken van grondig uitgevoerde multi-center studies ten aanzien van dit onderwerp, vormde dit gegeven de basis voor de implementatiestudie die in dit proefschrift beschreven wordt.

In dit proefschrift wordt de systematische implementatie van een compleet zorgprogramma, waarin opgenomen een korte ziekenhuisopname, voor vrouwen met borstkanker in vier Nederlandse ziekenhuizen onderzocht. Er wordt een uitspraak gedaan over het effect van het programma op patiëntuitkomsten zoals opnameduur, complicaties, heropnames, kwaliteit van zorg ervaren door patiënten, kwaliteit van werkelijk geleverde zorg, alsmede de kosteneffectiviteit van het programma en kosteneffectiviteit van het programma inclusief kosten en effecten van implementatie.

Het introductiehoofdstuk (Hoofdstuk 1) biedt een overzicht van de geschiedenis van borstkankerbehandeling, de definitie van postoperatief herstel, en ziekenhuisopname na borstkankerchirurgie. Daaraan gerelateerd, wordt het korte opname-programma zoals ontwikkeld in het Maastricht Universitair Medisch Centrum (MUMC) besproken. Sleutelfiguren in het programma zijn het multidisciplinaire team, de mammacareverpleegkundige(n) en de patiënt. Na de preoperatieve diagnose wordt de patiënt uitgebreid geïnformeerd over alle aspecten van chirurgie (de pre-, peri- en postoperatieve fase) in een één uur durend gesprek. In het programma wordt de nadruk gelegd op voorlichting aan de patiënt, met name over de perioperative periode. Dit wordt gerealiseerd door de informatie enkele keren te herhalen en te ondersteunen met schriftelijke informatie.

Tevens worden in het hoofdstuk de mogelijke effecten van het programma besproken op klinische uitkomstvariabelen, kwaliteit van zorg volgens het patiëntenperspectief 
en kosten van het implementeren van een dergelijk programma. Het concept van implementatie wordt beschreven, evenals het model dat werd gebruikt als raamwerk voor de implementatie. Aan het einde van het hoofdstuk wordt de opbouw van het proefschrift toegelicht en wordt een stroomdiagram van de studieonderdelen getoond.

In Hoofdstuk 2 wordt het studieprotocol voor de gehele studie beschreven, d.w.z. inclusief de economische evaluaties en de studie naar de waardering van patiënten betreffende de kwaliteit van zorg.

De implementatiestudie betrof een voor-na vergelijking welke werd uitgevoerd in vier ziekenhuizen in Nederland. De studie behelsde twee meetperioden van elk zes maanden, met daartussen zes maanden voor de implementatie. De primaire uitkomstmaat van de studie was het percentage patiënten behandeld in korte opname (dagopname of binnen 24 uur). Secundaire uitkomstmaten waren de kwaliteit van zorg vanuit het patiëntenperspectief, kosteneffectiviteit van het korte opnameprogramma 'sec', en kosteneffectiviteit van het programma inclusief de kosten van de implementatiestrategie. Op basis van een analyse van verwachte belemmerende en bevorderende factoren voor implementatie, werd de strategie aangepast aan de behoefte van elk ziekenhuis. Belangrijke facetten van implementatie waren: plenaire multidisciplinaire bijeenkomsten, klinische lessen en bijeenkomsten met de implementatieonderzoeker en enkele sleutelfiguren van ieder ziekenhuis (zogenaamde outreach visits).

In onze studie werd kwaliteit van zorg gemeten met behulp van het QUOTE borstkanker instrument. De methoden voor de economische evaluatie van het korte opname- programma 'sec' en inclusief de kosten van de implementatiestrategie, werden beschreven.

Hoofdstuk 3 beschrijft de ontwikkeling van een vragenlijst voor patiënten aangaande de kwaliteit van borstkankerzorg. Vaak worden items van dergelijke vragenlijsten ontwikkeld door gezondheidszorgprofessionals of onderzoekers in de gezondheidszorg, zonder betrokkenheid van de patiënten die geacht worden de vragenlijst in te vullen. In deze studie participeerden borstkankerpatiënten in de ontwikkeling van een instrument dat kwaliteit van zorg vanuit het patiëntenperspectief beschrijft. In totaal participeerden 72 patiënten in 8 focusgroepinterviews waarin het concept 'kwaliteit van borstkankerzorg' werd bediscussieerd. Deze interviews leidden tot 221 aspecten over kwaliteit van borstkankerzorg. Door reductiecriteria toe te passen bleef een set van 81 items over. Hierna werden zes concept mapping bijeenkomsten gehouden met 67 borstkankerpatiënten om deze 81 items te ordenen naar gelijkheid en belang. Na de analyse bleven er 55 kwaliteit van zorg aspecten over welke werden 
gegroepeerd in zes clusters. Deze aspecten werden gebruikt voor verdere ontwikkeling van de vragenlijst.

Hoofdstuk 4 richt zich op het kwantitatieve deel van de vragenlijstontwikkeling. Met de resultaten van de voorafgaande kwalitatieve methoden (zoals beschreven in Hoofdstuk 3) als uitgangspunt werd een testversie van de vragenlijst ontwikkeld. Van de 55 items gebruikt in de concept mapping bijeenkomsten, werden er 11 gebruikt voor zowel de mammacareverpleegkundige als voor de chirurg. Zes vragen werden toegevoegd op basis van open vragen aan borstkankerpatiënten waarin gevraagd werd naar ontbrekende elementen.

In de testversie werden 72 items geformuleerd als belang- en ervaringsvragen. De testversie werd getoetst bij 276 borstkankerpatiënten. Deze patiënten waren in de voorgaande drie tot 15 maanden geopereerd in één van de vier aan de implementatiestudie deelnemende ziekenhuizen of in het Maastricht Universitair Medisch Centrum.

Het instrument werd geoptimaliseerd door het gebruik van reductiecriteria, exploratieve factoranalyse en betrouwbaarheidsanalyse. Het aantal items in de uiteindelijke vragenlijst was 33. De items refereren naar de factoren 'patiëntenuitleg aangaande postoperatieve behandelinggerelateerde aspecten', 'de mammacareverple egkundige', 'de chirurg', 'uitleg aan patiënten aangaande activiteiten thuis' en 'uitleg aan patiënten aangaande preoperatieve behandelinggerelateerde aspecten'. De kracht van de vragenlijst is dat deze uitsluitend vragen bevat die van belang worden geacht door borstkankerpatiënten, dat patiënten deze zelf in kunnen vullen waardoor bias door sociaalwenselijke antwoorden wordt geminimaliseerd, dat het de anonimiteit van patiënten waarborgt en dat de vragenlijst makkelijk is in te vullen.

Hoofdstuk 5 beschrijft de analyse van belemmerende en bevorderende factoren. De analyse werd uitgevoerd op basis van de attitudes van gezondheidszorgprofessionals ten aanzien van implementatie van het korte opname-programma. De identificatie van belemmerende en bevorderende factoren is essentieel bij het implementeren van een programma dat afwijkt van dagelijkse routines. De gegevens werden verzameld in de ziekenhuizen die deelnamen aan de implementatiestudie. Meer dan 40 mogelijke belemmerende en bevorderende factoren voor succesvolle implementatie werden geëxtraheerd uit de notulen van alle contacten tussen onderzoekers en elk deelnemend ziekenhuis. Vervolgens werden deze items gecategoriseerd naar thema's. De meest voorkomende bevorderende factoren betroffen organisatorische zaken. De belemmerende factoren waren meestal ook op het niveau van de organisatie en van het programma zelf. 
Gebaseerd op de resultaten van deze kwalitatieve studie leek het succes van implementatie van het korte opname-programma af te hangen van de voorziening van postoperatieve zorg in de thuissituatie, en van beleidsmakers en verzekeraars. De laatste twee groepen moeten erkennen dat multidisciplinaire teams en teams waarin primaire en secundaire zorg wordt geïntegreerd, een belangrijke rol spelen bij het leveren van continuïteit van zorg. Specifieke aandacht moet gegeven worden aan de minderheidsgroep binnen de organisatie die het niet eens is met de plannen. De set van bevorderende en belemmerende factoren voor implementatie van het programma kunnen andere professionals inspireren bij het efficiënt implementeren van borstkankerchirurgie volgens het korte-opname programma.

In Hoofdstuk 6 wordt het effect gerapporteerd van de ziekenhuisspecifieke implementatiestrategie op het percentage patiënten dat daadwerkelijk is behandeld in korte opname (dagopname of opname en ontslag binnen 24 uur), op de opnameduur en op het aantal complicaties, heropnames, reoperaties en consulten aan de Spoed Eisende Hulp in verband met borstkanker gerelateerde problemen.

In deze studie werd een voor-na onderzoeksdesign toegepast. De interventie betrof het programma ontwikkeld door het Maastricht Universitair Medisch Centrum. Er werden verschillende methoden van implementatie toegepast zoals plenaire multidisciplinaire bijeenkomsten en outreach visits. In totaal namen 324 patiënten deel aan de studie. Het percentage patiënten dat behandeld werd in korte opname nam significant toe van $45 \%$ voor implementatie naar $82 \%$ na implementatie van het programma. De aanzienlijke toename van het aantal korte opnames in onze studie ging niet gepaard met een toename in het aantal complicaties, heropnames, reoperaties of aantal bezoeken aan de Spoed Eisende Hulp. De volgende factoren waren geassocieerd met een toegenomen kans op behandeling in korte opname: borstsparende chirurgie, het hebben van kinderen en het hebben van een baan. Een leeftijd hoger 64 jaar toonde een trend naar een lagere kans op korte opname. Samenvattend toonde deze studie aan dat introductie van het zorgprogramma waarvan korte opname een onderdeel was, uitvoerbaar en veilig is.

Hoofdstuk 7 behandelt de waardering van kwaliteit van zorg vanuit het patiëntenperspectief, voor en na implementatie van het complete zorgprogramma voor borstkanker patiënten in vier Nederlandse ziekenhuizen. Van de 324 deelnemers in de implementatiestudie stuurden 282 patiënten een volledig ingevulde vragenlijst terug ( $\mathrm{n}=138$ voor implementatie; $\mathrm{n}=144$ na implementatie). De resultaten lieten zien dat de kwaliteit van uitleg aan patiënten over activiteiten in de thuissituatie na ontslag voor verbetering in aanmerking kwam. De kwaliteit van zorg geleverd 
door de chirurg verbeterde iets tussen de twee metingen en de kwaliteit van zorg geleverd door de mammacareverpleegkundige bleef stabiel. Kwaliteit van uitleg aan patiënten over aspecten gerelateerd aan preoperatieve behandeling bleef stabiel en de uitleg over aspecten gerelateerd aan postoperatieve behandeling was adequaat in beide meetperioden. De waardering voor wacht- en doorlooptijden was verbeterd na implementatie. Echter, er was nog steeds ruimte voor verdere verbetering op deze aspecten. Concluderend kan gesteld worden dat een compleet zorgprogramma, waarin opgenomen een korte ziekenhuisopname werd geïntroduceerd met, gemiddeld, vergelijkbare kwaliteit van zorg. Specifieke, door patiënten geïnspireerde, speerpunten voor kwaliteitsverbetering betroffen uitleg over drains, prothesen, oefeningen na chirurgie, overlevingskansen en wacht- en doorlooptijden.

In Hoofdstuk 8 worden kosten en effecten van de periode na implementatie van het complete zorgprogramma, waarin opgenomen een korte ziekenhuisopname vergeleken met kosten en effecten van gebruikelijke zorg, d.w.z. vóór implementatie van het programma. Deze werden gecombineerd in een kosteneffectiviteitsanalyse welke uitgevoerd werd vanuit een maatschappelijk en een gezondheidszorg perspectief. De uitkomstmaat werd gedefinieerd als kosten per 'voor kwaliteit van leven gecorrigeerde levensjaren, ofwel 'quality adjusted life years' (QALYs). Gegevens van 262 deelnemers werden geanalyseerd. Het korte opname-programma was goedkoper (€7454,-) dan gebruikelijke zorg (€8409,-) vanuit het maatschappelijk perspectief en vanuit het gezondheidszorg perspectief (korte opname-programma: $€ 4335,-$; gebruikelijke zorg: €5218,-). De incrementele kosteneffectiviteitsratio kon niet worden berekend door gelijke effectiviteit voor beide groepen, d.w.z. het verschil in QALYs was nul. Bootstrapanalyse toonde dat het korte opname-programma een grote waarschijnlijkheid heeft van kosteneffectief zijn vergeleken met zorg zoals voorheen.

Hoofdstuk 9 beschrijft een economische evaluatie waarin kosten en effecten van een korte opname-programma werden gecombineerd met kosten en effecten van een ziekenhuisspecifieke multidimensionele implementatiestrategie. Kosten voor ontwikkeling en uitvoering van de implementatiestrategie werden verkregen van gezondheidszorgprofessionals en werden toegevoegd aan kosten van het korte opname-programma. De totale maatschappelijke kosten van het programma inclusief de implementatiekosten werden berekend over een periode van vijf jaar en deze werden gerelateerd aan de maten van effectiviteit: de toename van het aantal kort verblijf opnames en de toename van het aantal QALYs. De gemiddelde absolute toename van het aantal korte opnames vergeleken met de nulmeting was 36\% voor de 262 patiënten geanalyseerd in de economische evaluatie. Implementatiekosten waren gemiddeld 
$€ 23$,- per patiënt. Omdat er geen verschil was in QALYs kon er geen incrementele kosteneffectiviteitsratio worden berekend. Bootstrapanalyse toonde dat het complete zorgprogramma, na inclusie van de implementatiekosten, een grote waarschijnlijkheid had om kosteneffectief te zijn. Op basis van deze studieresultaten, wordt grootschalige implementatie van het programma aangeraden.

In het afsluitende discussiehoofdstuk (Hoofdstuk 10), worden de resultaten bediscussieerd en geïntegreerd. Verder worden er implicaties voor onderzoek en praktijk gegeven en worden er aanbevelingen gedaan. 



\section{Appendices}

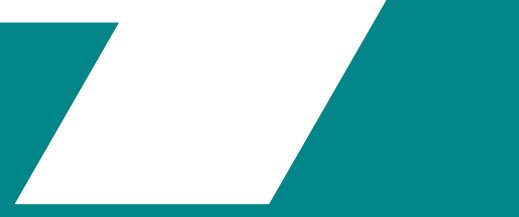




\section{Dankwoord}

Promotieonderzoek verrichten is in bepaalde opzichten vergelijkbaar met het maken van een fietstocht naar Rome, Barcelona of een rondje Ijsland; je leert je grenzen kennen en verleggen, je leert tegenslagen incasseren, je staat wat langer stil bij dingen die verdere mogelijkheden en kansen bieden, het is leerzaam, je ontwikkelt jezelf op diverse gebieden om dat ene doel te bereiken maar het is bovenal fantastisch om te doen. Het proefschrift dat nu voor $\mathrm{u}$ ligt was er niet geweest zonder de bijdragen van een groot aantal mensen. Daarom wil ik eenieder die heeft bijgedragen aan dit proefschrift bedanken en enkele mensen in het bijzonder:

Prof. dr. M.F. von Meyenfeldt, beste Maarten, jij was diegene die de route had bedacht. Je smoes om mij naar het azM te lokken om promotieonderzoek te gaan doen ('ik wil je sollicitatiebrieven voor een AGNIO-plek heelkunde wel becommentariëren') was een ongelofelijk goede. De combinatie van een bedachtzame, rustig werkende professor en de nogal impulsieve, multi-taskende, time-managende flapuit zoals je me noemde, bleek een ongelofelijk goede. Of je nu met een hernia met platte bedrust thuis lag, of de stewardess jou maande te boarden, of dat je met 40 graden koorts met een paracetamolletje achter de kiezen stond te opereren; als het nodig was, maakte je altijd tijd om te overleggen of stukken kritisch te lezen. Het was dè basis voor dit mooie resultaat. Ik wil je bedanken voor de vrijheid waarmee ik dit onderzoek hebben kunnen uitvoeren, voor het vertrouwen dat je in me had, voor onze fijne samenwerking en ik hoop op een mooi vervolg in de toekomst.

Prof. dr. T. van der Weijden, beste Trudy, jij leerde mij om me bewust te worden van alle dingen die tijdens de implementatie'reis' gebeurden. Je had continu inzicht in en overzicht van de onderzoeksaspecten die nog aandacht behoefden, je las alle stukken snel en nauwkeurig en zorgde ervoor dat iedereen zich aan de oorspronkelijke opdracht hield zodat de focus helder bleef. Van jouw manier van feedback geven kunnen sommige opleiders nog veel leren.

Beste Carmen,hoewel het echte KEA-werk pas aan het einde van de studie plaatsvond, ben je vanaf het begin betrokken geweest bij de koers die gevaren werd. Ik heb veel geleerd van je scherpe analyses, oog voor detail, enerverende discussies en jouw 'to the point' commentaren op manuscripten. Bedankt voor het mij inwijden in de KEA-wereld en het geduld dat je met en het vertrouwen dat je in deze niet-HTA-er hebt gehad.

Naast mijn promotor en co-promotoren ben ik uiteraard dank verschuldigd aan de 
beoordelingscommissie van dit proefschrift, voor de snelle en vakkundige beoordeling: Prof. dr. Severens, Prof. dr. Kruitwagen, Prof. dr. Rutgers, Dr. Tange en Prof. dr. de Vries, ik dank u.

'Ein genie uberblickt der Chaos' Kessels. Ik heb bewondering voor je statistische kennis en mogelijkheid om je in werkelijk alles in te lezen om uit te helpen. Soms was onze samenwerking als een fietsdag die niet lekker liep. Even pauze, nadenken en erna fris weer door. Maar al met al is ons doel op een mooie wijze bereikt en daar wil ik je voor bedanken. Dr. Voogd, beste Adri, jij was als reservebrandstof die soms nodig was. Onze lijntjes waren kort, snel, en vaak was (gelukkig voor mij) contact per e-mail of telefoon tussen Rotterdam en Maastricht voldoende. Dank je wel voor al je hulp en flexibiliteit. Dr. Sixma, beste Herman, door jouw enthousiasme en ontspannen houding leerde ik op een snelle, leuke manier erg veel van de werelden die kwaliteit van zorg en sociale wetenschappen heten. Dank hiervoor.

De vier early adopter ziekenhuizen zijn de focus geweest van de implementatieactiviteiten. Lokale begeleiders, u vormde het frame van de studie. Prof. dr. Roukema, beste Anne, ik wil je bedanken voor je scherpe, heldere vragen en opmerkingen tijdens de MaDO-teambijeenkomsten, de leuke bijeenkomsten tijdens de EBCC's en je gave om alles uit een persoon te halen die een persoon in zich heeft. Prof. dr. van de Velde, dank voor uw bijdragen, met name wanneer het mondiale borstkankerexperts betrof. Dr. van der Ent, uw ziekenhuis was geen 'makkie' in mijn studie maar zorgde wel voor goede, leerzame discussies in onze projectgroep. Dr. Bell \& dr. Finaly-Marais, dank voor uw betrokkenheid in de studie. Altijd waren de chirurgen in het Laurentius Ziekenhuis aanwezig en betrokken bij de $\mathrm{MaDO}$-teambijeenkomsten wat zeker heeft bijgedragen aan de mooie resultaten. Ik ben te laat om mijn dank uit te spreken aan collega Dr. Debets, een enorm gedreven chirurg, niet alleen voor zijn patiënten maar ook voor wetenschappelijke activiteiten zoals de MaDO-studie.

Bijzonder veel dank ben ik ook verschuldigd aan alle andere deelnemers aan en ondersteuners van de MaDO-teambijeenkomsten zonder wie de implementatie onmogelijk was geweest; Manon, Dorien, Jos, Brigitte, Marieëlle, Ine, Laurette en Marcel uit het St. Elisabeth Ziekenhuis, Marianne, Paula, Nelly, Els, Ben, Mia, Hetty, Esther, Monique uit het Laurentiusziekenhuis en Elly, Gemma, Annette, Lieneke, Adrie, Annemiek, Hanneke, Jacqueline, Mirjam, Ben, Liesbeth, Monique Kroeze, Monique Krijger, Birgit en Rita uit het Leids Universitair Medisch Centrum, Desiree, Marjan, Chrit, Yvonne, Ron, en Miriam uit het Orbis Medisch Centrum. 
van de MaDO-studie, zijn er veel mensen die een bijdrage hebben geleverd aan dit onderzoek. Marlene en Caroline, dank voor het mij bekend maken met het short stay programma. Joyce, ik hoop dat ik later met zo iemand al jij zal werken bij wie ik zeker weet dat dingen goed geregeld worden. Marianne, als office manager heb jij ook veel dingen voor me 'geritseld', waarvoor dank. Johanna, Evelien en Yvonne, dank voor de altijd beschikbare ondersteuning 'ff tussendoor'. Dionus, Gees \& El, wat heerlijk dat er dispuutsgenoten zijn die, naast het drinken van een lekker biertje, ook enorm hard kunnen werken en mee kunnen denken. Ik weet niet wat ik zonder jullie had gemoeten: bedankt! Djamila, dank voor je werk bij het verzamelen van de data. Lieke en Denise, dank voor het helpen tijdens de concept mapping bijeenkomsten. Mevr. van Buggenum, mevr. Verdonk, mevr. Witteman, mevr. Michiels, mevr. Koelink, mevr. Noordzij, dank voor de adviezen aangaande de eerste versie van het kostenboekje. Annelinde en Julia, dank voor het helpen bij het vouwen. Anita Legtenberg, dank voor het snelle praktische werk dat je verrichte tijdens het ontwikkelden van de QUOTE. Medewerkers van de MUMC-drukkerij, dank voor het altijd snel afkrijgen van die enorme pakketten vragenlijsten. Suzanne von Meyenfeldt, dank voor al je 'linguistic advice'.

Naast alle mensen die hebben meegeholpen bij de opzet en uitvoering van de studie zijn de borstkankerpatiënten die hebben deelgenomen aan het ontwikkelen van de QUOTE vragenlijst en aan de MaDO-studie van ongekend belang geweest. Dank.

Dank ook aan mijn collega-onderzoekers. Merel, hoe verwarrend de namen voor anderen ook waren, ik ben blij dat de MaDO- en MaZorg-studies naast elkaar liepen en wij elkaar in Nice hebben leren kennen. Het uitwisselen van werkervaringen, onderzoeksadviezen, publicatieplannen, de 'bakkies' en overige opvang tijdens mijn tijd in Maastricht en tijdens de 'terugkomdagen' waren waardevol. Ik ben blij dat ik 'iets' terug heb kunnen doen...Xavier, dank voor het zijn van zo'n attente vriend en collega. Sanne, wanneer gaan we nu dan echt eens samen cursussen volgen? Robbert, ik ben blij dat ik 'met' jou heb gewoond in het mooiste stukje van Mestreech, de Helstraôt en nu van je radiologische kennis kan leren. Maartje \& Ruben, het was een bijzondere en toch ook echt wel mooie (koffie)tijd in die labkamer met scheikundige kranen die onze levensgrote, onhandige bureau's markeerden. Dank hiervoor! Ik hoop dat we elkaar nog vaak zien als AIOS chirurgie. Rogier, onze onderzoeksrelativerende msnchatsessies waarbij we weinig van elkaars bezigheden begrepen, waren erg leuk. Ook al zou een dergelijke sessie nu meer gepast zijn gezien de afstand, ik kom liever een keertje langs.... 
Pauline, thank you for your friendship, for your hospitality during my time at Sickkids (and afterwards), and for making the effort to be here on this special day. Minke, jouw enorme motivatie voor het onderzoek voorafgaand aan de opleiding tot specialist heeft zeker de doorslag gegeven dat ik dit onderzoek ben gaan doen. Ik wil je bedanken hiervoor, voor de gastvrijheid in "Toronno" en ik ben blij met de bijzondere vriendschap die Canada ons heeft opgeleverd. Madeleine, je hoort bij het kopje Canada, collega-onderzoekers en 'de anderen', dat zegt eigenlijk genoeg. Ik ben blij dat ik je bij 'Enter the Haggis' in Toronto heb leren kennen. Je bent een echte onderzoeker (ook al vindt je zelf soms van niet), een hele gedreven arts maar bovenal een hele waardevolle vriendin die ik voor geen goud zou willen missen.

Prof. dr. Roukema, dr. Burger, dr. van Egmond, dr. van der Heijden, dr. Heisterkamp, dr. Heyligers, dr. Oostvogel, dr. Verhofstad en dr. Vriens, ' bazen', dank voor het in mij gestelde vertrouwen. De manier waarop ik opgevangen en opgenomen ben in uw ziekenhuis is voor mij van onschatbare waarde. Ik wist niet dat opgeleid worden en de mogelijkheid krijgen om je eigen opleiding te maken zo leuk kon zijn.

Collega-assistenten, Eelke, Patricia, Jorg, Jan-Willem, Jur, Winanda, Sarah, Albert, Leon, Tom, Bas, Fieke, Priscilla en Marielle, ik ben gewoonweg blij met jullie als collega's.

En dan ...'de anderen'...Loes, Ier, Annik, Rusje, Mir, Diet, Baux, Maai, Marth, dank voor jullie begrip en interesse en het bieden van 'ouderwetse ontspanning' tijdens het onderzoek en in het laatste jaar. Alma-Melissa, het is nu toch echt tijd dat we die enorme afstand tussen ons overbruggen....Brechtje, Hermien, Alexander \& Olav, ik ben blij dat ik zo'n mooi cluppie aan die rare tijd heb over gehouden. Gwen \& Vin, fijn dat jullie 'in de buurt wonen'; 2010 wordt een topjaar! Mijntje, wie had toen gedacht dat die goudwinden de basis zouden zijn voor zo'n mooie vriendschap?! Bedankt voor 'het er zijn' op voor mij onvergetelijke momenten, de heerlijke relaxsessies en onderzoekstechnisch wil ik je natuurlijk bedanken voor je lay-outactiviteiten gedurende de studie. Sjefkes (en aanhang), dank voor de eeuwige grappen over Eugenio, de emmer van boven en de lekkende bus tijdens de mooie stapavondjes. Oude tijden blijven herleven! Lieve Jos(je), dingen zijn veranderd en in drukke tijden kan zelfs een afstand van $150 \mathrm{~km}$ verderop een belemmering zijn om elkaar met enige regelmaat te zien. Ik hoop dat het voor mij nu in ieder geval iets makkelijker wordt wat vaker naar het zuiden te komen.

Lieve Lau, ik ben blij dat we allebei zo'n enorme kater hadden die eerste dag bij dat kampeerweekend in de buurt van Maastricht! Je was bij het begin van mijn dokter 
worden en bent er bij nu ik doctor word. Ik ben blij en trots dat jij mijn paranimf bent.

Marie-Louise, Gerard, Roel, Amber \& Coen, dank dat jullie 'deze Brabantse' vanaf het eerste moment dat ik jullie ontmoette, in het gezin der (min of meer) muggen hebben opgenomen.

Lieve Kirs, dank voor het lenen van je fietsmetafoor en natuurlijk het testen van mijn handvaardigheden in de vorm van een mooie cursus. We moeten snel met elkaar gaan fietsen! Menno, ik ben blij met de Zwolse bijdrage aan onze familie.

Lieve Dag, dank voor je immer relativerende blik op alles wat ik doe, dat je er bent op momenten dat het gewoon heel fijn is en natuurlijk voor het maken van het prachtige beeld.

Lieve pap en mam, jullie waren de 'forza, forza, forza' aan de kant van de weg; een onvoorwaardelijke steun wat er ook gebeurt. Pap, onze schrijfweek in de Beaujolais zal ik nooit vergeten; de ontspanning, de rust, de gesprekken en de wijntjes 'na het werk'. Je broodjes gehakt en de stroopwafels gedurende mijn onderzoeksjaren waren als de Snickers tijdens een klim. Enorm bedankt voor de juridische bijstand in de laatste periode van mijn proefschrift; we did it! Mam, je bent in vele opzichten een inspiratiebron voor mij als vrouw die toont dat dingen niet allemaal hoeven zoals het vroeger was en dat je veel dingen kunt bereiken als je er maar voor gaat. Het was voor mij daarom niet meer dan logisch dat ik je aan mijn zijde wilde hebben bij mijn verdediging. Ik wil je bedanken voor je bijdragen met betrekking tot de managementperikelen van het onderzoek. De cursussen in Eindhoven waren zeer geestverruimend en zeker voor herhaling vatbaar.

Ik ben trots dat jullie mijn ouders zijn.

Lieve Bart, jij bent diegene met wie ik alles heb meegemaakt op deze tocht vanaf die eerste ochtend in de keuken aan de Grote Gracht; de overwegingen om dit onderzoek te gaan doen, de lange maar vooral ook mooie tijd tijdens het op en neer reizen tussen Maastricht en Delft (soms geholpen door de voordelen van een multi-centerstudie), de lay-out hulp bij dingen waar dokters duidelijk niet voor in de wieg zijn gelegd, de eerste paper-afwijzing op die mooie dag in Buenos Aires, tegelijkertijd ook de sjampoempel voor de paper acceptaties, het werken om in opleiding te komen, de moeilijke momenten die met die opleiding soms gepaard gingen maar ook de barriers, de facilitators en niet in het minste: het relativeren, de ontspanning en nu eindelijk onze eigen stulp waarin ik dit proefschrift heb kunnen afschrijven. Overall hebben we met 
z'n tweeën een prachtfundering, denk ik zo. Het is tijd voor het uitstippelen van een nieuwe (fiets)tocht maar laten we als startpunt dan eindelijk het al ruim (vele malen) verdiende restaurant aan de Maas nemen.... bij deze nodig ik je uit! Mascha 


\section{About the author}

Mascha de Kok was born on January 26th, 1980 in Liempde, the Netherlands. After graduating from grammar school (Dutch: Gymnasium) at the Jacob Roelands Lyceum in Boxtel, she studied medicine at Maastricht University, where she obtained her medical degree in August 2004. While at medical school, she worked for two years as a student-assistant at the Skillslab, Maastricht University, and was chair of Ko-Beraad, the Maastricht association of medical interns (2003-2004).

She did several electives and internships at hospitals abroad. In 2001 she followed an elective in pediatrics and infectious diseases, at the Sardjito General Hospital, Yogyakarta, Indonesia. In 2002, she conducted a laboratory study named "the peristaltic bronchial muscle activity of the fetal rat" at the Hospital for Sick Children, Toronto, Canada. She performed the internship in internal medicine at the Pretoria Academic Hospital \& Kalafong Hospital in Pretoria, South Africa in 2003, and after finishing her final internship at the Department of Surgery at the Central Clinical Hospital in Moscow, Russia in 2004, she obtained her MD.

From December 2004 until November 2007 she worked on her PhD project at the Department of Surgery at the Maastricht University Medical Centre. This project, entitled "Introduction of a breast cancer care programme in ultra short stay setting in 4 early adopter centres: implementation and evaluation", supported financially by ZonMw, culminated in this dissertation. The studies that were conducted as part of this project were performed at the departments of surgery at the Orbis Medical Center (Sittard), the Laurentius Hospital (Roermond), the St. Elisabeth Hospital (Tilburg), and the Leiden University Medical Center (Leiden). The project was performed under supervision of Prof. dr. M.F. von Meyenfeldt, Prof. dr. T van der Weijden, and Dr. C.D. Dirksen. For part of this work Mascha was nominated for the Breast Surgery International Prize at the International Surgical Week, in Montreal, Canada (2007).

In January 2008 she started her surgical residency at the Erasmus Medical Center in Rotterdam. She began her surgical training in the Sint Franciscus Gasthuis in Rotterdam on 1 July 2008 until 1 May 2009, and continued her training at the St. Elisabeth Hospital in Tilburg under supervision of Prof. dr. J.A. Roukema and Dr. F.H.W.M. van der Heijden from 1 January 2010. 


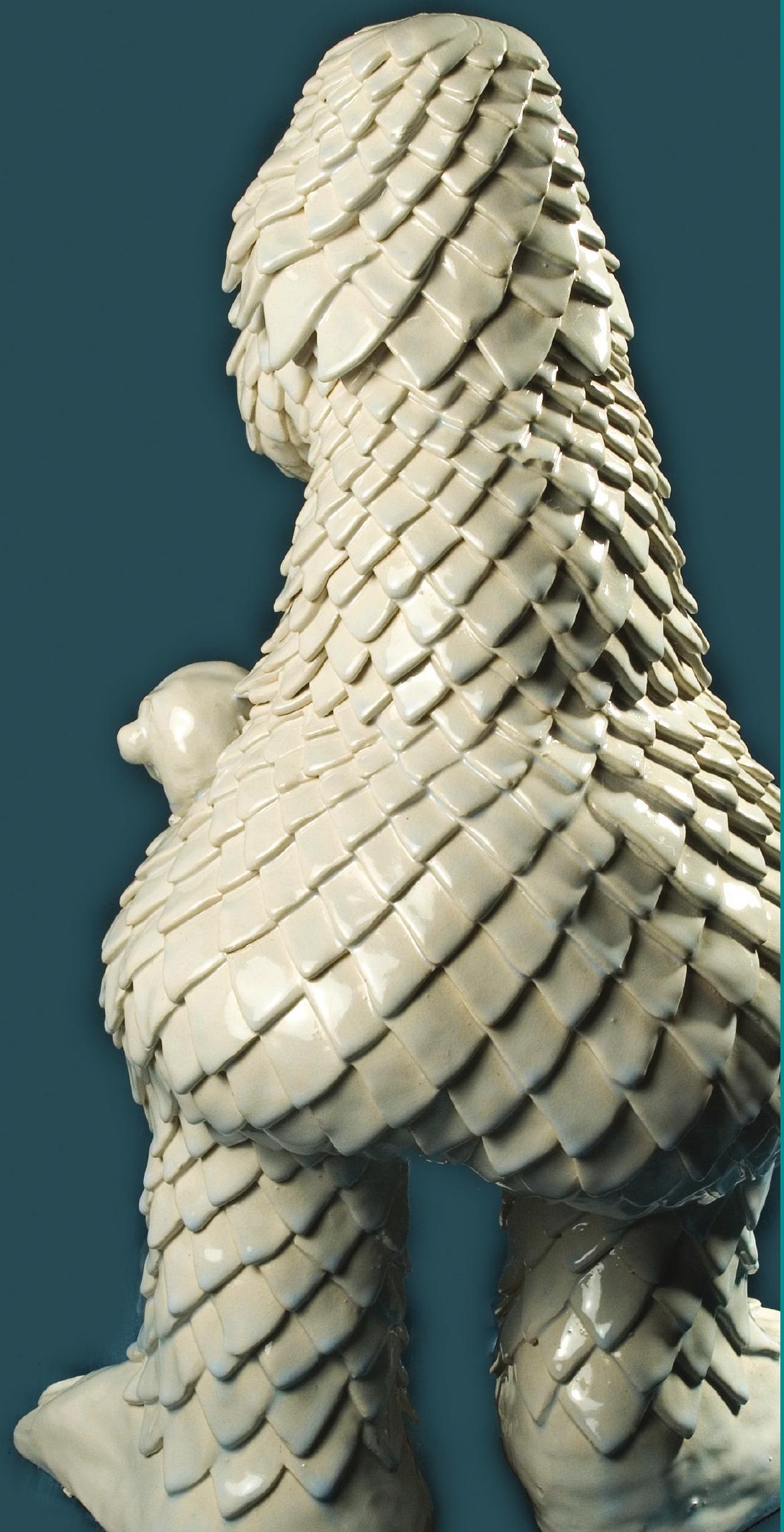

ญ

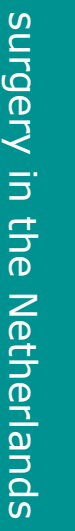

